EDSON VASQUES MOREIRA

\title{
DETERMINAÇÃO DA QUALIDADE DA RADIOGRAFIA DIGITAL APLICADA ÀS SOLDAS DE GASODUTOS E OLEODUTOS TERRESTRES E MARÍTIMOS
}

Tese apresentada à Faculdade de Engenharia do Campus de Guaratinguetá, Universidade Estadual Paulista, para a obtenção do título de Doutor em Engenharia Mecânica na área de Materiais.

Orientador: Prof. Dr. Marcelo dos Santos Pereira

Guaratinguetá 


\begin{tabular}{|c|}
\hline Moreira, Edson Vasques \\
Determinação da qualidade da radiografia digital aplicada \\
às soldas de gasodutos e oleodutos terrestres e marítimos / \\
Edson Vasques Moreira. - Guaratinguetá: [s.n], 2010. \\
165f.: il. \\
Bibliografia: f.158-165 \\
Tese (doutorado) - Universidade Estadual Paulista, \\
Faculdade de Engenharia do Campus de Guaratinguetá, 2010. \\
Orientador: Prof. Dr. Marcelo dos Santos Pereira \\
1. Radiografia 2. Solda e soldagem 3. Gasodutos \\
4. Oleodutos. I. Título \\
CDU 616-073 (043)
\end{tabular}




\section{unesp $\stackrel{\Delta}{\Delta}$ UNIVERSIDADE ESTADUAL PAULISTA CAMPUS DE GUARATINGUETÁ}

EDSON VASQUES MOREIRA

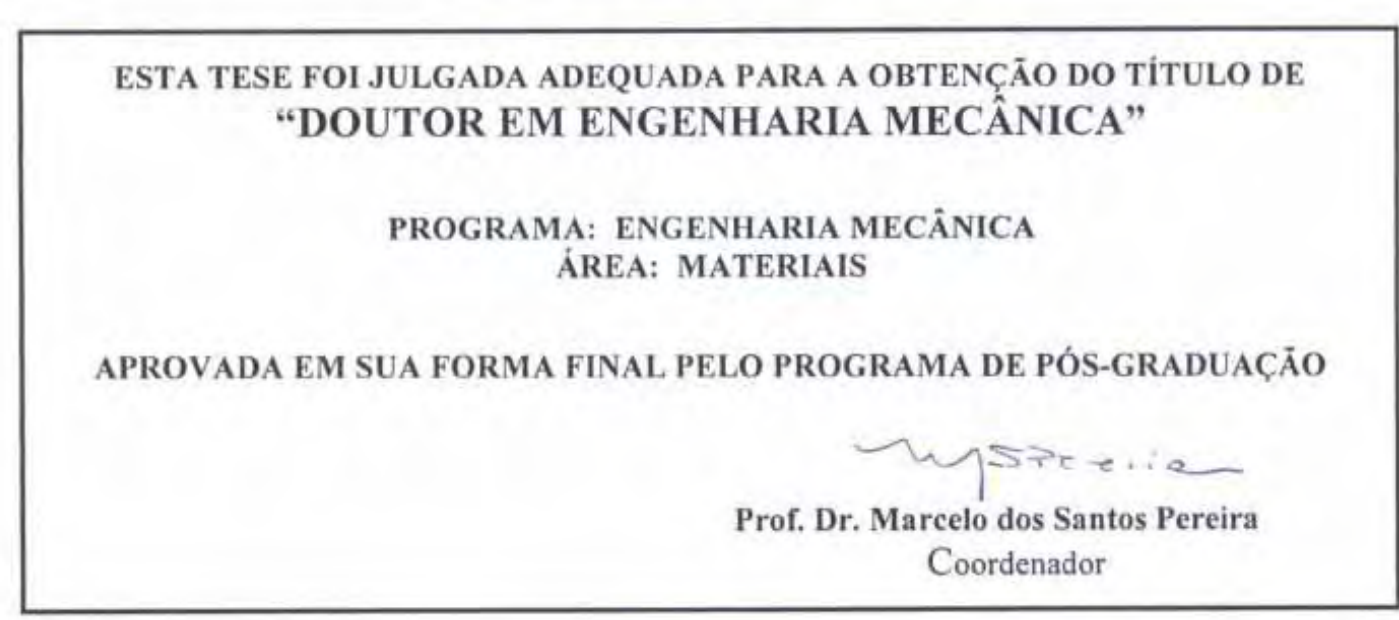

BANCA EXAMINADORA:

Prof. Dr. MARCELO DOS|SANTOS PEREIRA Orientador / Unesp-Feg

Prof. Dr. EDSøN COCCHIERI BOTELHO

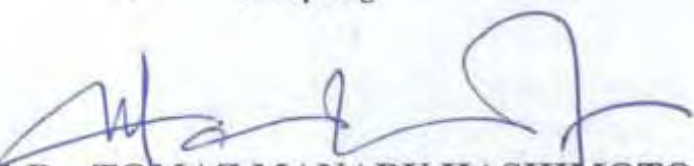

Prof. Dr. TOMAZ MANABU HASHIMOTO

Unesp/Feg

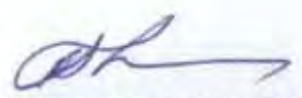

Prof. Dr. RICARDO TADEU LOPES

UFRJ

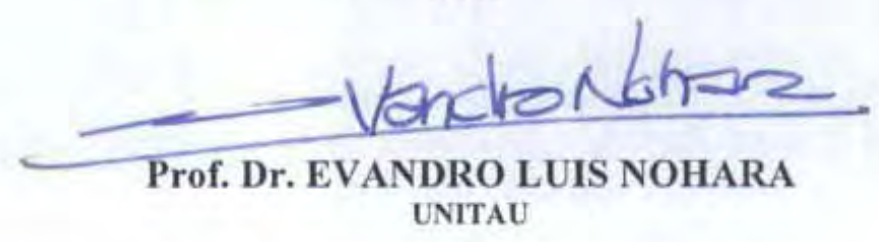

Fevereiro de 2010 


\section{DADOS CURRICULARES}

\section{EDSON VASQUES MOREIRA}

NASCIMENTO 19.12.1953 - PINDAMONHANGABA / SP

FILIAÇÃO
\[ \begin{array}{l}\text { José Moreira } \\ \text { Carmen Vasques Moreira } \\ \text { Curso de Graduação em Engenharia de Materiais } \\ \text { Materiais Metálicos } \\ \text { Universidade Federal de São Carlos - UFSCAR }\end{array} \]

2005/2007 Curso de Mestrado em Engenharia Mecânica

Materiais e Processos

Universidade de Taubaté - UNITAU

2008/2010 Curso de Doutorado em Engenharia Mecânica

Materiais

Universidade Estadual Paulista - UNESP

Campus de Guaratinguetá - Escola de Engenharia de Guaratinguetá 
À minha esposa Sílvia,

Filhos: Tatiana, Lívia e Fábio e ao meu neto Matheus. 


\section{AGRADECIMENTOS}

Este trabalho é fruto de muita dedicação e que teve um grande apoio de várias pessoas e que agora se tornou uma realidade, da qual muito me orgulho.

Especial agradecimento ao Prof. Dr. Marcelo dos Santos Pereira, pela decisiva e especial dedicação e pela orientação sempre objetiva e exata.

À Yxlon International pelas imagens e apoio para execução dos testes em Hamburgo, Alemanha, com especial agradecimento ao amigo Miguel Souza.

A todos os professores e alunos do Programa de Pós-graduação de Engenharia Mecânica - Materiais, desta universidade.

Ao Departamento de Engenharia do Produto da TenarisConfab, Luis Carlos Chad, Marcos Ponciano e Fábio Arroyo Moreira pelo apoio sempre incondicional.

Aos colegas soldadores e demais funcionários da Confab Equipamentos que prepararam os corpos-de-prova e que tiveram a árdua e difícil tarefa de colocar os defeitos necessários. Agradeço simbolicamente ao amigo Dunga em nome de todos.

Aos meus colegas e amigos do setor de ensaios não destrutivos, Robson Pedroso Manão, Jorge José de Carvalho e Carlos Lemes de Castro pela ajuda nas providências e arranjos para que tudo saísse de acordo com o planejado.

E aquela que está sempre presente e que com certeza ilumina o meu caminho, minha querida mãe, Carmen. 
"Embora ninguém possa voltar atrás e fazer um novo começo, qualquer um pode começar agora e fazer um novo fim" Chico Cândido Xavier 
MOREIRA, E. V., Determinação da qualidade da Radiografia Digital aplicada às Soldas de Gasodutos e Oleodutos Terrestres e Marítimos. 2010. 165f. Tese (Doutorado em Engenharia Mecânica) - Faculdade de Engenharia do Campus de Guaratinguetá, Universidade Estadual Paulista, Guaratinguetá, 2010.

\section{RESUMO}

As necessidades das empresas de explorar petróleo e gás no Brasil em águas profundas e ultras profundas, incluindo os reservatórios do pré-sal, têm exigido um desenvolvimento de melhores produtos e recursos tecnológicos para os dutos. As características dos tubos de aço, o insumo mais importante destes dutos, são as mais afetadas pelas mudanças exigidas, pelas técnicas de fabricação e pelos controles realizados durante o processo de manufatura destes tubos. As exigências das especificações das chapas de aço utilizadas estão maiores, o processo de formação e soldagem, é afetado pela busca de melhores procedimentos. Os processos de controle da qualidade das soldas dos tubos têm buscado aumentar a sua sensibilidade, visando à detecção de descontinuidades menores das que hoje são detectadas pelos métodos tradicionais. Em termos de ensaios não destrutivos, as exigências impostas para o ensaio radiográfico estão no limite do desempenho dos atuais filmes industriais disponíveis, além do compromisso sensibilidade versus tempo de exposição ser sempre um fator importante a ser considerado na produtividade exigida para atendimento dos ciclos de produção e acompanhar a velocidade das montagens dos tubos em campo. $\mathrm{O}$ objetivo desta tese foi estudar e determinar a qualidade da técnica da radiografia digital em relação à radiografia convencional para inspeção de juntas soldadas de tubos utilizando os parâmetros de avaliação, tais como, resolução espacial, relação sinal ruído, sensibilidade ao contraste, níveis de tons de cinza, etc. que são aplicáveis à imagens digitais. Para a avaliação da técnica da radiografia digital foram preparados 20 corpos-de-prova de juntas soldadas, com defeitos reais em 06 espessuras diferentes, distribuídos na faixa de 4,9 a 32,3 $\mathrm{mm}$. Estes corpos-de-prova foram radiografados com a técnica convencional e com a digital. Na técnica convencional dois modelos de filmes industriais, os mais sensíveis, foram utilizados e na técnica digital se utilizou um detector plano com tamanho de pixel de $127 \mu \mathrm{m}$, modelo PaxScan 2520V fabricado pela empresa Varian Medical System. O software ISee! foi utilizado para a avaliação das imagens geradas. Pelos resultados obtidos pode-se verificar que a radiografia digital utilizando o método direto com os equipamentos avaliados, atende perfeitamente as exigências mais rigorosas dos gasodutos e oleodutos, terrestres e marítimos, ou seja, as exigências das normas ISO 10893-7 Classe B, DNV-OS-F101, API 5L e ISO 3183 que são utilizadas neste segmento de produto foram perfeitamente atendidas. Esta técnica agrega vários benefícios como: melhor qualidade, sensibilidade ao contraste e pequenos defeitos, aspectos de segurança e meio ambiente e saúde, maior probabilidade de detecção de defeitos, entre outros.

PALAVRAS-CHAVE: Radiografia, Gasodutos, Oleodutos, Soldas e soldagem. 
MOREIRA, E. V.; Quality determination of digital radiography applied to weld seam of gas and oil pipelines on-shore and off-shore. 2009. 165p. Thesis (Doctorate in Mechanical Engineering) - College of Engineering, Campus of Guaratinguetá, São Paulo State University, Guaratinguetá.

\begin{abstract}
The needs of the petroleum and gas industries in deepwater and ultra-deepwater oil and gas fields offshore of Brazil, including pre-salt reservoirs, are required to develop better products and technological resources for the pipelines. The characteristics of steel pipes, the most important duct of these pipelines are the most affected by the requirement changes, by manufacturing techniques and by the controls carried out during the manufacturing process of these pipes. The requirements of steel plates specifications used, forming and welding process are more restrictive and affected by seeking better procedures. The quality control processes of welds of the pipes have sought to increase its sensitivity to detect minor discontinuities in comparison with the traditional methods. In terms of non-destructive tests, the requirements for the radiographic testing are within the limit of performance of current traditional industrial films available; in addition to undertaking sensitivity versus time of exposure is always an important factor to be considered in productivity required for production cycles and following the installation speed of the tubes in the field. The goal of this thesis was to study and determine the technical quality of digital radiography in relation to conventional radiography for inspection seam weld of pipes using the evaluation parameters each as basic spatial resolution, signal noise ratio, contrast sensitivity, gray level, etc. applicable to digital image. To evaluate the digital radiography technique were prepared 20 welded seam samples with defects in 06 wall thickness, distributes in the range of 4,9 to $32,3 \mathrm{~mm}$. These samples were tested with conventional and digital radiographic techniques. Two models of industrials films were used for the conventional technique, the must sensible, and in the digital technique used a DDA with $127 \mu \mathrm{m}$ pixel size, model PaxScan 2520V manufactured by Varian Medical System. The software ISee! was used to evaluate the generated image. Through the results obtained is possible to verify that the digital radiography, using the direct method with the evaluated equipments, fulfill the most stringent requirements of gas pipelines and oil pipelines onshore and offshore, or the requirements of ISO 10893-7 Class B, DNV-OS-F101, ISO 3183 and API 5L that are used in this segment of product were perfectly met. This technique aggregates several benefits like: better quality, contrast sensitivity, detect ability of minor defects, safety and environmental aspects and health, major probability of detection defects, among others.
\end{abstract}

KEYWORDS: Radiography, Gas-pipeline, Oil-pipeline, Weld seam. 


\section{LISTA DE FIGURAS}

FIGURA 1.1 - Projeto de duto em águas profundas - Pré-sal........................................23

FIGURA 3.1 - Primeira imagem digital, Russell Kirsch - 176 pixel..............................30

FIGURA 3.2 - Radiografia digital (a) Diagnóstico de tratamento de canal.

(b) Panorâmica da boca.

FIGURA 3.3 - Diagrama simplificado da seção do olho humano....................................33

FIGURA 3.4 - Ângulo de visão versus numero de bastonetes e cones...........................33

FIGURA 3.5 - Representação gráfica do olho vendo uma palmeira.

$\mathrm{O}$ ponto $\mathrm{C}$ é o centro da lente ótico.

FIGURA 3.6 - Curva da intensidade da luz versus o brilho subjetivo do olho humano.

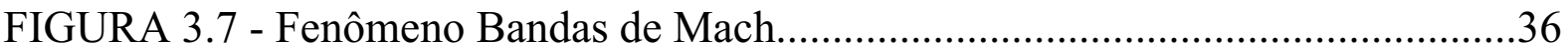

FIGURA 3.8 - Fenômeno de contraste simultâneo..........................................................37

FIGURA 3.9 - Algumas ilusões de óticas bem conhecidas.............................................37

FIGURA 3.10 - Conceito de uma imagem digital...........................................................38

FIGURA 3.11 - Comportamento entre os valores de pixel e os tons de cinza...............38

FIGURA 3.12 - Uma imagem de 1024 x 1024, de 8 bits reduzida para o tamanho de $32 \times 32$ pixels. O número de níveis de cinza foi mantido a 256 .

FIGURA 3.13 - (a) Imagem de 1024x1024, 8 bits. (b) Imagem de 512x512 redefinida para $1024 \times 1024$ pixels por duplicação de linha e coluna. (c) até (f) Imagens redefinidas de 32×32, 64×64, $128 \times 128$ e $256 \times 256$ para $1024 \times 1024$ pixels.

FIGURA 3.14 - (a) 452x374, imagem com 256 níveis de cinza. (b) a (d) imagem exibida com 128, 64 e 32 níveis de cinza, mantendo constante a resolução espacial. (e) a (g) imagens exibidas com 16, 8, 4 e 2 níveis de cinza.

FIGURA 3.15 - Gerar uma imagem digital. (a) Imagem (b) Imagem continua. (c) Amostragem. (d) Quantificação.

FIGURA 3.16 - (a) Imagem continua projetada em uma matriz de sensores

(b) Resultado da amostragem e quantificação da imagem. 
FIGURA 3.17 - (a) Sensor único de imagem. (b) Linha de sensores.

(c) Matriz de sensores

FIGURA 3.18 - Combinação de um sensor simples com movimento para gerar imagem em 2-D

FIGURA 3.19 - Aquisição de imagem usando (a) Régua de sensores.

(b) Régua circular de sensores.

FIGURA 3.20 - Exemplo do processo de aquisição de uma imagem digital 48

FIGURA 3.21 - Fonte de raios X (TAUHATA et al., 2003).....

FIGURA 3.22 - Espectro típico dos Raios X.

FIGURA 3.23 - (a) Método para determinação da área focal.

(b) Imagem do ponto focal/filamento 50

FIGURA 3.24 - Efeito fotoelétrico 51

FIGURA 3.25 - Efeito Compton. 52

FIGURA 3.26 - Formação de pares. 53

FIGURA 3.27 - Importância relativa dos processos. .53

FIGURA 3.28 - Imagem radiográfica de defeitos típicos em soldas. .56

FIGURA 3.29 - Técnica de exposição PS-VS. (a, b, c) Junta circunferencial. (d) Junta plana.

FIGURA 3.30 - (a) Inspeção de cargas e containers. (b) Inspeção de aros de rodas. .58

FIGURA 3.31 - Aplicações da radiografia digital 59

FIGURA 3.32 - Ambiente integrado de imagens da radiografia digital 62

FIGURA 3.33 - Rejeitos da radiografia convencional (a) Reveladores e fixadores. (b) Embalagens plásticas.

FIGURA 3.34 - Deteç̧ão de defeito por sistema automático. (a) Imagem original. (b) Defeito detectado. .65

FIGURA 3.35 - Imagens criadas pelo sistema de processamento de imagens que identifica e avalia as imagens radiográficas dos defeitos de solda em tempo real. (a) imagem original. (b) imagem binária. (c) imagem binária após redução de ruído. (d) imagem original com os defeitos identificados. 
FIGURA 3. 36 - Fluxograma de um processo de avaliação de imagem

FIGURA 3.37 - Exemplo de processamento de imagem (a) Imagem do cordão de solda como obtida (b) Imagem com filtro passa alto aplicado.

FIGURA 3.38 - Imagens de defeitos identificadas por um sistema automático de imagens (a) Imagem de um rechupe.

(b) Imagem de bolhas de gás.

FIGURA 3.39 - Imagem digital de um duto de uma polegada avaliado por um sistema semi-automático de controle.

FIGURA 3.40 - Comparação entre Digital, Filme e Radioscopia.

FIGURA 3.41 - Probabilidade de detecção de defeitos com PS-VS, PD-VS e Radioscopia. 70

FIGURA 3.42 - Exemplo de um sistema de backup em rede.

FIGURA 3.43 - Comparação da resolução geométrica de vários métodos de imagem.

FIGURA 3.44 - Esquema do MTF que representa os atributos de resolução de um sistema radiográfico digital..

FIGURA 3.45 - (a) Alto valor de MTF. (b) Baixo valor de MTF.............................73

FIGURA 3.46 - Conteúdo da imagem com freqüência específica............................74

FIGURA 3.47 - Esquema do NPS representando os atributos de ruído de um sistema radiográfico digital. .75

FIGURA 3.48 - Efeito do ruído na perceptibilidade dos defeitos. 77

FIGURA 3.49 - Influência do ruído na visibilidade do entalhe na radiografia.............78

FIGURA 3.50 - IQI de arame (ISO 19232-1, 2004) .............................................80

FIGURA 3.51 - IQI de Arame Duplo ( ISO 19232-5, 2004 )...................................80

FIGURA 3.52 - Penumbra da imagem. (a) Imagem ideal (b) Imagem com penumbra ou falta de nitidez.

FIGURA 3.53 - Disposição geométrica entre fonte filme e objeto. .82

FIGURA 3.54 - Critério para avaliação do perfil do IQI de arames duplos. 83

FIGURA 3.55 - Fluxograma de como atender a exigência da penumbra da imagem 
FIGURA 3.56 - Valor ideal da penumbra geométrica, Ug..........................................85

FIGURA 3.57 - Valor ideal da ampliação..................................................................86

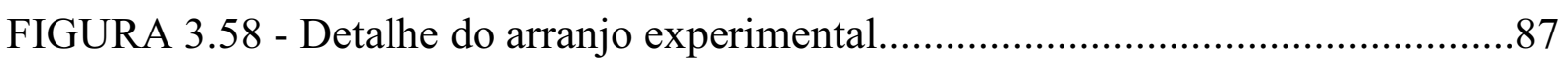

FIGURA 3.59 - Radiografia do par mais fino de arames..............................................87

FIGURA 3.60 - Imagens radiográficas dos pares de arames - Influência da ampliação na penumbra obtida.....................................................8

FIGURA 3.61 - Foto de um DDA e o esquema básico...................................................8

FIGURA 3.62 - Estrutura e funcionamento de um DDA com cintiliador.......................89

FIGURA 3.63 - (a) Matriz de sensores de silício amorfo. (b) Fotomicrografia

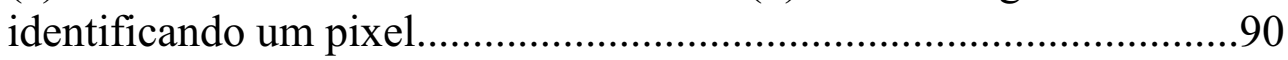

FIGURA 3.64 - Diagrama do circuito de uma matriz de sensores de silício amorfo.................................................................................91

FIGURA 3.65 - Conversão da luz pelos cintiladores de Fósforo e CsI...........................92

FIGURA 3.66 - Estrutura de um cintilador. (a) De fósforo (b) Iodeto de Césio...........93

FIGURA 3.67 - Exemplo de calibração (a) Imagem inadequada. (b) Imagem adequada em um DDA......................................................................94

FIGURA 3.68 - Defeitos comuns em um DDA (BAVENDIEK; 2005).........................95

FIGURA 3.69 - Tela em funcionamento, com um pixel morto na região central.........96

FIGURA 3.70 - Estratégia para correção de pixel com defeito. (a) Pixel morto.

(b) Conjunto de pixels defeituosos.......................................................96

FIGURA 4.1 - Fluxograma das etapas do trabalho.......................................................97

FIGURA 4.2 - Detector plano Varian PaxScan 2520V .................................................102

FIGURA 4.3 - Ampliação da imagem radiográfica.......................................................103

FIGURA 4.4 - Esquema da colocação do detector dentro do tubo................................104

FIGURA 4.5 - Determinação da Distância Mínima Objeto-Detector.............................105

FIGURA 4.6 - Arranjo para a radiografia digital. (a) Esquema e

(b) Detalhamento .................................................................................107

FIGURA 4.7 - Colocação dos Indicadores de Qualidade de Imagem...........................109

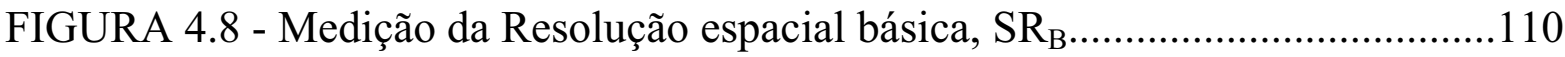


FIGURA 4.9 - Método alternativo para medição dos valores de $\mathrm{SR}_{\mathrm{B}}$.

FIGURA 4.10 - Perfil do IQI de Arame Duplo para curva MTF.

FIGURA 4.11 - Curva de MTF para o CP 01 com tempo de integração de 8 segundos.

FIGURA 4.12 - Esquema de medição dos valores de SNR $_{\mathbf{N}}$ …...................................118

FIGURA 4.13 - Medição dos valores de $\mathrm{SNR}_{\mathrm{N}}$

FIGURA 5.1 - Medições da resolução espacial básica para a técnica convencional..

FIGURA 5.2 - Medições da resolução espacial básica para a técnica digital, sem calço metálico.

FIGURA 5.3 - Medições da resolução espacial básica para a técnica digital, com calço metálico.

FIGURA 5.4 - Curvas MTF. (a) CP07, (b) CP14 e (c) CP12 …………………........127

FIGURA 5.4 - (Continuação) Curvas MTF. (d) CP01, (e) CP03 e (f) CP05................128

FIGURA 5.5 - Sensibilidade ao IQI de contraste tipo arame.

Espessuras 4,9; 6,4 e 9,7 mm (ISO/DIS 10893-7).

FIGURA 5.6 - Sensibilidade ao IQI de contraste tipo arame.

Espessuras 19,2; 25,3 e 32,3 mm (ISO/DIS 10893-7)........................134

FIGURA 5.7 - Sensibilidade ao IQI de contraste tipo arame.

Espessuras 4,9 e 6,4 $\mathrm{mm}$ (Solda).

FIGURA 5.8 - Sensibilidade ao IQI de contraste tipo arame.

Espessuras 9,7 mm (Solda)

FIGURA 5.9 - Sensibilidade ao IQI de contraste tipo arame.

Espessuras 19,2 mm (Solda). .136

FIGURA 5.10 - Sensibilidade ao IQI de contraste tipo arame.

Espessura 25,3 mm.

FIGURA 5.11 - Sensibilidade ao IQI de contraste tipo arame.

Espessura de 32,3 mm.

FIGURA 5.12 - Valores médios obtidos da $\mathrm{SNR}_{\mathrm{N}}$ para as espessuras de $4,9,6,4,9,7,19,2$ e $25,3 \mathrm{~mm}$.

FIGURA 5.13 - Valores médios obtidos da $\mathrm{SNR}_{\mathrm{N}}$ para espessura de 32,3 mm 
FIGURA 5.14 - Valores da $\mathrm{SNR}_{\mathrm{N}}$ para o CP18 - DOD $80 \mathrm{~mm}$

FIGURA 5.15 - Sensibilidade ao contraste (IQI de arame) em função da

$\mathrm{SNR}_{\mathrm{N}}$ e do Tempo de Integração - CP18

FIGURA 5.16 - Espessura de 4,9 mm - CP04. (a) Filme D4, (b) 1s e (c) 32s...........144

FIGURA 5.17 - Espessura de 6,4 mm - CP12. (a) Filme D4, (b) 2s e (c) 32s..........145

FIGURA 5.18 - Espessura de 9,7 mm - CP07. (a) Filme D4, (b) 2s e (c) 32s..........145

FIGURA 5.19 - Espessura de 19,2 mm - CP01. (a) Filme D4, (b) 4s e (c) 32s........146

FIGURA 5.20 - Espessura de 25,3 mm - CP03. (a) Filme D4, (b) 8s e (c) 32s........146

FIGURA 5.21 - Espessura de 32,3 mm - CP18. (a) Filme D4, (b) 16s e (c) 32s.......147

FIGURA 5.22 - Defeitos críticos - Comparação entre as técnicas...........................148

FIGURA 5.23 - Defeitos críticos complementares - Comparação entre as técnicas.

FIGURA 5.24 - Comparação dos Tempos de Exposição e Integração

FIGURA 5.25 - Comparação das Exposições Relativas entre a Técnica Digital e Convencional. 


\section{LISTA DE TABELAS}

TABELA 3.1 - Características típicas entre Filme, CR e DR.......................................61

TABELA 3.2 - Custo por exposição entre as técnicas (BOIY, 2006)............................63

TABELA 3.3 - IQI de arame (ISO 19232-1).........................................................

TABELA 3.4 - IQI de arame duplo (ISO 19232-5, 2004 )........................................81

TABELA 4.1 - Valores exigidos no ensaio de tração......................................................98

TABELA 4.2 - Composição Química Exigida (API 5L, 2007).....................................98

TABELA 4.3 - Relação de corpos-de-prova.................................................................99

TABELA 4.4 - Junta soldada e tipos de defeitos criados............................................100

TABELA 4.5 - Características dos filmes utilizados...................................................101

TABELA 4.6 - Parâmetros utilizados para ensaio com filmes......................................101

TABELA 4.7 - Especificação do Detector plano PaxScan 2520V ………………........103

TABELA 4.8 - Mínima Distância Objeto ao Detector....................................................106

TABELA 4.9 - Fator de ampliação para DOD mínimo e DFD de 700 mm.................106

TABELA 4.10 - Distância mínima do foco ao detector, para fator de

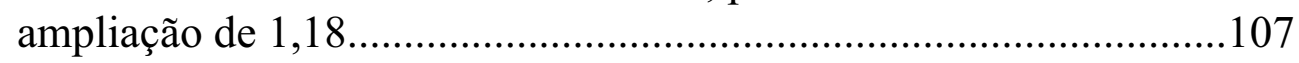

TABELA 4.11 - Parâmetros utilizados para radiografia digital..................................108

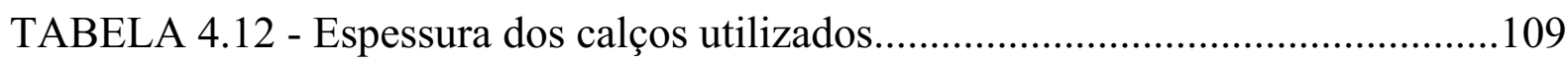

TABELA 4.13 - Valores dimensionais do IQI de Arame Duplo..................................113

TABELA 4.14 - Dados para construção da curva MTF..............................................113

TABELA 4.15 - Valores de resolução espacial para o CP 01 com tempo de integração de $8 \mathrm{~s}$.

TABELA 4.16 - Arame essencial para IQI de contraste de arame

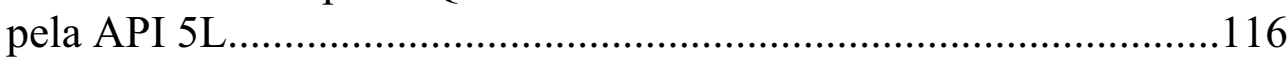

TABELA 4.17 - Arame essencial exigido pela DNV-OS-F101_.................................116

TABELA 4.18 - Arame essencial proposto pela ISO/DIS 10893-7............................117

TABELA 4.19 - Arame Duplo proposto pela ISO/DIS 10893-7................................117 
TABELA 5.1 - Valores obtidos do ensaio de tração dos corpos-de-prova

TABELA 5.2 - Análise química dos corpos-de-prova.

TABELA 5.3 - Resolução Espacial Básica $\left(\mathrm{SR}_{\mathrm{B}}\right)$ para a

Técnica Convencional.

TABELA 5.4 - Resolução Espacial Básica $\left(\mathrm{SR}_{\mathrm{B}}\right)$ para a Técnica Digital, Experimental.

TABELA 5.5 - Valores da resolução espacial do sistema - MTF 20\% 129

TABELA 5.6 - Exigência do IQI de contraste para IQI de arame duplo e do IQI de Arame - Técnica digital.

TABELA 5.7 - Arame exigido e experimental - Técnica convencional, filme AGFA D4 e KODAK M100.

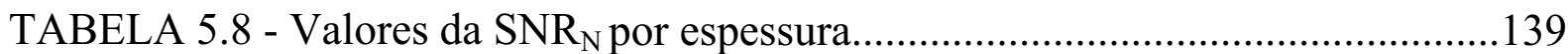

TABELA 5.9 - Valores da SNR $_{N}$ para CP18 com longa exposição...........................141

TABELA 5.10 - Tempos de Integração Mínimos para ISO/DIS 10893-7..................150

TABELA 5.11 - Tempos de Integração Mínimos para DNV-OS-F101, API 5L e ISO 3183 


\section{LISTA DE ABREVIATURAS E SIGLAS}

ABENDI

ADR

API

ARBL

a-Si

ASM

ASTM

AWS

BAM

CCD

$\mathrm{Cd} / \mathrm{m}^{2}$

CMOS

$\mathbf{C P}$

CNEN

CS

CsI

DICONDE

DDA

DFD

DNV

DOD

DQE
Associação Brasileira de Ensaios Não Destrutivos e Inspeção

Automatic Detection Recognition

American Petroleum Institute

Alta Resistência e Baixa Liga

Silício amorfo

American Society of Materials

American Society for Testing and Materials

American Welding Society

Bundesanstalt für Materialforschung und prüfung

Charge-Coupled Devices

Candela por metro quadrado

Complementary Metal Oxide Semiconductor

Corpo-de-prova

Comissão Nacional de Energia Nuclear

Contrast Sensitivity

Iodeto de césio

Digital Imaging and Communication in Nondestructive Evaluation

Digital Detector Array

Distância da Fonte ao Detector

Det Norsek Veritas

Distância do Objeto ao Detector

Detective Quantum Efficiency 
DQEe

EDM

EN

END

FF

FP

GD

Gd2O2S

GEIT

GMAW

IE

IQI

ISO

LE

LR

$\mu e f f$

MTF

NBR

NBS

NIST

NPS

PDVD

PDVS

$\mathbf{P l} / \mathbf{m m}$

PO
Detective Quantum Efficiency Effective

Eletric Discharge Machining

European Standard

Ensaios não Destrutivos

Falta de Fusão

Falta de Penetração

Gradiente a uma Densidade Ótica, D

Oxi Sulfito de Gadolínio

General Electric Inspection Technologies

Gas Metal Arc Welding

Inclusão de Escória

Indicador de Qualidade de Imagem

International Standard Organization

Limite de Escoamento

Limite de Resistência

Coeficiente de Atenuação Efetivo

Função da Transferência da Modulação

Norma Brasileira Registrada

National Bureau of Standards

National Institute of Standard and Technology

Noise Power Spectrum

Parede Dupla Vista Dupla

Parede Dupla Vista Simples

Par de linhas por milímetro

Poro 


$\begin{array}{ll}\text { POD } & \text { Probability of Detection } \\ \text { PSL } & \text { Product Specification Level } \\ \text { PSVS } & \text { Parede Simples Vista Simples } \\ \text { RC } & \text { Radiografia Computadorizada } \\ \text { RD } & \text { Radiografia Digital } \\ \text { RF } & \text { Radiofreqüência } \\ \text { SR } & \text { Resolução Espacial Básica } \\ \text { SNQC } & \text { Sistema Nacional de Qualificação e Certificação } \\ \text { SNR } & \text { Relação Sinal Ruído } \\ \text { SNR } & \text { Relação Sinal Ruído Normalizada } \\ \text { Tiff } & \text { Tagged Image File Format } \\ \text { TFT } & \text { Thin film transistor } \\ \text { TR } & \text { Trinca } \\ \text { TRC } & \text { Tubo de Raios Catódicos } \\ \text { Ug } & \text { Geometricy Unsharpness } \\ \text { 2-D } & \text { Duas dimensões dimensões } \\ \text { 3-D } & \end{array}$




\section{SUMÁRIO}

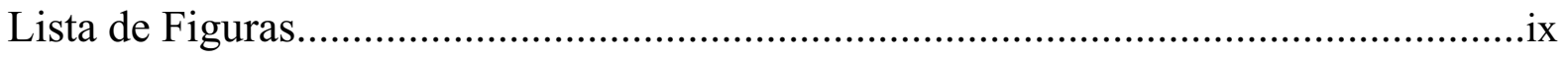

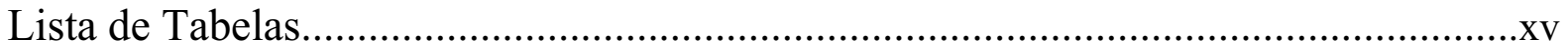

Lista de Abreviaturas e Siglas..................................................................................

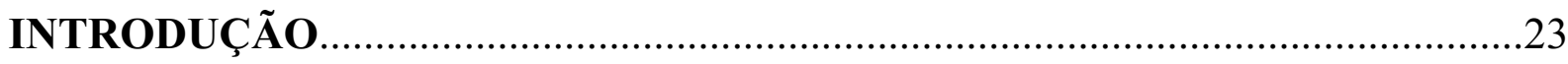

OBJETIVOS

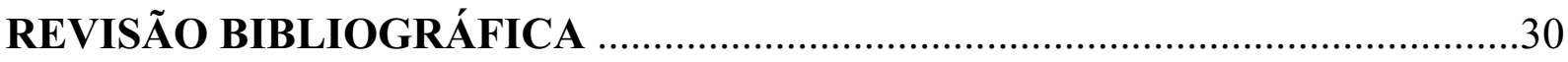

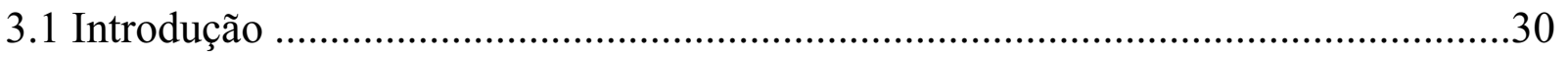

$3.2 \mathrm{O}$ olho humano.

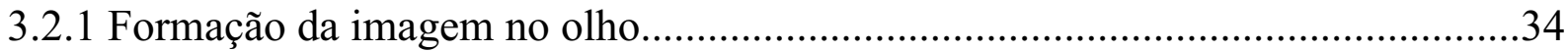

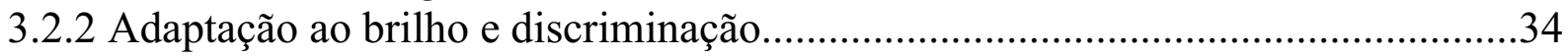

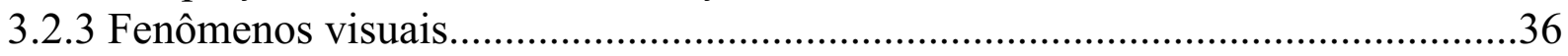

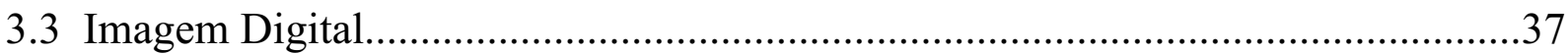

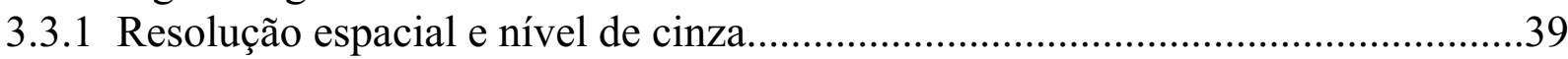

3.3.2 Amostragem e quantificação de imagens................................................................42

3.3.3 Tipos de sensores utilizados para aquisição de imagens.......................................44

3.3.3.1 Aquisição de imagem usando um sensor simples...............................................45

3.3.3.2 Aquisição de imagem usando régua de sensores................................................46

3.3.3.3 Aquisição de imagem usando uma matriz de sensores........................................47

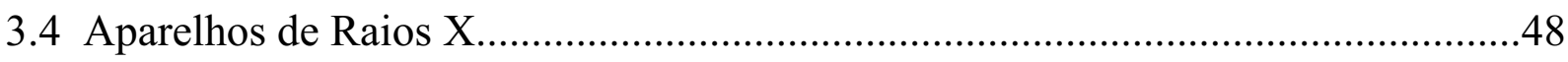

3.5 Forma de interação da radiação com a matéria …………………...........................50

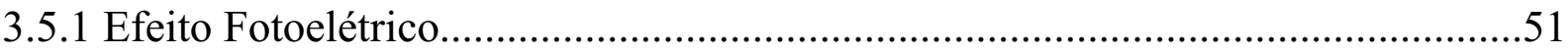

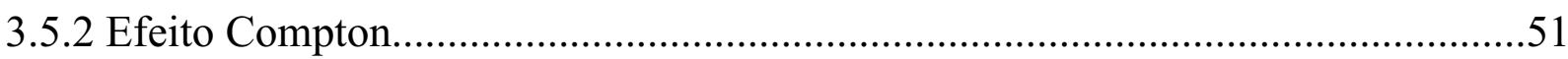

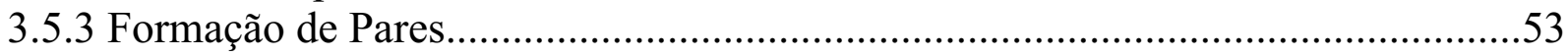

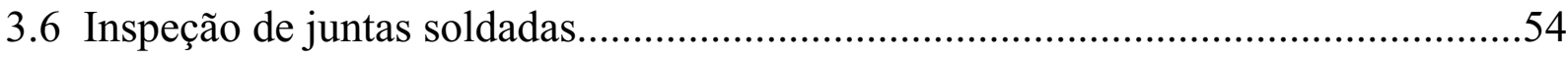

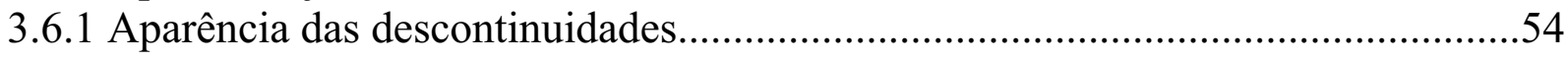

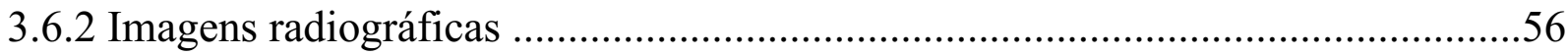

3.6.3 Técnicas de exposição ...................................................................................57

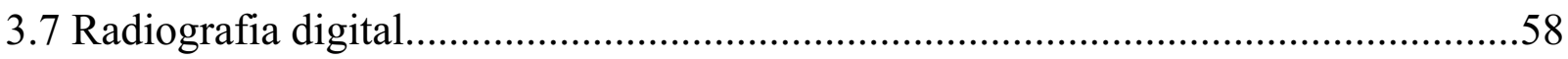

3.7.1 Aplicações atuais da Radiografia Digital ..............................................................58

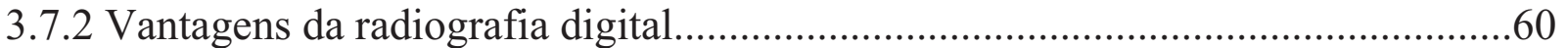

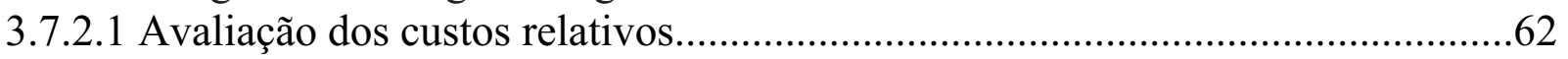

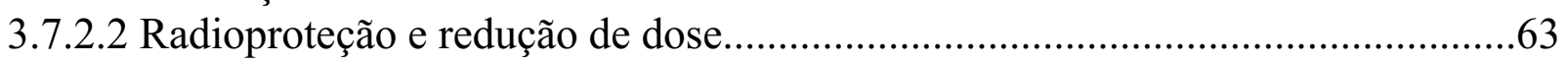

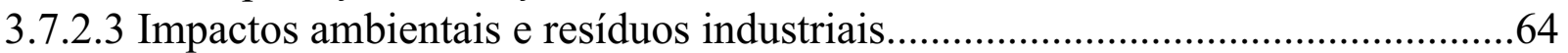


3.7.2.4 Reconhecimento automático de defeitos. .65

3.7.2.5 Comparação do desempenho e probabilidade de detecção de defeitos..............69

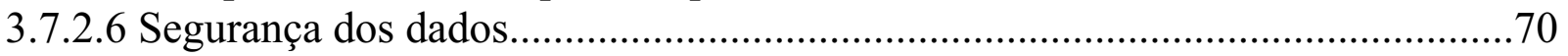

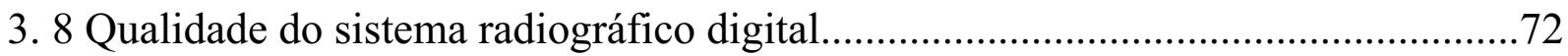

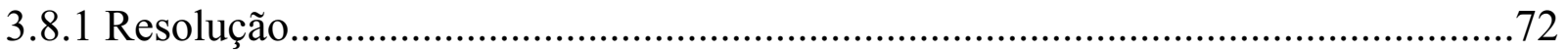

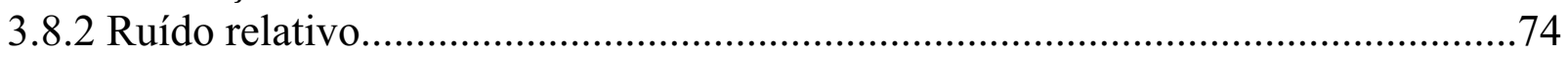

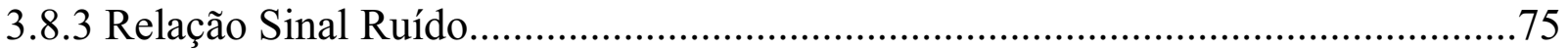

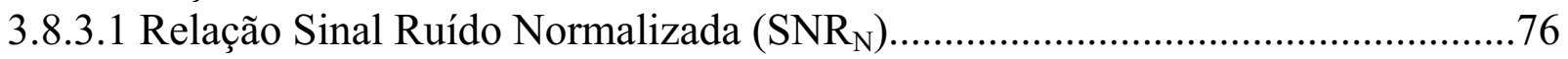

3.8.4 Sensibilidade ao Contraste e Relação Contraste Ruído (Contrast Noise Ratio)....77

3.8.5 Indicadores de Qualidade de Imagem, IQI....................................................78

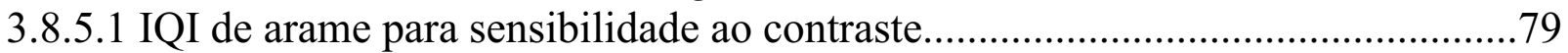

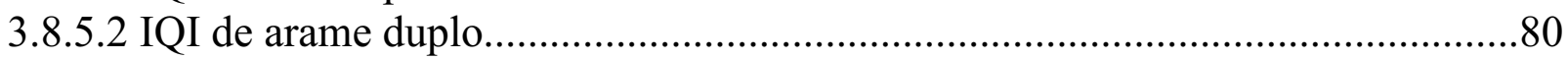

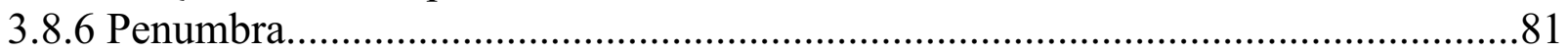

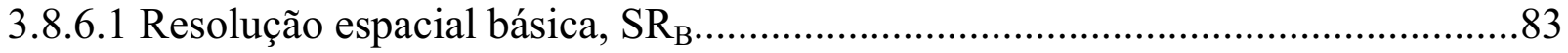

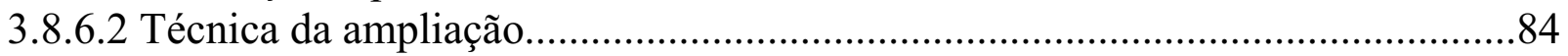

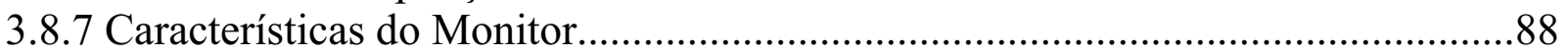

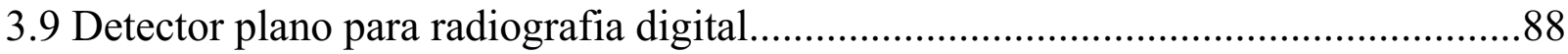

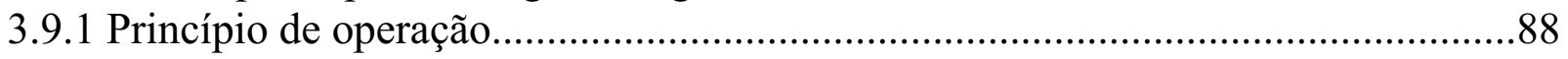

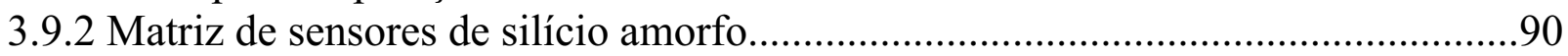

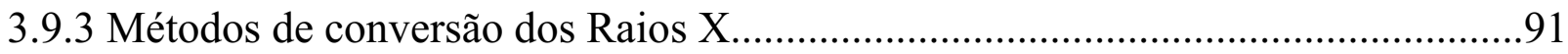

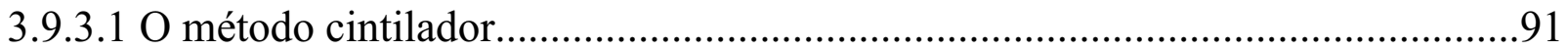

3.10 Programa para controle da qualidade do sistema..................................................92

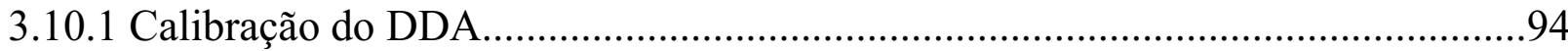

3.10.2 Tratamento para pixel morto...........................................................................95

PROCEDIMENTO EXPERIMENTAL E METODOLOGIA................................97

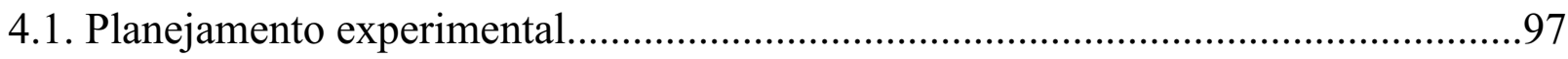

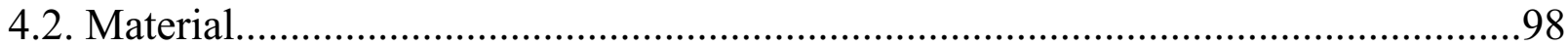

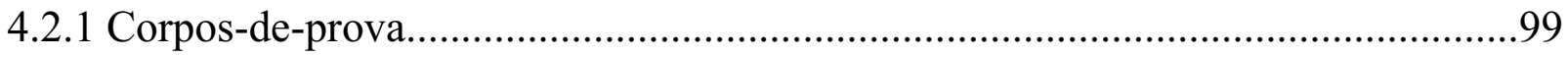

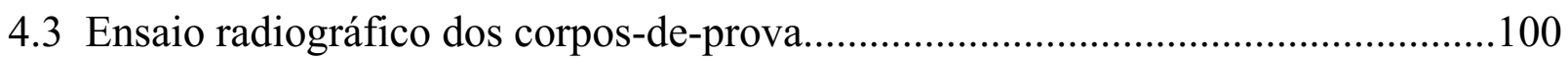

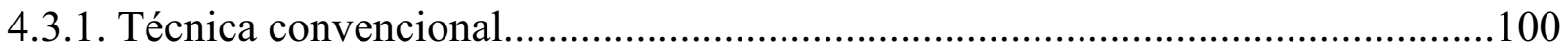

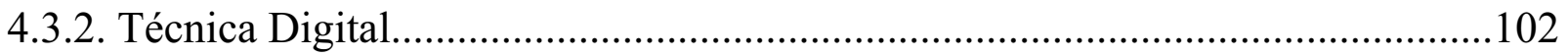

4.3.2.1 Cálculo para determinação das Distâncias.....................................................103

4.3.2.2 Determinação da Resolução Espacial Básica......................................................108

4.3.2.3 Determinação da Sensibilidade ao IQI de Contraste do tipo Arame..................115

4.3.2.4 Determinação da Relação Sinal Ruído Normalizado, $\mathrm{SNR}_{\mathrm{N}}$ ……………........118

4.3.2.5 Verificação da sensibilidade à defeitos reais......................................................119

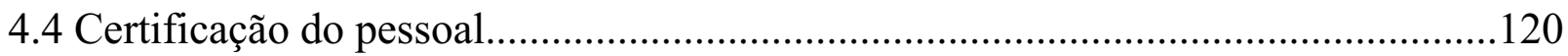




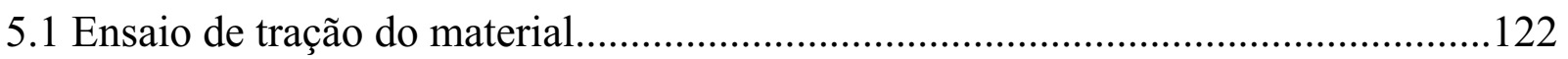

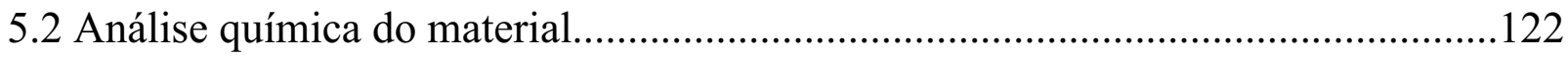

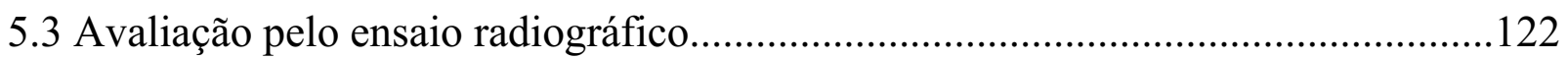

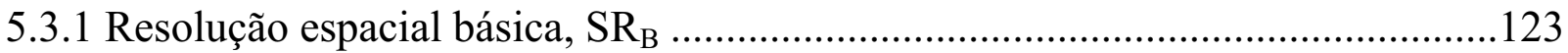

5.3.2 Sensibilidade ao IQI de contraste do tipo arame...................................................131

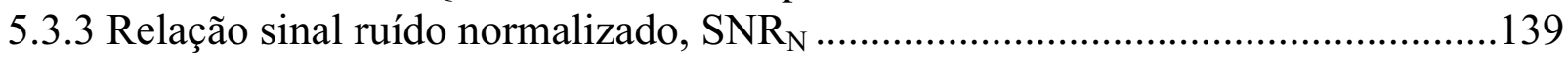

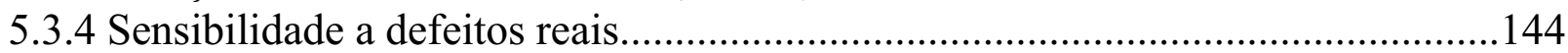

5.3.4.1 Galeria de imagens de defeitos e comparação entre as técnicas.........................148

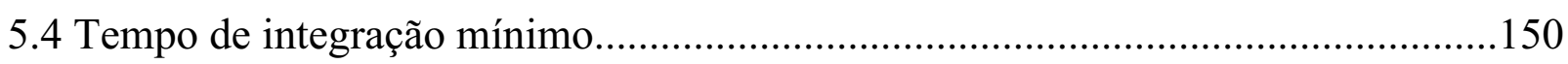

5.5 Comparação das exposições relativas entre as técnicas..........................................153

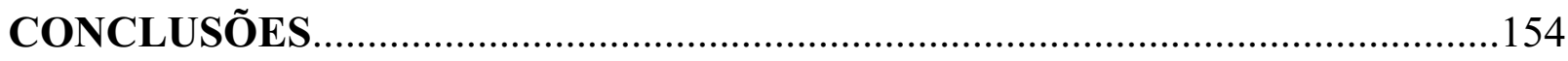

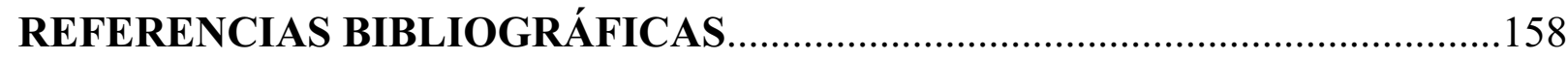




\section{Capítulo 1}

\section{Introdução}

As empresas em busca de petróleo e gás em campos cada vez mais profundos têm exigido um desenvolvimento de melhores produtos e recursos tecnológicos para os dutos a serem utilizados, como é o caso do Brasil com a exploração de águas profundas, incluindo os reservatórios do pré-sal, conforme é mostrado na Figura 1.1. As especificações e normas utilizadas têm aumentado o nível de qualidade do produto, entre outras, diminuírem os tamanhos das descontinuidades aceitas.

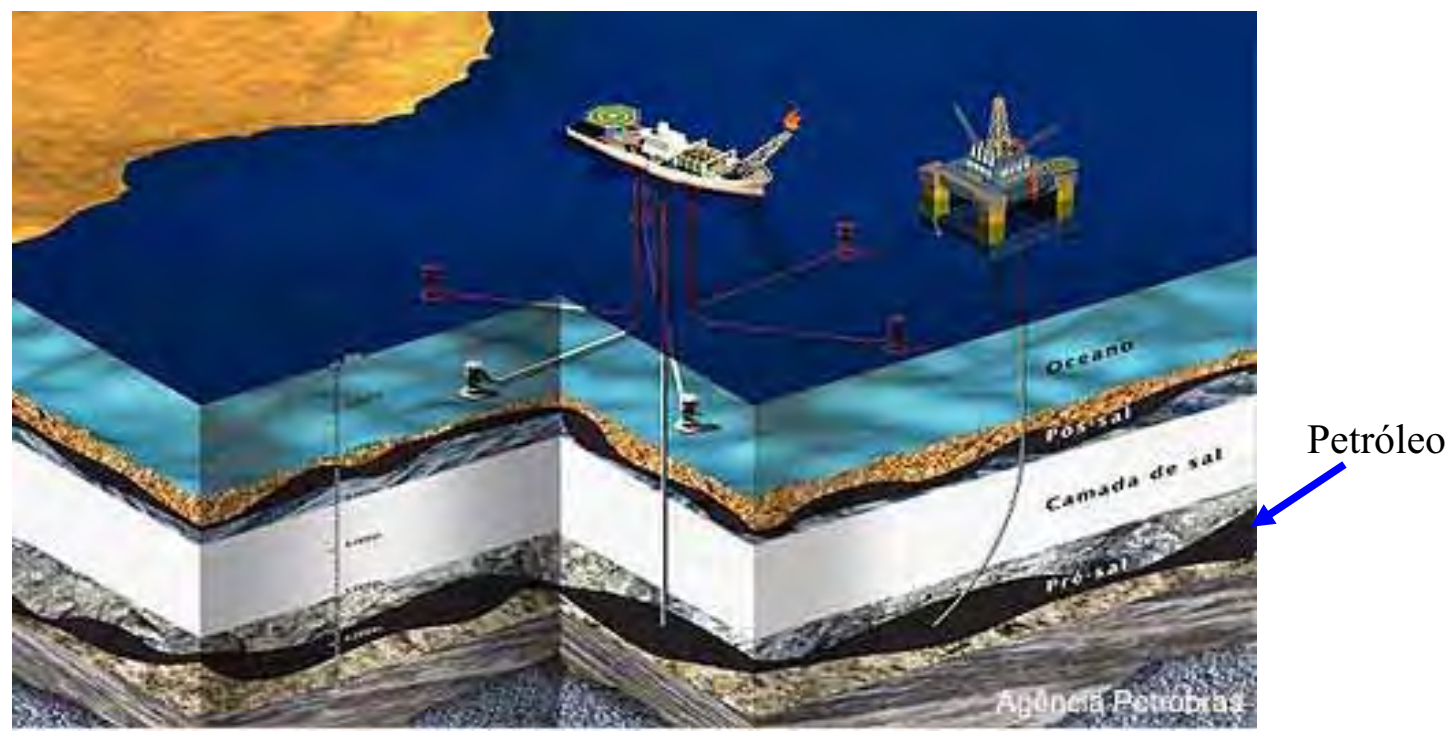

Figura 1.1 - Projeto de duto em águas profundas. Pré-sal (PETROBRAS, 2009).

As características dos tubos de aço, o insumo mais importante destes dutos, são as mais afetadas pelas mudanças exigidas, sendo que e as técnicas de fabricação e controle da manufatura destes tubos, têm buscado a excelência. As características técnicas do aço das chapas utilizadas, o processo de formação e soldagem também estão sendo afetados pela busca de melhores procedimentos. Os processos de controle da qualidade das soldas dos tubos têm buscado aumentar a sua sensibilidade, visando à detecção de descontinuidades menores (ISO 3183; DNV-OS-F101, 2007). 
Dos ensaios não destrutivos, as exigências impostas para o ensaio radiográfico estão no limite do desempenho dos filmes industriais disponíveis, além do compromisso sensibilidade versus tempo de exposição ser sempre um fator importante a ser considerado na produtividade exigida para atendimento dos ciclos de produção que tem de acompanhar a velocidade das montagens dos tubos no campo.

O ensaio radiográfico é muito utilizado durante a fabricação dos tubos e, até o momento, a técnica em uso é com filmes. Esta, por mais que se possa automatizar, é artesanal e demanda um grande esforço repetitivo dos operadores e inspetores envolvidos. As atividades envolvidas, neste tipo de inspeção, vão desde a identificação, colocação do filme, exposição, revelação, fixação, lavagem, laudo até arquivamento e controle por vários anos. Uma das tarefas mais sensíveis deste processo é o laudo das radiografias, onde o inspetor avalia várias radiografias em busca de descontinuidades no cordão de solda que possam ser prejudiciais ao uso futuro do tubo, os denominados defeitos.

A empresa TenarisConfab atualmente é uma das maiores consumidora de filmes industriais no Brasil, com consumo diário de aproximadamente 2000 unidades. Os critérios de aceitação são estabelecidos, normalmente, considerando as dimensões e distribuição dos defeitos e seu tipo. As ferramentas atuais para ajudar o inspetor nesta tarefa são, além de um negatoscópio com intensidade de luz regulável, lentes de aumento, lupas, escalas, etc.

Em termos de normalização da ISO (Internacional Organization for Standartization), o comitê técnico ISO/TC 17, SC 19 está elaborando a norma ISO/DIS 10893-7 (Non-destructive testing of steel tubes - Digital radiographic testing of the weld seam of welded steel tubes for the detection of imperfections) que irá estabelecer as exigências mínimas para a aplicação da radiografia digital em soldas destes tubos. Nesta norma estão sendo incluídas as melhores práticas para aplicação da técnica digital e serviram de base para a elaboração desta tese, juntamente com as normas DNV-OS-F101, API 5L e ISO 3183, normas estas aplicadas mundialmente para a manufatura de tubos (DNV-OS-F101, 2007; API 5L, 2007; ISO 3183, 2007). 
Um dos métodos de imagem previsto na norma ISO/DIS 10893-7 é a radiografia direta (Direct radiography, DR), que utiliza detectores planos (Digital Detector Array, $D D A$ ), pois até o momento não existe uma norma especifica para aplicação em tubos para alta pressão com o uso deste tipo de equipamento.

O DDA, foi escolhido devido ao alto grau de automatização, mais adequado as linhas de produção de produtos seriados, pois as etapas de manuseio e preparação não são necessárias. Este método traz também a redução do tempo de exposição e do tempo de ciclo de operação, que resulta em benefícios à saúde e a segurança dos trabalhadores, além de melhorias significativas relativas ao meio ambiente pela não utilização de filmes e químicos reveladores e fixadores.

A motivação para a aplicação da radiografia digital no segmento de petróleo e gás é devido ao "estado da arte" e ao nível tecnológico e benefícios que se obteve da técnica, nas áreas médica, odontológica, aeroespacial, nuclear, componentes eletrônicos, segurança, arte, etc., onde os tradicionais filmes industriais estão sendo substituídos (AMIN, 2008; BETTUZZI et al., 2004; SAMEI, RAVIN, 2008; VIEIRA et al., 2006; VAN DER STELT, 2005 e 2008; PINCU, KLEINBERGER, 2008).

Nos diversos segmentos, a técnica digital tem sido utilizada como melhoria da qualidade, na redução de doses de exposição e operadores, ganho de produtividade e na melhoria das análises da probabilidade de detecção de defeitos (Probability of Detection, $P O D$ ), aplicadas na análise de integridade de equipamentos (ZSCHERPEL, 2005; MOHR, WILLEMS, 2008; BECKMANN et al., 2008).

No Brasil, alguns procedimentos e aplicações com a radiografia digital, tanto computadorizada como a direta, têm sido avaliados, porém são poucos os casos ainda devidamente normalizados (FERREIRA, 2009; MOREIRA et al., 2009; MOREIRA, 2007; MOREIRA et al., 2007; N-2821, 2007; OLIVEIRA, 2007; RABELLO et al., 2007; SILVA, 2008; SIMÕES et al., 2008).

Baseado nestes fatos, a motivação desta tese é executar os ensaios e medições avaliando os parâmetros da relação sinal ruído das imagens, determinar a resolução espacial básica para cada uma das espessuras envolvidas, determinar a sensibilidade ao 
contraste tanto na região do metal base como na região do cordão de solda, a sensibilidade à pequenos defeitos, fazer a comparação da sensibilidade obtida entre a técnica digital e a convencional, bem como, comparar os tempos de exposição e de integração e também as respectivas exposições relativas.

Os resultados encontrados nesta tese serviram de base para comprovar a possibilidade da sua aplicação no processo de fabricação de tubos utilizados no segmento de petróleo e gás, pois as exigencias são maiores e também devido as dificuldades relativas ao tipo de material, produtividade e sensibilidade.

Iqualmente irá contribuir para a discussão e definições de critérios na elaboração final da norma ISO/DIS 10893-7, e futuramente servirá como base para a elaboração da norma brasileira sobre o assunto.

Desta forma, esta tese encontra-se dividida em 5 capítulos, a saber:

No capítulo 2 estão explicados os objetivos desta tese e as principais etapas e parâmetros verificados.

No capítulo 3 é apresentada a fundamentação teórica do trabalho realizado sobre a técnica radiográfica digital utilizada sendo este basicamente sub-dividido em: fundamentos da imagem digital, tipos de sensores, aparelhos de raios $\mathrm{X}$, forma de interação da radiação com a matéria, inspeção de juntas soldadas.

Especificamente sobre a radiografia digital foram explicadas as aplicações atuais e suas vantagens, parâmetros essenciais para garantia da qualidade da imagem, detector plano, princípio de operação, tipos, métodos de conversão dos raios $\mathrm{X}$, programa para controle da qualidade do sistema digital incluindo calibração e tratamento para pixel morto. 
No capítulo 4 encontram-se apresentados os procedimentos experimentais, metodologias aplicadas e os equipamentos e sistemas utilizados.

No capítulo 5 são mostrados os resultados dos experimentos realizados e as respectivas discussões comparando as técnicas avaliadas.

No capítulo 6 são encontradas as conclusões finais e sugeridos novos temas para serem estudados. 


\section{Capítulo 2}

\section{Objetivos}

O objetivo principal desta tese foi avaliar a qualidade da técnica da radiografia digital, através dos parametros indicados abaixo, em relação à radiografia convencional, que utiliza os tradicionais filmes radiográficos industriais, em juntas soldadas de tubos utilizados em oleodutos e gasodutos marítimos e terrestres.

Para isto, foram realizados experimentos que envolvem a verificação da qualidade das imagens, da sensibilidade destas técnicas na detecção de defeitos críticos, do desempenho em relação às exigências das normas DNV-OS-F101, API 5L, ISO 3183 e os valores propostos que a norma ISO/DIS 10893-7, que está em desenvolvimento e da comparação entre os tempos de exposição e os respectivos resultados.

Na realização do objetivo, as seguintes etapas foram desenvolvidas:

- Avaliação da resolução espacial básica, $\mathbf{S R}_{\mathbf{B}}$ (Basic Spacial Resolution), pela utilização dos Indicadores de Qualidade de Imagem (IQI) de arame duplo colocados no metal base, com e sem calço metálico, pelos métodos do arame duplo e pelo cálculo da função de transferência de modulação (Modulation Transfer Function, MTF), confrontando os resultados com as exigências e propostas das normas envolvidas.

- Avaliação da sensibilidade ao contraste CS (Contrast Sensitivity) através do Indicador de Qualidade de Imagem (IQI), de contraste do tipo arame colocados no metal base e na região da solda, comparando os resultados com as exigências e os valores propostos das normas envolvidas. 
- Medidas e avaliação dos valores da relação sinal ruído normalizada, $\boldsymbol{S N \boldsymbol { R } _ { \boldsymbol { N } }}$ (Signal Noise Ratio Normalized) das imagens digitais obtidas com vários tempos de integração, em relação às exigências das normas envolvidas.

- Obtenção das imagens digitais e radiografias convencionais dos mesmos corpos-de-prova com defeitos críticos, para comparar a sensibilidade da detecção de cada uma das técnicas, nas 6 espessuras de metal base, a saber, 4,9; 6,$4 ; 9,7 ; 19,2 ; 25,3$ e $32,3 \mathrm{~mm}$ e com os respectivos valores correspondentes a espessura total que incluem as alturas dos reforços de solda.

- Análise e discussão dos resultados comparando com as exigências das normas, os valores que estão sendo prospostos para a norma ISO/DIS 10893-7 e especificações aplicáveis para redação desta tese de doutorado.

- Comparação dos tempos de exposição na técnica convencional e os tempos de integração na técnica digital, visando verificar os ganhos de produtividade.

- Comparação dos valores das exposições relativas aplicadas na técnica convencional e digital, visando comparar melhorias relativas a radioproteção dos operadores e inspetores envolvidos. 


\section{Capítulo 3}

\section{Revisão Bibliográfica}

\subsection{Introdução}

A primeira imagem digital está completando 50 anos, abrindo o caminho para as imagens de satélites, scanners, código de barras, etc. A imagem granulada de um bebê, de apenas 5x5 centímetros, Figura 3.1, 176 pixels, foi feita por Russell Kirsch, no National Bureau of Standards (NBS), agora conhecido por National Institute of Standards and Technology (NIST).

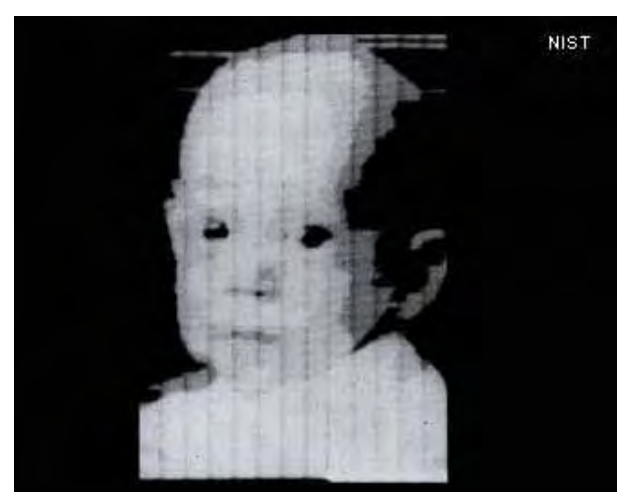

Figura 3.1 - Primeira imagem digital - 176 pixels (KIRSCH, 1957)

A tecnologia da imagem digital, utilizada atualmente pela radiografia digital, é devida, principalmente, ao crescimento da memória e da velocidade dos sistemas computadorizados. Nos anos de 1980, imagem de 512 x 512 pixels com 8 bits (256 Kilobites) era considerada muito grande e trazia problemas de armazenamento e para os monitores daquela época. Agora no século XXI, arquivos de imagens de $1500 \mathrm{x}$ 2000 com 16 bits de dados (6 MB) são muito comuns, e podem ser transmitidos, armazenados e mostrados por sistemas de computadores com preço relativamente baixos (BOSSI et. al.; 2002).

Atualmente a maior imagem digital do mundo foi criada pela empresa canadense Aperio, que criou uma fotografia digital com a qualidade de um Terapixel, ou seja, com um trilhão de pixels. $\mathrm{O}$ arquivo de imagem tem $143 \mathrm{~GB}$ e tem o formato BigTIFF, inventado para a utilização em análises de exames médicos (TERRA,2007). 
A radiografia digital encontra-se disponível para os dentistas há 25 anos, porém as clínicas não têm substituído a técnica convencional devido aos custos envolvidos. Na medida em que as clínicas dentárias estão conhecendo os benefícios, este cenário pode ser alterado. Os dentistas podem melhorar a imagem para a sua interpretação e, além disto, podem corrigí-las se foram pouco expostas ou muito expostas, pela melhoria do contraste e do brilho ou de diagnósticos específicos, tais como cáries, implantes, etc. Na Figura 3.2 estão representados dois exemplos de ferramenta de medida que auxilia o dentista no diagnóstico de um tratamento de canal (a) e radiografia digital panorâmica dos dentes (b) (VAN DER STELT, 2008).
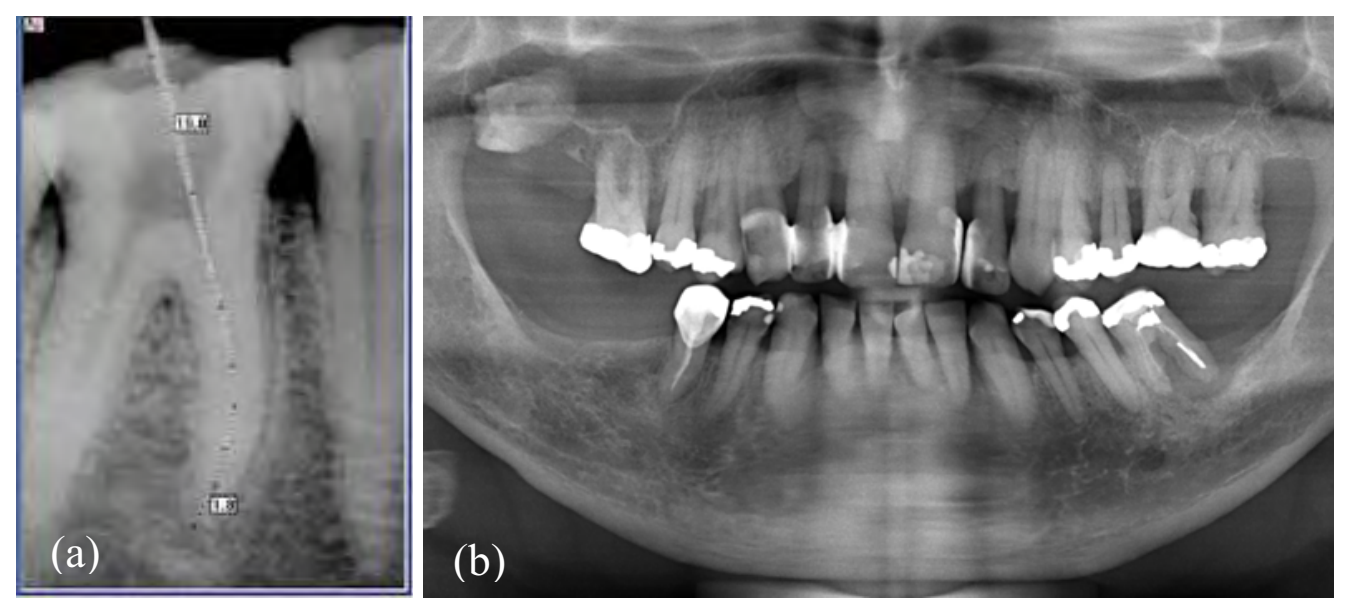

Figura 3.2 - Radiografia digital (a) Diagnóstico de tratamento de canal. (b) Panorâmica da boca (VAN DER STELT, 2008).

Todos os sistemas para radiografia digital foram desenvolvidos como sistemas médicos e hoje está efetivo e considerado um método eficiente para imagens radiográficas. Os modernos detectores de raios $\mathrm{X}$ médicos mostram a imagem diretamente no computador. Isto facilita o acesso às imagens arquivadas, que podem ser visualizadas no monitor e, simultaneamente, melhoradas por algoritmos de processamentos inteligentes. Há também a redução da dose recebida pelo paciente. Por estas razões os detectores digitais têm substituído, nos últimos anos, os filmes e agregado técnicas radiológicas nas aplicações médicas. A radiografia industrial tem se beneficiado deste progresso e as soluções médicas têm sido transferidas e adaptadas às necessidades das aplicações dos ensaios não destrutivos (VAN DER STELT, 2008). A radiografia digital computadorizada teve sua primeira aplicação em 1975, quando George Luckey desenvolveu a placa flexível de fósforo para armazenamento de imagem na Eastman Kodak Company. No mesmo ano, foi patenteado o primeiro 
sistema de fósforo de armazenamento escaneado, dando origem à moderna radiografia computadorizada. No entanto, só em 1983 foi comercializado o primeiro sistema que empregava a tecnologia de fósforo de armazenamento (MANGO; 2004, ALLEN, DRAKE; 2005).

\subsection{O olho humano.}

Na Figura 3.3 é representada uma secção do olho humano. O olho é aproximadamente uma esfera, com o diâmetro em média de $20 \mathrm{~mm}$. Três membranas envolvem os olhos: a córnea e esclera capa externa, coróide e retina. A córnea é uma pele dura e transparente que cobre a superfície anterior do olho. A continuação da córnea, a esclera é uma membrana opaca que envolve o restante do globo óptico. A coróide é uma membrana que fica diretamente abaixo da esclera e contém os vasos sanguíneos que servem como a maior fonte de nutrição do olho (GONZALEZ, WOODS, 2002).

A membrana mais interna do olho é a retina, a qual fica no interior da parede posterior. Quando o olho é focado, a luz do objeto fora do olho é criada como imagem na retina. A visão é conferida pela distribuição da luz sobre os receptores situados na superfície da retina. Existem duas classes de receptores: cones e bastonetes. Cada olho tem entre 6 e 7 milhões. Eles estão localizados principalmente na parte central da retina, chamada fóvea, e são altamente sensíveis à cor.

Seres humanos podem resolver detalhes finos com esses cones em grande medida porque cada um está conectado ao seu próprio nervo. Músculos controlando a rotação das bolas dos olhos giram o olho até que a imagem de um objeto de interesse recaia na fóvea. A visão do cone é chamada de visão fotópica ou luz brilhante. $\mathrm{O}$ número de cones é muito maior: alguns 75 a 150 milhões são distribuídos sobre a superfície da retina. A grande área de distribuição e o fato de que vários cones estão conectados a um nervo final simples reduz a quantidade de detalhes discerníveis por estes receptores. 
Bastonetes servem para dar, em geral, a imagem do campo de visão. Eles não estão envolvidos na visão de cor e são sensíveis a baixos níveis de iluminação. Por exemplo, objetos que aparecem bem coloridos na luz do dia, quando vistos a noite aparecem incolores, porque apenas os bastonetes são estimulados.

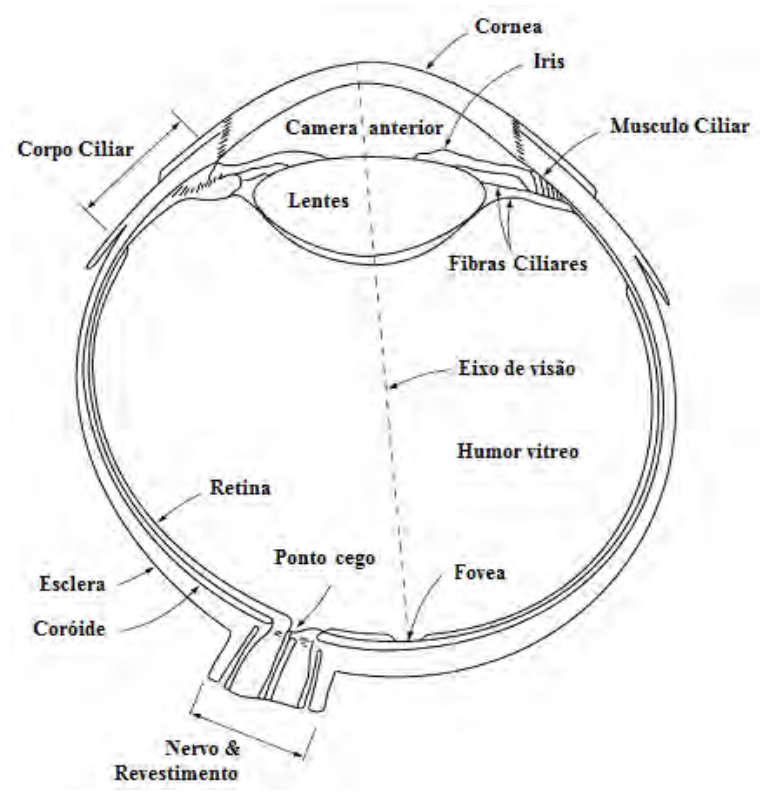

Figura 3.3 - Diagrama simplificado da seção do olho humano (GONZALEZ, WOODS, 2002).

A Figura 3.4 mostra a densidade de bastonetes e cones para uma seção transversal do olho direito que atravessam a região de emergência do nervo óptico do olho. A ausência de receptores nesta área resulta no chamado ponto cego. Exceto para esta região, a distribuição dos receptores é radialmente simétrica sobre a fóvea. A densidade do receptor é medida em graus, a partir da fóvea (isto é, em graus fora do eixo, conforme medido pelo ângulo formado pelo eixo visual e uma linha que passa através do centro da lente e interseção da retina) (GONZALEZ, WOODS, 2002).

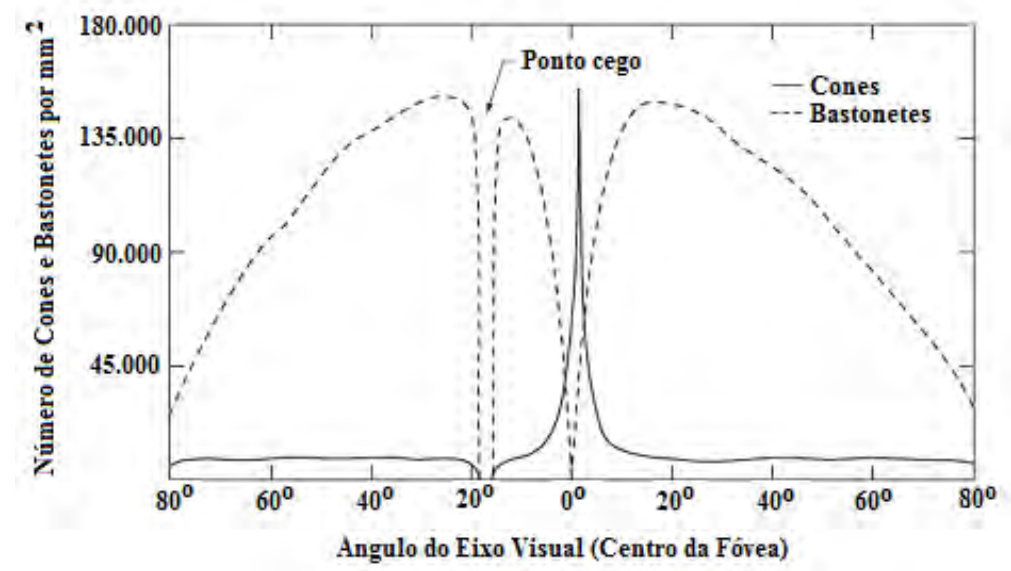

Figura 3.4 - Ângulo de visão versus número de bastonetes e cones (GONZALEZ, WOODS, 2002). 
É observado na Figura 3.4 que cones são mais densos no centro da retina (na área central da Fóvea). Observa-se também que a densidade de bastonetes aumenta até o ângulo de $20^{\circ}$ fora do eixo visual e, em seguida, começa a diminuir até a extremidade da periferia da retina.

\subsubsection{Formação da imagem no olho}

A principal diferença entre a lente do olho e uma lente óptica é que o foco é flexível. Conforme ilustrado na Figura 3.5, o raio de curvatura da superfície anterior da lente é maior que o raio da sua superfície posterior. A forma da lente é controlada pela tensão nas fibras do corpo ciliar. Para focar em objetos distantes, os músculos controlam a lente para ter uma forma relativamente plana. Da mesma forma, estes músculos controlam a lente para se tornar mais espessa, para focar em objetos perto do olho. A distância entre o centro da lente e a retina (chamada de distância focal) varia de $14 \mathrm{~mm}$ a $17 \mathrm{~mm}$, e com este poder de refração as lentes aumentam do mínimo ao máximo.

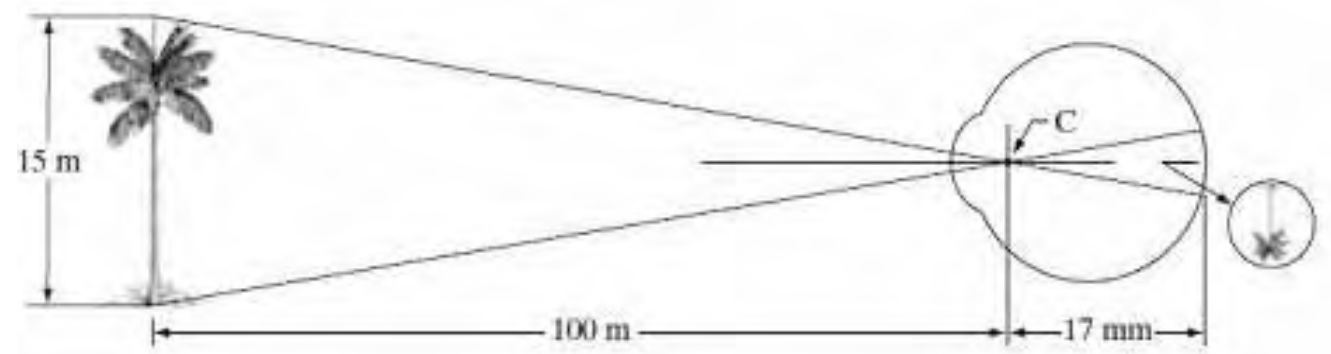

Figura 3.5 - Representação gráfica, olho vendo palmeira. Ponto C é o centro da lente ótica (GONZALEZ, WOODS, 2002).

A imagem da retina reflete inicialmente na área da fóvea e há excitação dos receptores de luz, que transforma a energia radiante em impulsos elétricos que são decodificados pelo cérebro (GONZALEZ, WOODS; 2002).

\subsubsection{Adaptação ao brilho e discriminação}

Devido às imagens digitais serem exibidas como um conjunto distinto de intensidades, a capacidade do olho de discriminar entre níveis de intensidades diferentes é uma consideração importante na apresentação dos resultados do 
processamento de imagem. A faixa de níveis de intensidade da luz que o sistema visual humano pode se adaptar é enorme, da ordem de $10^{10}$, do limite do escuro (penumbra) ao limite do claro.

Dados experimentais indicam que o brilho subjetivo, ou seja, a percepção da intensidade pelo sistema visual humano, é uma função logarítmica da intensidade da luz incidente sobre o olho (GONZALES, WOODS; 2002). Na Figura 3.6 a curva da intensidade da luz versus o brilho subjetivo ilustra esta característica.

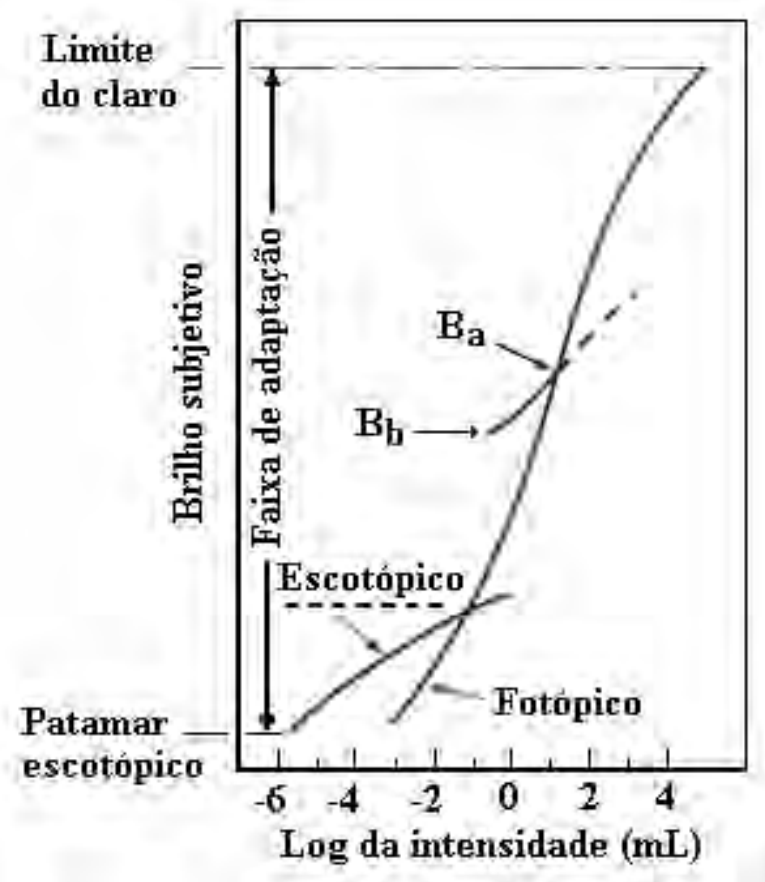

Figura 3.6 - Curva da intensidade da luz versus o brilho subjetivo do olho humano (WOODS; 2002).

A curva sólida longa representa a faixa de intensidades o qual o sistema visual consegue se adaptar. Na visão fotópica (percepção visual com alta intensidade de luz) por si só, o intervalo é de $10^{6}$. A transição da escotópica (percepção visual com baixa intensidade de luz) para a visão fotópica é gradual ao longo do intervalo aproximado de 0,001 a 0,1 mililambert ( -3 a $-1 \mathrm{~mL}$ na escala logarítmica), como as ramificações dupla da curva de adaptação neste intervalo mostrado. O ponto essencial na interpretação do intervalo dinâmico, representado na Fig. 3.6, é que o sistema visual não pode operar no tal intervalo simultaneamente. Em vez disso, ele realiza esta grande variação por alterações na sua sensibilidade geral, através de um fenômeno conhecido como adaptação ao brilho. O intervalo completo de níveis de intensidade distintos, que o olho pode perceber simultaneamente é pequeno quando comparado com o intervalo 
de adaptação total. Para qualquer dado conjunto de condições, o nível atual de sensibilidade do sistema visual é chamado de nível de adaptação ao brilho, que pode corresponder, por exemplo, a luminosidade no ponto $B_{\mathbf{a}}$ da Figura 3.6 (GONZALEZ, WOODS; 2002).

\subsubsection{Fenômenos visuais.}

Dois fenômenos demonstram claramente que o brilho aparente não é função só da intensidade. O primeiro é que o sistema visual tende a subestimar ou superestimar a intensidade perto do limite entre as regiões de diferentes intensidades. Na Figura 3.7 é representado um exemplo deste fenômeno. Embora a intensidade real da escala seja constante, a intensidade percebida é aumentada, especialmente perto desta região. Este é chamado de "Bandas de Mach", pois foi Ernst Mach que descreveu este fenômeno em 1865 (PRATT; 2001).

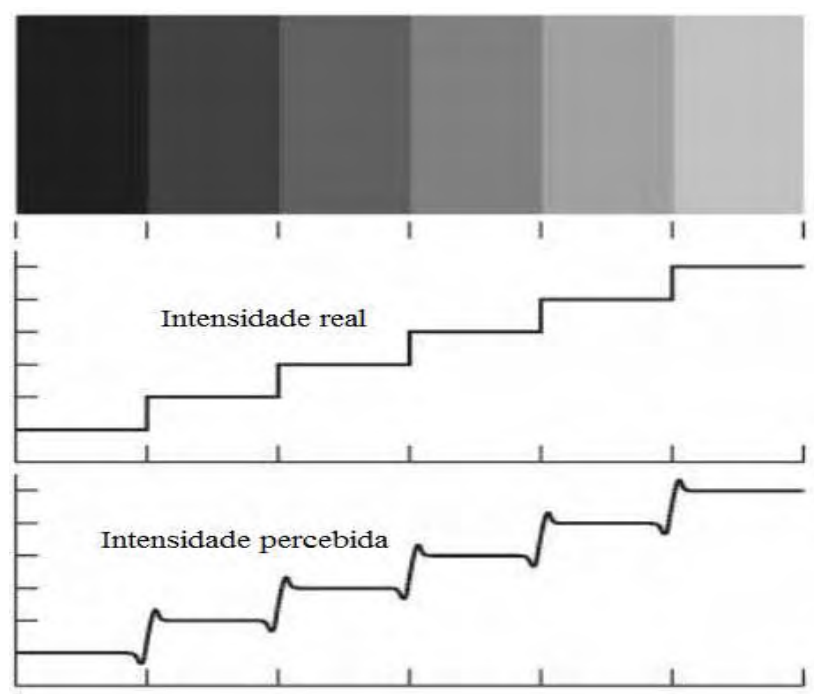

Figura 3.7 - Fenômeno Bandas de Mach (PRATT; 2001).

O segundo fenômeno, chamado de contraste simultâneo, está relacionado com o fato de que uma região com certo brilho não depende simplesmente de sua intensidade, como é demonstrado na Figura 3.8. Todos os quadrados do centro têm exatamente a mesma intensidade, no entanto, aparentam se tornar mais escuros quando a intensidade do quadrado do fundo se torna mais claro (PRATT; 2001). 

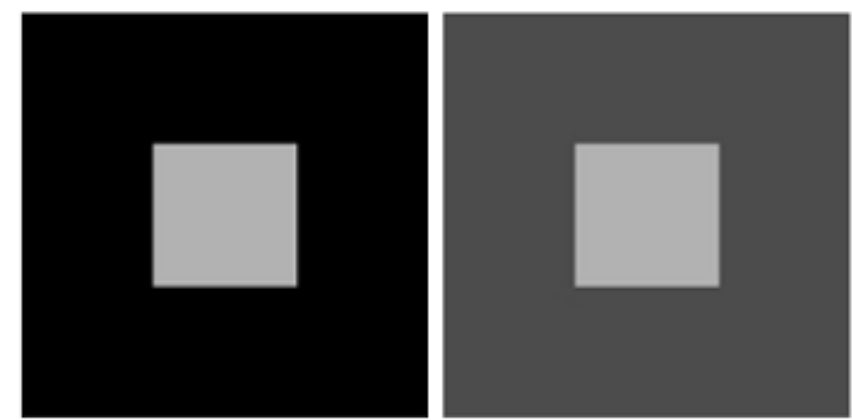

Figura 3.8 - Fenômeno de contraste simultâneo (PRATT; 2001).

Outros exemplos de fenômenos da percepção humana são as ilusões de ótica, nas quais os olhos preenchem informações inexistentes. Alguns exemplos são mostrados na Figura 3.9. Na Figura 3.9a, o contorno de um quadrado é visto claramente, apesar de não existirem as linhas que representam as arestas. $\mathrm{O}$ mesmo efeito ocorre com um círculo, que pode ser visto na Figura 3.9b. Observa-se que apenas algumas linhas são suficientes para dar a ilusão de um círculo completo. Os dois segmentos de linha horizontais na Figura 3.9c são do mesmo comprimento, mas o superior aparenta ser mais curto que o inferior.

Finalmente, todas as linhas na Figura $3.9 \mathrm{~d}$ são orientadas a $45^{\circ}$ sendo equidistantes e paralelas. Há um efeito de ilusão, em função dos traços na vertical e horizontal, de que essas linhas não são paralelas. Ilusões de ótica são características do sistema visual humano que não são totalmente compreendidas (GONZALEZ, WOODS; 2002).

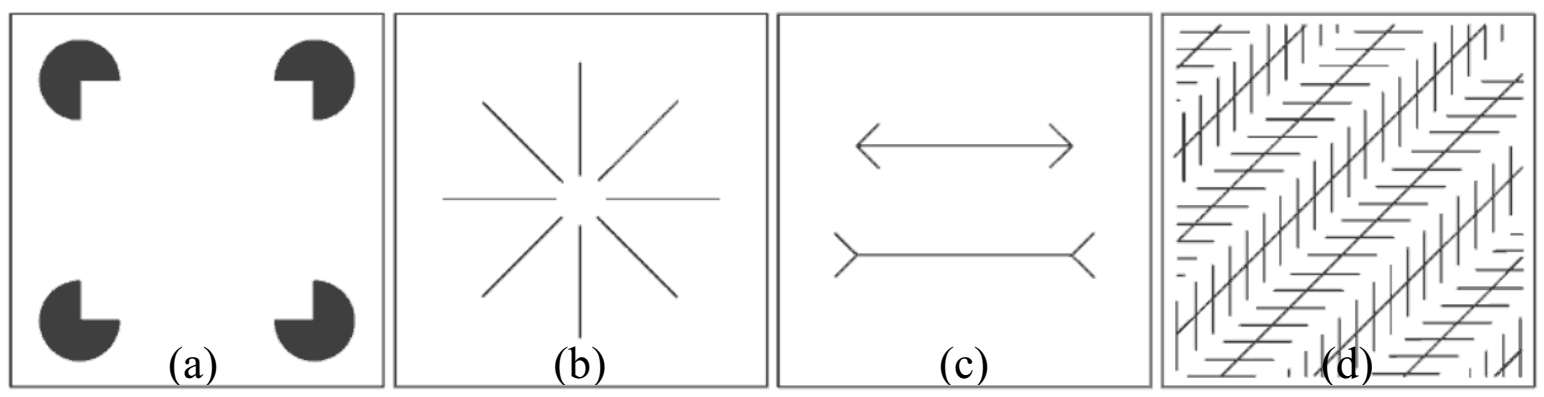

Figura 3.9 - Algumas ilusões de óticas bem conhecidas (GONZALEZ, WOODS; 2002).

\subsection{Imagem Digital}

Uma imagem digital, por outro lado, é composta de um conjunto de células que são ordenadas em linhas e colunas, onde cada célula é caracterizada por três números: a coordenada $\mathrm{x}$, a coordenada y e o valor de cinza. $\mathrm{O}$ valor de cinza é um número que 
corresponde com a intensidade dos raios $\mathrm{X}$ recebida naquele local durante a exposição do sensor. Uma célula individual é chamada de "elemento de imagem", que foi reduzida para "pixel". A palavra pixel baseia-se, em inglês, numa contração do pix ("imagem") e el (para "elemento"). Os números que descrevem cada pixel são armazenados no arquivo da imagem.

Na Figura 3.10 (a) até (d) pode ser observada, a imagem radiológica como obtida depois que o feixe de raios X passou através de um objeto (a) e a imagem sobreposta esquematicamente à grade de pixels (b). Em (c) é mostrada a representação numérica dos valores de cada pixel correspondente aos níveis de cinza, devido as intensidades de raios $\mathrm{X}$ recebidas em cada posição, e em (d) a imagem digital que é mostrada na tela do computador, onde cada pixel do sensor corresponde a um pixel na tela do monitor.

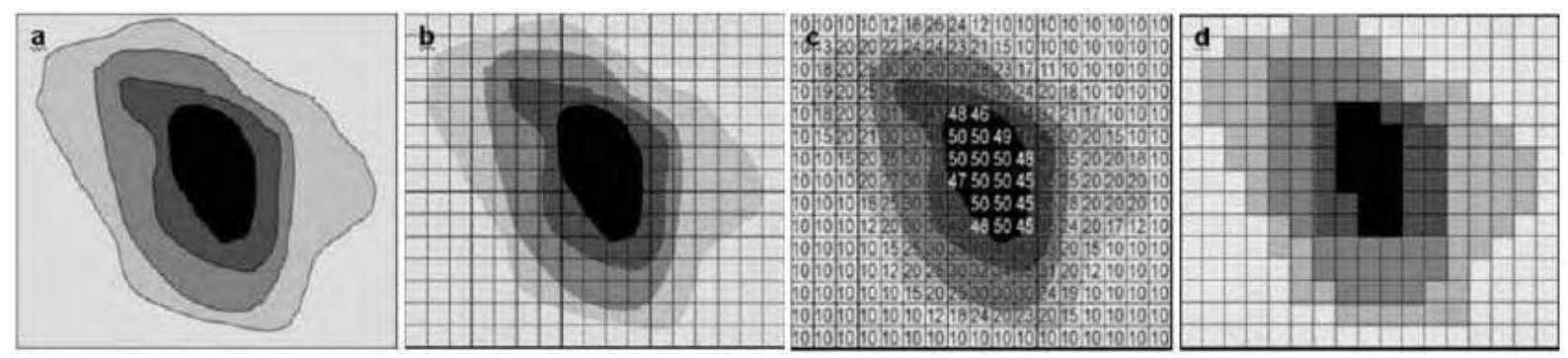

Figura 3.10 - Conceito de uma imagem digital (VAN DER STELT, 2008).

A imagem digital é armazenada através de dígitos binários denominados bits, que podem assumir os valores 0 ou 1 . A um conjunto de bits chama-se de byte. Os bits e bytes são usados para representar os pixels da imagem digital. Diferentes configurações de bytes representam as diversas tonalidades de grau de cinza nos pixels. A Figura 3.11 mostra a relação entre as configurações de bytes, valores de pixel e tonalidades de cinza.

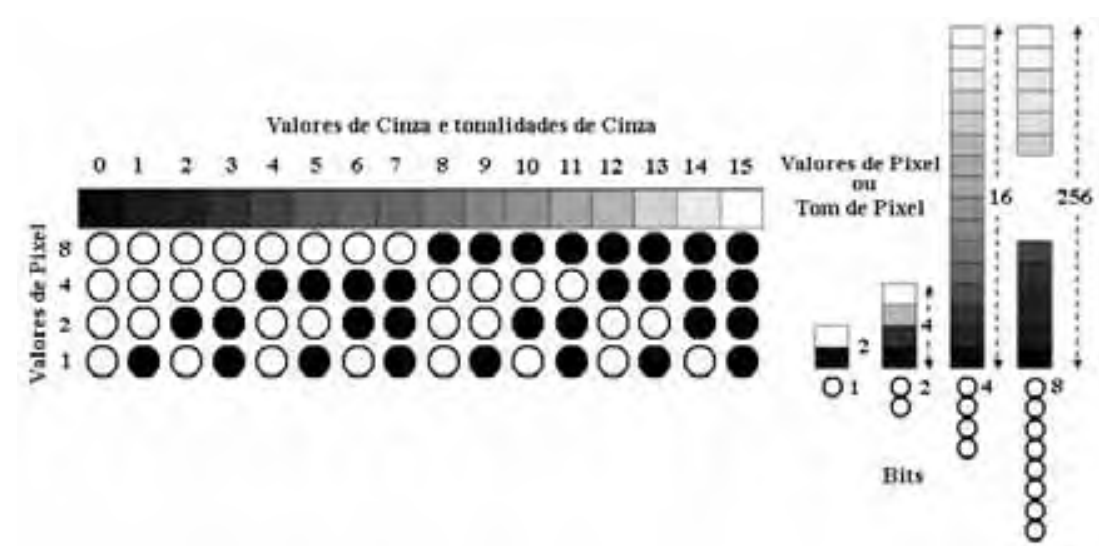

Figura 3.11 - Comportamento entre os valores de pixel e os tons de cinza (OLIVEIRA, 2007). 


\subsubsection{Resolução espacial e nível de cinza}

Amostragem é o principal fator que determina a resolução espacial de uma imagem. Basicamente, resolução espacial é o menor detalhe perceptível em uma imagem. Suponha que será construído um gráfico com linhas verticais na largura W, com o espaçamento entre pares de linhas também com largura W. Um par de linhas consiste de uma linha e o seu espaço adjacente. Assim por definição, a largura de um par de linhas é de $2 \mathrm{~W}$ e existem $1 / 2 \mathrm{~W}$ pares de linhas por unidade de distância. Uma definição amplamente usada é simplesmente "o menor número de pares de linhas discerníveis por unidade de distância, por exemplo, 100 pares de linhas por milímetro.

A resolução de níveis de cinza, da mesma forma, se refere à menor alteração perceptível no nível de cinza. Porém, como foi citado anteriormente, discernir alterações dos níveis de cinza é um processo de medição subjetivo. Deve-se considerar o número de amostras utilizadas para gerar uma imagem digital, mas isso não é verdade para o número de níveis de cinza.

O número de níveis de cinza é normalmente um número inteiro na potência de 2. O número mais comum é 3 ( 8 bits, $2^{3}$ ) e o 4 (16 bits, $2^{4}$ ), que são usados em algumas aplicações, onde é necessária a melhoria de intervalos específicos de níveis de cinza. Quando uma medida real da resolução física informando pixels e o nível de detalhes resolvidos é exigido, deve-se referir a um nível "L" de imagem digital com M x N de tamanho. Assim, todas as vezes que necessitar uma referência real do detalhe a ser resolvido deverá ser utilizado a terminologia correta para esclarecer (GONZALEZ, WOODS; 2002).

Na Figura 3.12 é representada uma imagem de tamanho de 1024x1024 pixels, cujos níveis de cinza são representados por 8 bits, sendo que as outras imagens mostradas são os resultados da diminuição da resolução da imagem de 1024x1024. 


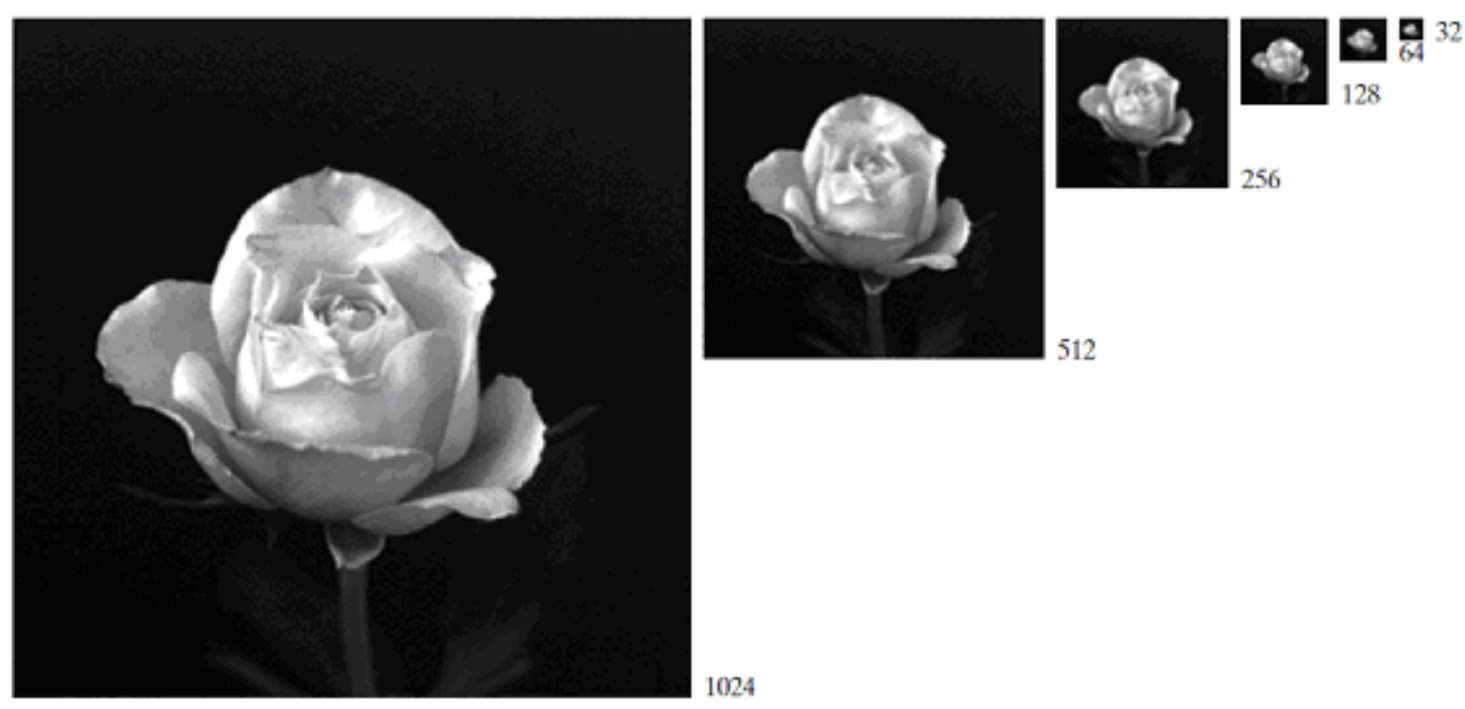

Figura 3.12 - Uma imagem de 1024 x 1024, de 8 bits reduzida para o tamanho de 32 x 32 pixels. O número de níveis de cinza foi mantido a 256 (GONZALEZ, WOODS; 2002).

A diminuição da resolução foi realizada, excluindo o número de linhas e colunas da imagem original. Por exemplo, a imagem de 512 x 512 foi obtida pela exclusão de todas as outras linhas e colunas da imagem de 1024 x 1024. A imagem de $256 \times 256$ foi gerada pela exclusão de todas as outras linhas e colunas da imagem de 512 x 512 e assim por diante. O número de níveis de cinza foi mantido a 256. Estas imagens mostram as proporções dimensionais entre diferentes densidades de amostragem, mas suas diferenças de tamanho dificultam a ver os efeitos resultantes de uma redução do número de amostras (GONZALEZ, WOODS; 2002).

A forma mais fácil de comparar esses efeitos é trazer todas as imagens que foram reduzidas até ao tamanho de 1024 x 1024 por duplicação de pixel das linhas e colunas. Os resultados são mostrados na Figura 3.13(b) até (f).

A Figura 3.13(a) é a mesma imagem 1024 x 1024, com 256 níveis de cinza, como demonstrado na Figura 3.12. Ela é repetida para facilitar comparações. Comparando a imagem de 1024x1024, Figura 3.13(a), com a imagem de 512 x 512, na Figura 3.13(b), observa-se que não são observadas diferenças destas imagens lado a lado. O nível de detalhe perdido é pequeno para ser percebido na página impressa, com a escala a qual estas imagens estão sendo mostradas. 

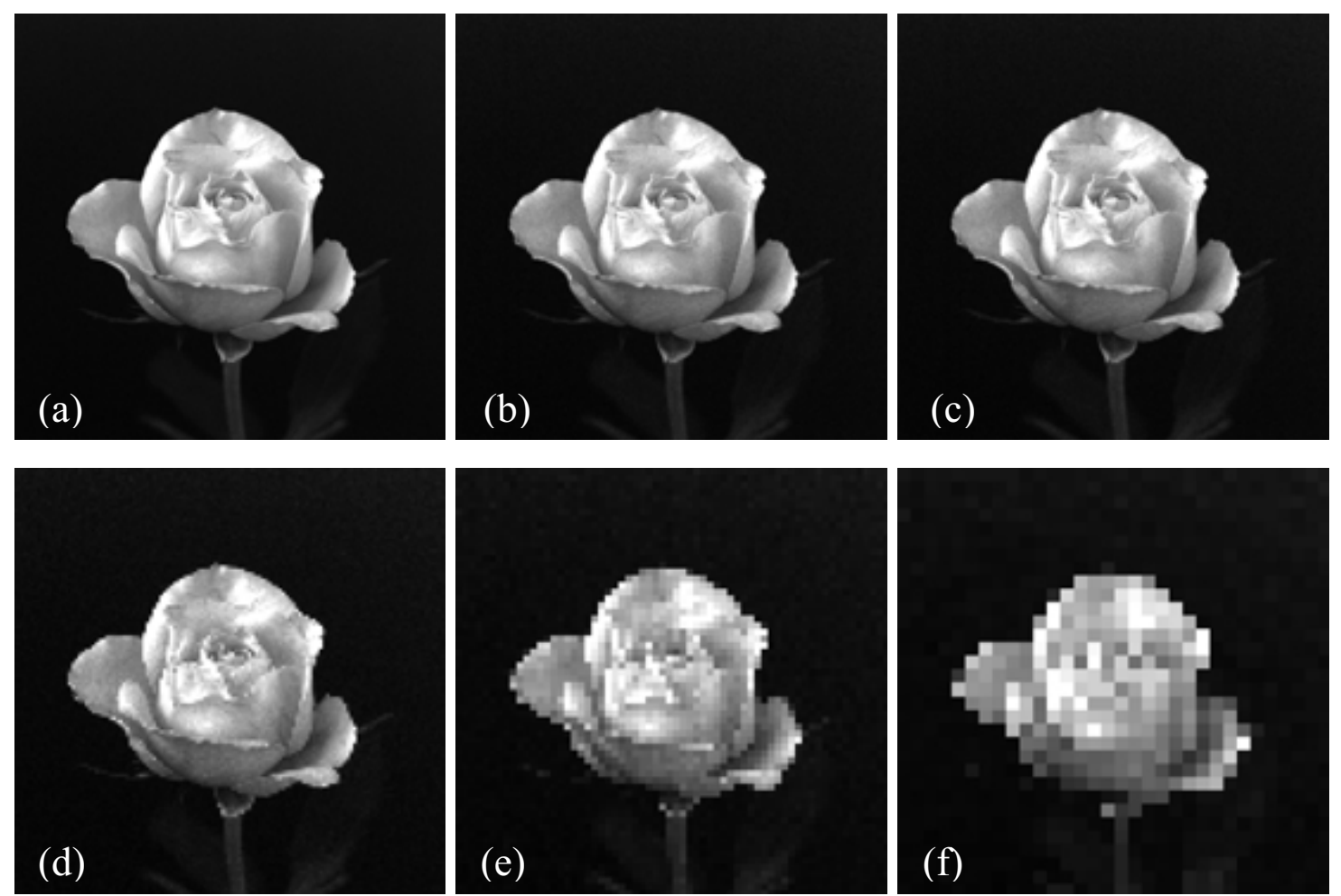

Figura 3.13 (a) Imagem de 1024 x 1024, 8 bits. (b) Imagem de 512 x 512 redefinida para 1024 x 1024 pixels por duplicação de linha e coluna. (c) até (f) Imagens redefinidas de 32 x 32, 64 x 64, 128 x 128 e 256 x 256 para 1024 x 1024 pixels (GONZALEZ, WOODS; 2002).

Em seguida, a imagem de 256 x 256, na Figura 3.13(c), mostra um quadriculado muito pequeno nas bordas entre as pétalas de flores e o plano de fundo preto e começa a aparecer uma granulação ligeiramente mais pronunciada por toda a imagem. Estes efeitos são muito mais visíveis na imagem de 128 x 128, na Figura 3.13(d), e eles tornam-se pronunciados nas imagens 64 × 64 e 32 × 32, nas Figuras 3.13(e) e (f), respectivamente.

A Figura 3.14(a) é de uma imagem de projeção da tomografia 452 x 374, exibido com $\mathrm{k}=8$ (256 níveis de cinza), obtida por meio da fixação da fonte de raios X em uma posição e, assim, produzindo uma imagem 2-D em qualquer direção desejada (GONZALEZ, WOODS; 2002). Podem-se observar efeitos típicos da variação do número de níveis de cinza em uma imagem digital. Neste exemplo, foi mantido o número de amostras constante e reduzido o número de níveis de cinza de 256 para 2, em potências de 2 . 

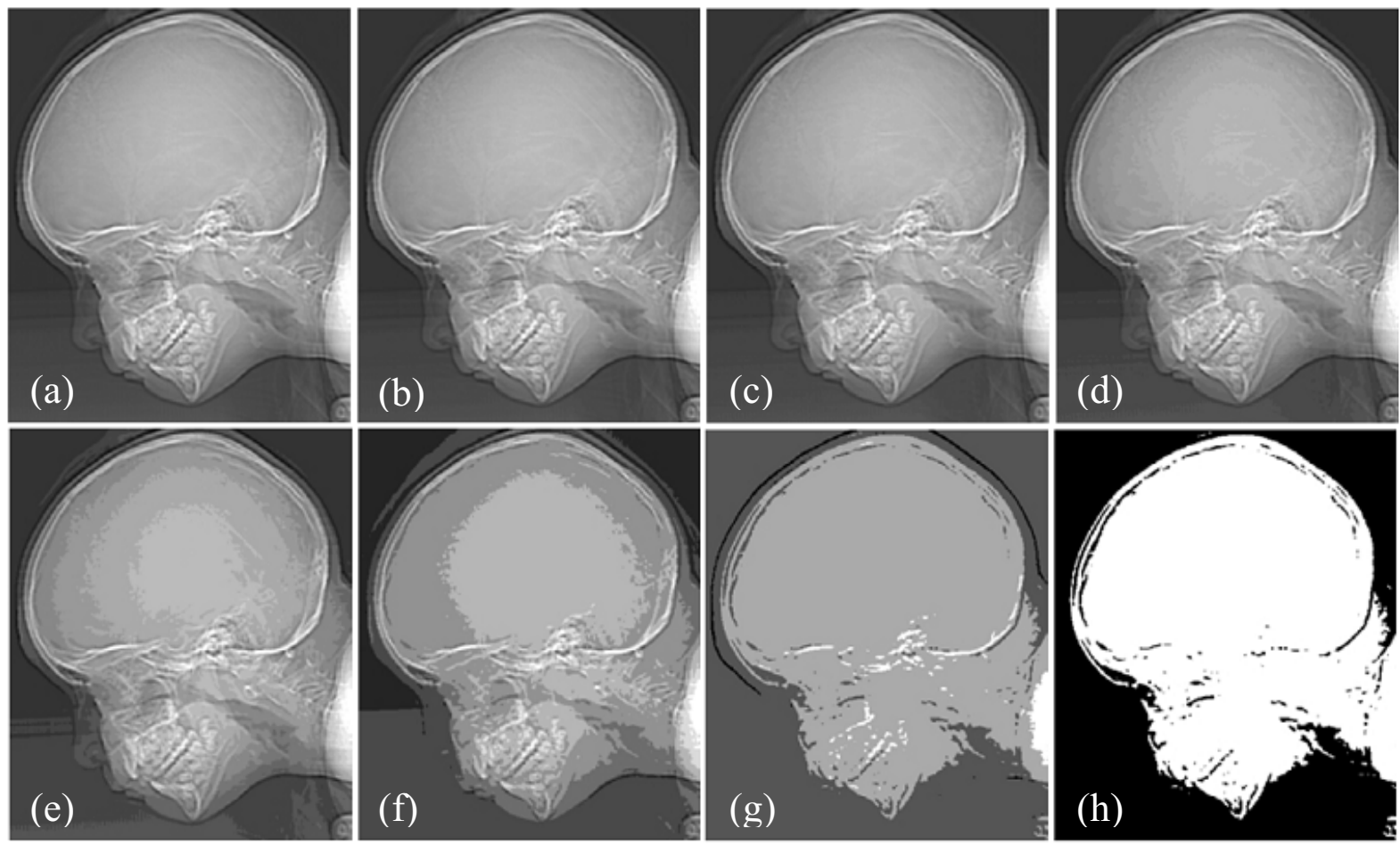

Figura 3.14 (a) 452 x 374, imagem com 256 níveis de cinza. (b) a (d) imagem exibida com 128, 64 e 32 níveis de cinza, mantendo constante a resolução espacial. (e) a (g) imagens exibidas com 16, 8, 4 e 2 níveis de cinza (GONZALEZ, WOODS; 2002).

As Figuras 3.14(b) até (h) foram obtidas pela redução do número de bits de $\mathrm{k}=7$ para $\mathrm{k}=1$, mantendo a resolução espacial constante em 452 × 374 pixels. As imagens com níveis de cinza de 256, 128 e 64 são visualmente idênticas. A imagem com 32 níveis de cinza mostrada na Figura 3.14(d), no entanto, tem um conjunto quase que imperceptível de estrutura muito fina com áreas claras de níveis de cinza (particularmente do crânio). Este efeito, causados pela utilização de um número insuficiente de níveis de cinza em áreas suaves de uma imagem digital, é chamado de falso contorno. Falso contorno geralmente é bem visível nas imagens exibidas usando 16 ou menos níveis de cinza. As imagens são mostradas nas Figuras 3.14(e) até (h) (GONZALEZ, WOODS; 2002).

\subsubsection{Amostragem e quantificação de imagens}

A saída da maioria dos sensores é uma tensão com forma de onda contínua, cuja amplitude e o comportamento espacial estão relacionados com o fenômeno físico que está sendo detectado. Para criar uma imagem digital, é necessário converter para a forma digital os dados que são continuamente detectados, e isto envolve dois 
processos: amostragem e quantificação. Uma imagem pode ser contínua com respeito às coordenadas x e y e também em amplitude. Para convertê-la em forma digital, devese amostrar as duas coordenadas e a amplitude. Digitalizar os valores das coordenadas é chamado de amostragem e os valores da amplitude de quantificação (GONZALEZ, WOODS; 2002).

$\mathrm{Na}$ Figura 3.15b podem ser observadas as amplitudes dos valores dos níveis de cinza da imagem contínua ao longo da linha AB, da Figura 3.15a. Notar o ruído da imagem que é causado pelas variações aleatórias. Para exemplificar, pode-se colher amostras igualmente espaçadas ao longo da linha AB, como mostrado na Figura 3.15c, e que está marcado com pequenos quadrados brancos sobrepostos a curva e indicando o local onde foi tomada a amostra.
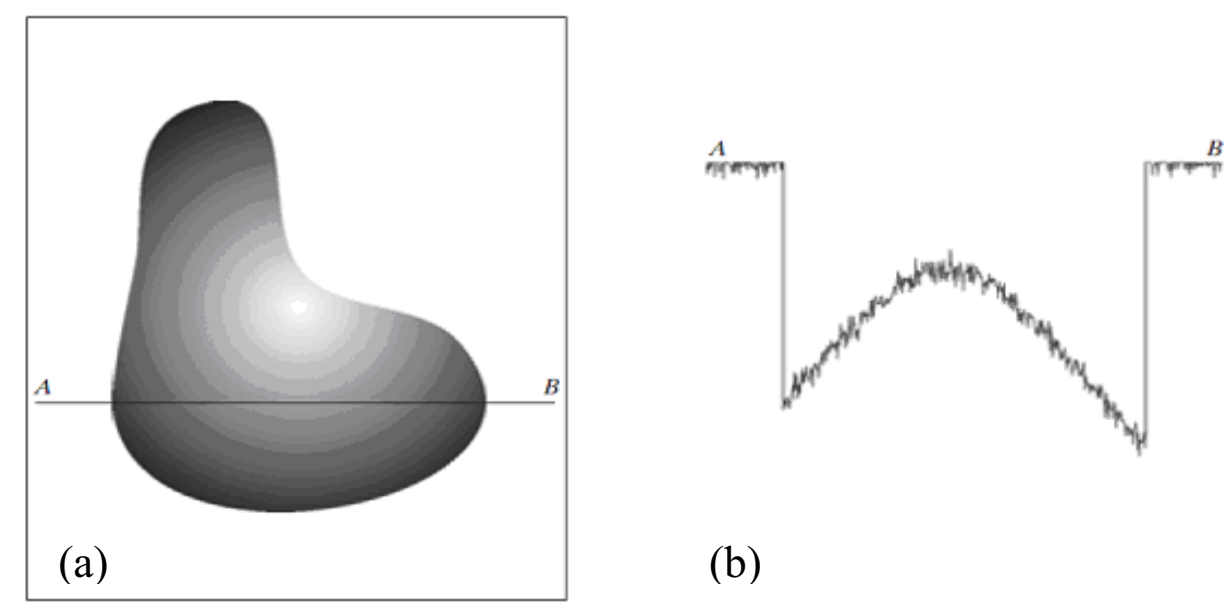

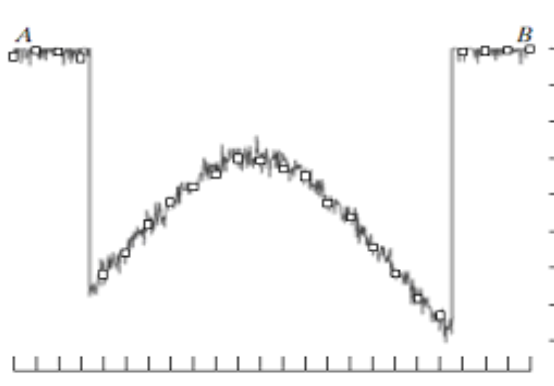

(c)
A.mostragem (b)

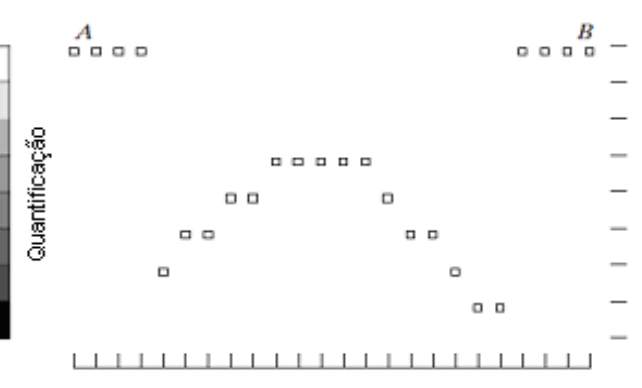

(d)

Figura 3.15 - Gerar uma imagem digital. (a) Imagem (b) Imagem continua. (c) Amostragem. (d) Quantificação. (GONZALEZ, WOODS; 2002).

Os valores das amostragens, quantificações são convertidos em níveis de cinza utilizando a escala vertical mostrada do lado direito da Figura $3.15 \mathrm{c}$, que possui 8 níveis (3 bits), e que variam de preto até branco. As amostragens e as quantificações digitais resultantes deste procedimento, linha por linha, produzem uma imagem digital 
bidimensional, e são mostradas na Figura 3.15d. É assumido que a imagem é contínua nos dois sentidos das coordenadas e com relação à amplitude.

$\mathrm{Na}$ prática, a amostragem é determinada pelo sensor utilizado para gerar a imagem e a exatidão de seu movimento mecânico. Quando uma matriz de sensores é utilizada, não há nenhum movimento e o número de sensores da matriz estabelece os limites de amostragem em ambas as direções (GONZALEZ, WOODS; 2002).

A quantificação feita pelos sensores é da mesma maneira que a citada anteriormente. Na Figura 3.16 é ilustrado esse conceito. Na Figura 3.16(a) é representada uma imagem contínua projetada do plano de uma matriz de sensores e na Figura 3.16(b) é mostrada a imagem após a coleta das amostras e da quantificação. Neste caso, a qualidade da imagem digital é determinada pela quantidade de amostras (dimensões dos sensores) e dos níveis de cinza disponíveis.

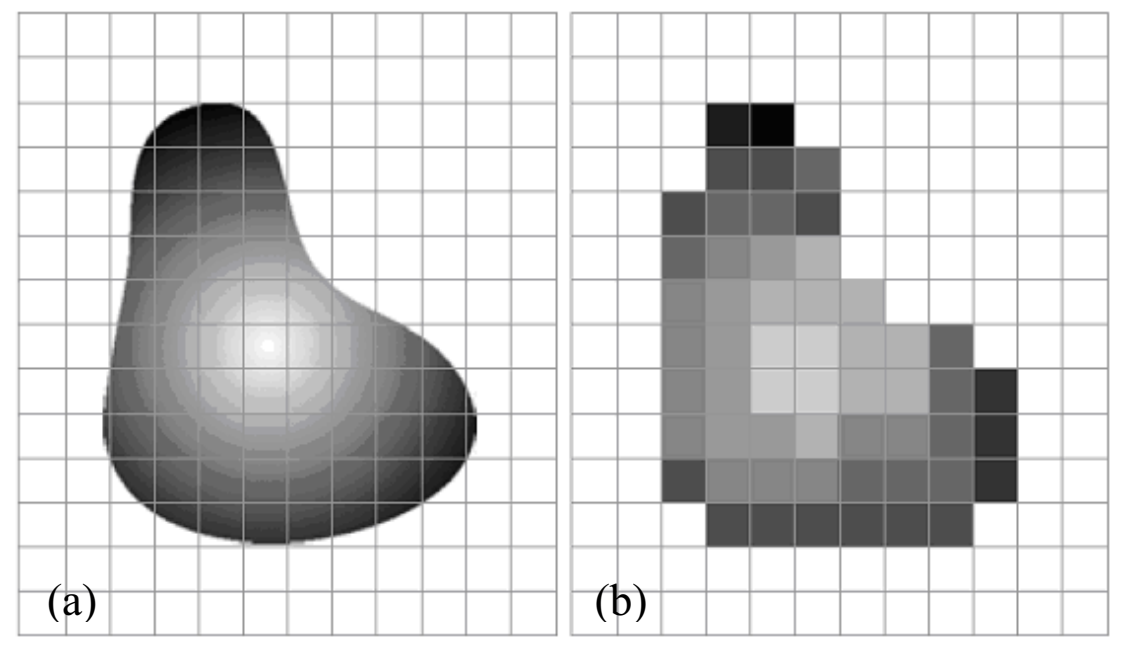

Figura 3.16 - (a) Imagem continua projetada em uma matriz de sensores (b) Resultado da amostragem e quantificação da imagem (GONZALEZ, WOODS; 2002).

\subsubsection{Tipos de sensores utilizados para aquisição de imagens.}

As imagens de interesse para este trabalho são geradas pela combinação de uma fonte de "iluminação", e a reflexão ou absorção da energia a partir dessa fonte pelos elementos da "cena" sendo visualisada. Nota-se que foram colocadas as palavras iluminação e cena entre aspas para enfatizar que são situações gerais onde uma fonte 
de luz visível ilumina uma cena tridimensional (3-D) comum. Por exemplo, a iluminação pode ser originária de uma fonte de raios $\mathrm{X}$ e os elementos da cena podem ser peças, corpos humanos ou mesmo bagagens. Dependendo da natureza da fonte a energia de "iluminação" é refletida ou transmitida através dos objetos (GONZALEZ, WOODS; 2002). Na Figura 3.17 são apresentadas as três principais modalidades de sensores utilizadas para transformar energia de iluminação em images.

\subsubsection{Aquisição de imagem usando um sensor simples.}

Na Figura 3.17a é mostrado um componente com um único sensor. O tipo mais conhecido é o fotodíodo, que é construído com materiais de silício e cuja tensão de saída é proporcional à intensidade de luz.

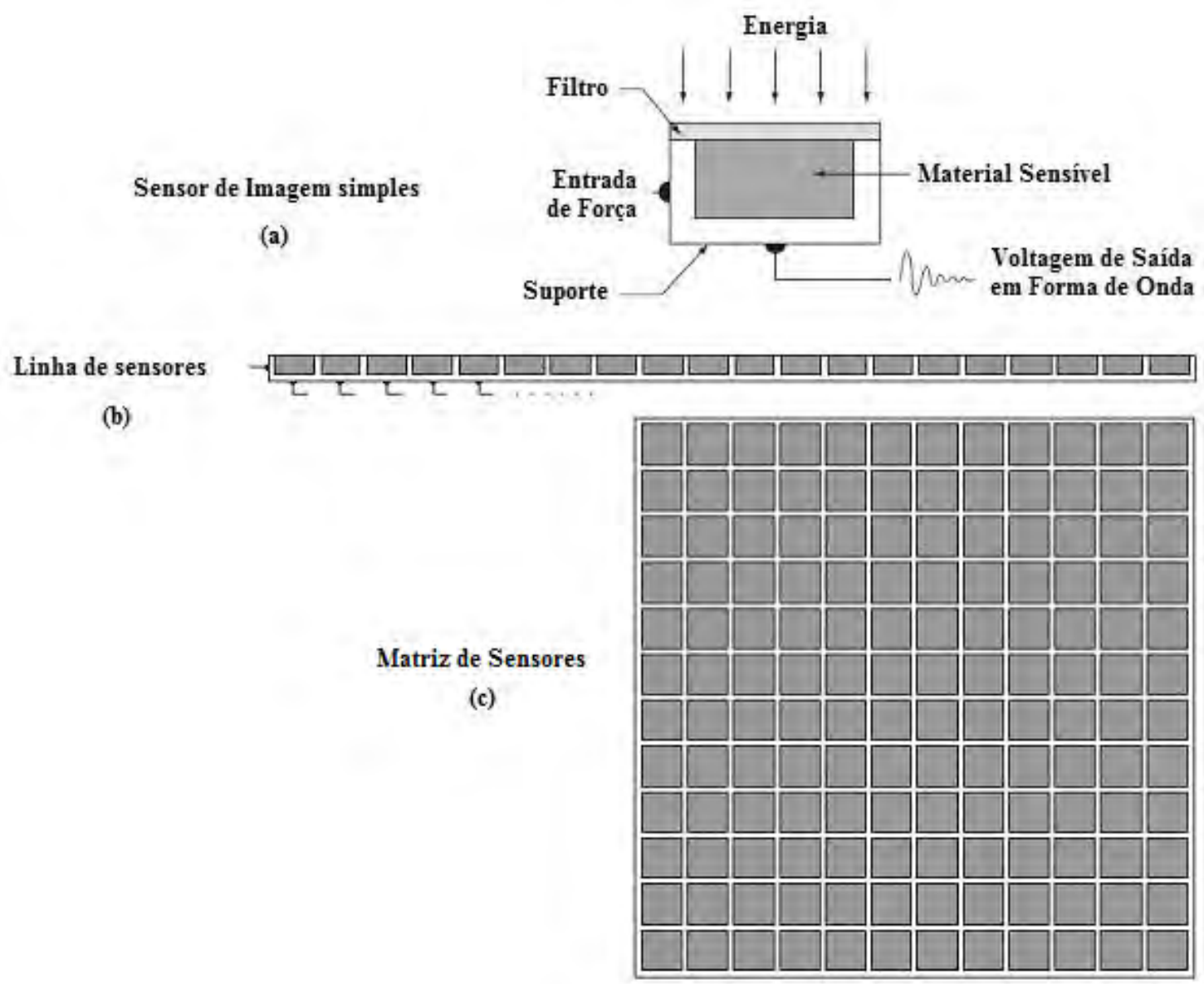

Figura 3.17 - (a) Sensor único de imagem. (b) Linha de sensores. (c) Matriz de sensores. (GONZALEZ, WOODS; 2002).

A fim de gerar uma imagem 2-D usando um sensor, deve-se criar deslocamentos relativos em ambas as direções x e y entre o sensor e a área que será criada a imagem. 
Na Figura 3.18 é mostrado um arranjo, onde um filme é montado em um tambor cuja rotação mecânica fornece deslocamento em uma dimensão e o sensor é montado em uma haste que tem o movimento na direção perpendicular. Uma vez que o movimento mecânico possa ser controlado com alta precisão, este método é uma maneira de baixo custo (mas lenta) para obter imagens de alta resolução. Outro arranjo mecânico similar usa um filme plano, com o sensor movimentando nas duas direções lineares.

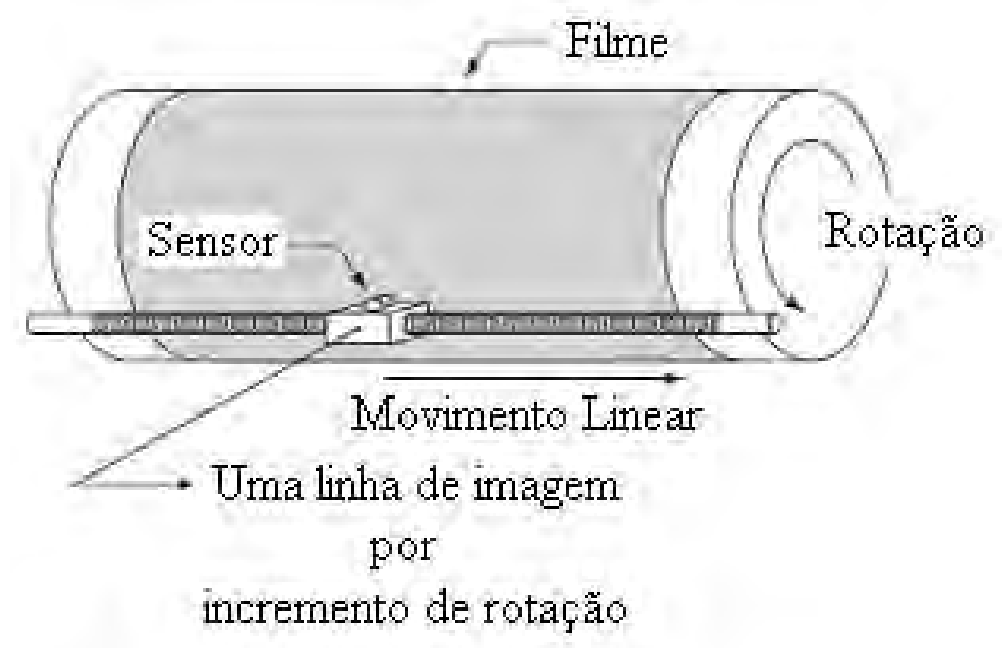

Figura 3.18 - Combinação de um sensor simples com movimento para gerar imagem em 2-D (GONZALEZ, WOODS; 2002).

\subsubsection{Aquisição de imagem usando régua de sensores.}

Sensores são colocados em linha em uma régua, como mostrado na Figura 3.17b. Esta régua fornece elementos de processamento de imagens em uma direção e o movimento perpendicular à fita fornece imagens na outra direção, como apresentado na Figura 3.19a. Este é o tipo de arranjo utilizado na maioria dos scanners (GONZALEZ, WOODS; 2002).

Réguas de detecção com 4000 ou mais sensores em linha são possíveis. As réguas de sensores são utilizadas na aquisição de imagens aéreas, onde o sistema é montado em uma aeronave que voa com altitude e velocidade constante sobre a área a ser criada a imagem, e em grandes sistemas, para inspeção de containers ou caminhões, para comprovação do tipo de carga informada. 


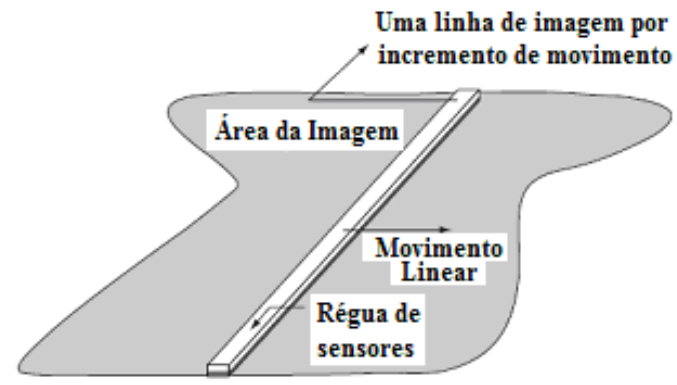

(a)

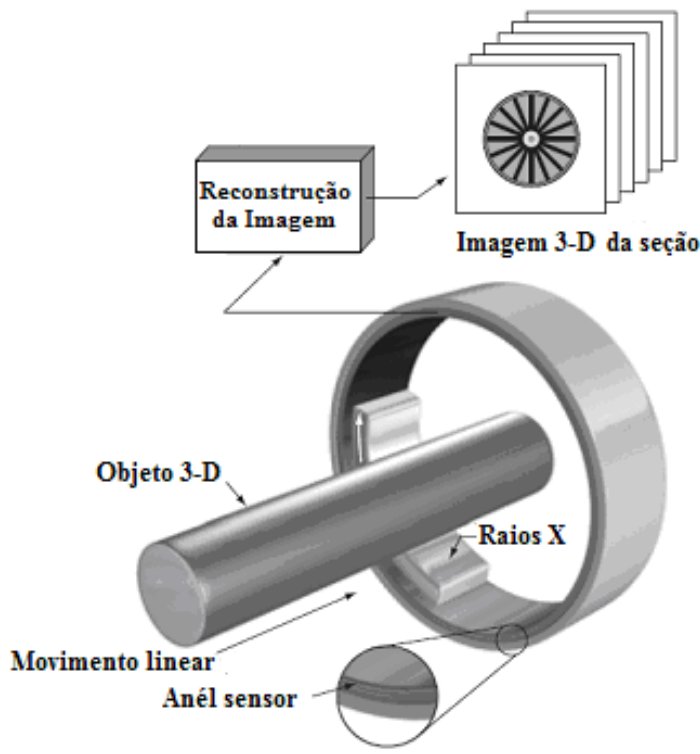

(b)

Figura 3.19 - Aquisição de imagem usando (a) Régua de sensores. (b) Régua circular de sensores. (GONZALEZ, WOODS; 2002).

Uma régua de sensores montada como um anel é utilizada na medicina e na indústria para obter imagens em 3-D da secção transversal ("fatia") dos objetos, como é mostrado na Figura 3.19b. Uma fonte de raios X girando fornece "iluminação" e os sensores opostos à fonte, recolhem a energia dos raios $\mathrm{X}$ que passam através do objeto. Esta é a base para a tomografia médica e industrial computadorizada. É importante observar que o sinal de saída dos sensores deve ser processado com complexos algoritmos de reconstrução, cujo objetivo é transformar os dados em imagens transversais.

\subsubsection{Aquisição de imagem usando uma matriz de sensores.}

Na Figura 3.17c são mostrados sensores individuais organizados na forma de uma matriz 2-D. Muitos equipamentos eletromagnéticos e alguns de ultrassom, além das cameras digitais, utilizam o formato de matriz de sensores. Outra aplicação são as que utilizam DDA (DDA, Detectores Digitais Array) que são aplicados na radiografia digital direta, que estão sendo utilizadas na medicina, odontologia e está iniciando nos ensaios não destrutivos industriais (GONZALEZ, WOODS; 2002). A resposta de cada sensor é proporcional a integral da energia luminosa projetada na superfície do sensor. O modo principal no qual a matriz de sensores é usada é mostrado na Figura 3.20. 


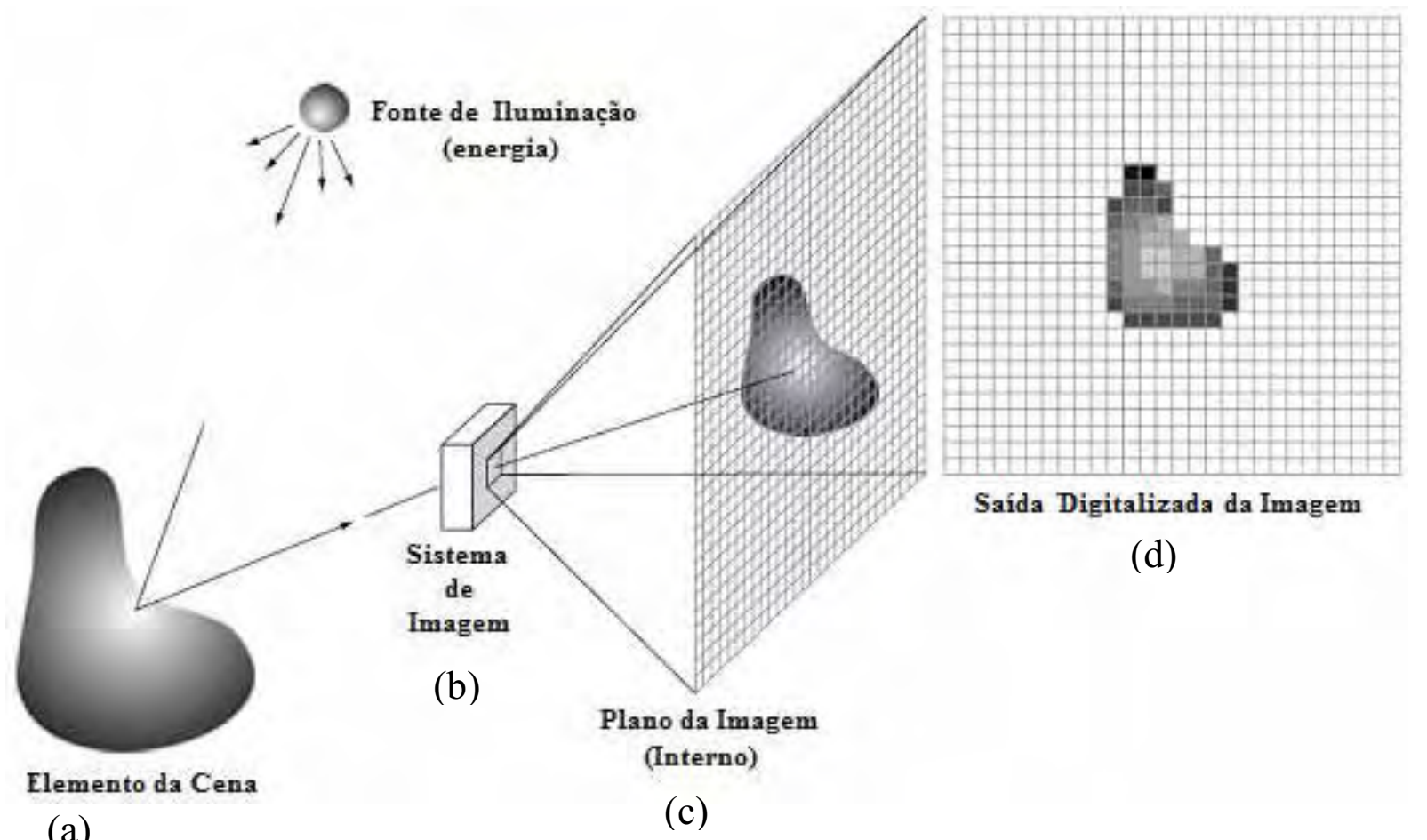

(a)

Figura 3.20 - Exemplo do processo de aquisição de uma imagem digital. (a) Elemento da cena com fonte de luz. (b) Sistema de imagem. (c) Plano de imagem. (d) Imagem digitalizada. (GONZALEZ, WOODS; 2002).

Na Figura 3.20 é mostrada a energia de uma fonte de iluminação refletida em um elemento da cena (a), sendo que a primeira operação executada pelo sistema de processamento é a aquisição da energia pela matriz de sensores (b), que projeta a cena exibida até o plano da imagem (c) e na seqüência se obtem a saída da imagem digitalizada (d).

\subsection{Aparelhos de Raios X.}

Equipamentos de raios $\mathrm{X}$ industriais se dividem basicamente em dois componentes: o painel de comando e a ampola (ABENDI, 2005). No painel de comando estão os controles, indicadores, chaves de segurança e medidores, além de conter todo o equipamento do circuito gerador de alta voltagem. É por meio do painel de controle que se fazem os ajustes de voltagem, amperagem, e tempo de exposição, além de comando de acionamento do aparelho.

A ampola é responsável pela emissão dos raios X e é composta de um envólucro de vidro que é dividido basicamente em duas partes: o ânodo e o cátodo. No cátodo há um filamento por onde passa uma corrente da ordem de miliamperes. Entre o ânodo e 
cátodo é gerada alta-tensão (milhares de volts). Assim, os elétrons liberados no filamento quando aquecido, irão ser incidir na placa, denominada alvo, gerando calor e os raios X. De uma forma simplista, pode-se dizer que a kilovoltagem aplicada em uma ampola é responsável pela capacidade de penetração nos materiais, enquanto que a amperagem é responsável pela quantidade de elétrons gerados e, assim são diretamente proporcionais ao tempo de exposição.

Na Figura 3.21 é apresentado um tipo de ampola de raios $\mathrm{X}$ que é comumente utilizada no ensaio radiográfico (TAUHATA et al., 2003).

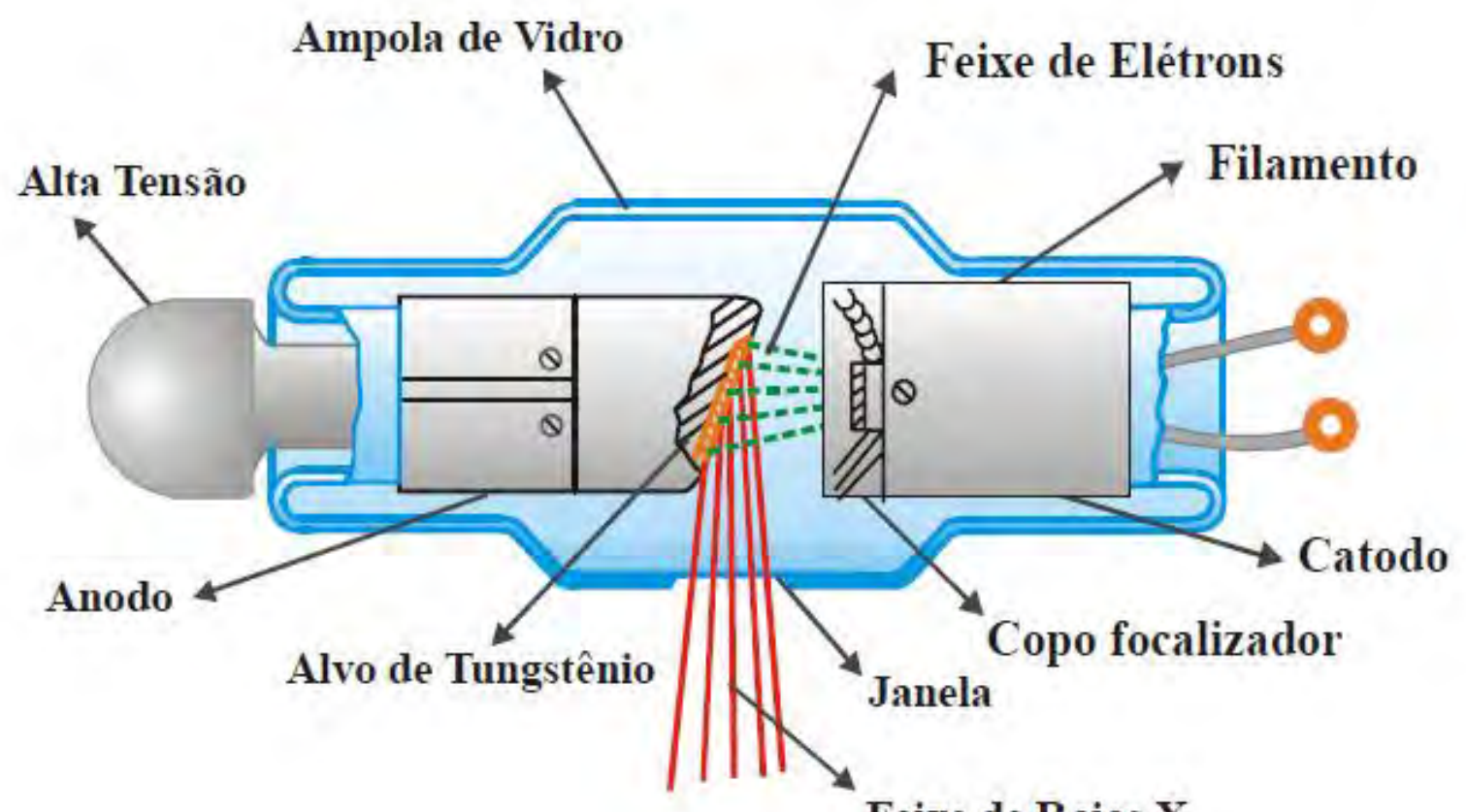

Figura 3.21 - Fonte de raios X (TAUHATA et al., 2003).

$\mathrm{O}$ efeito de Bremsstrahlung ocorre quando um elétron acelerado tem a sua trajetória repentinamente frenada pelo alvo de tungstênio, enquanto fótons de várias energias são gerados, formando um espectro contínuo de Bremsstrahlung, conforme mostrado na Figura 3.22. Embora a probabilidade de ocorrência de emissão de fótons de Raios-X por desaceleração brusca seja pequena, esta ainda é a maior fonte de geração de fótons de raios-X em relação a outros fenômenos, e portanto é a mais utilizada. 


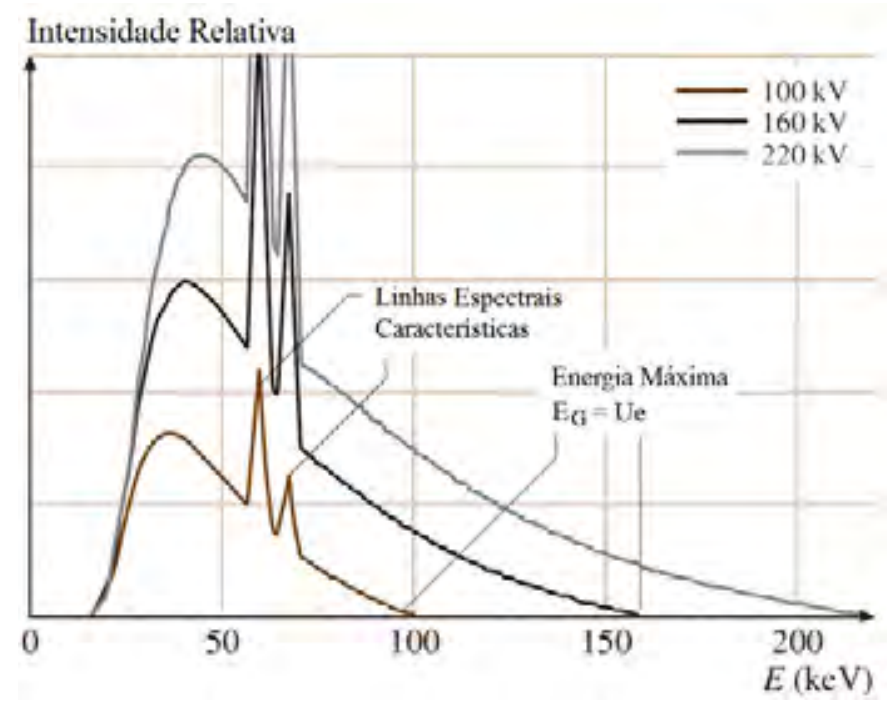

Figura 3.22 - Espectro típico dos Raios X (CZICHOS; SAITO; SMITH, 2006).

Um item muito importante para a obtenção de uma boa qualidade de imagem é o tamanho focal, pois quanto menor esta dimensão maior será a definição ou nitidez da imagem. Na Figura 3.23 pode-se observar um esquema de um dos métodos para determinação das dimensões da área focal (KODAK, 1980).

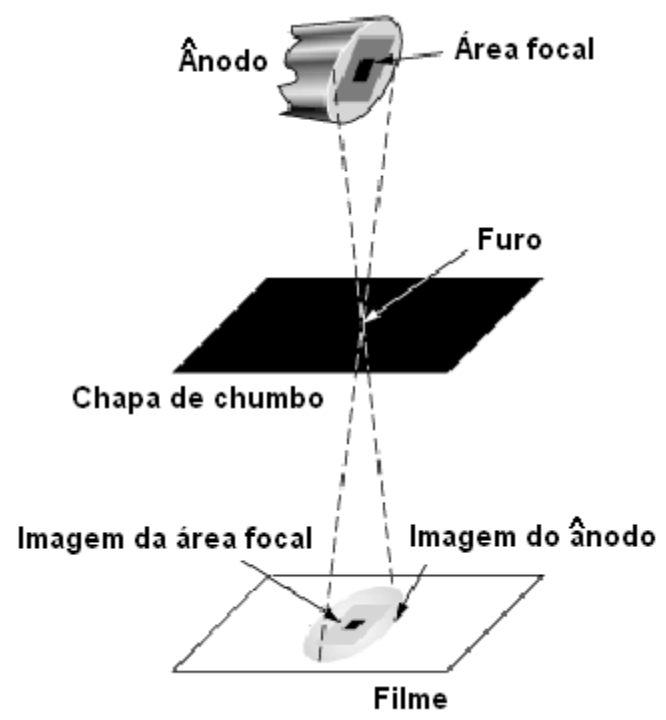

(a)

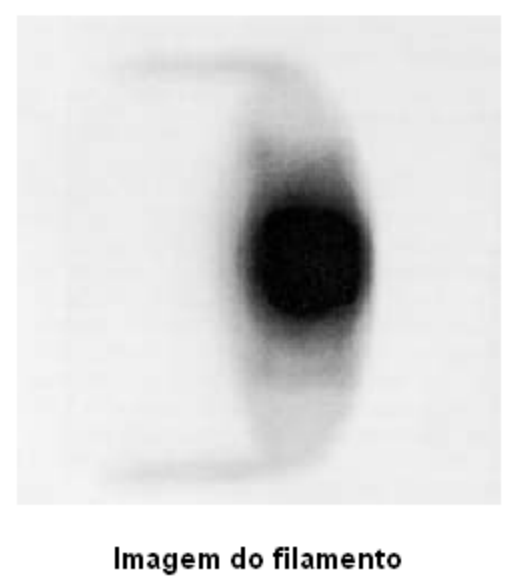

(b)

Figura 3.23 - (a) Método para determinação da área focal. (b) Imagem do ponto focal/filamento.

\subsection{Forma de interação da radiação com a matéria}

Os raios $\mathrm{X}$ emitidos, ao passarem pela peça que está sendo radiografada interagem com qualquer material e sofrem variação na sua intensidade, devido basicamente a alguns fenômenos físicos que ocorrem simultaneamente. Os principais 
fenômenos de interação da radiação com a matéria são denominados Efeito Fotoelétrico, Efeito Compton e Produção de Pares (TAUHATA et al.; 2003).

\subsubsection{Efeito Fotoelétrico}

O efeito fotoelétrico (ou absorção) é caracterizado pela transferência total da energia da radiação $\mathrm{X}$ (fóton) que chega a um único elétron orbital, que é expelido com uma energia cinética, Ec. A representação do efeito Fotoelétrico é mostrada esquematicamente na Figura 3.24 (TAUHATA et al.; 2003).

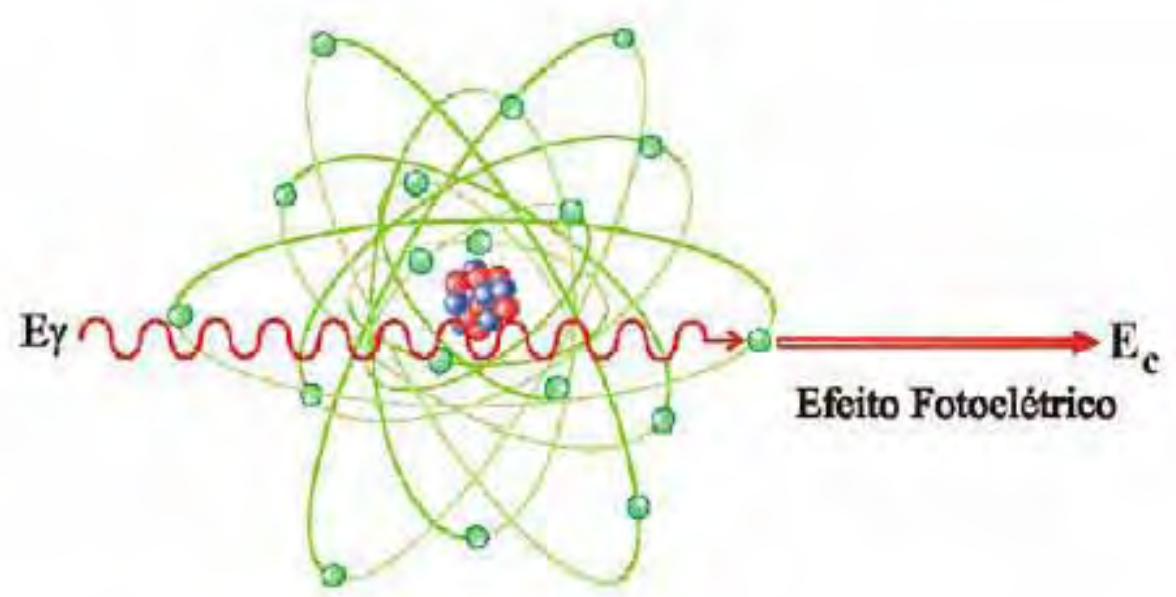

Figura 3.24 - Efeito Fotoelétrico (TAUHATA et al.; 2003).

A direção de saída do fotoelétron em relação à de incidência do fóton varia com a energia. Para altas energias (acima de $3 \mathrm{MeV}$ ), a probabilidade do elétron sair na direção e sentido do fóton é alta. Para baixas energias (abaixo de $20 \mathrm{keV}$ ) a maior probabilidade é a de sair com um ângulo de $70^{\circ}$. O efeito fotoelétrico é predominante para baixas energias e para elementos químicos de elevado número atômicos $\mathrm{Z}$. A probabilidade de ocorrência aumenta com $\mathrm{Z}^{4}$ e decresce rapidamente com o aumento da energia.

\subsubsection{Efeito Compton}

No efeito Compton (espalhamento ou difusão), o fóton é espalhado por um elétron de baixa energia de ligação, que recebe somente parte de sua energia, continuando sua trajetória dentro do material, em outra direção. Como a transferência de energia depende 
da direção do elétron incidente e neste caso é aleatória. Assim um fóton incidente, com uma energia fixa, pode resultar em elétrons com valores de energia desde zero até um valor máximo. Sua distribuição no espectro de contagem é aleatória, aproximadamente retangular. A representação do efeito Compton é mostrada esquematicamente na Figura 3.25 .

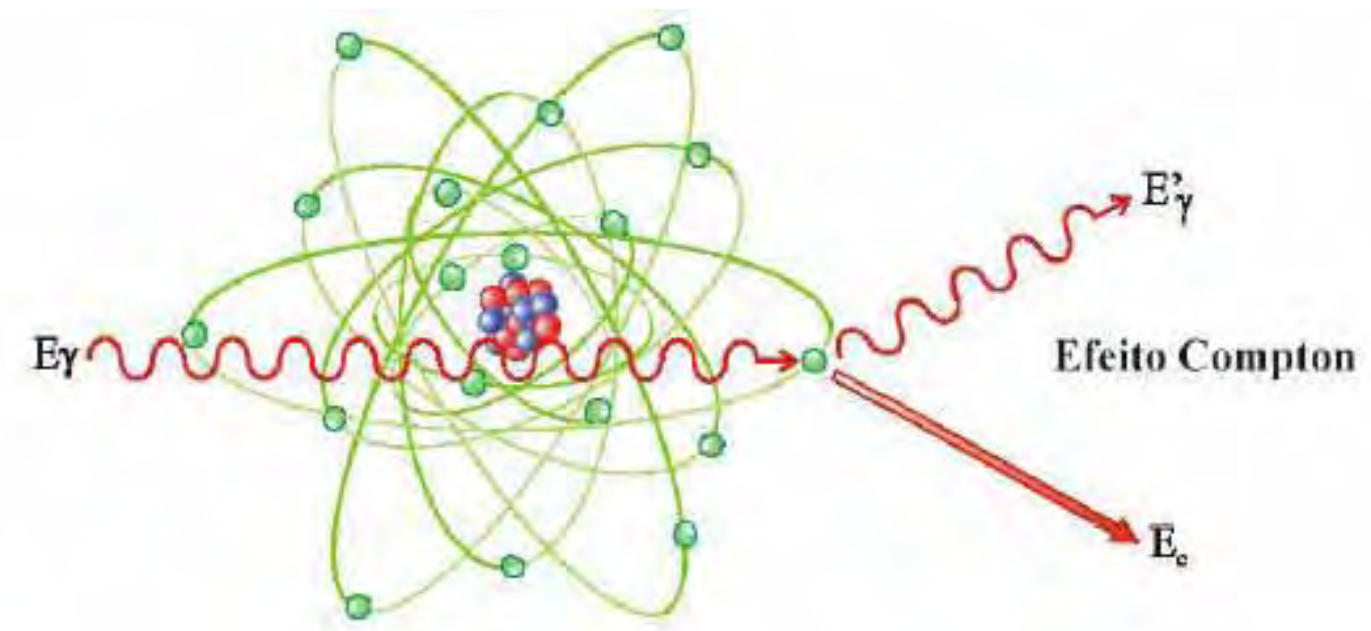

Figura 3.25 - Efeito Compton (TAUHATA et al.; 2003).

Quando a energia de ligação dos elétrons orbitais se torna desprezível face à energia do fóton incidente, a probabilidade de ocorrência de espalhamento Compton aumenta consideravelmente.

\subsubsection{Formação de Pares}

Uma das formas predominantes de absorção da radiação eletromagnética de alta energia é a produção de um par elétron-pósitron. Este efeito ocorre quando fótons de energia igual ou superior a $1 \mathrm{MeV}$ passam perto de núcleos de número atômico elevado, interagindo com o forte campo elétrico nuclear. Nesta interação, a radiação desaparece e dá origem a um par elétron-pósitron. As duas partículas transferem a sua energia cinética para o meio material, sendo que o pósitron volta a se combinar com um elétron do meio e dá origem a 2 fótons, cada um com energia de aproximadamente 0,5 MeV. A representação do efeito de formação de pares é apresentada esquematicamente na Figura 3.26. 


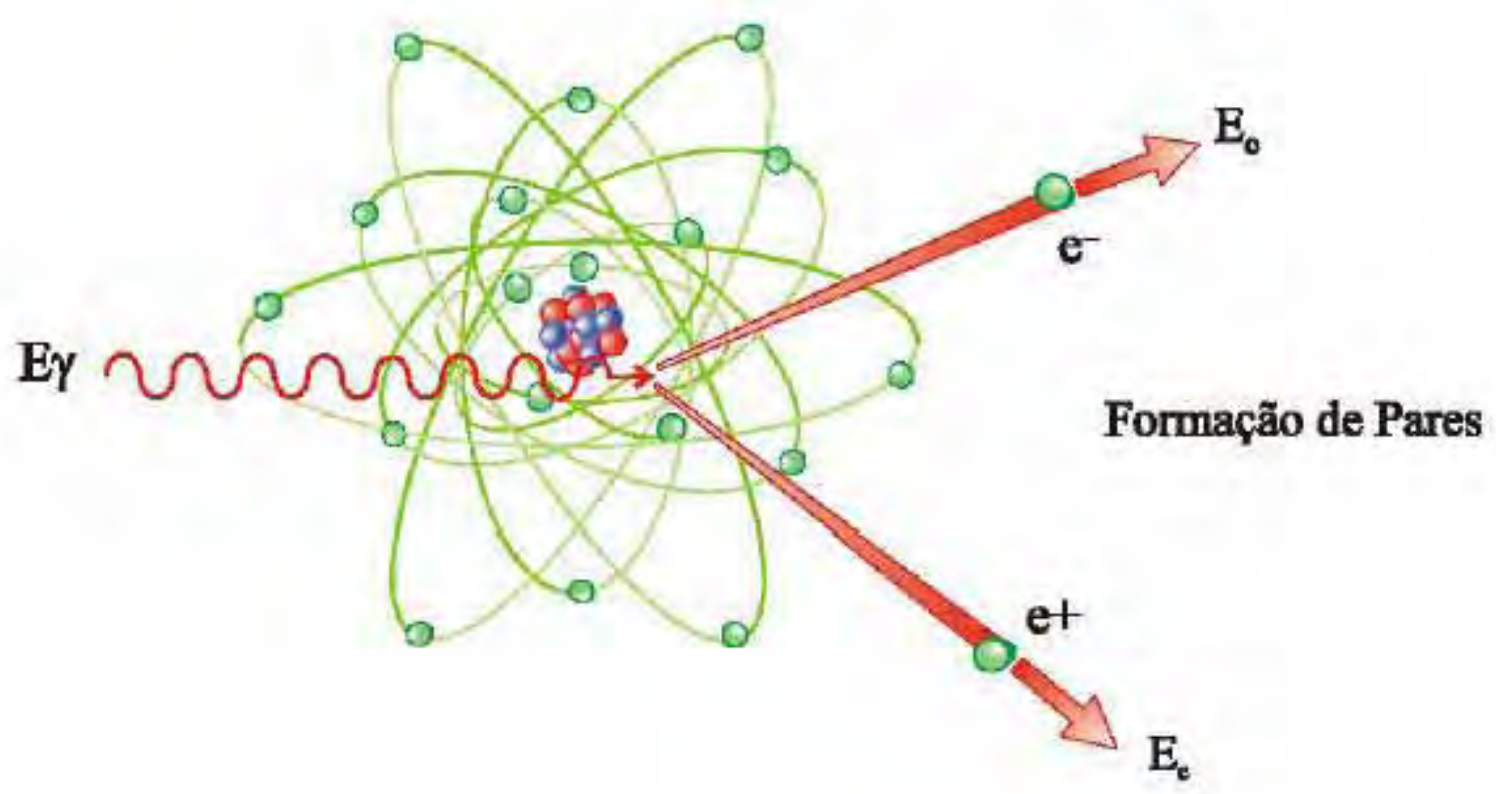

Figura 3.26 - Formação de pares (TAUHATA et al.; 2003).

As interações fotoelétricas predominam para todos os materiais em energias de fótons suficientemente baixas. À medida que a energia cresce, o efeito fotoelétrico permanece predominante apenas para elementos de elevado número atômico. Já para elementos com baixos valores de Z, o efeito Compton torna-se predominante. Em energias a partir de $1 \mathrm{MeV}$, a produção de pares passa a contribuir nas interações dos fótons (CZICHOS; SAITO; SMITH, 2006). Para que se possa entender qual processo é prediminante de acordo com a energia utilizada e o material sendo testado, na Figura 3.27 é mostrada a variação da participação de cada um desses processos para cada valor de $\mathrm{Z}$ e a energia dos fótons incidentes.

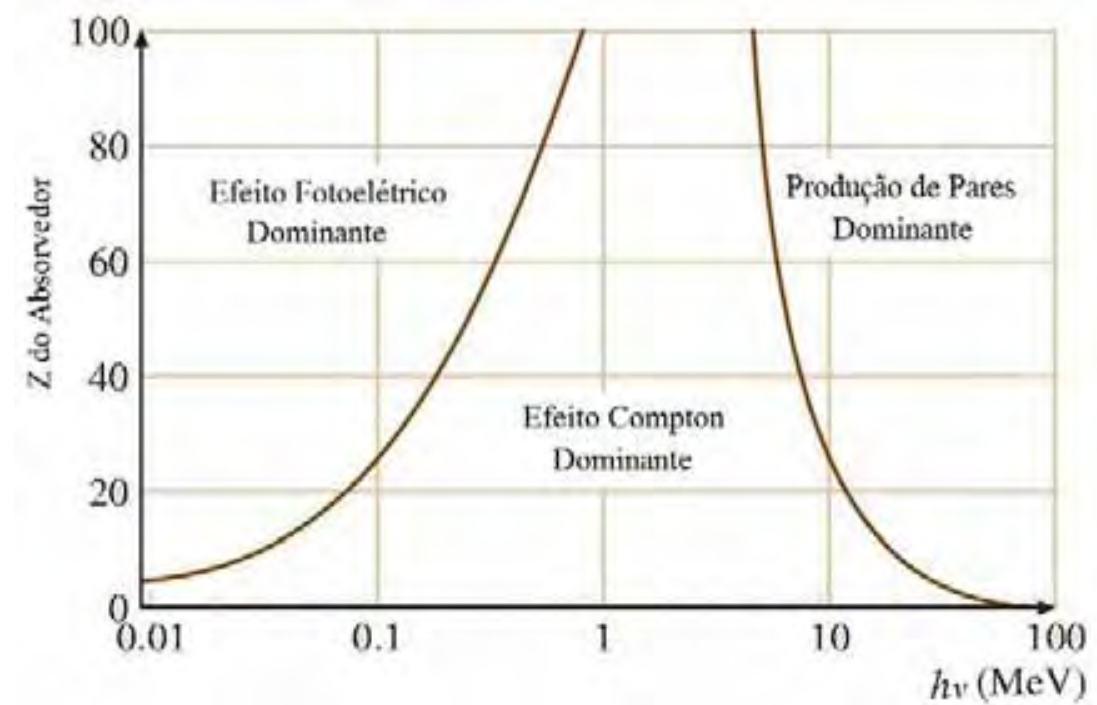

Figura 3.27 - Importância relativa dos processos (CZICHOS; SAITO; SMITH, 2006). 


\subsection{Inspeção de juntas soldadas}

As normas e especificações de fabricação de tubos para oleodutos e gasodutos, que são largamente aplicadas mundialmente, são a API 5L, a ISO 3183, a DNV-OSF101 e no caso da norma ISO/DIS 10893-7 que está desenvolvimento é a primeira que aborda a inspeção radiografica digital. Assim, especial atenção deve ser dada para a norma ISO/DIS 10893-7, Non-destructive testing of steel tubes - Digital radiographic testing of the weld seam of welded steel tubes for the detection of imperfections, pois esta propoe as exigências mínimas para a aplicação da radiografia digital em soldas de tubos de aço soldados no segmento de petroleo e petroquímico. Esta norma está sendo proposta estabelecendo parâmetros que utiliza as melhores práticas para aplicação da técnica digital, e nesta tese com a realização de testes práticos podem contribuir na definição de critérios e na discussão desta.

Esta proposta de norma foi a principal referencia utilizada nesta tese, juntamente com as demais normas. Outras normas são referenciadas durante o uso das normas citadas tais como a ISO 12096, ISO/DIS 10893-6, ISO 19232-1, ISO 19232-5 (ISO 12096, 1996; ISO/DIS 10893-6, 2009; ISO 19232-1, 2004; ISO 19232-5, 2004).

\subsubsection{Aparência das descontinuidades}

As descontinuidades são quaisquer variações na homogeneidade de uma peça ou material, tanto em sua estrutura como em sua forma. Por meio da análise da influência que a descontinuidade terá sobre a utilização do equipamento podem ser definidos critérios de aceitação. As descontinuidades podem ser atribuídas a diferentes causas, podendo ocorrer durante o próprio processo de fabricação do material, durante o processamento ou durante o uso de equipamento (ABENDI, 2005). As descontinuidades internas em juntas soldadas mais comuns são (N-1738, 2003):

\section{Porosidade}

Durante a fusão da solda, pode haver o aprisionamento de gases devido a várias razões como: o tipo de eletrodo utilizado, má regulagem do arco, deficiência na técnica do operador, umidade etc. As porosidades podem ter a forma esférica ou cilíndrica, 
porém algumas destas assumem uma forma alongada, cilíndrica e sua imagem radiográfica vai depender de uma orientação em relação ao feixe de radiação incidente. Outra forma típica é aquela que tem a aparência de um galho ramificado, chamada, também, de porosidade vermiforme.

\section{Inclusões de escória}

Ocorrem devido ao aprisionamento de escória ou materiais estranhos durante o processo de soldagem. Elas se apresentam com mais freqüência em soldas de passes múltiplos, principalmente quando a limpeza não é bem efetuada entre passes.

\section{Falta de penetração}

É considerada falta de penetração a falta de material depositado na raiz da solda, devido ao material depositado não ter chegado até a raiz. No caso de não haver passe de raiz (selagem), a falta de penetração pode ficar aparente. A aparência radiográfica, em ambos os casos, é uma linha escura, intermitente ou contínua, no centro do cordão.

\section{Trincas}

As trincas são descontinuidades produzidas por rupturas no metal como resultado de tensões produzidas durante a soldagem, sendo mais visível na radiografia, quando o feixe de radiação incide sobre a peça em uma direção sensivelmente paralela ao plano que contém a trinca. A trinca produz uma imagem radiográfica na forma de uma linha escura com direção irregular. A largura desta linha dependerá da largura da trinca. Se a direção do plano que contém a trinca coincidir com o feixe de radiação, sua imagem será escura, e se a direção do plano não for como mencionado ela perderá densidade, podendo não aparecer. Devido ao fato da trinca ser considerada como o mais grave defeito de uma solda, deve-se ter uma atenção especial para a sua detecção.

\section{Falta de fusão}

Descontinuidades são geradas devido a falta de fusão entre o metal depositado e o metal base. A falta de fusão só é bem caracterizada em uma radiografia quando a direção do feixe incidente coincide com o plano do defeito. A imagem radiográfica da 
falta de fusão é uma linha escura, estreita, paralela ao eixo da solda, em um ou em ambos os lados.

\subsubsection{Imagens radiográficas}

Nas Figuras 3.28(a) a (j) podem-se observar imagens radiográficas, utilizando a técnica convencional, obtidas de juntas soldadas e as descontinuidades são: mordedura, desalinhamento, falta de penetração, falta de fusão, trincas e porosidades. (GEIT, 2004).
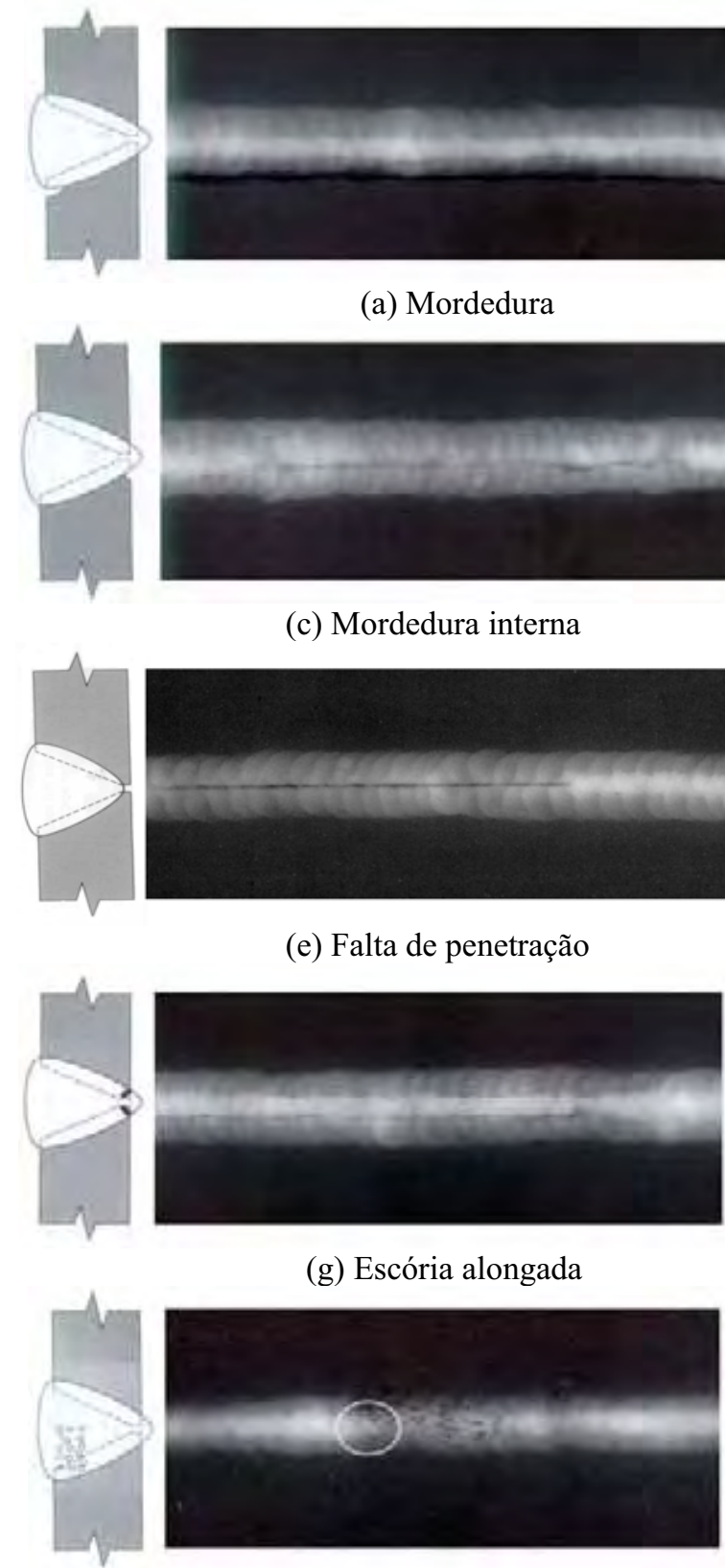

(i) Porosidade agrupada

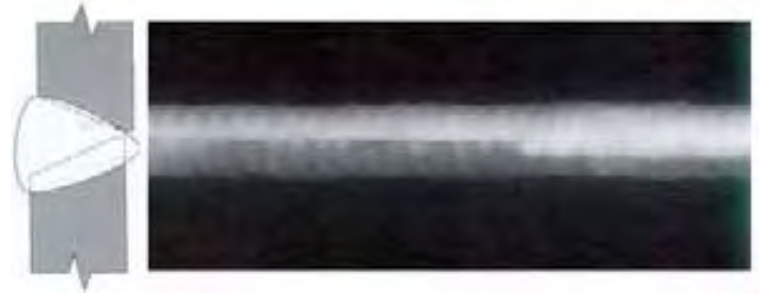

(b) Desalinhamento com falta de penetração
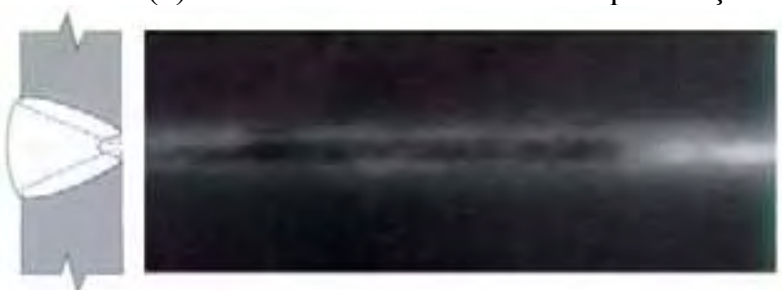

(d) Concavidade interna
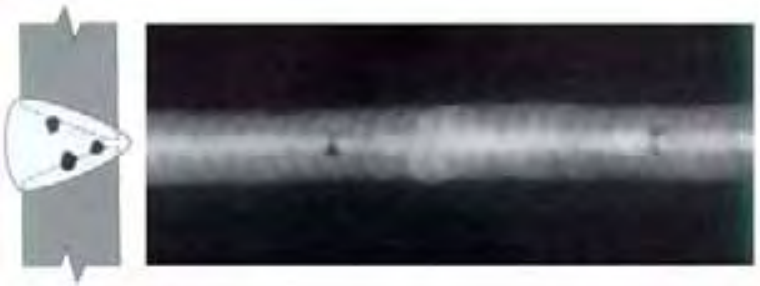

(f) Inclusão de escória entre passes
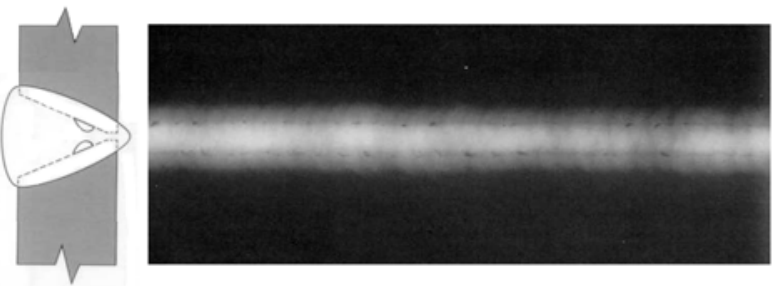

(h) Falta de fusão
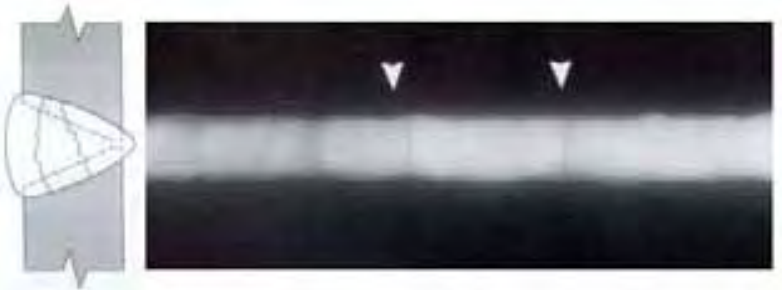

(j) Trinca longitudinal

Figura 3.28 - Imagem radiográfica de defeitos típicos em soldas (GEIT, 2004). 


\subsubsection{Técnicas de exposição}

Existem várias técnicas de exposição para a execução do ensaio radiográfico para juntas soldadas, a técnica de parede simples - vista simples (PS-VS), onde o feixe de radiação atravessa uma espessura da peça e a projeta no filme ou detector, pode ser chamada de exposição panorâmica para juntas circunferenciais, conforme é mostrado na Figura 3.29(a) até (d).

Na técnica de parede dupla - vista simples (PD-VS) o feixe de radiação atravessa duas espessuras da peça. Entretanto, projeta no filme, somente a seção da peça que está mais próxima do mesmo. Na técnica de parede dupla-vista dupla (PD-VD) o feixe de radiação também atravessa duas espessuras. Entretanto, projeta no filme a imagem das duas seções da peça, esta técnica é normalmente utilizada para inspeção de juntas soldadas de tubos de pequeno diametro (ABENDI, 2005).

Nas fábricas de tubos de grandes diametros, a técnica aplicada é a técnica de parede simples - vista simples (PS-VS), esta é a principal técnica utilizada na inspeção radiográfica, e a mais fácil de ser interpretada, conforme apresentado na Figura 3.29.

(a)

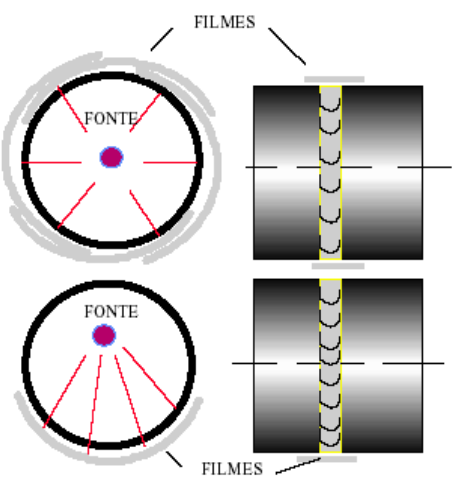

Técnica de exposição parede simples - vista simples

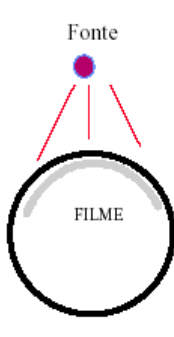

(c)

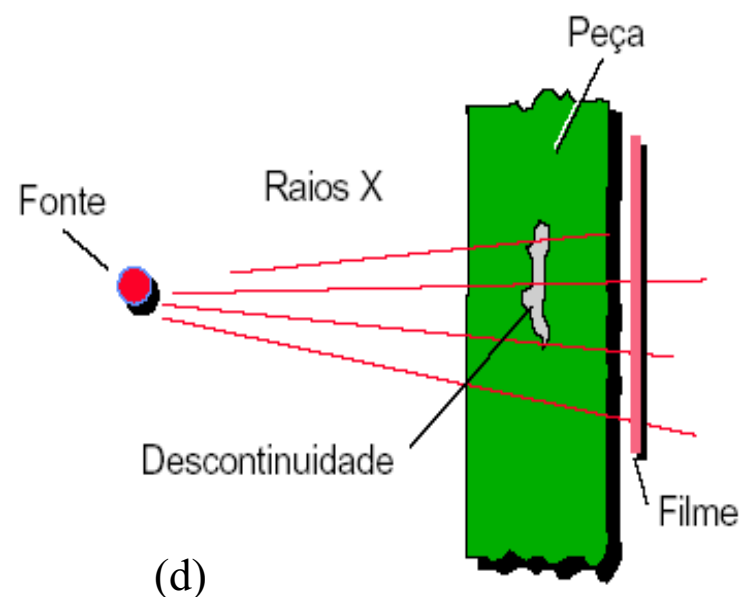

Figura 3.29 - Técnica de exposição PS-VS - (a, b, c) Junta circunferencial. (d) Junta plana. (ABENDI, 2005). 


\subsection{Radiografia digital}

Embora uma imagem digital, que vista na tela como uma coleção das áreas mais brilhantes e mais escuras, muito se assemelha a tradicional imagem baseada em filme, a natureza de uma imagem digital é diferente. Uma imagem radiográfica convencional é composta por áreas escuras onde os grãos de prata da emulsão são áreas densamente empacotadas e por áreas claras onde os grãos são mais dispersos. As condições de exposição e o processo de desenvolvimento determinam o brilho e o contraste que são fixos nas imagens tradicionais. Nas imagens digitais alguns parâmetros podem ser corrigidos depois que tenham sido produzidos. Isso pode ser usado para corrigir uma sobreexposição ou pouca exposição de uma imagem, e assim evitar a necessidade de uma nova exposição. É possível ajustar o contraste e a densidade para melhorar o reconhecimento de áreas específicas. Assim, variando o contraste será mais fácil perceber pequenos detalhes, e um inspetor devidamente qualificado pode observar muito mais informações de um sistema digital, em relação ao analógico. Isso é feito, distribuindo os valores de cinza dos pixels mais uniformemente ao longo da escala completa de valores de cinza. Assim, com uma única imagem e única exposição, se pode-se avaliar todas as áreas da peça. Além do "processamento de imagem" outras ferramentas encontram-se disponíveis tais como a eficaz ferramenta para aumentar ou dar um close/zoom na imagem ou parte dela, com a qual o inspetor pode perceber detalhes mais facilmente.

\subsubsection{Aplicações atuais da Radiografia Digital}

Atualmente o uso da radiografia digital tem sido adotado por diversas áreas e aplicações, que podem ser observadas na Figura 3.30 (a) e (b).

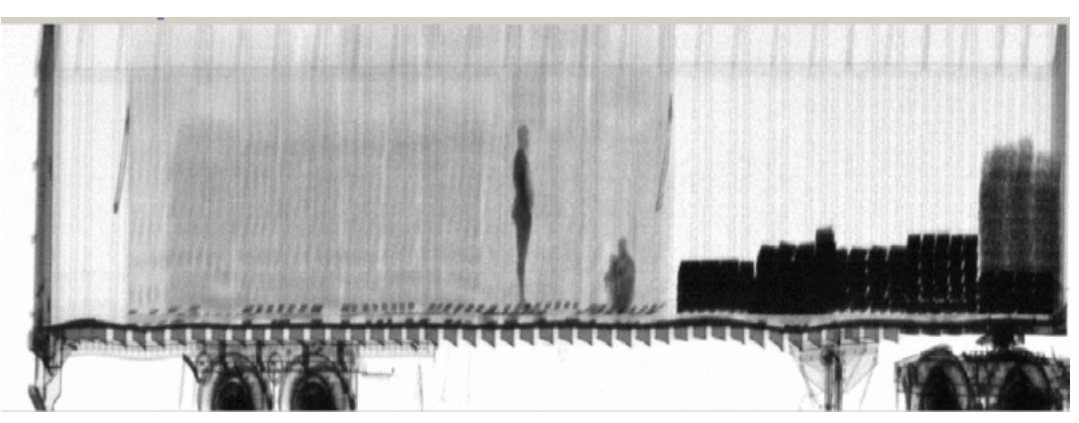

(a)

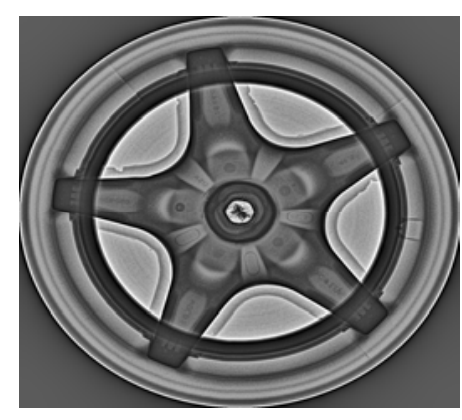

(b)

Figura 3.30 - (a) Inspeção de cargas e containers. (b) Inspeção de aros de rodas. (PINCU; JEWELL, 2005). 
A tecnologia digital vem sendo adaptada dia a dia e tem agregado muitas melhorias, tanto na qualidade da imagem, na rapidez dos laudos, como na redução das doses recebidas pelos pacientes, órgãos, operadores, radiologos, etc. Na Figura 3.31 são representadas mais aplicações da radiografia digital, nos mais variados segmentos.
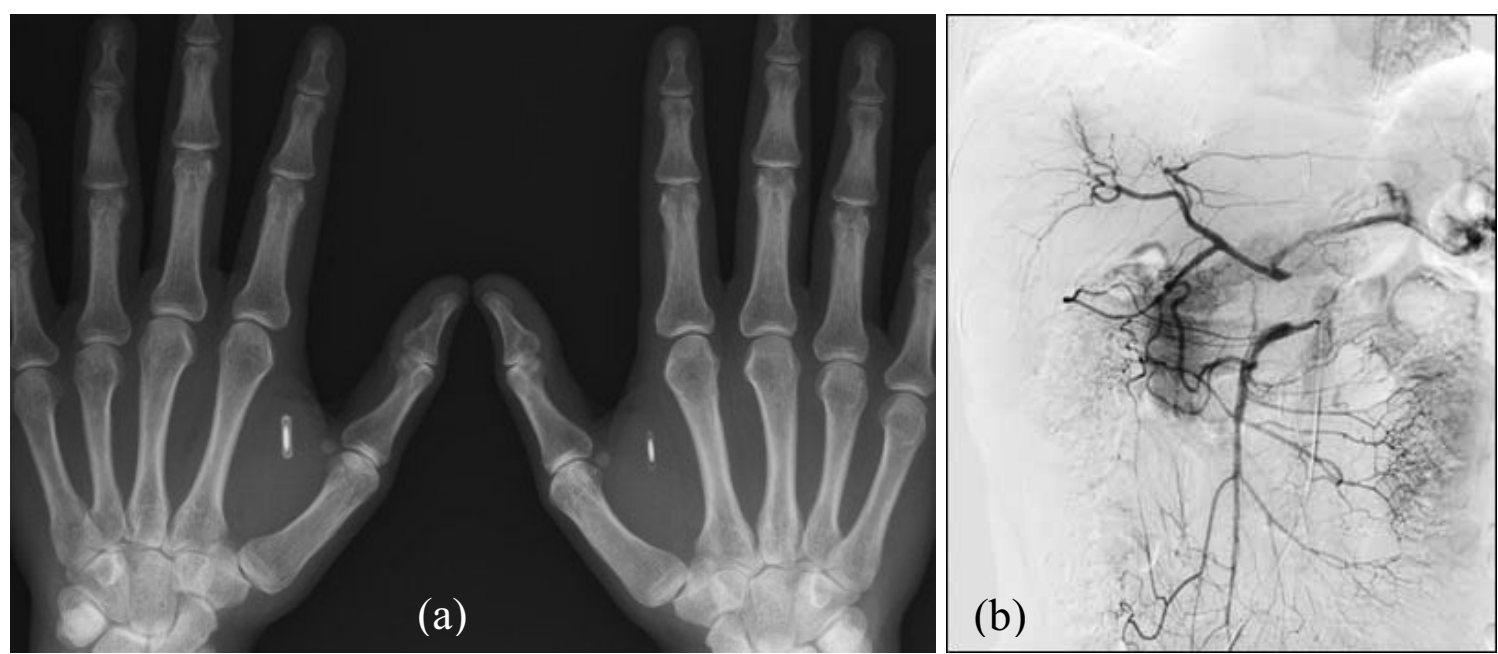

Área médica. (a) Radiografia digital da mãos. (b) RD do coração.

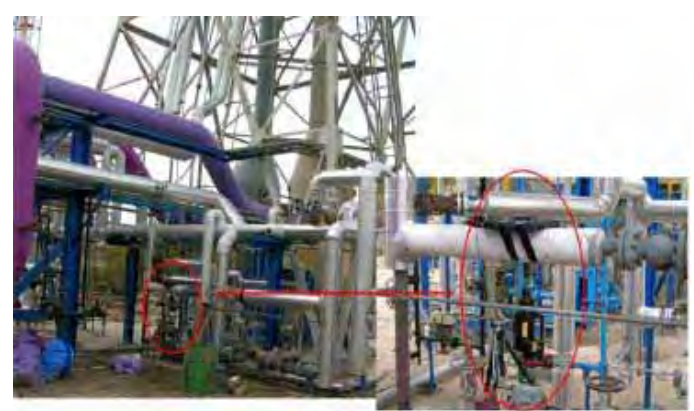

(c)

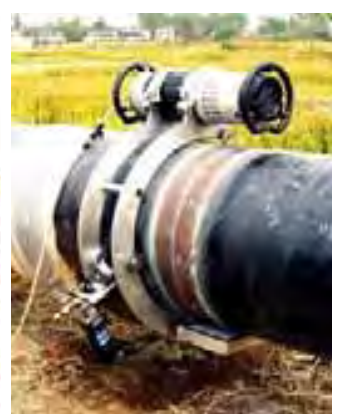

(d)

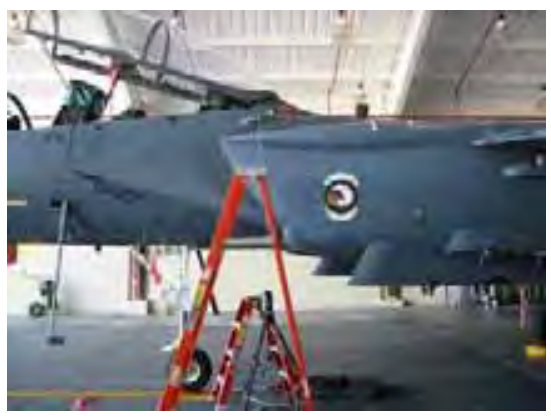

(e)

Área Petróleo e aeroespacial - (c) Tubulações. (d) RD em juntas de gasoduto. (e) Aeronave militar.
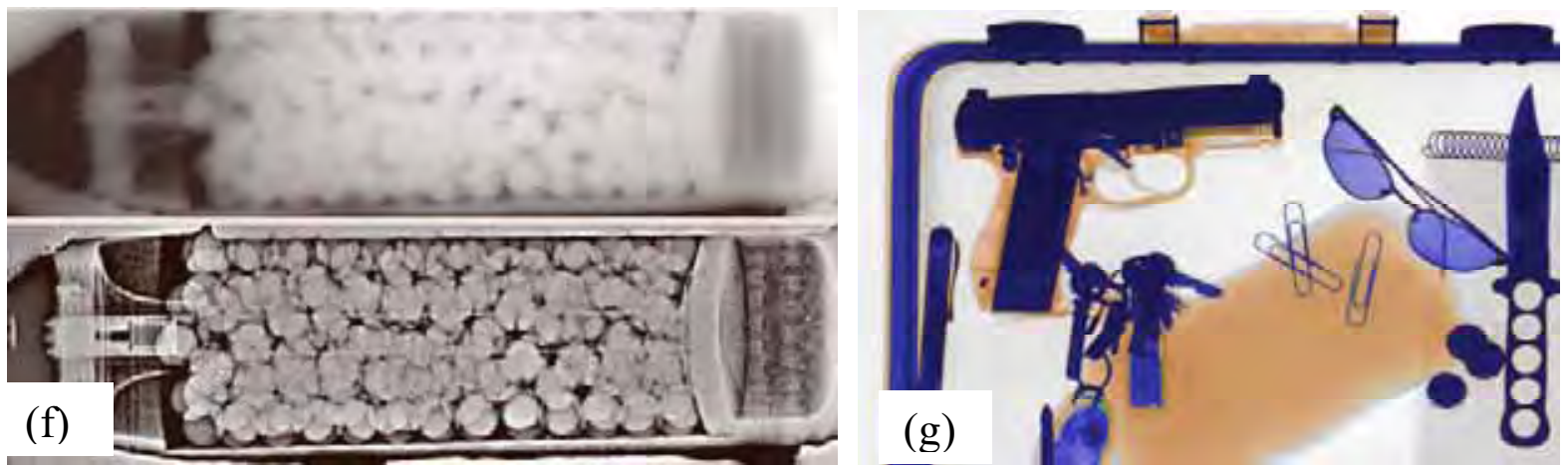

Segurança pública - (f) Granada e Imagem filtrada com filtro passa alto. (g) Mala suspeita.

Figura 3.31 - Aplicações da radiografia digital (PINCU; JEWELL, 2005). 


\subsubsection{Vantagens da radiografia digital}

São várias as vantagens da radiografia digital sobre radiografia com filme podendo-se destacar (FARMAN, LEVATO, GANE, SCARFE; 2008):

- Exibição imediata da imagem, com os detectores planos;

- Exibição interativa pelo monitor, com a possibilidade de melhorar as imagens e fazer medições diretas;

- Armazenamento integrado, fornecendo acesso às imagens por meio de software de gestão de dados;

- Segurança de estratégias de backup;

- Arquivamento externo, ou seja, obtenção de imagens duplicadas para uso por outras estações de trabalho;

- Mecanismos de segurança para identificar imagens originais e diferenciá-las das imagens alteradas;

- Possibilidade de colocar comentários, identificação, parâmetros de exposição utilizados e outros;

- Interoperacionalidade entre diferentes equipamentos e softwares e formatos de imagens (DICONDE);

- Interação remota com outras unidades e acesso pela internet.

A norma ASTM E 2339 "Standard practice for digital imaging and communication in nondestructive evaluation" (DICONDE) estabelece as regras para transferências de dados entre sistemas e organização dos dados das imagens sem perda da informação (ASTM E 2339; 2006).

Várias características são atribuídas como vantagens da radiografia digital (Digital Radiography, $D R$ ) em relação à técnica convencional que utiliza filme radiográfico industrial ou mesmo quanto à radiografia computadorizada (Computed Radiography, CR)(PURSCHKE, 2004). Na Tabela 3.1 estão descritas várias vantagens do emprego da DR, onde destacam-se a velocidade, a relação sinal ruído, faixa dinâmica, custo de operação e a reutilização. 
Tabela 3.1 - Características típicas entre Filme, CR e DR (BOIY; 2006).

\begin{tabular}{llll}
\hline Propriedades & Filme & CR & DR \\
\hline Velocidade & Lenta & Média & Rápida \\
Resolução Espacial, $\mu \mathrm{m}$ & $10-50$ & $50-250$ & $50-400$ \\
Relação Sinal Ruído, SNR & $50-250$ & $100-250$ & $250-2000$ \\
Faixa Dinâmica & $256: 1$ & $>4000: 1$ & $>4000: 1$ \\
Custo do Investimento & Baixo & Moderado & Moderado para Alto \\
Custo de Operação & Alto & Moderado & Baixo \\
Portabilidade & Alta & Alta & Moderada \\
Reutilização & 1 & $1000-10.000$ & $10.000-1.000 .000$ \\
Robustez Mecânica & Excelente & Média & Média para Baixa \\
Dimensões & Várias & Várias & Limitadas \\
\hline
\end{tabular}

Outra vantagem desta metodologia é a possibilidade da integração total do ambiente com as imagens das radiografias digitais, e assim agregar melhorias da eficiência dos processos e da gestão de todas as imagens. O sistema pode ser idealizado de forma a criar uma rede local e com acesso remoto via intranet e internet (FARMAN, LEVATO, GANE, SCARFE; 2008).

Um ambiente totalmente digital começa com as aquisições das imagens pelo detector plano, seguido de avaliação e arquivo pelo inspetor nível 2 das imagens das radiográfias digitais, incluindo o uso de gráficos estatísticos de controle e imagens fotográficas de irregularidades superficiais visíveis (NBR ISO 9712, 2004). O sistema permite o compartilhamento das imagens para utilização nas análises do progresso de soldagem, pesquisa e desenvolvimento, nas reuniões, palestras e conferência em qualquer parte do mundo, além de um monitoramento remoto pelo inspetor nível 3 responsável. Permite ainda que o engenheiro de solda prepare os planos para reparos e avaliações dos defeitos, além do acesso das imagens pelos inspetores do cliente, auditores, laboratórios, servindo de apoio para discussão dos especialistas. Na Figura 3.32 encontra-se esquematizado um ambiente integrado de trabalho com imagens geradas pela radiografia digital (FARMAN, LEVATO, GANE, SCARFE; 2008). 


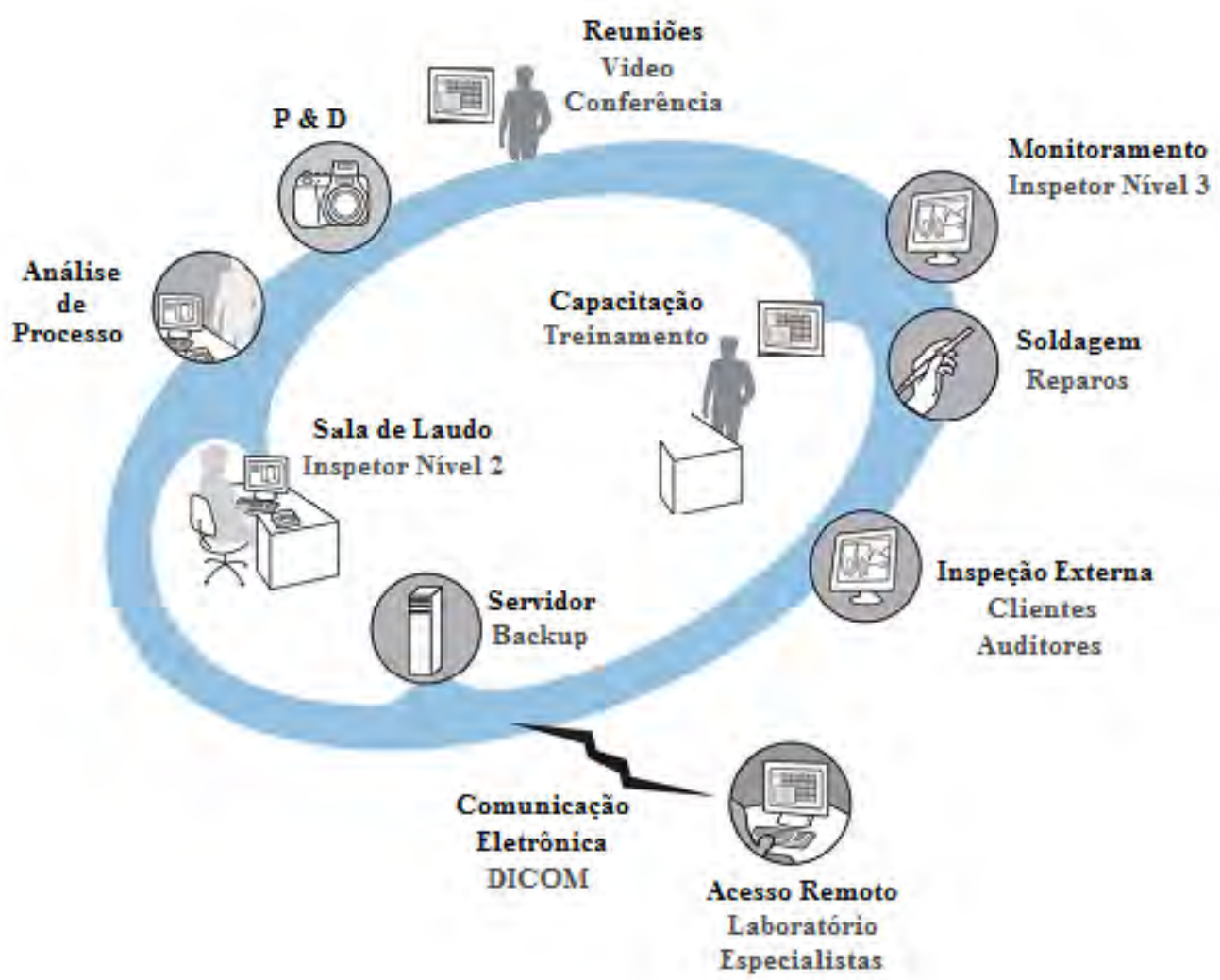

Figura 3.32 - Ambiente integrado de imagens digitais (FARMAN, LEVATO, GANE, SCARFE; 2008).

Um dos resultados mais poderosos da tecnologia integrada é o potencial para organizar as imagens em um formato que está disponível para treinamento e capacitação de inspetores, em tempo real. Com a tecnologia digital, o engenheiro de solda pode ver as imagens e o procedimento de soldagem em qualquer local que tenha uma estação de trabalho. Isso the permite o acesso imediato às imagens de defeitos e, se ele estiver conectado à Internet, ele poderá compartilhar as informações, reduzindo significativamente o tempo necessário para discussão com os responsáveis pelo processo, gerentes e mesmo clientes. O tipo de ligação pode ser com ou sem fios usando transmissão de rádio frequência $(\mathrm{RF})$ ou Bluetooth. O monitor deve ser de alta resolução com uma ampla capacidade de contraste de tons de cinza.

\subsubsection{Avaliação dos custos relativos}

As inspeções radiográficas geralmente são realizadas por razões de qualidade e de segurança. No entanto, normalmente há motivação para controlar e até mesmo reduzir os custos de executar estas inspeções. Assim, uma das razões para considerar uma mudança da radiografia com filme para a digital é reduzir as despesas gerais. 
Neste sentido, uma conversão bem sucedida é quando um investimento resulta em uma redução nos custos de inspeção. Os custos de inspeção incluem produtos de consumo, como filme, produtos químicos, cassetes, chumbos, placas de imagens CR, etc. Custos adicionais são necessários para realizar as inspeções, rebatimentos, incluindo logística de movimentação de peças para o setor de radiografia, custos associados à aquisição, o desenvolvimento e a análise do filmes ou imagens e os custos de arquivamento e emissão de relatórios de mão-de-obra. Há também os custos indiretos, tais como a manutenção, inspecção tempo de ciclo, os custos de inventário etc. Todas juntas, estas categorias de custo podem ser combinadas para incluir no "custo total" para um processo de inspeção. Os custos por exposição relativos entre o filme, CR e DR são mostrados na Tabela 3.2., tendo como base uma média de 67.500 radiografias realizadas por um período de um ano. Assim, a radiografia direta (DR), em relação ao filme, tem uma redução do custo de $61 \%$ (BOIY, 2006).

Tabela 3.2 - Custo por exposição entre as técnicas (BOIY, 2006).

\begin{tabular}{lccc}
\hline \multicolumn{1}{c}{ Item } & Filme & CR & DR \\
\hline Execução & 1,8 & 1,0 & 0,9 \\
Diagnóstico & 1,8 & 1,2 & 0,9 \\
Equipamentos & 2 & 1,0 & 1,0 \\
Consumíveis & 3 & 0,6 & 0,2 \\
Total & $\mathbf{8 , 6}$ & $\mathbf{3 , 8}$ & $\mathbf{3 , 0}$ \\
Economia anual & & & $\mathbf{- 6 1 \%}$ \\
\hline
\end{tabular}

\subsubsection{Radioproteção e redução de dose}

De acordo com as regras básicas da radioproteção, as radiações podem ser controladas pelas seguintes variáveis: tempo, distância e blindagem. A dose absorvida por uma pessoa ou aquela emitida para o ambiente é entre outras, diretamente proporcional ao tempo em que ela permanece exposta à radiação, sendo diretamente ligado ao tempo de exposição. Qualquer trabalho em uma área que envolve radiação deve ser cuidadosamente programado e realizado no menor tempo possível. A dose de radiação é inversamente proporcional ao quadrado da distância. Sendo assim, decresce com o quadrado da distância da fonte à pessoa e a blindagem que normalmente é feita 
por parede de concreto vibrado ou de chumbo tem sua eficiência ligada a fatores da atenuação do material da blindagem (CNEN-NN-3.01; 2005).

Com o uso da radiografia digital a redução do tempo de exposição médio, previsto, em comparação com a técnica convencional, é alguma coisa entre 50 e $90 \%$. Como o tempo de exposição é reduzido, normalmente ocorre um aumento do número de radiografias batidas, devido a maior produtividade que o novo método agrega. Assim, existe a preocupação de que os usuários de sistemas digitais estejam conscientes em não aumentar o número de radiografias batidas desnecessariamente quando passarem de convencional para digital, visto que outra vantagem da radiografia digital é não ser necessário fazer os rebatimentos devido a densidade, manchas, etc.., comuns na técnica convencional. Todo serviço de radioproteção deve ser reavaliado os possíveis impactos nos cálculos das blindagens existentes, em decorrência de uma situação de maior produtividade.

\subsubsection{Impactos ambientais e resíduos industriais.}

O mesmo processo que foi percebido na transição da substituição dos filmes fotográficos para as câmeras digitais com arquivos eletrônicos, está acontecendo com o uso da radiografia digital, ao invés da técnica convencional. Existem fortes motivações em relação ao meio ambiente, que começa com a redução dos níveis de radiação e a eliminação do uso de filmes radiográficos industriais, reveladores, fixadores, águas de lavagens, processadoras, secadoras, salas de arquivamento de filmes virgens e já processados sob condições controladas, etc..

Outro item que envolve uma mudança significativa é o impacto ambiental gerado pela eliminação dos rejeitos causados pelo uso dos próprios filmes, reveladores e fixadores, conforme apresentado na Figura 3.33. No caso dos detectores planos mais uma vantagem que pode ser destacada, se o sistema for automatizado, é a eliminação da necessidade do operador entrar na área de risco (PINCU, 2005). 

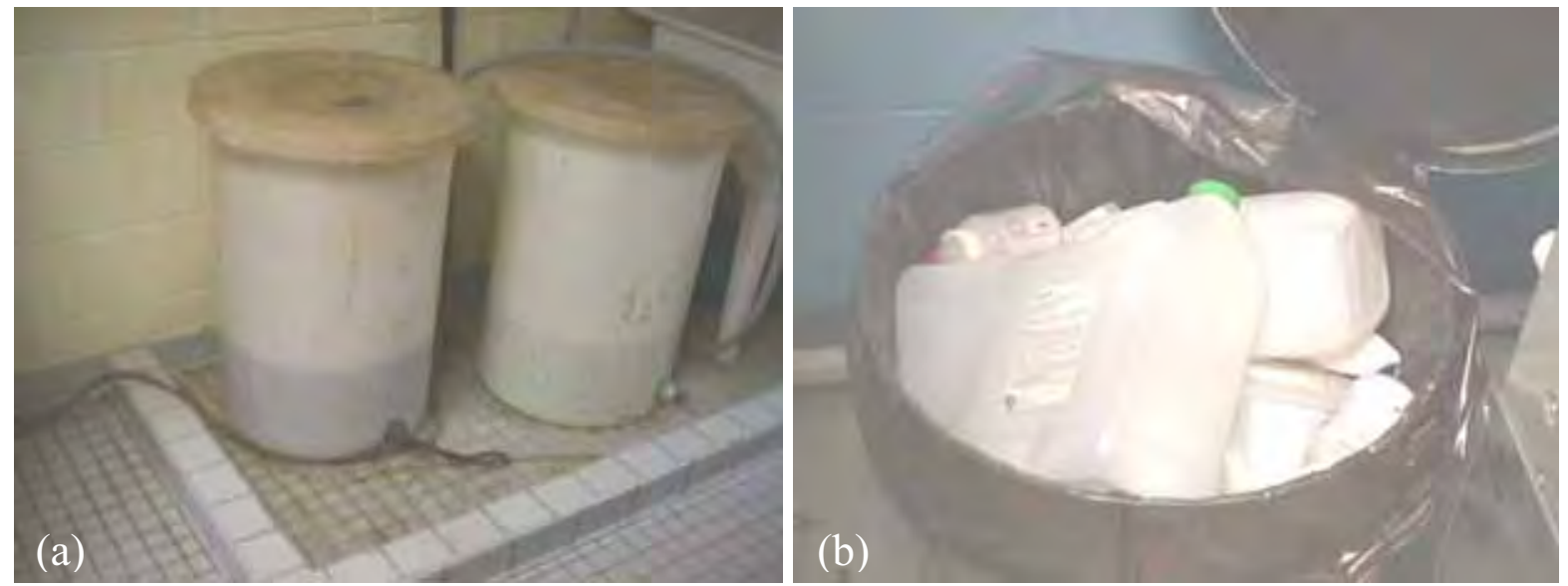

Figura 3.33 - Rejeitos da radiografia convencional (a) Reveladores e fixadores. (b) Embalagens plásticas.

\subsubsection{Reconhecimento automático de defeitos}

Vários sistemas automáticos de avaliação de defeitos foram desenvolvidos e a cada momento novos modelos são apresentados em busca da perfeição em comparação a referência humana. No caso da inspeção radiográfica, após o desenvolvimento da radiografia digital e da melhoria significativa dos equipamentos para digitalização de imagens, os sistemas de reconhecimento automático de defeitos passaram a ser factíveis. A busca pelo desempenho com total acerto terá de continuar para segmento de produto ou processo aplicável. Na Figura 3.34 é mostrado um exemplo de uma bandeja da roda de um carro, com um defeito detectado (CZICHOS, SAITO, SMITH; 2006).
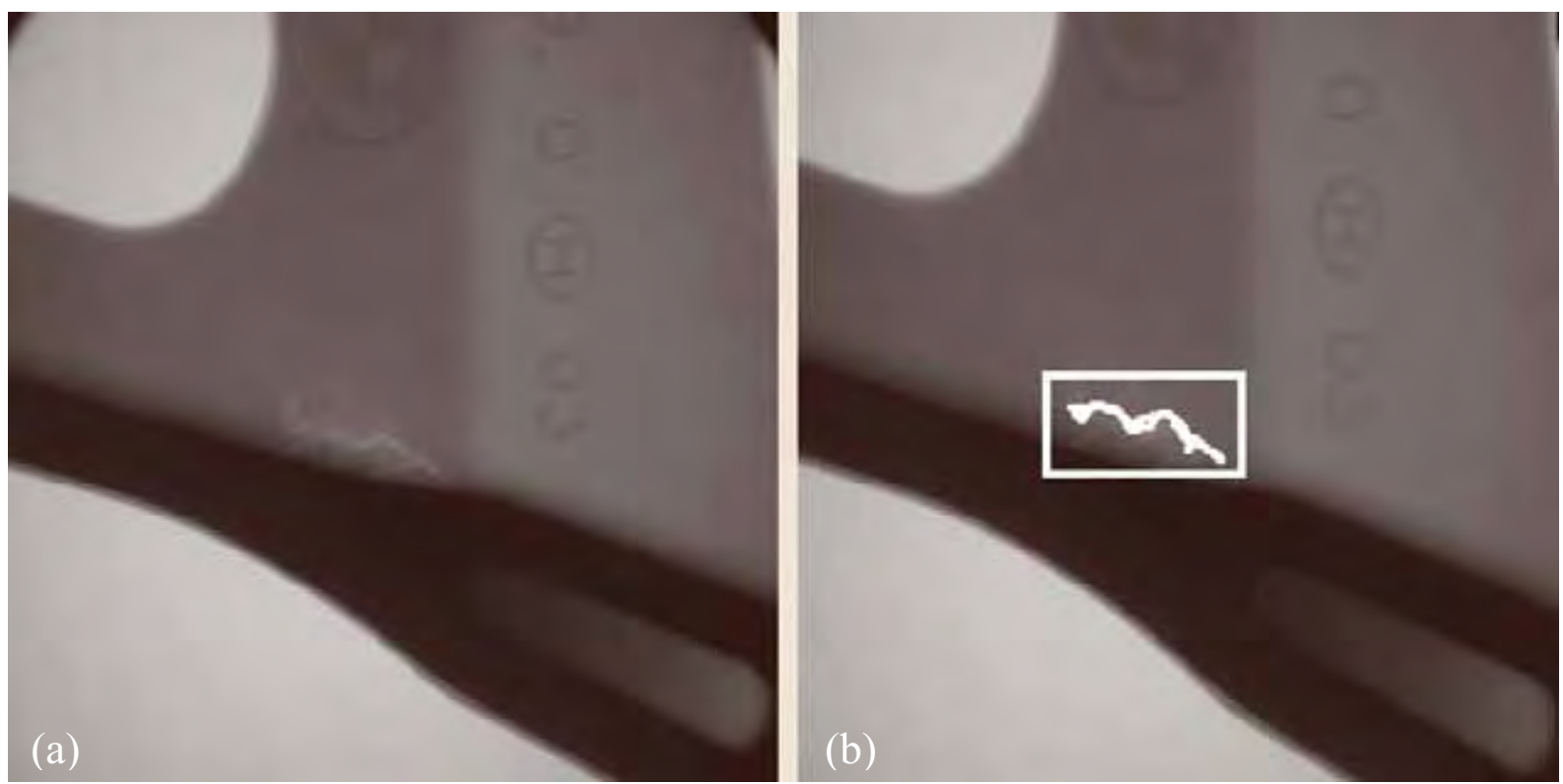

Figura 3.34 - Detecção de defeito por sistema automático. (a) Imagem original (b) Defeito detectado. 
Estes sistemas se baseiam em algoritmos matemáticos que avaliam um conjunto de parâmetros para cada indicação ou imagem e o compara com um catálogo de defeitos conhecidos ou mesmo padrões de alarme das imagens. Cada aplicação específica utiliza parâmetros de reconhecimento que tenha passado por exaustivas simulações que comprovadamente validaram sua eficiência.

Para comparar diferentes radiografias, e extrair a informação necessária e vital das imagens, é necessário calibrar os valores dos níveis de cinza contra a espessura do material e calibrar as dimensões lineares. Uma vez que estas condições estejam bem estabelecidas, estas devem ser sistematicamente utilizadas para uma gama de tipos de inspeções.

Na Figura 3.35 são apresentadas as imagens de quatro diferentes etapas do processo tratamento e de avaliação exemplificado. Na primeira etapa são removidos os detalhes irrelevantes da imagem digitalizada, que pode ser feito subtraindo a imagem de fundo, que foi gerada pelo uso de um filtro passa baixo. Embora as radiografias normalmente possuam um brilho central que difere das bordas, essa diferença é eliminada pela subtração da imagem de fundo da imagem original. Na etapa seguinte é possível definir um limite e identificar como possíveis defeitos todos os pixels cujos valores de níveis de cinza que excederam esse limite (ASM; 1997).

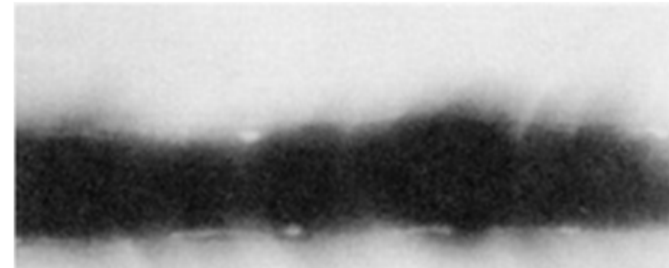

(a)

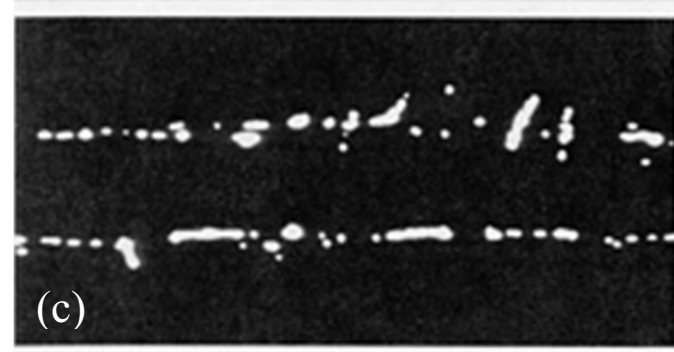

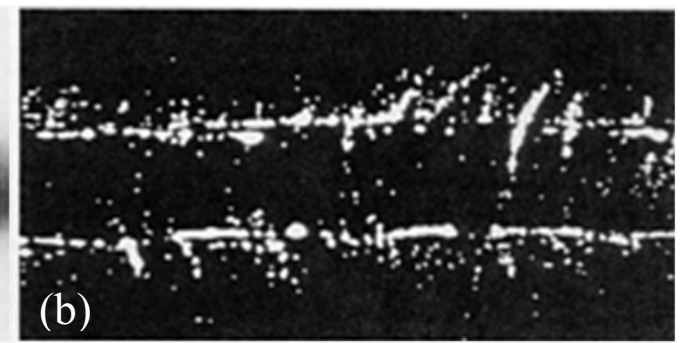

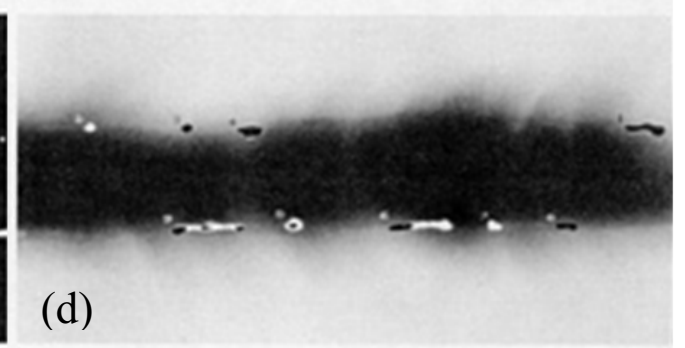

Figura 3.35 - Imagens criadas pelo sistema de processamento de imagens que identifica e avalia as imagens radiográficas dos defeitos de solda em tempo real. (a) imagem original. (b) imagem binária. (c) imagem binária após redução de ruído. (d) imagem original com os defeitos identificados. 
Na Figura 3.36 está descrito um fluxograma de um procedimento de avaliação automática de imagens.

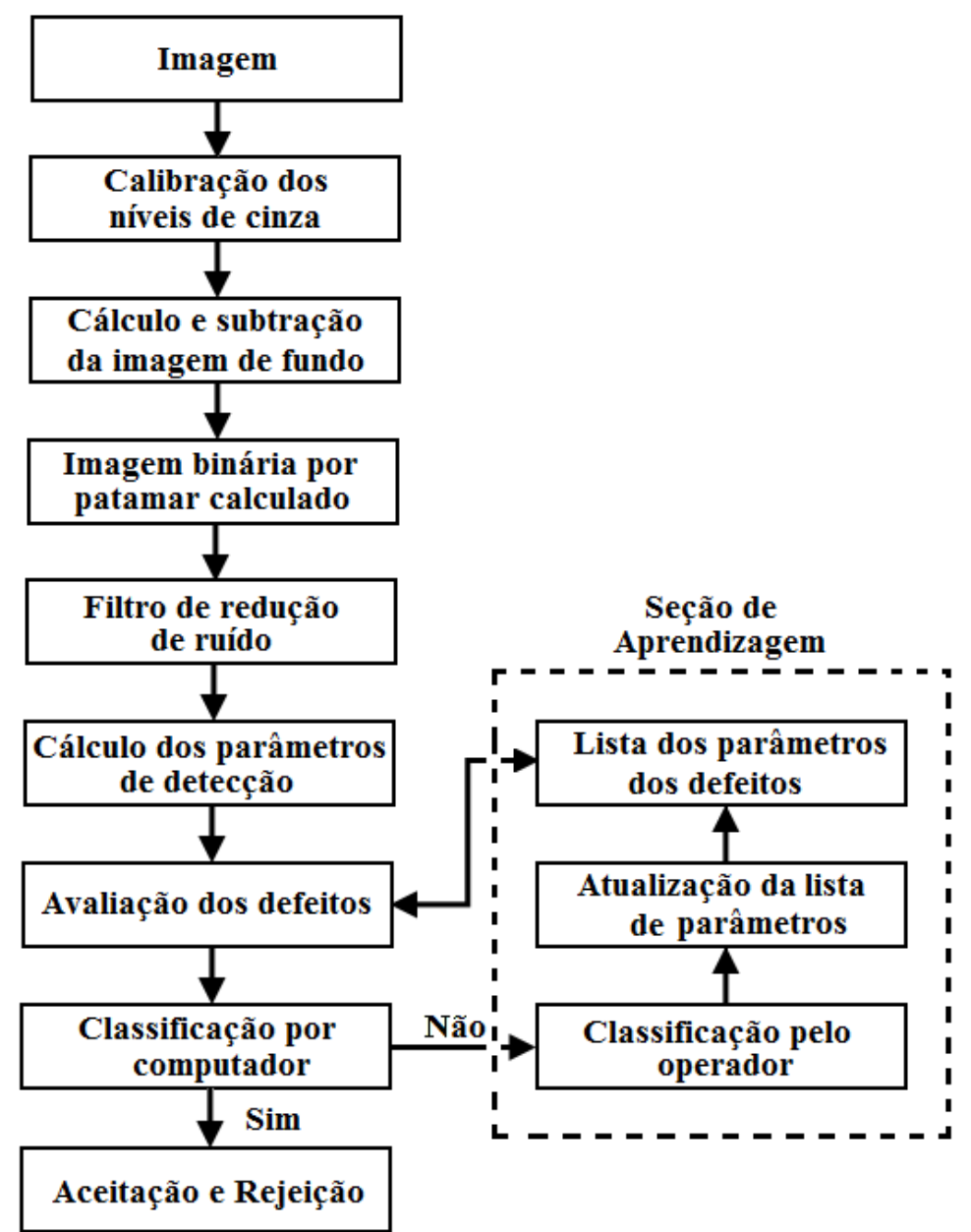

Figura 3. 36 - Fluxograma de um processo de avaliação de imagem.

Na Figura 3.37 pode-se observar outro exemplo de imagem processada, um cordão de solda com várias regiões com trincas: (a) como obtida pelo sistema de RD. (b) após aplicação de filtro passa alto (ZSCHERPEL, BAVENDIEK, 2005).
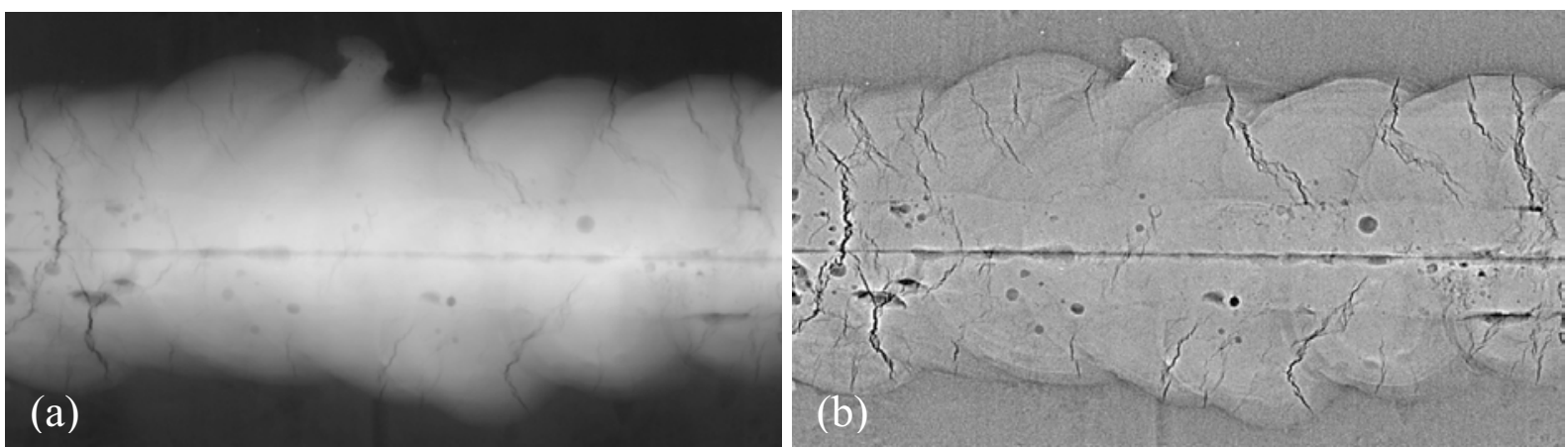

Figura 3.37 - Exemplo de processamento de imagem (a) Imagem do cordão de solda como obtida. (b) Imagem com filtro passa alto aplicado. 
Na Figura 3.38 é mostrado um exemplo de um tipo de aplicação da indústria automotiva que, devido ao aumento do tipo e quantidade de peças com exigência de ensaio radiográfico, caracterizado por sistemas com elevada produtividade, onde são empregados métodos de classificação, análise e de reconhecimento de defeitos totalmente automáticos (Automatic Defect Recognition, ADR) para garantia da qualidade das peças fundidas (HEROLD, GRIGAT, BAVENDIEK; 2004).

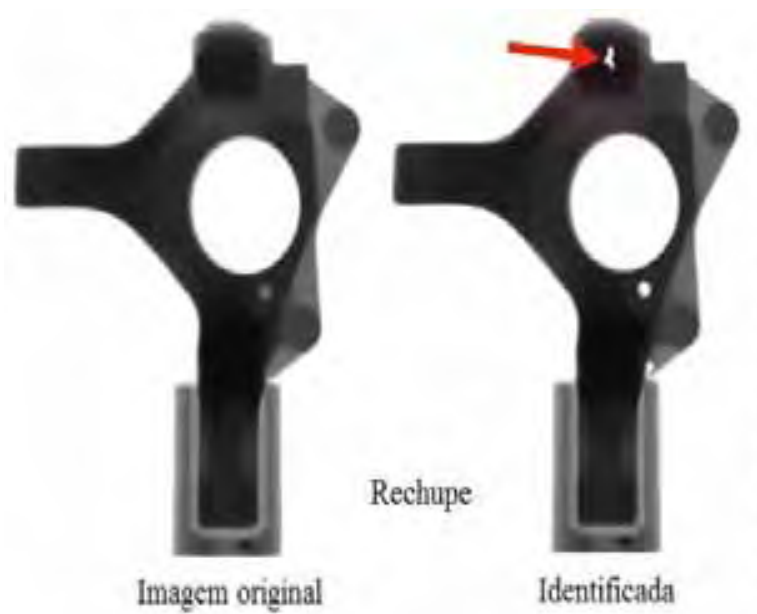

(a)

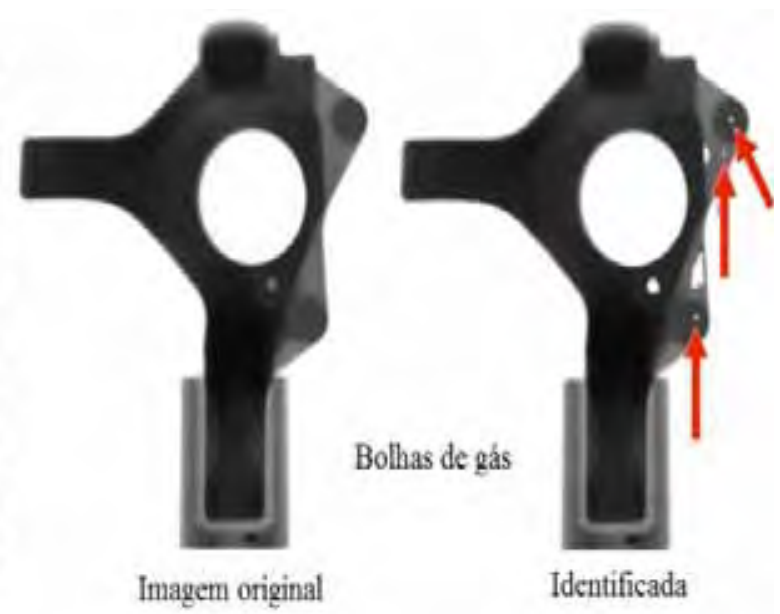

(b)

Figura 3.38 - Imagens de defeitos identificadas por um sistema automático de imagens. (a) Imagem de um rechupe. (b) Imagem de bolhas de gás.

Finalmente, outro tipo de sistema de reconhecimento automático de defeitos encontra-se apresentado na Figura 3.39, onde se pode observar imagens de um duto com diâmetro de $25 \mathrm{~mm}$ soldado. A imagem digital (a) mostra a região da solda com a aplicação do filtro passa alto e a imagem (b) a região, contendo várias indicações circulares, ampliada. A imagem (c) mostra a tela do sistema semi-automático com indicações do algoritmo. Este exemplo também mostra o potencial de um sistema de um controle semi-automático, onde o computador indica os prováveis defeitos e o inspetor obtém o tamanho da indicação, podendo tomar a decisão final.

O sistema semi-automático garante que defeitos potenciais não irão ser perdidos e fornece um limite fixo para a decisão entre bom ou mau (BAVENDIEK, K.; EWERT U.; ZSCHERPEL U.; 2007). 
(a)

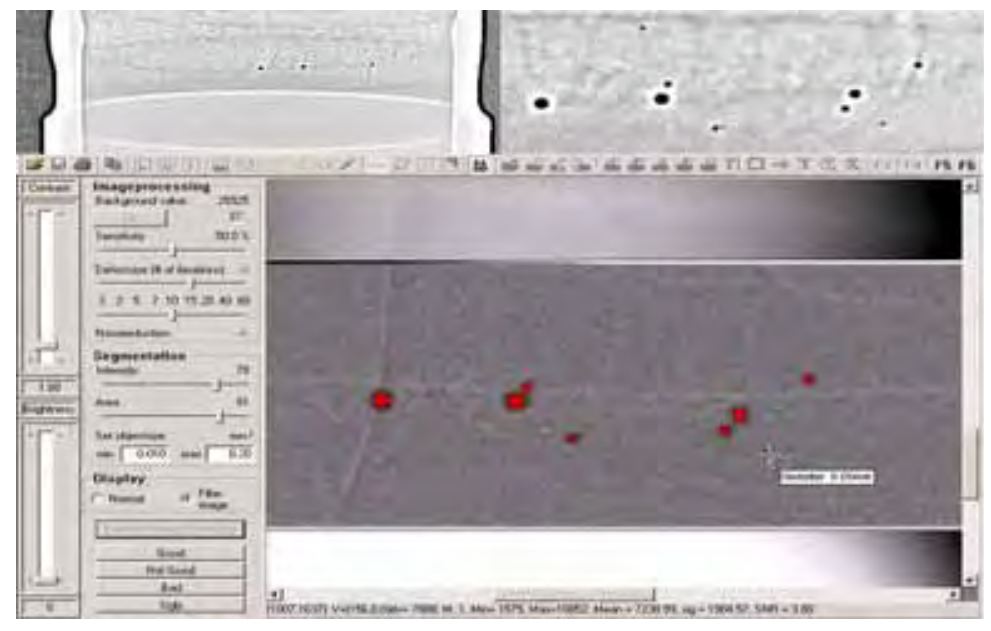

(c)

Figura 3.39 - Imagem digital de um duto de uma polegada avaliado por um sistema semi-automático de controle.

\subsubsection{Comparação do desempenho e probabilidade de detecção de defeitos}

O desempenho de detecção de defeitos em soldas de tubos de inconel, com diâmetro de 101,6 mm e espessura de 1,98 mm, em pesquisas da empresa Boeing, mostrou um ótimo desempenho do detector plano de silício amorfo (DR), Thales Flash Scan 35, utilizando a técnica parede dupla - vista simples (PD-VS), em comparação com a técnica convencional com filme nas técnicas parede dupla - vista dupla (PDVD) e PD-VS e com a radioscopia com intensificador de imagem NAI, utilizando PDVS. O acerto perfeito foi baseado nos entalhes de diferentes dimensões, criados por EDM (Electric Discharge Machining) na região da solda. A Figura 3.40, mostra que o uso da RD obteve um acerto de 94\%, o filme na técnica PD-VS apresentou 79\%, a radioscopia 70\% com PD-VS e com o pior desempenho o filme utilizando a técnica PD-VD (BAVENDIEK et al., 2006).

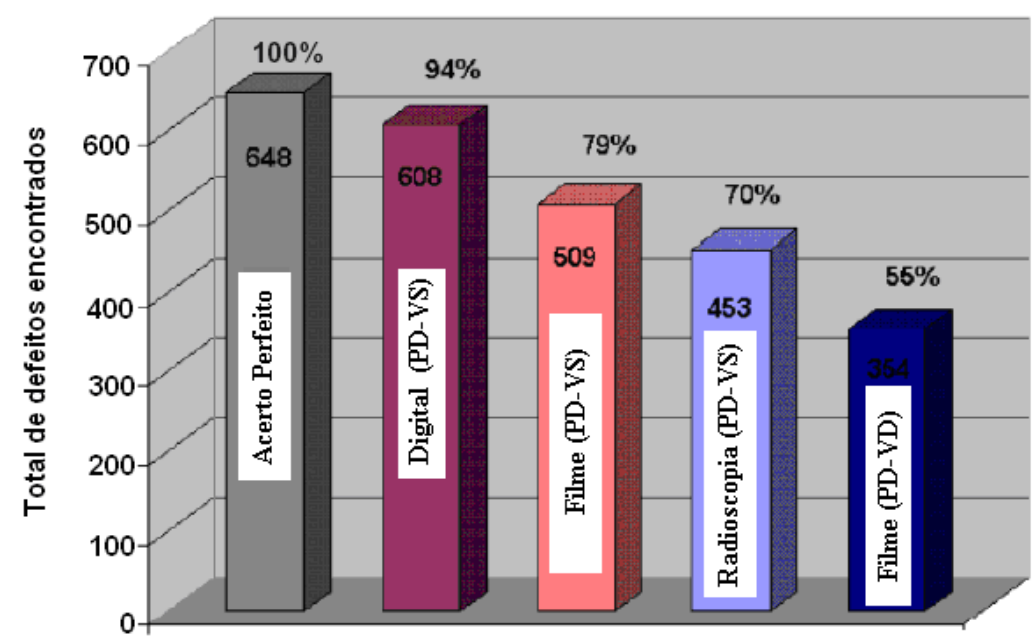

Figura 3.40 - Comparação entre Digital, filme com PD-VD e PD-VS e Radioscopia (BAVENDIEK et al., 2006). 
Em termos da probabilidade de detecção de defeitos (Probability of Detection, $P o D)$, pode-se observar na Figura 3.41, a comparação dos resultados do experimento. A linha vermelha e a curva correspondente à radiografia digital mostram que uma falha de $0,05 \mathrm{~mm}^{2}$ é detectada com a mesma probabilidade de $94 \%$ que uma falha de 0,12 $\mathrm{mm}^{2}$ com filme (PD-VS), que tem mais do dobro de dimensão. Para a mesma probabilidade quando é utilizado o filme com PD-VD é necessário um defeito maior que $0,5 \mathrm{~mm}^{2}$, ou seja, uma dimensão 10 vezes maior. Também se observa que para uma PoD de $100 \%$ é preciso um defeito de aproximadamente $0,1 \mathrm{~mm}^{2}$ para a digital, $0,22 \mathrm{~mm}^{2}$ para o filme parede simples-vista simples e $0,36 \mathrm{~mm}^{2}$ para a radioscopia. Esta diferença é dada pela profundidade dos defeitos que é o resultado da maior sensibilidade ao contraste da radiografia digital (BAVENDIEK et al., 2006).

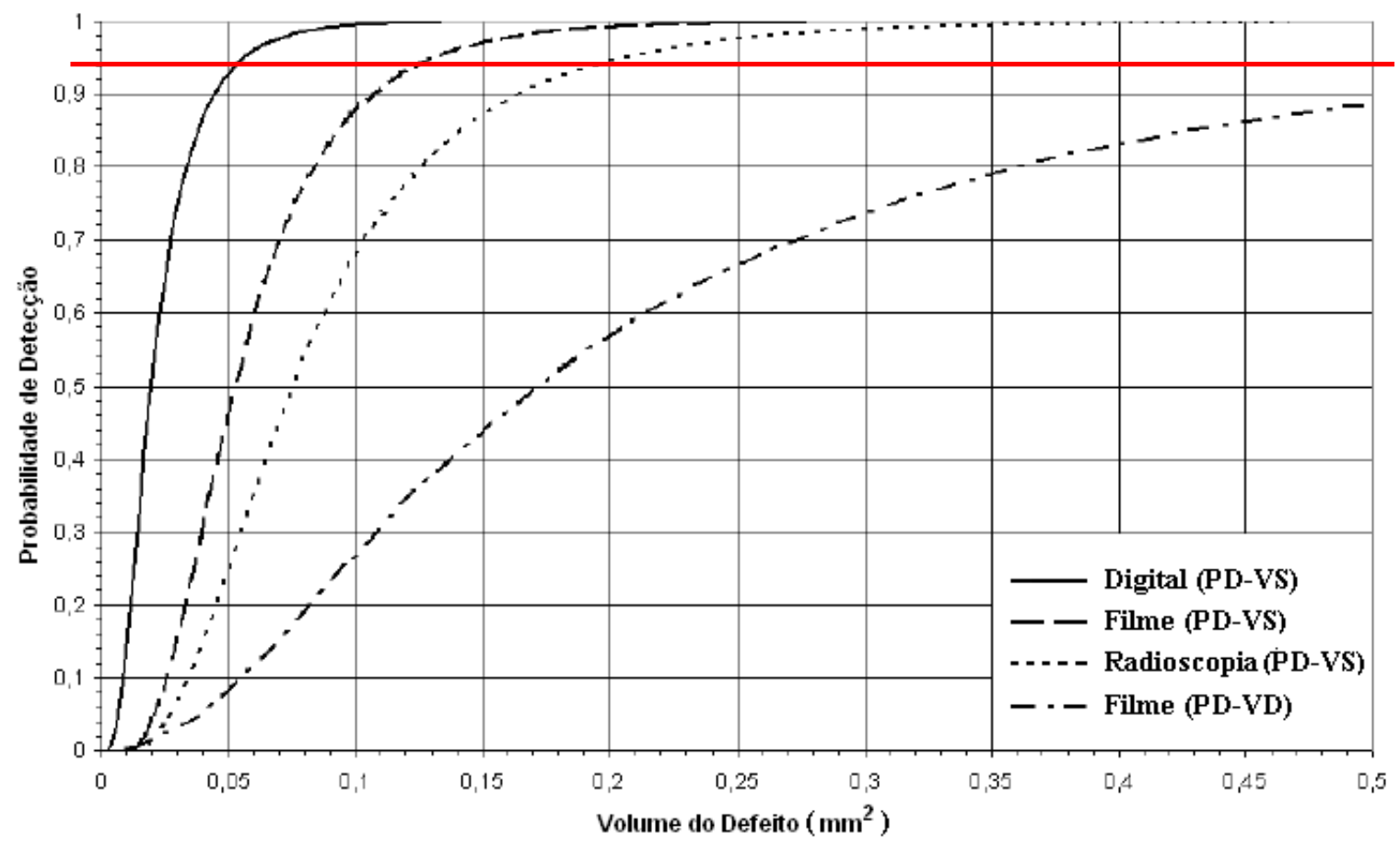

Figura 3.41 - Probabilidade de deteç̧ão de defeitos, comparação por volume, comprimento e profundidade. (BAVENDIEK et al., 2006).

\subsubsection{Segurança dos dados}

Para maximizar a produtividade e manter a competitividade de hoje, 24 horas por dia, 7 dias por semana sob demanda corporativa, funcionários, clientes, parceiros e fornecedores, tanto dentro como fora da empresa, precisam de acesso contínuo aos dados (TSM, 2006). No caso da norma ISO/DIS 10893-7, é exigido que os métodos de armazenagem das imagens devam ser de tal forma que as imagens originais sejam 
armazenadas mantendo a resolução completa, conforme liberada pelo sistema. Os procedimentos de armazenamento dos dados devem ser redundantes e suportados por estratégias adequadas de backup, para garantir o armazenamento dos dados, por pelo menos por 10 anos (ASTM E 2597, 2007; ISO/DIS 10893-7, 2009).

Os backups são classificados quanto a sua forma de execução e podem ser incremental ou do tipo arquivo. $O$ do tipo incremental é aquele que realiza a cópia somente dos arquivos que sofreram alterações desde o último backup e o do tipo arquivo realiza a cópia completa de todos os arquivos. Atualmente os sistemas de backup são programáveis e feitos por robôs que trocam as fitas e atualizam o sistema de acordo com a estratégia adotada. Na Figura 3.42 pode-se observar um exemplo do sistema de backup, onde os dados da rede são continuamente atualizados e duplicados.

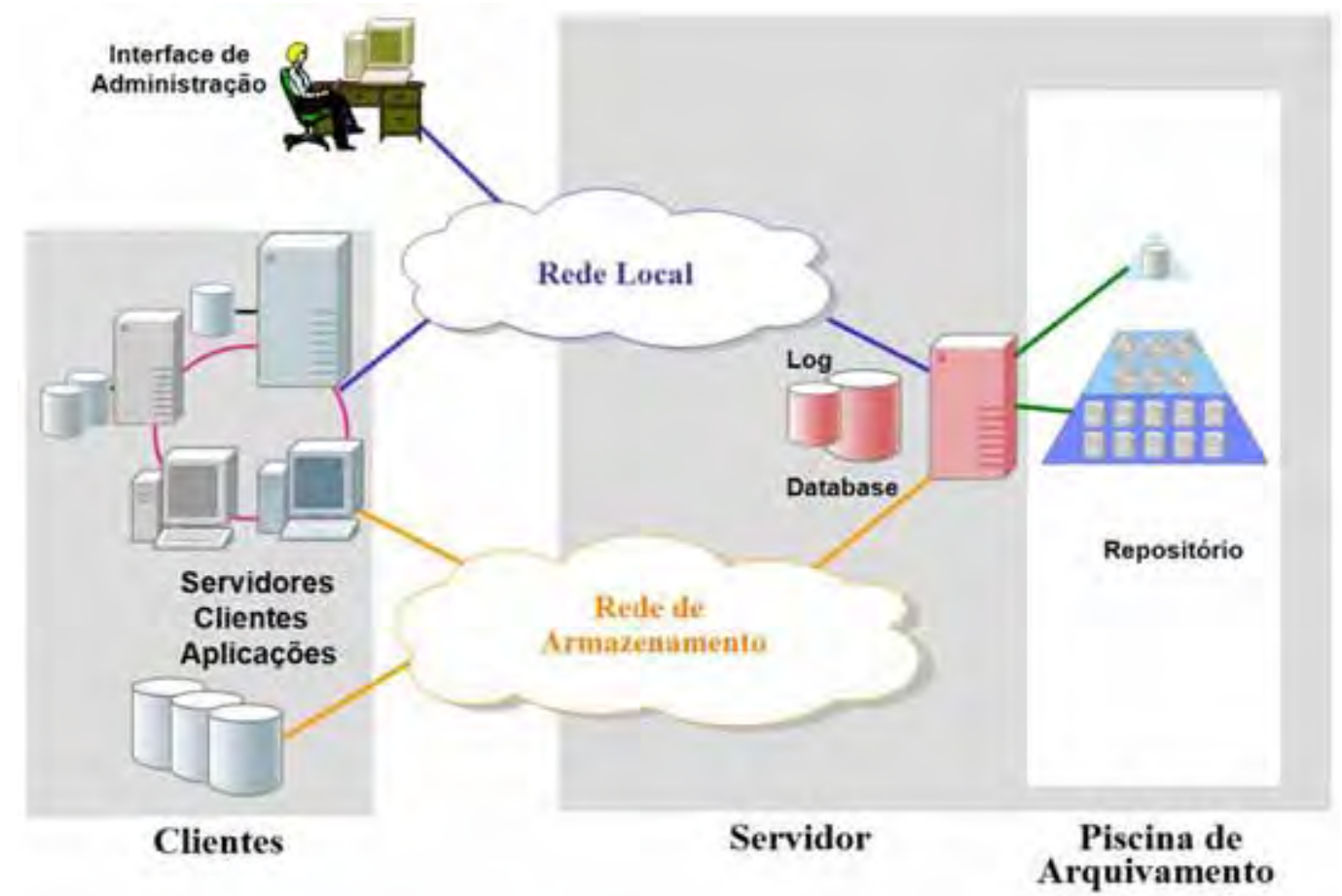

Figura 3.42 - Exemplo de um sistema de backup em rede (TSM, 2006).

As estratégias de backup minimamente prevêem que um disco danificado deve ser recuperado rapidamente e automaticamente para ajudar a minimizar as interrupções operacionais. Se houver falha do servidor as operações devem ser restabelecidas com um servidor virtual ou servidor em espera, enquanto o sistema está sendo substituído ou reparado. Quando acontecer um desastre como incêndio, enchente ou outros é essencial ter uma cópia das informações importantes atualizada em outro local que está fora da zona de desastre. Os processos de "backup" devem ser freqüentes, ou até 
mesmo contínuos, para evitar que os dados sejam perdidos. Quando os dados transitam entre sites, eles precisam ser protegidos contra possíveis violações de segurança, pois uma violação da segurança dos dados pode ser devastadora para a reputação da sua empresa (TSM, 2006).

\subsection{Qualidade do sistema radiográfico digital}

O desempenho da imagem usando sistemas de radiografia digital, é definido, principalmente, por três parâmetros fundamentais da qualidade da imagem: a resolução geométrica, o contraste relativo e do ruído relativo. A seguir são explicados vários métodos de controle de uma imagem e seu fundamento.

\subsubsection{Resolução geométrica.}

Resolução geométrica na direção X e Y descreve a capacidade de um sistema de processamento de imagens em distinguir ou resolver pequenos detalhes próximos de uma imagem sendo esta também conhecida como um pixel efetivo que corresponde a $1 / 2$ da penumbra do detector. Quando o sistema não está focado, as imagens dos detalhes individuais ficam misturadas até que eles já não conseguem ser distinguíveis.

Na Figura 3.43 são apresentados os valores aproximados da falta de foco e da resolução geométrica, expresso em pares de linhas por milímetro (pl/mm), encontrados em vários métodos de imagem, e demonstra o porquê que alguns métodos de imagem serem muito melhores do que outros na visualização de detalhes (BAVENDIEK et al.; 2006; SAMEI, RAVIN; 2008).

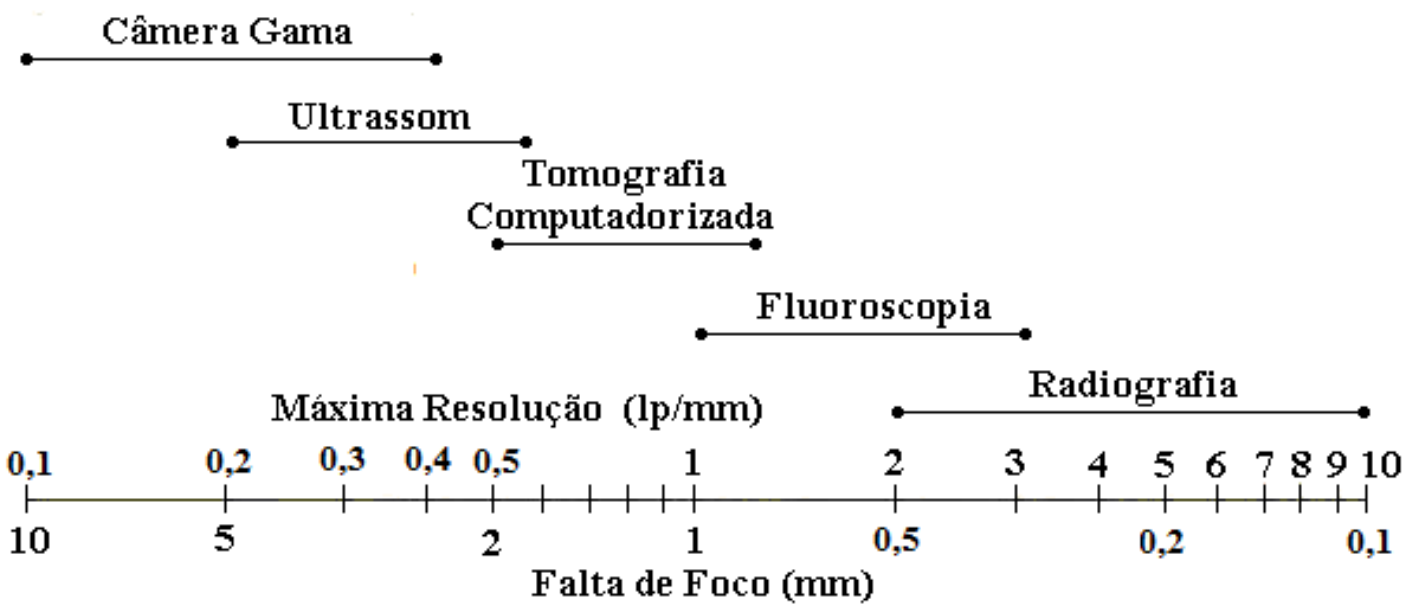

Figura 3.43 - Comparação da resolução geométrica de vários métodos de imagem (SAMEI, RAVIN; 2008). 
A resolução de um sistema de processamento de imagens é mais bem caracterizada em termos de sua função da transferência de modulação (Modulation Transfer Function, MTF), uma medida de capacidade do sistema em reproduzir o contraste da imagem de um contraste do objeto em várias freqüências espaciais, ou nível de detalhes (Figura 3.44).

\section{MTF}

A MTF para um sistema de imagem é equivalente a avaliar a resposta da freqüência de um sistema de áudio, porém a MTF é avaliada em termos de freqüência espacial, ou seja, ciclos por unidade de distância (VIEIRA et al., 2008).

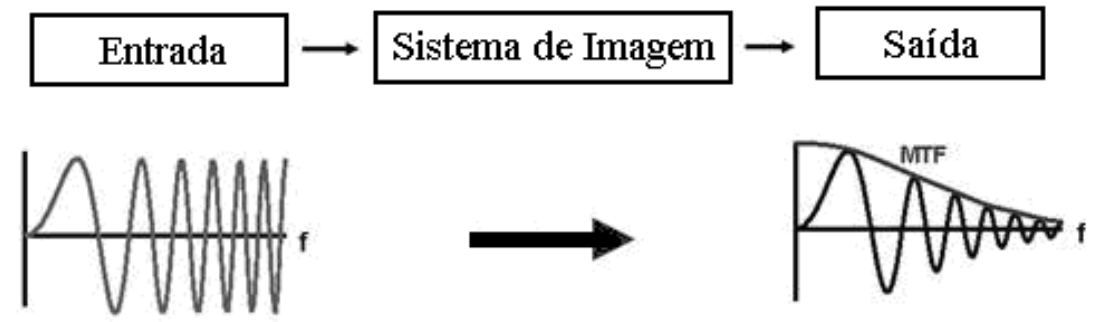

Figura 3.44 - Esquema da MTF que representa os atributos de resolução de um sistema radiográfico digital.

A maioria dos sistemas radiográficos é capaz de processar baixas freqüências (ou seja, detalhes mais grosseiros) melhores do que as freqüências mais altas (ou seja, detalhes mais finos), levando a uma perda de nitidez de imagem. A MTF é uma curva da relação entre as modulações de entrada e de saída, em função da sua freqüência espacial (SAMEI, RAVIN; 2008). Quanto maior os valores da MTF, melhor a nitidez e resolução de uma imagem, como ilustrado na Figura 3.45.

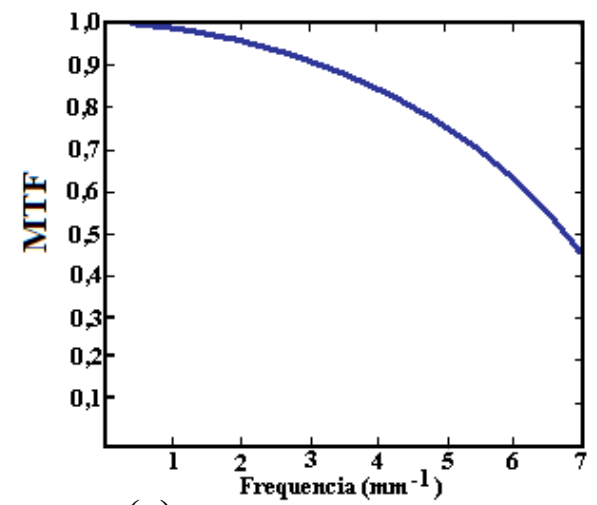

(a)

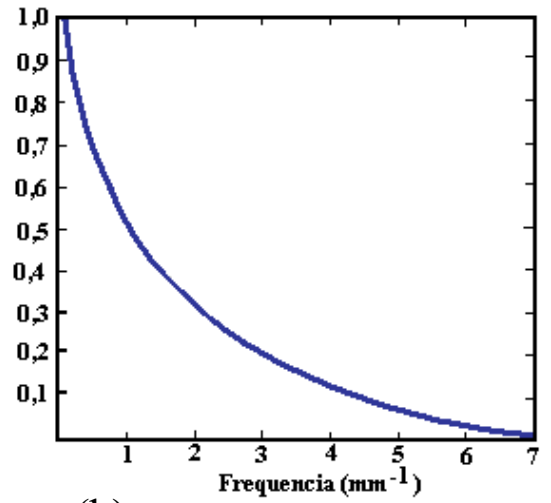

(b)

Figura 3.45 - (a) Alto valor de MTF. (b) Baixo valor de MTF. 
A diferença entre as curvas é que a da esquerda (Figura 3.45a) apresenta valores maiores de MTF para as mesmas freqüências comparando com a da direita (Figura 3.45b). O conteúdo da imagem com uma freqüência específica é encontrado multiplicando-se o conteúdo de objeto pela MTF. Por exemplo, na Figura 3.46, o objeto contém $0,8(80 \%)$ com uma freqüência de 2 ciclos por milímetro. A MTF nessa freqüência é 0,7 . Multiplicar estas duas quantidades mostra que a imagem conterá apenas 0,56 (56 \%) nessa freqüência. A área tracejada é a porção do espectro de freqüência espacial do objeto que é perdida devido a MTF do sistema de processamento de imagens (VIEIRA et al., 2008).

Quaisquer componentes de freqüência do objeto que estão acima do limite de resolução do sistema são completamente perdidos. Com efeito, a MTF do sistema de processamento de imagens pode cortar os componentes de freqüência superiores associados a um objeto e a imagem vai ser constituída por apenas componentes de freqüência mais baixas.
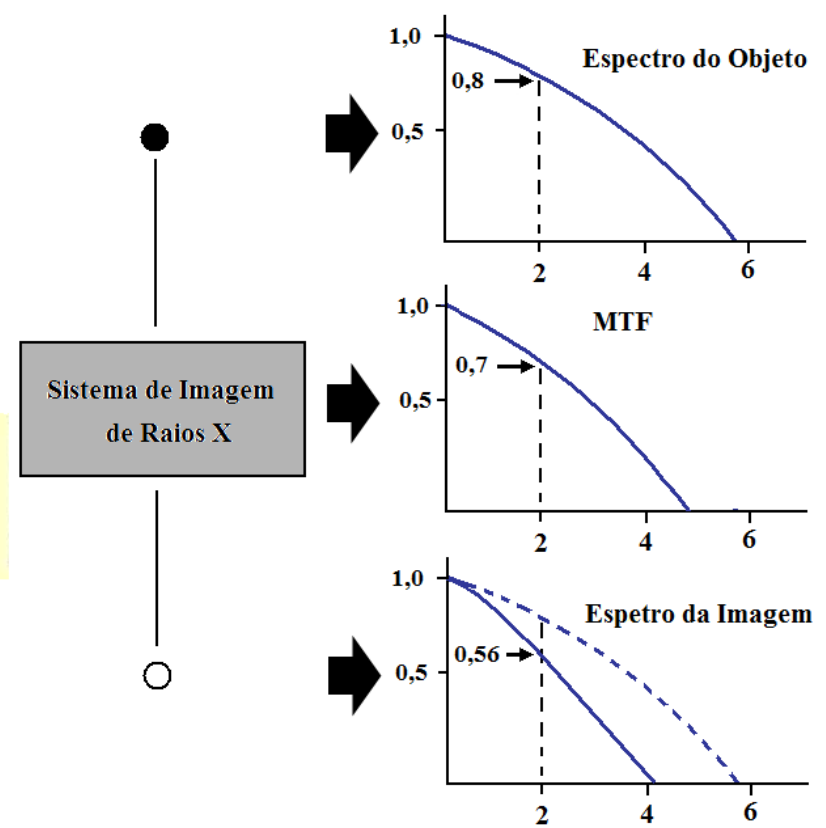

Figura 3.46 - Conteúdo da imagem com freqüência específica (SAMEI, RAVIN; 2008).

\subsubsection{Ruído relativo}

Em termos de controle de qualidade o ruído se refere às variações dentro de uma imagem que não corresponde ao objeto original, e que interfere com a visualização de uma descontinuidade e, conseqüentemente, com a interpretação da imagem. O ruído 
radiográfico é bem caracterizado pelo espectro de energia do ruído (Noise Power Spectrum - NPS).

NPS

O NPS define a quantidade do ruído dentro de uma imagem associado com freqüências espaciais específicas do ruído, conforme é mostrado na Figura 3.47.

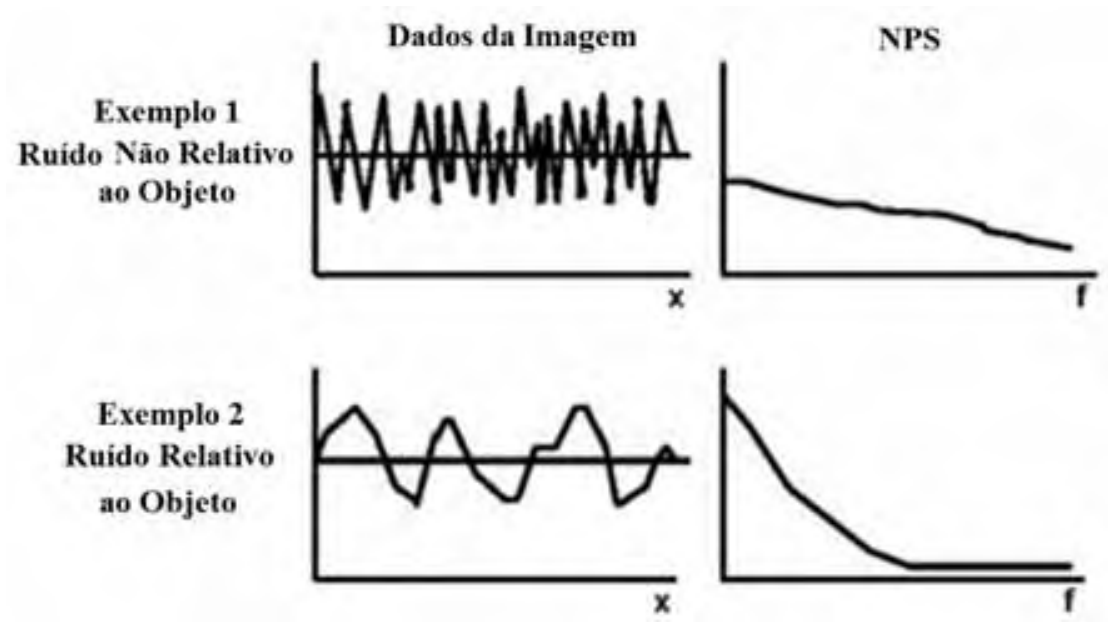

Figura 3.47 - Esquema do NPS representando os atributos de ruído de um sistema radiográfico digital.

As flutuações associadas com a aquisição de uma radiografia digital são mais visíveis ao exibir uma imagem uniforme sem descontinuidades no campo de visão. Variações em grande escala na imagem caracterizam-se, convencionalmente, como falta de uniformidade, enquanto as flutuações em menor escala são caracterizadas como o ruído, e estas medidas são baseadas na resolução dos níveis de cinza presentes nas imagens. Como a MTF, vários métodos experimentais foram desenvolvidos para medir o NPS de sistemas radiográficos digitais a partir dessas imagens uniformes.

\subsubsection{Relação Sinal Ruído}

A resolução, descrita em termos da MTF, reflete a capacidade do sistema de processamento de imagens para representar o sinal (ou seja, contraste) na imagem, enquanto o ruído ou o NPS, por outro lado, reflete o aspecto de ruído do desempenho do sistema. A qualidade da imagem, em termos da capacidade de ver uma descontinuidade em uma imagem, depende de uma combinação desses atributos sob a forma de relação sinal ruído (SNR). Como o contraste da imagem é inversamente 
proporcional à $(\mathrm{SNR})^{2}$, este determina o tamanho da descontinuidade que pode ser detectado confiavelmente em imagens radiográficas digitais.

A eficiência de detecção quântica ( $D Q E$ - Detective Quantum Efficiency) é um fator que indica a eficiência de como a informação da imagem detectada é transmitida e mostrada como imagem final. Ela é definida como a razão entre o quadrado da relação sinal-ruído da saída sobre o quadrado da relação sinal-ruído da entrada e seu valor é sempre inferior a 100 \%, como visualizado na equação 3.1 (OLIVEIRA, 2007).

$$
\mathrm{DQE}=\left(\mathrm{SNR}_{\text {Saida }}\right)^{2} /\left(\mathrm{SNR}_{\text {Entrada }}\right)^{2}
$$

\subsubsection{Relação Sinal Ruído Normalizada $\left(\mathrm{SNR}_{\mathrm{N}}\right)$}

A relação sinal ruído pode ser representada como a relação entre o valor médio da intensidade do sinal dividido pelo desvio padrão do ruído do sinal nesta intensidade. Esta intensidade representa o valor numérico de um pixel na imagem, sendo proporcional à dose de radiação, e é, comumente, referenciado como tom ou nível de cinza. O valor é igual a zero se a dose de radiação é zero. O máximo que pode atingir corresponde ao limite da faixa dinâmica do sistema, sendo, por exemplo, 256, 4096 e 16384 níveis de cinza para um equipamento de 8, 12 e 14 bits, respectivamente.

Trabalhar com a SNR da imagem é muito mais interessante, pois a intensidade de sinal é um parâmetro extremamente susceptível a fatores como ganho do sensor e da miliamperagem do filamento do tubo de raios $\mathrm{X}$. Os valores de cinza dos pixels em imagens digitais dependem do ruído e da intensidade do sinal, independente do processamento do contraste e do brilho para visualização de imagens. Assim o SNR foi proposto e aceito como um valor de equivalência para a densidade óptica em um determinado filme (EN 14784-1, 2005; EN 14784-2, 2005; ASTM E 2445, 2005; ASTM E2446, 2005).

Filmes são caracterizados pelo gradiente GD (à densidade = 2) e granulação ou ruído $\sigma \mathrm{D}$, sendo que, o parâmetro mais importante para a percepção de pequenas 


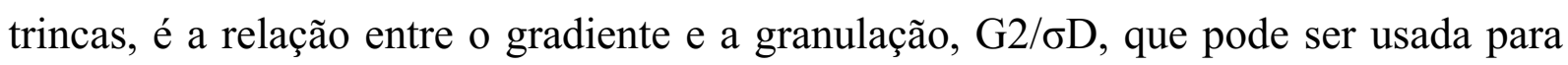
calcular a SNR correspondente, conforme equação (3.2).

$$
\mathrm{SNR}_{\mathrm{N}}=\mathrm{SNR}_{\text {média }} \cdot 88,6 / \mathrm{SR}_{\mathrm{b}}
$$

Assim, quanto maior o valor da relação sinal ruído, melhor será a perceptibilidade das descontinuidades, conforme pode ser observado na Figura 3.48 (BAVENDIEK, 2005).
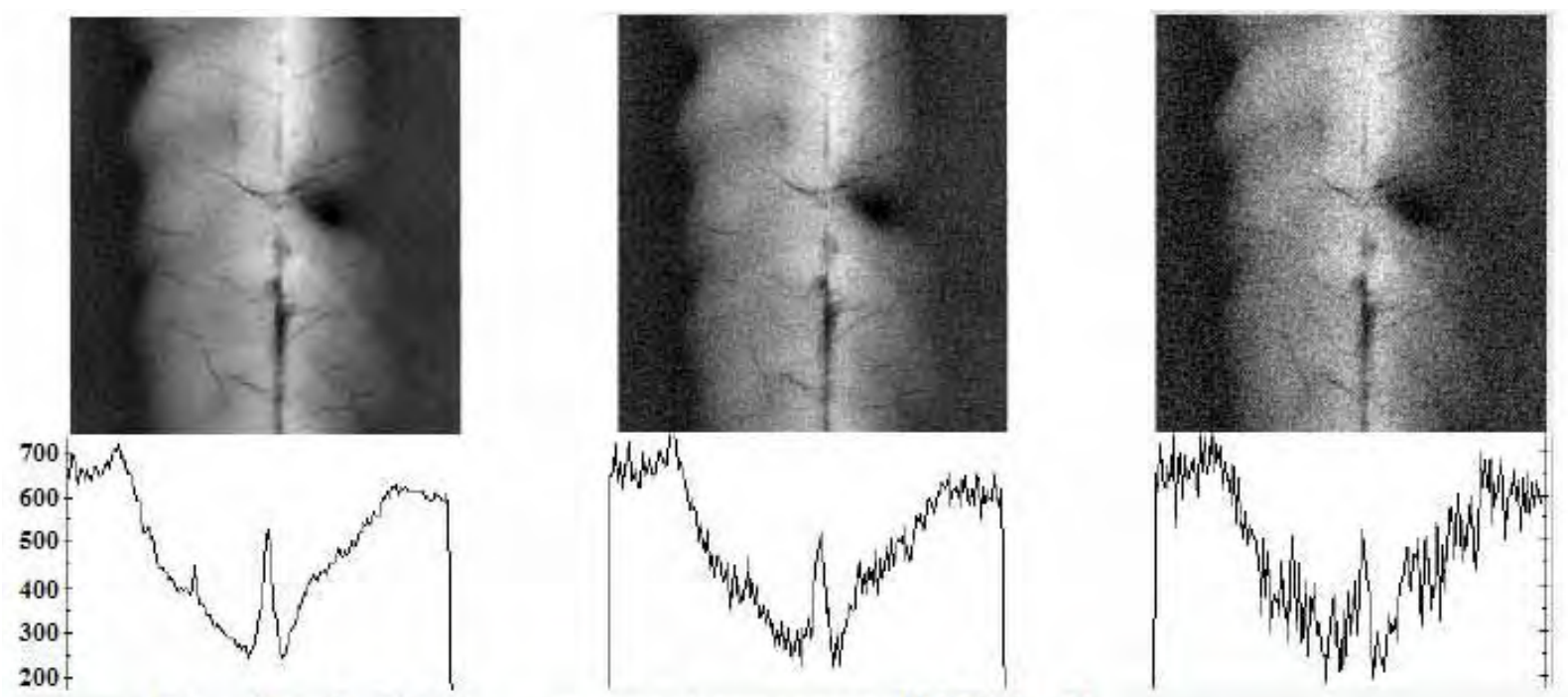

\section{Perda da informação / perceptibilidade}

Figura 3.48 - Efeito do ruído na perceptibilidade dos defeitos (BAVENDIEK, 2005).

\subsubsection{Sensibilidade ao contraste e Relação Contraste Ruído.}

A sensibilidade ao contraste é a resolução do contraste de uma imagem na direção do feixe de Raios X e ela descreve a menor diferença na espessura do material o qual pode ser visualizada na imagem. A qualidade de imagem radiográfica óptica depende, por sua definição clássica, do contraste, do nível de ruído e da penumbra. Para a radiografia digital, além da relação sinal/ruído (SNR), é introduzida a relação contraste e ruído (CNR), considerando que o inverso CNR é a sensibilidade ao contraste (CS), que normalmente é medida com IQI's. Defeitos e IQIs só são apenas discerníveis se o contraste é mais alto do que o ruído da imagem. Ruído é causado pelas flutuações das intensidades de sinal dos diferentes elementos do detector devido a detecção quantica estatística e as diferentes sensibilidades do detector. Arames são 
visíveis se a relação contraste ruído CNR é de aproximadamente 1 , e furos com diâmetro de $1 \%$ da espessura radiografada são visíveis se CNR é maior que 2,5 (EWERT et al., 2008).

Uma maior dose de exposição aumenta o CNR proporcional à raiz quadrada do tempo de exposição, ou dose, devido ao quantum estatístico dos raios X. A qualidade da imagem depende do coeficiente de atenuação efetivo ( $\mu$ eff) e da SNR de resposta do detector. O coeficiente de atenuação efetivo depende da voltagem do tubo, do material e da espessura do objeto, dos filtros de tubo e das telas de detector, bem como da radiação dispersa. Na Figura 3.49 é ilustrado o efeito da SNR e da CNR na visualização de um entalhe.

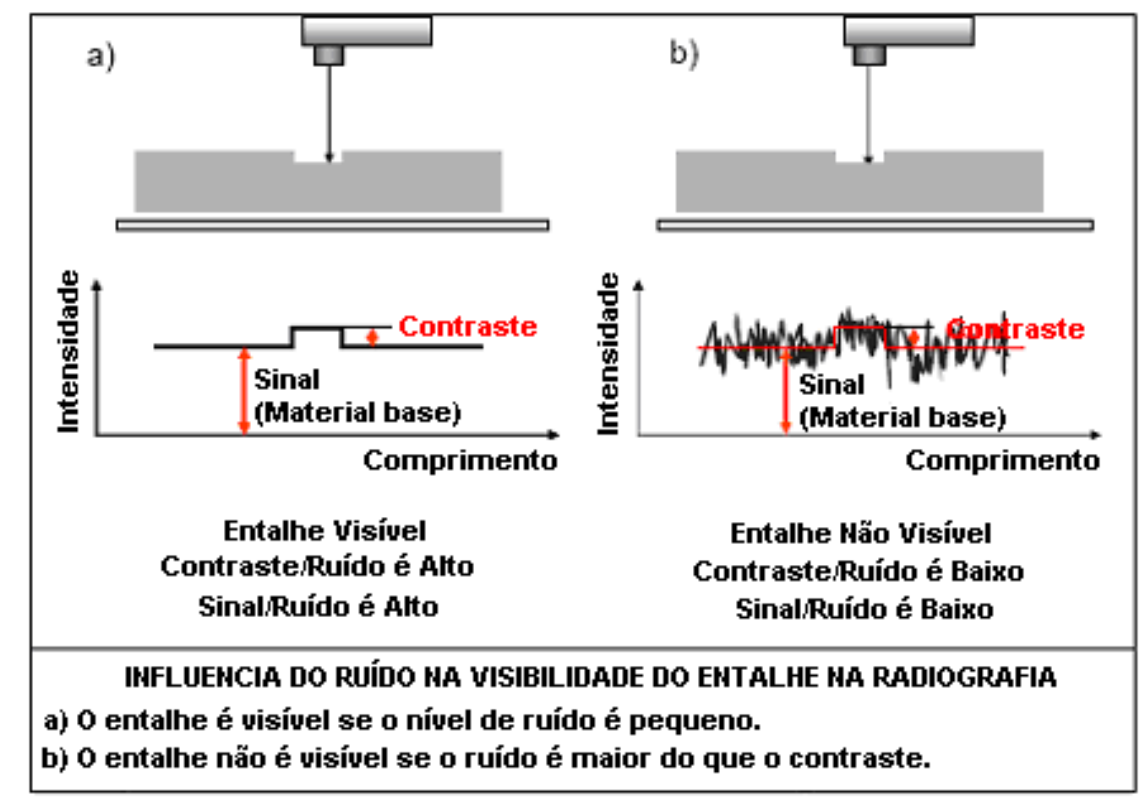

Figura 3.49 - Influência do ruído na visibilidade do entalhe na radiografia (EWERT et al., 2008).

\subsubsection{Indicadores de Qualidade de Imagem, IQI.}

Para que se possa avaliar a qualidade da imagem de uma radiografia e comprovar se o procedimento está sendo eficiente, são empregadas pequenas peças padronizadas, internacionalmente, chamadas de indicador de qualidade de imagem, IQI. O tipo ou norma de fabricação do IQI é definido pelas especificações do projeto de construção do equipamento que será radiografado. O IQI é uma peça construída de um material radiograficamente similar ao material da peça ensaiada, com forma geométrica simples e que contém algumas variações de forma bem definidas, tais como furos, entalhes ou arames de diâmetro definidos. Normalmente são colocados 
sobre o objeto radiografado, do lado da fonte de radiação. O número que indica a qualidade da imagem é o número do arame ou furo mais fino visível na imagem radiográfica. O número do arame exigido é definido para cada faixa de espessura radiografada de material. No caso de solda geralmente inclui a altura do reforço de solda. A classe de qualidade de imagem é função do rigor com que a inspeção deve ser feita e deve ser especificada pela norma do produto. O tipo de IQI, utilizado nesta tese, foi o de arame, descrito no item 3.8.5.1 ( ISO 19232-1, 2004; KODAK, 1980).

\subsubsection{IQI de arame para sensibilidade ao contraste}

O IQI, conforme a norma ISO 19232-1, é fabricado com 7 arames, dispostos paralelamente, cujo material é radiograficamente similar ao material ensaiado. A relação entre o diâmetro do arame e seu número respectivo é descrito na norma indicada, conforme descrito na Tabela 3.3.

Tabela 3.3 - IQI de arame (ISO 19232-1)

\begin{tabular}{cccccc}
\hline Número & $\begin{array}{c}\text { Diâmetro } \\
\mathbf{m m}\end{array}$ & $\begin{array}{c}\text { Tolerância } \\
\mathbf{m m}\end{array}$ & Número & $\begin{array}{c}\text { Diâmetro } \\
\mathbf{m m}\end{array}$ & $\begin{array}{c}\text { Tolerância } \\
\mathbf{m m}\end{array}$ \\
\hline $\mathbf{1}$ & 3,20 & $+/-0,03$ & $\mathbf{1 1}$ & 0,32 & $+/-0,01$ \\
$\mathbf{2}$ & 2,50 & $+/-0,03$ & $\mathbf{1 2}$ & 0,25 & $+/-0,01$ \\
$\mathbf{3}$ & 2,00 & $+/-0,03$ & $\mathbf{1 3}$ & 0,20 & $+/-0,01$ \\
$\mathbf{4}$ & 1,60 & $+/-0,02$ & $\mathbf{1 4}$ & 0,16 & $+/-0,01$ \\
$\mathbf{5}$ & 1,25 & $+/-0,02$ & $\mathbf{1 5}$ & 0,125 & $+/-0,005$ \\
$\mathbf{6}$ & 1,00 & $+/-0,02$ & $\mathbf{1 6}$ & 0,100 & $+/-0,005$ \\
$\mathbf{7}$ & 0,80 & $+/-0,02$ & $\mathbf{1 7}$ & 0,800 & $+/-0,005$ \\
$\mathbf{8}$ & 0,63 & $+/-0,02$ & $\mathbf{1 8}$ & 0,063 & $+/-0,005$ \\
$\mathbf{9}$ & 0,50 & $+/-0,01$ & $\mathbf{1 9}$ & 0,050 & $+/-0,005$ \\
$\mathbf{1 0}$ & 0,40 & $+/-0,01$ & $\mathrm{x}$ & $\mathrm{x}$ & $\mathrm{x}$ \\
\hline
\end{tabular}

Quanto maior o número do arame, menor é o seu diâmetro. Isto indica que exigências mais rigorosas ou um nível de qualidade maior exigem que sejam visualizados arames mais finos, conforme é apresentado na Figura 3.50.

O IQI, sempre que possível, deve ser colocado sobre a solda de forma que os arames estejam perpendiculares à linha da solda, e é considerado distinguível se aparecer um comprimento mínimo de $10 \mathrm{~mm}$ na área de interesse. 


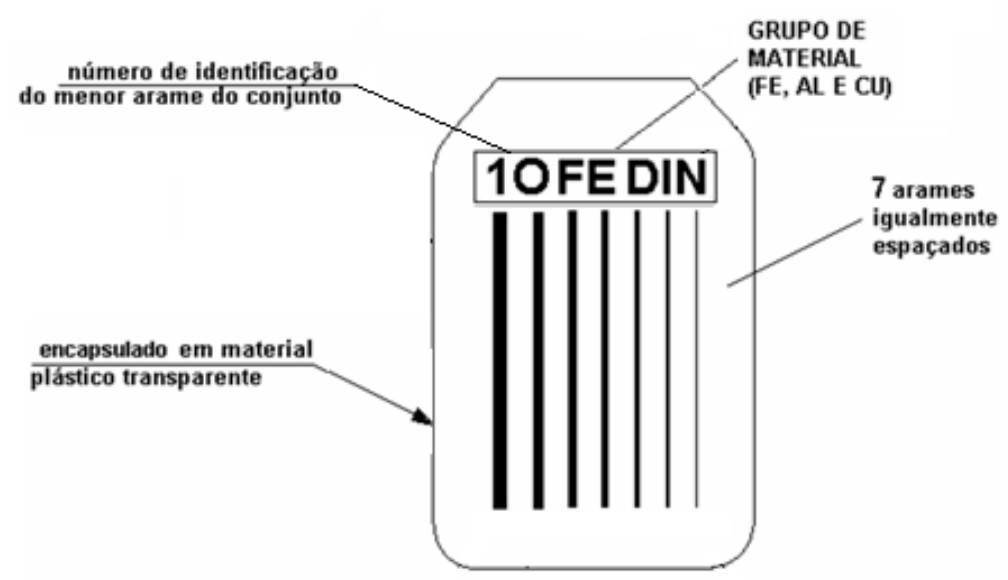

Figura 3.50 - IQI de arame (ISO 19232-1, 2004).

\subsubsection{IQI de arame duplo}

$\mathrm{O}$ indicador de qualidade de imagem de arame duplo é fabricado de acordo com a norma ISO 19232-5, conforme é mostrado na Figura 3.51. O IQI de arame duplo deve ser usado em conjunto com o IQI de contraste de arame e deve ser colocado no lado da fonte alinhado com o feixe normal da radiação e, no caso da radiografia digital, com uma pequena inclinação de $5^{0}$ em relação ao alinhamento dos pixels do detector e assim, evitar problemas de visualização dos pixels gerados pela imagem dos arames. Para análise do IQI de arame duplo deve-se utilizar uma lupa com 4X de aumento. O limite de discernimento da técnica utilizada é o par de arames onde não se vê o espaço entre eles e o valor da penumbra obtida, $\mathrm{U}$ é $2 \mathrm{~d}$, onde d é o diâmetro deste arame, conforme indicado na Tabela 3.4 (ISO 19232-5; 2004).

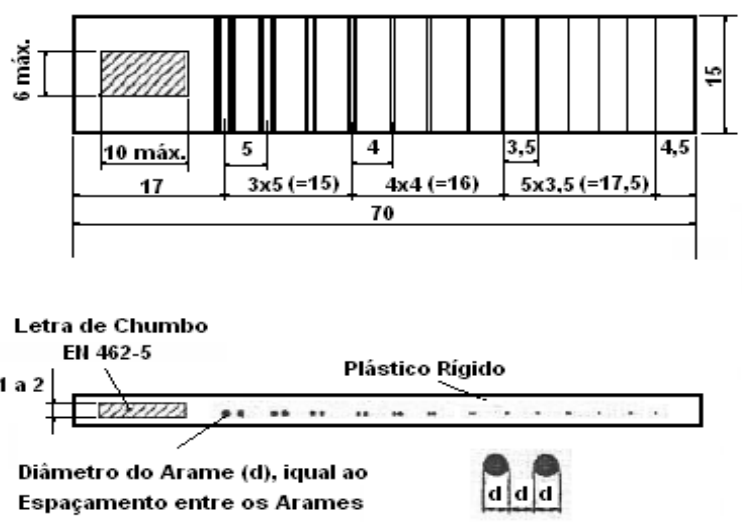

Dimensöes em mm

Figura 3.51 - IQI de Arame Duplo (ISO 19232-5, 2004). 
$\mathrm{Na}$ Tabela 3.4 estão descritos os números dos elementos, os valores de penumbra correspondentes, as dimensões dos arames do IQI de arame duplo, suas tolerâncias e a quantidade de par de linhas por milímetro, $\mathrm{pl} / \mathrm{mm}$.

Tabela 3.4 - IQI de arame duplo (ISO 19232-5, 2004 ).

\begin{tabular}{ccccc}
\hline Elemento & $\begin{array}{c}\text { Penumbra } \\
(\mathbf{m m})\end{array}$ & $\begin{array}{c}\text { Diâmetro do } \\
\text { Arame }(\mathbf{m m})\end{array}$ & $\begin{array}{c}\text { Tolerância } \\
(\mathbf{m m})\end{array}$ & $\mathbf{p l / m m}$ \\
\hline 13D & 0,10 & 0,050 & & 10,000 \\
12D & 0,13 & 0,063 & & 7,936 \\
11D & 0,16 & 0,080 & $+/-0,006$ & 6,250 \\
10D & 0,20 & 0,100 & & 5,000 \\
9D & 0,26 & 0,130 & & 3,846 \\
8D & 0,32 & 0,160 & & 3,125 \\
7D & 0,40 & 0,200 & & 2,500 \\
6D & 0,50 & 0,250 & $+/-0,010$ & 2,000 \\
5D & 0,64 & 0,320 & & 1,563 \\
4D & 0,80 & 0,400 & & 1,250 \\
3D & 1,00 & 0,500 & & 1,000 \\
2D & 1,26 & 0,630 & $+/-0,020$ & 0,794 \\
1D & 1,60 & 0,800 & & 0,625 \\
\hline
\end{tabular}

\subsubsection{Penumbra}

A penumbra geométrica, ou falta de nitidez da imagem ocorre devido a fatores geométricos, e este parâmetro interfere diretamente na detecção e na avaliação das descontinuidades (os critérios de aceitação em sua maioria são por tamanho). A maioria das normas aplicáveis ao ensaio radiográfico estabelece valores máximos para a penumbra. O efeito da penumbra na imagem é mostrado na Figura 3.52. Na Figura 3.52a é mostrada uma imagem ideal, onde a intensidade da imagem é constante por toda a extensão, além das bordas apresentarem uma abrupta mudança de intensidade que contribui para a nitidez da imagem. No caso da Figura $3.52 \mathrm{~b}$ a intensidade variável e a mudança gradual nas bordas, contribuem para a falta de nitidez da imagem e o aumento da penumbra (SILVA, 2009).

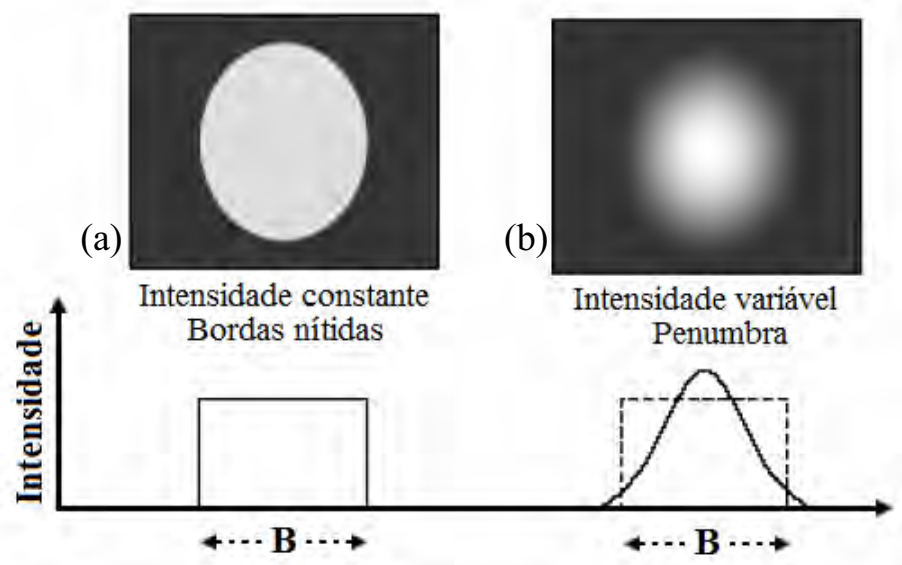

Figura 3.52 - Penumbra - (a) Imagem ideal. (b) Imagem com penumbra ou sem nitidez (SILVA, 2009). 
A penumbra é diretamente sensível as mudanças geométricas que envolvem o tamanho da fonte "f", da distância da fonte ao objeto DFO, da distância do objeto ao detector "DOD” e da espessura da peça "e“. Na Figura 3.53 está demonstrado o efeito da relação entre estes parâmetros com a penumbra da imagem. Na Figura 3.53a a dimensão "f" é muito pequena, que é considerada um ponto e representa um caso ideal. Se "f" for aumentado, mantendo-se a "DFO", na imagem será notada uma zona de penumbra, reduzindo a nitidez (definição), conforme a Figura 3.53b. Se for mantida a dimensão " $\mathrm{f}$ " e reduzida a "DFO" a imagem apresentará uma zona de penumbra muito maior, e a nitidez da imagem será perdida, conforme pode ser observado na Figura 3.53c (ABENDE, 2005).

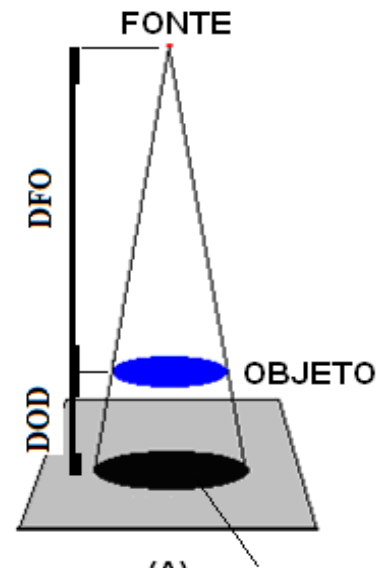

(A) IMAGEM

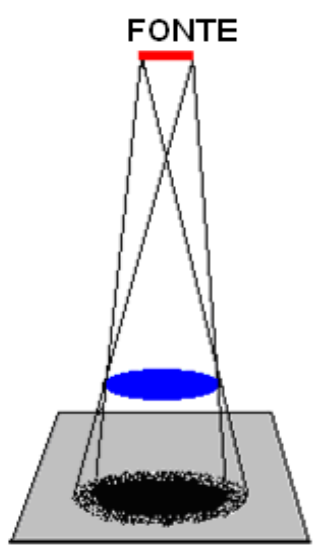

(B)

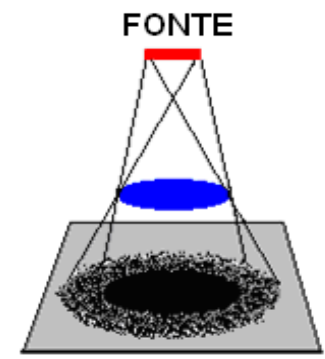

(C)

Figura 3.53 - Disposição geométrica entre fonte-filme-objeto (KODAK, 1980).

$\mathrm{O}$ ângulo do plano do objeto em relação aos raios $\mathrm{X}$ incidentes produz um efeito similar quando não for mantido em $90^{\circ}$. Só que, neste caso, ocorre uma distorção da imagem. Normalmente as normas estabelecem limites para a espessura penetrada nas extremidades da extensão inspecionada em relação ao centro do feixe. Quando a técnica mais rigorosa deve ser empregada é de $10 \%$, e de $20 \%$ para a técnica normal. Estes limites tem objetivo de evitar possíveis distorções da imagem radiográfica.

A penumbra geométrica, Ug, para a técnica digital, é medida experimentalmente, utilizando o IQI de arame duplo e é o maior número de par de arames (menor diâmetro dos arames) com uma separação de profundidade abaixo de $20 \%$, ou seja, o primeiro par mais fino não resolvido. Este IQI deve ser posicionado em um ângulo de aproximadamente $5^{\circ}$ em relação à orientação dos pixels do detector, para 
evitar efeitos de serrilhado (aliasing) na imagem. A avaliação pode ser feita com o uso de uma lupa com aumento de 4 vezes, verificando se pelo menos $20 \%$ do comprimento dos arames apresentam uma separação visível. Um procedimento mais conclusivo, e que é mais aplicado na radiografia digital, é fazer a medição com uma linha de perfil de níveis de cinza (ISO 19232-5; 2004).

Na Figura 3.54 é mostrada, esquematicamente, uma avaliação feita no menor par do IQI de arame duplo. No caso desta avaliação, o par medido é considerado visível, pois o pico apresentou o valor de $20 \%$ em relação ao valor máximo obtido.

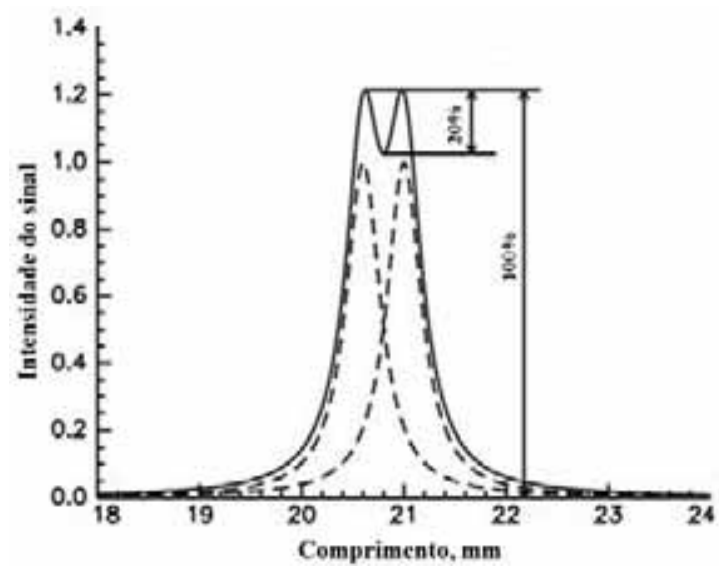

Figura 3.54 - Critério para avaliação do perfil do IQI de arames duplos (ISO 19232-5; 2004).

\subsubsection{Resolução espacial básica, $\mathrm{SR}_{\mathrm{B}}$}

\footnotetext{
“A resolução espacial é definida como sendo a menor separação entre dois pontos da imagem que podem ser distinguíveis ou visualizados, ou simplesmente o nível de detalhes que se pode ver numa imagem, e é um dos principais parâmetros que afetam a qualidade da imagem digital (FERREIRA; 2009)".
}

A quantidade de linhas próximas que podem ser visualizadas (resolvidas) em uma imagem é chamada de resolução espacial, e ela depende das propriedades do sistema onde está sendo gerada a imagem, e não apenas da resolução de pixel em pixel por polegada (ppi). Para fins práticos, a "clareza" da imagem é definida pela sua resolução espacial e não pelo número de pixels. De fato, a resolução espacial refere-se ao número de valores de pixel independentes por unidade de comprimento. 
A resolução espacial básica, em $\mu \mathrm{m}$, de um sistema de radiografia digital de matriz de detectores corresponde ao tamanho de pixel efetivo, sendo o menor detalhe resolvido perpendicularmente à direção de incidência do feixe de radiação. Este parâmetro é medido pelo método do IQI de fio duplo devido a sua simplicidade, e que inicialmente determina o valor da penumbra geométrica da imagem $(\mathrm{Ug})$.

Após, o valor da resolução espacial básica $\mathrm{SR}_{\mathrm{B}}$ é obtida pela equação (3.3).

$$
\mathrm{SR}_{\mathrm{B}}=1 / 2 \mathrm{Ug}
$$

\subsubsection{Técnica da ampliação}

Um obstáculo para a implementação de sistemas DDA é o grande tamanho do pixel $(>50 \mu \mathrm{m})$ do detector em comparação com os pequenos tamanhos de grãos do filme (que leva a película a ter altíssima resolução espacial). Esta dificuldade deve ser contornada tirando proveito da propriedade exclusiva dos DDAs que é aumentar a relação sinal ruído, SNR na imagem e/ou, então, aumentar posteriormente a ampliação geométrica do raios X, se necessário (SAMEI, RAVIN; 2008).

Uma visão geral das etapas deste processo é mostrada na Figura 3.55, onde IQIs de tamanhos apropriados são usados para avaliar a penumbra da imagem e a sensibilidade ao contraste para a inspeção de um material de certa espessura. Se a sensibilidade do IQI e a penumbra não podem ser detectadas na primeira imagem, a SNR deve ser aumentada (uma significativa vantagem do DDA), e então, se o IQIs não são visíveis, a técnica de ampliação deverá ser aplicada com o aumento da distância entre o DDA e o objeto.

Finalmente, depois de empregar os dois métodos, se os valores IQI exigidos ainda não são visíveis, esse DDA não pode ser utilizado para esta inspeção (ISO/DIS 10893-7). 


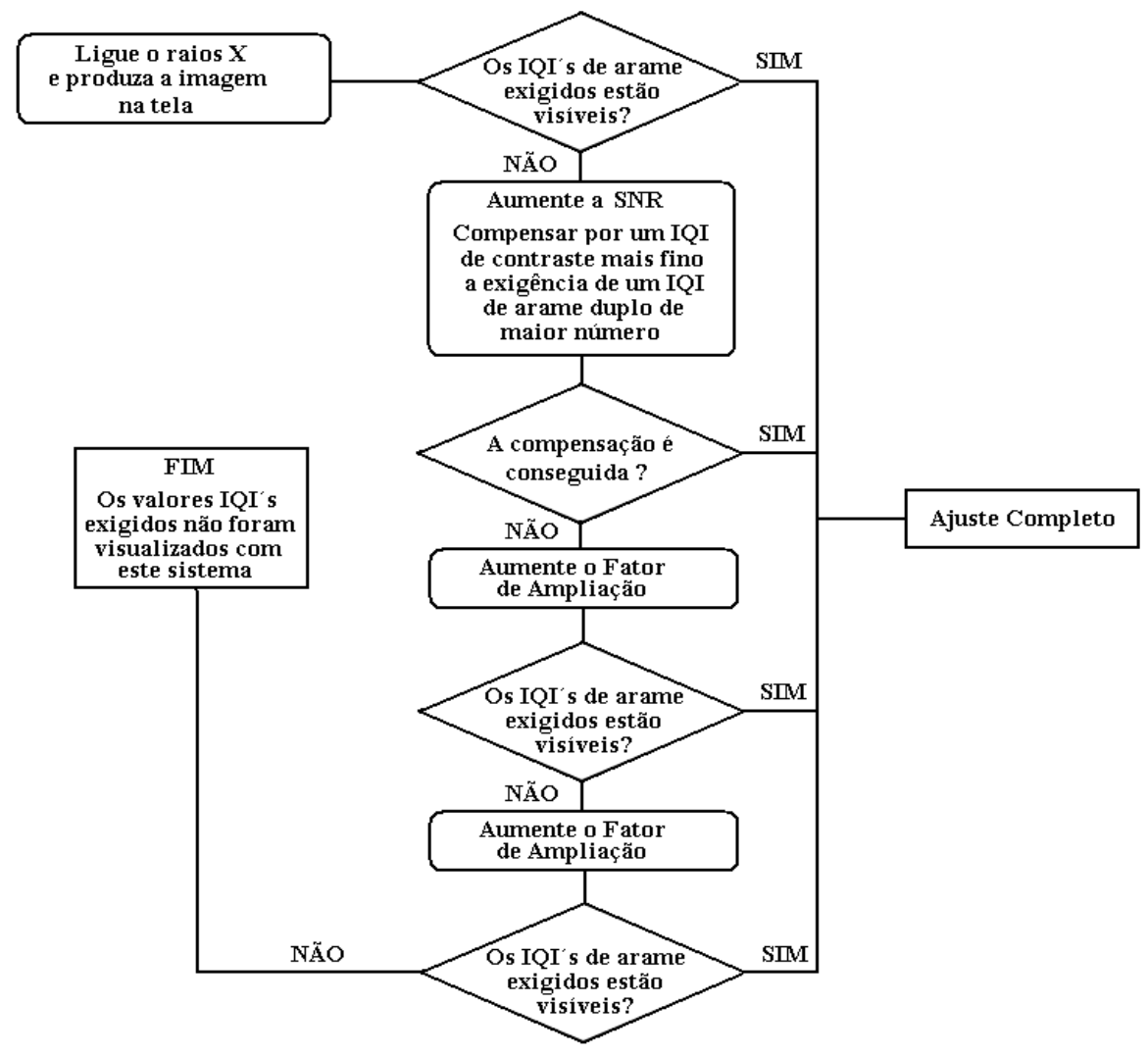

Figura 3.55 - Fluxograma de como atender a exigência da penumbra da imagem

\section{Projeção da ampliação}

O valor ideal da projeção da ampliação ocorre quando o valor da penumbra geométrica é igual à dimensão do pixel do detector, ou seja, "p" igual a "f", como mostrado na Figura 3.56 (BLAKELEY, SPARTIOTIS; 2006).

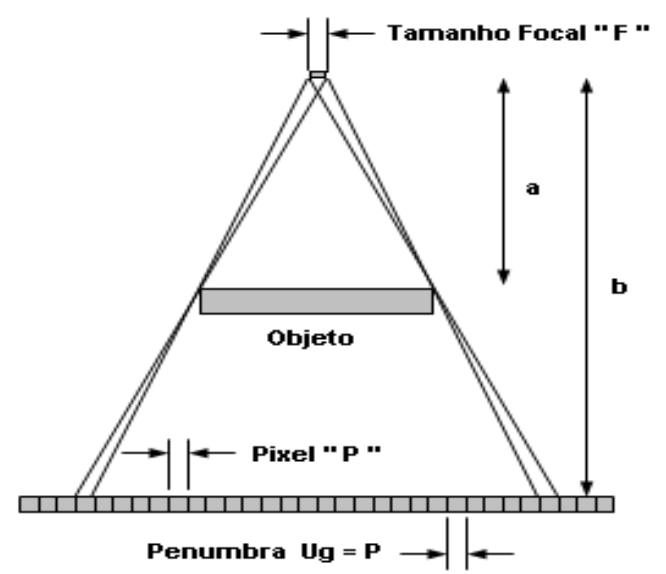

Figura 3.56 - Valor ideal da penumbra geométrica, (BLAKELEY, SPARTIOTIS; 2006).

Se o valor da ampliação é maior do que este valor ótimo, a penumbra da imagem limitará a resolução da imagem final. Se for menor, a resolução da imagem será 
limitada pela dimensão finita do pixel. Se a distância da fonte ao detector (DFD) 'b' é conhecida, juntamente com a dimensão de pixel 'p' e o tamanho focal 'f', então a distância da fonte ao objeto 'a' pode ser calculada pela equação (3.4), abaixo:

$$
a=f \frac{b}{(p+f)}
$$

Se for usada muito pouca ampliação, então a resolução da imagem final é limitada pela dimensão do pixel do detector, e se for usado excesso de ampliação, então a imagem terá um aumento demasiado da penumbra geométrica. Isto mostra que há pouco ou quase nenhuma melhoria quando é aplicada uma grande ampliação da imagem. A ampliação causa desnecessária diminuição do tamanho do pixel, aumenta o tamanho do arquivo e diminui o tamanho disponível da imagem do detector (menor área coberta), além de perder alguns detalhes da imagem (BLAKELEY, SPARTIOTIS; 2006). Na Figura 3.57 é representado este princípio, e também se pode observar o ponto ideal da ampliação.

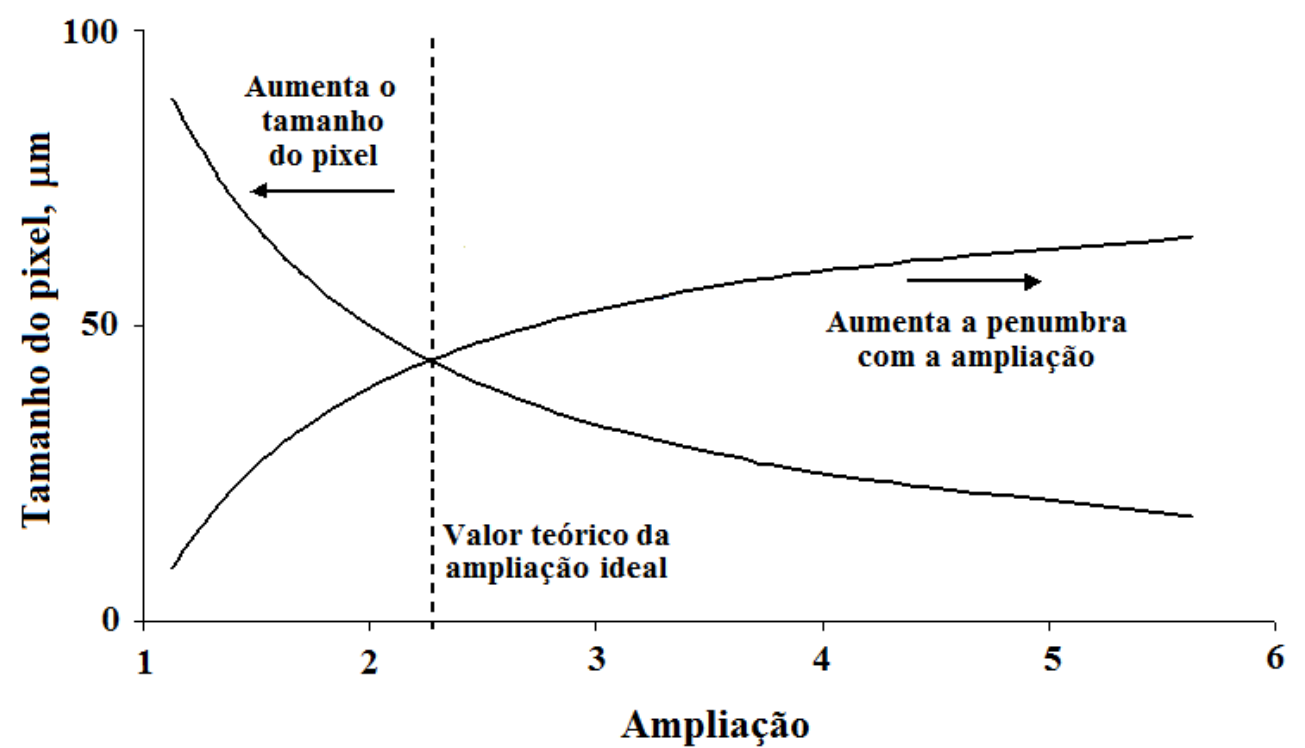

Figura 3.57 - Valor ideal da ampliação (BLAKELEY, SPARTIOTIS; 2006).

Para verificar o valor da ampliação ideal, experimentalmente, um IQI de fio duplo foi utilizado para medir a penumbra geométrica de uma série de imagens, ao longo de uma ampla gama de valores de ampliação. Na Figura 3.58 são apresentados os detalhes do arranjo experimental (SAMEI, RAVIN; 2008). 

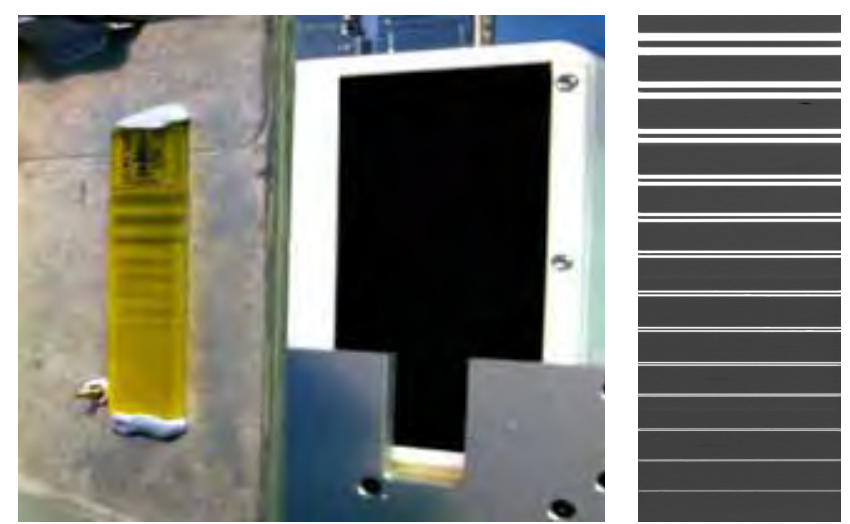

Figura 3.58 - Detalhe do arranjo experimental (BLAKELEY, SPARTIOTIS; 2006).

O perfil dos níveis de cinza do par mais fino de arames foi verificado, conforme é mostrado na Figura 3.59a. Os valores dos níveis de cinza foram medidos em vários pontos ao longo da linha de perfil, e o gráfico foi elaborado onde os valores encontrados foram utilizados de acordo com a distância, em pixel, na linha do perfil, como mostrado na Figura 3.59b (BLAKELEY, SPARTIOTIS; 2006).

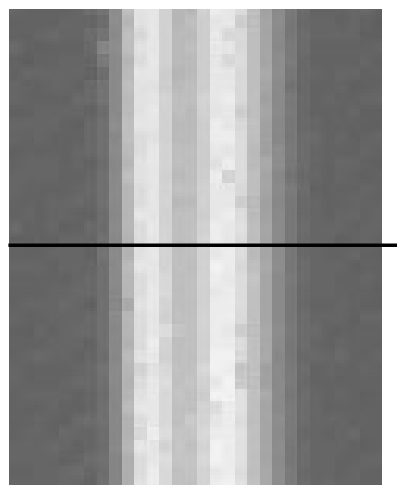

(a)

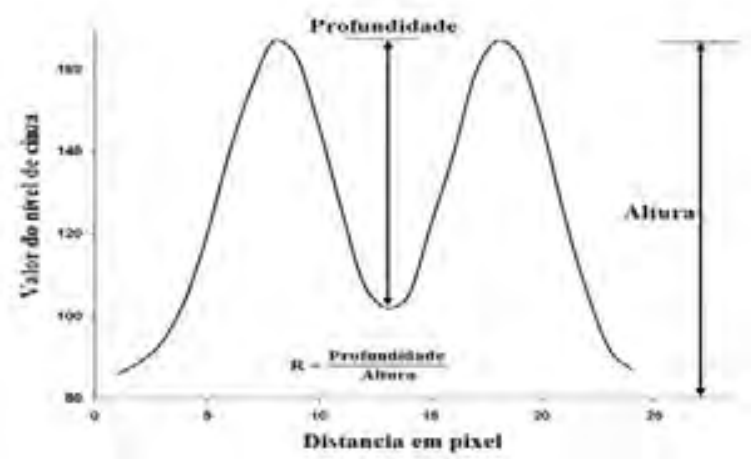

(b)

Figura 3.59 - Radiografia do par mais fino de arames (BLAKELEY, SPARTIOTIS; 2006).

A Figura 3.60 mostra a influência da ampliação na penumbra obtida de três exemplos de radiografias do mesmo par de arames.

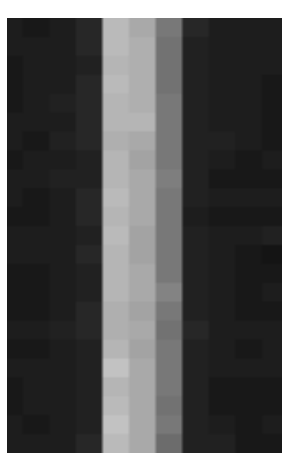

(a)

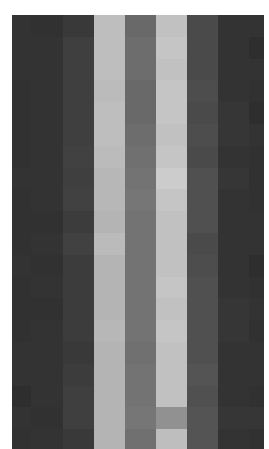

(b)

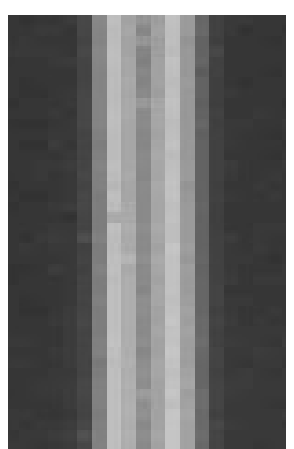

(c)

Figura 3.60 - Imagens radiográficas dos pares de arames - Influência da ampliação na penumbra obtida (BLAKELEY, SPARTIOTIS; 2006).

(a) Pouca ampliação.

Pares de fios não são resolvidos.

(b) Valor ideal de ampliação.

Fios claramente são resolvidos.

(c ) Muita ampliação.

A falta de nitidez fez com que

os pares de fios se misturassem. 


\subsubsection{Características do Monitor}

O monitor para a avaliação da imagem da radiografia digital deve cumprir várias exigências, para que ele possa mostrar as imagens com a garantia da qualidade mínima.

Exemplos de exigências são: brilho mínimo de $250 \mathrm{~cd} / \mathrm{m}^{2}$, tonalidades de cinza de no mínimo 256, exibição com mínima relação de densidade de luz de 1:250 e quantidade mínima de 1000 x 1000 pixels, com tamanho < 0,25 mm (ISO/DIS 108937). O monitor deve ter suas características verificadas e certificadas periodicamente utilizando os padrões necessários e adequados, incluindo uma imagem padrão de teste.

\subsection{Detector plano para radiografia digital}

O detector plano que é considerado uma potencial solução para ser utilizado em radiografias digitais na área industrial é o detector digital de matriz (DDA ou Digital Detector Array). Na Figura 3.61 é possível visualizar uma foto de um DDA.

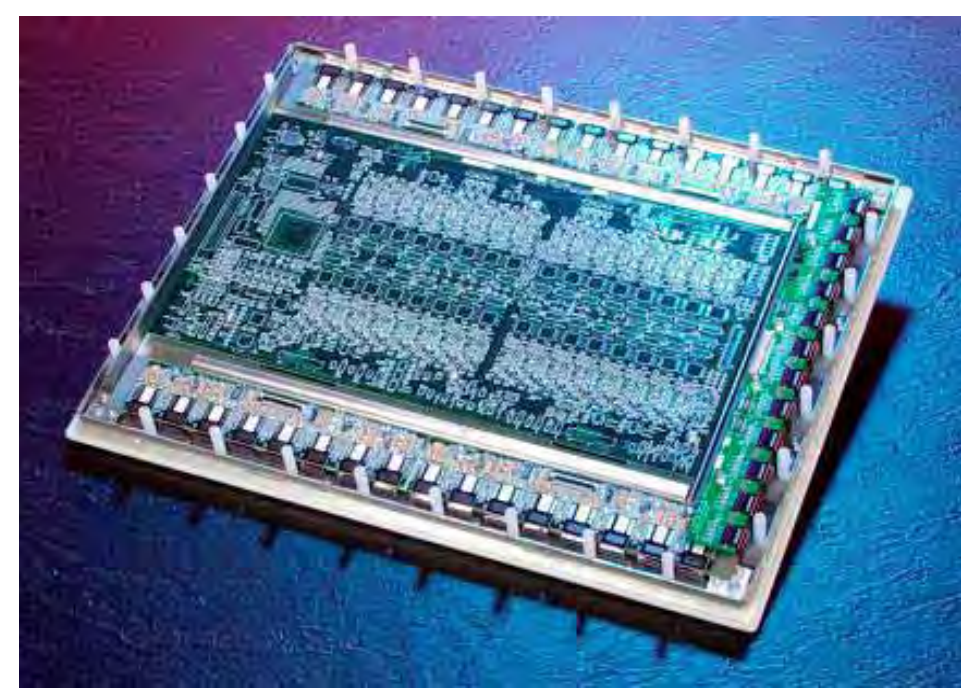

Figura 3.61 - Foto de um DDA e o esquema básico (VARIAN, 2009).

\subsubsection{Princípio de operação}

O DDA utilizado neste trabalho é constituído de uma matriz de foto diodos de silício amorfo com cintilador. O sistema de funcionamento deste tipo de DDA, basicamente, inicia quando a película do cintilador recebe o feixe de raios $\mathrm{X}$ e, assim, o converte em luz, pelo efeito da fluorescência. 
Os fotodiodos recebem a luz e a converte em sinal elétrico que ativa cada pixel. O pixel ativado com os dados eletrônicos recebidos transfere a imagem para o sistema através de uma interface de alta velocidade.

Na Figura 3.62 é ilustrada a estrutura básica e o esquema de funcionamento de um DDA.

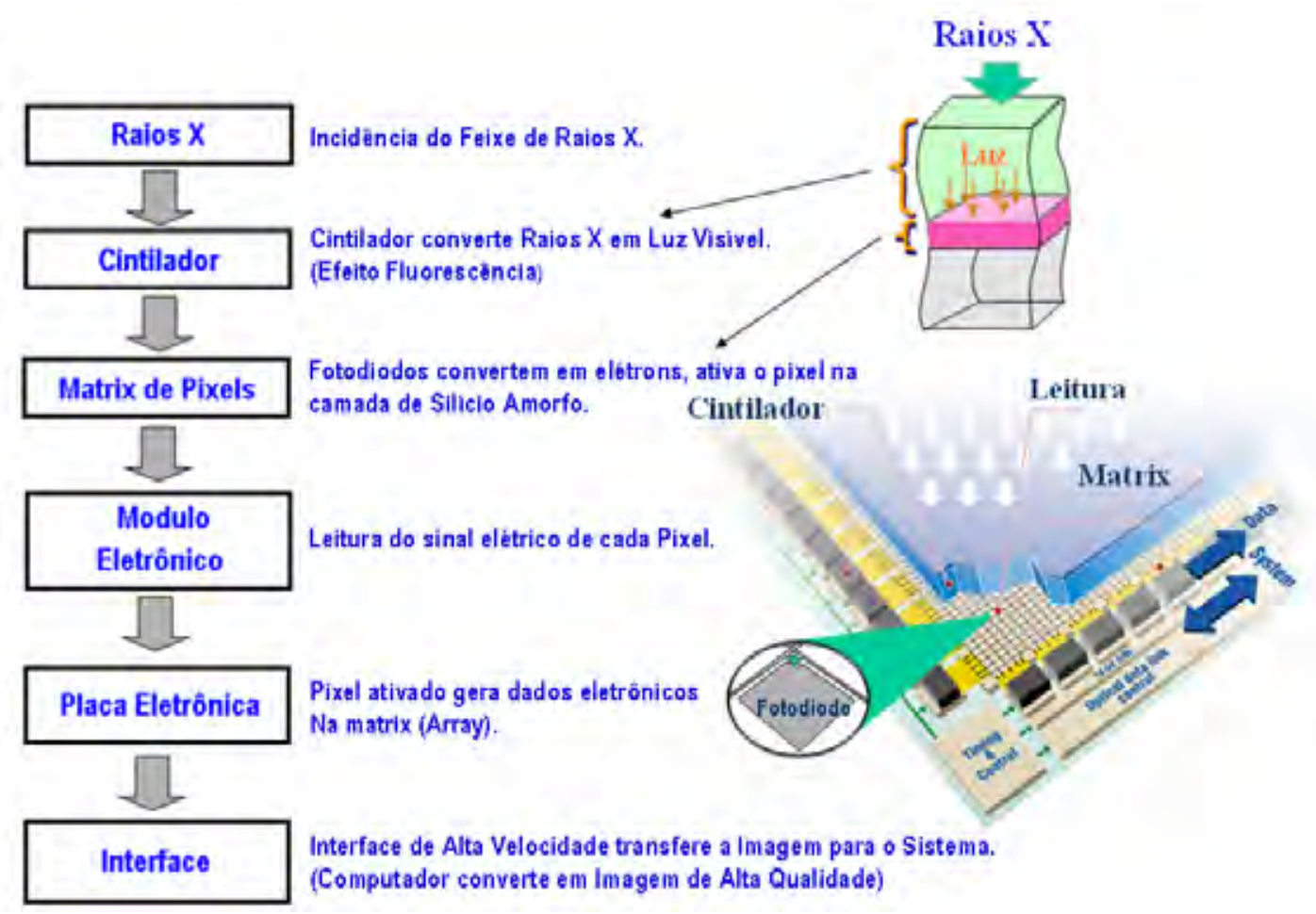

Figura 3.62 - Estrutura e funcionamento de um DDA com cintilador (VARIAN, 2008).

\subsubsection{Matriz de sensores de silício amorfo}

Os detectores digitais com matriz de sensores (DDA - Digital Detector Array) de silício amorfo (a-Si) são os utilizados nas indústrias de eletrônicos, petroquímicos automotivo, aeroespacial, pois fornecem muitas vantagens sobre os filmes industriais, no que se refere ao ensaio radiográfico. Os principais benefícios são os tempos para aquisição das imagens, arquivamento e busca mais fáceis, processamento e melhoria das imagens, análise e reconhecimento de defeito que pode ser automatizado, dependendo do produto a ser inspecionado. Esses detectores mostram bom desempenho da relação sinal-ruído e conseguem imagens com alto contraste, mesmo para curtos tempos de exposição (VENKATACHALAM et al., 2006). 
O objetivo da matriz de sensores é acumular cargas geradas pela absorção de raios x e fornecê-la, linha por linha, durante a varredura, para os amplificadores de cargas. O componente de armazenamento de carga é um capacitor fotocondutor de aquisição de imagem ou uma matriz de fotodiodos usada com uma película de cintilador. A chave usada para permitir que a carga seja descarregada pode ser um diodo, um par de diodos ou um transistor de película fina (TFT). Na matriz mostrada na Figura 3.63, a chave utilizada é um transistor de película fina (TFT ou thin-film transistor). O TFT é feito pelo depósito de lâminas finas para os contatos metálicos.

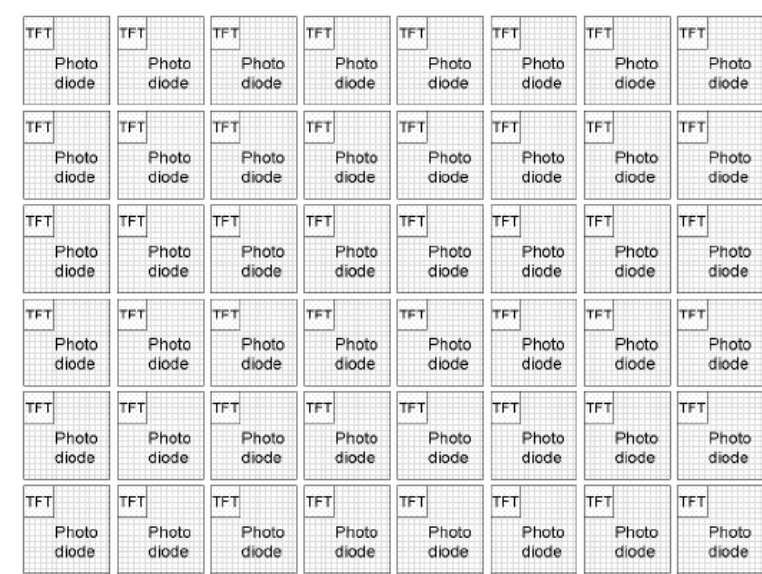

(a)

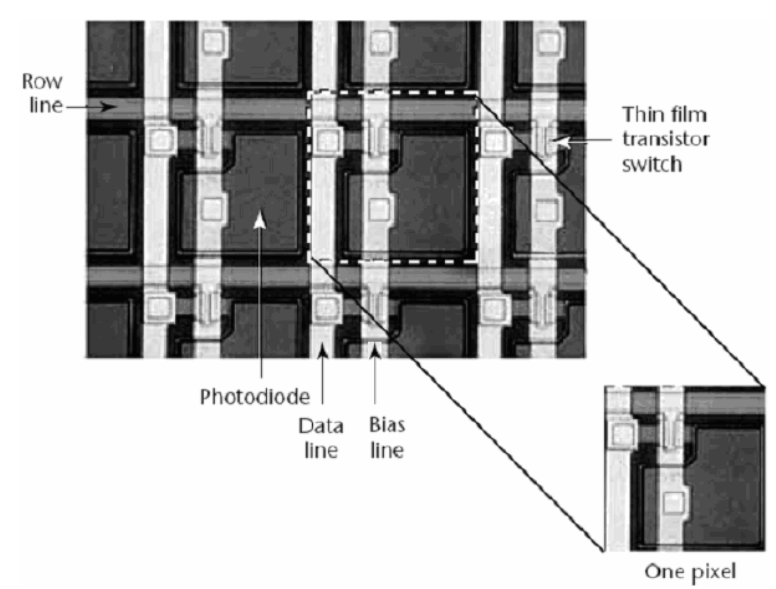

(b)

Figura 3.63 - (a) Matriz de sensores de silício amorfo. (b) Foto micrografia identificando um pixel (VARIAN, 2009).

Em operação, todos os fotodiodos têm a polaridade revertida pela aplicação de uma tensão externa. Enquanto as chaves TFT são desligadas, a carga gerada pela luz emitida pelo cintilador acumula nos diodos. Quando se necessita a leitura, uma linha de registro é energizada para ligar as chaves nessa linha. As cargas de todos os fotodiodos da linha selecionada são descarregadas simultaneamente por meio das linhas de dados. $\mathrm{O}$ esquema dos componentes principais encontra-se apresentado na Figura 3.64. Em grandes matrizes, são produzidos milhares de sinais que devem ser lidos de forma organizada para que a informação de cada um deles represente a posição correta do pixel. Normalmente a varredura é feita de forma progressiva. 


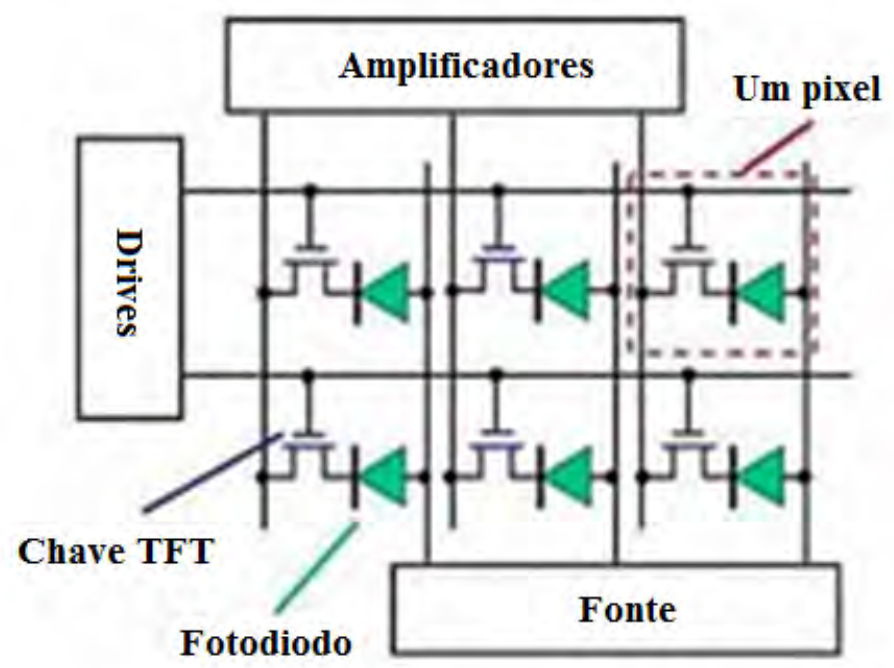

Figura 3.64 - Diagrama do circuito de uma matriz de sensores de silício amorfo (VARIAN, 2009).

Um objetivo importante no projeto da matriz de sensores é maximizar a área da imagem que é detectada pelo fotodiodo (alto "fator de enchimento"), de tal forma que seja perdida somente uma quantidade mínima de luz. Os sinais são transportados por linhas finas de metais.

\subsubsection{Métodos de conversão dos Raios X.}

Três métodos para converter os raios $\mathrm{X}$ em carga para leitura eletrônica podem ser utilizados nos silícios amorfos. São estes os métodos: intrínseco, fotocondutor e o de cintilador. Em todos os três métodos, a carga é acumulada durante um tempo antes de ser lida. O método mais adequado à área industrial para inspeção de soldas é o método do cintilador devido as suas características.

\subsubsection{O método cintilador}

Um cintilador é um composto que absorve os raios $\mathrm{X}$ e converte a energia em luz visível. Um bom cintilador produz muitos fótons de luz para cada fóton de raios $\mathrm{X}$ recebido, ou seja, de 20 a 50 fótons visíveis são produzidos por $1 \mathrm{kV}$ de energia de raios X. Cintiladores normalmente são compostos por um material de elevado número atômico, que tem alta absorção de raios X, e um ativador de baixa concentração para facilitar a emissão de fótons visíveis. Cintiladores podem ser granulares como o fósforo ou o iodeto de césio (CsI, Cesium Iodide). 
Na Figura 3.65 são mostrados os comportamentos destes cintiladores em termos de quantidade e forma de emissão da luz quando sensibilizados pelos raios $\mathrm{X}$.

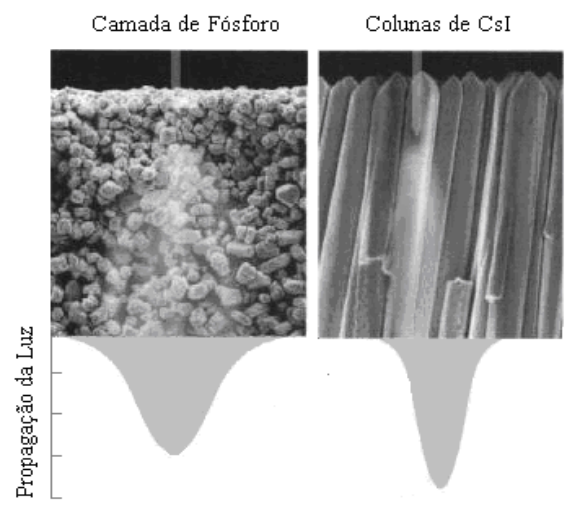

Figura 3.65 - Conversão da luz pelos cintiladores de Fósforo e CsI (VARIAN, 2008).

\section{Estrutura de um cintilador de fósforo e de iodeto de césio}

Cintilador de fósforo. Fósforos são materiais que brilham quando expostos aos raios X. Para o brilho máximo, a utilização de fósforos no processamento de imagens de raios $\mathrm{X}$ é feito de óxido de sulfetos de terras raras, dopados com outras terras raras. Os mais comuns são óxidos sulfetos de gadolínio e lantânio, dopados com térbio. Vários tamanhos de grãos e misturas químicas são utilizados para produzir uma variedade de resolução e de brilho. Esses foram concebidos para serem colocados juntos com o filme de raios $\mathrm{X}$ para melhorar a sensibilidade, mas eles também são colocados nas matrizes de fotodiodos de silício amorfo para torná-los com sensibilidade, pelo menos tão boa quanto a do filme. O esquema do uso do cintilador de fósforo encontra-se apresentado na Figura 3.66a (VARIAN, 2008).

Cintilador de CsI. Para uma melhor combinação de resolução e brilho é utilizado o iodeto de césio. CsI tem a propriedade que é crescer como uma matriz densa de agulhas finas (10 a $20 \mu \mathrm{m}$ de diâmetro). Isso produz cristais que atuam como tubos de luz para os fótons visíveis, gerados próximos a camada do lado da entrada, aceitando camadas muito espessas (até $1 \mathrm{~mm}$ ) para serem utilizadas como uma excelente solução para manter a resolução. Devido ao césio ter um alto número atômico, ele é um excelente absorvedor de raios $\mathrm{X}$, assim ele se torna muito eficiente a estes raios. 
A combinação de CsI e silício amorfo tem a DQE mais alta de todos os materiais produzidos atualmente. O esquema do uso do cintilador de CsI está mostrado na Figura 3.66b (VARIAN, 2008).

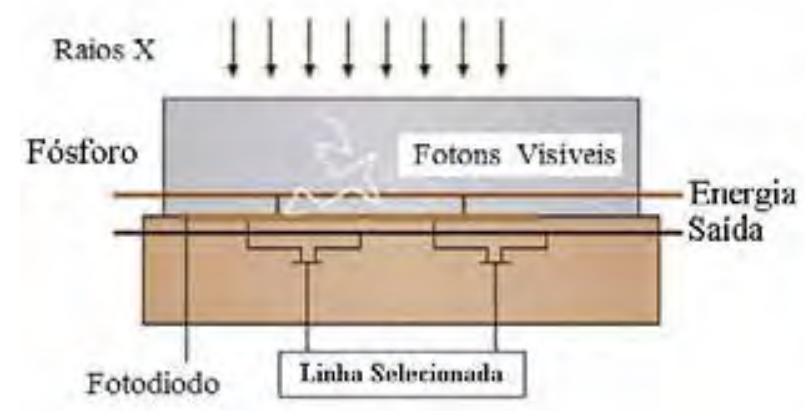

(a)

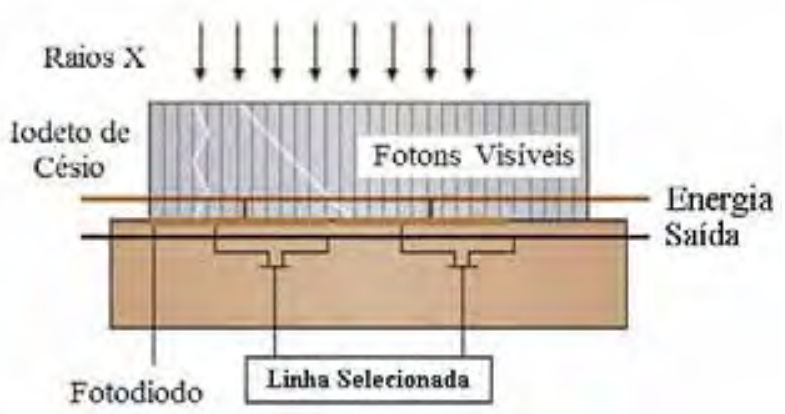

(b)

Figura 3.66 - Estrutura de um cintilador. (a) De fósforo (b) Iodeto de Césio (CsI).

\subsection{Programa para controle da qualidade do sistema.}

Para garantir um desempenho confiável e resultados reprodutíveis de um sistema radiográfico digital, o sistema deve ser corretamente instalado, mantido e monitorado por meio de um programa de controle de qualidade (SAMEI, RAVIN; 2008).

Testes de aceitação: na instalação e antes da utilização de um sistema radiográfico digital é preciso realizar uma série de testes de aceitação. Aspectos chave do desempenho do sistema a serem incluídos são o MTF, o NPS, DQE, etc.

Calibração de sistema: sistemas radiográficos digitais são sensíveis as imagens não uniformes devido à falta de linearidade dos sensores. Tais problemas, em geral, são corrigidos por um procedimento adequado de calibração e que precisa ser executado com uma freqüência que garanta o desempenho do sistema.

Manutenção preventiva: o sistema precisa submeter-se a rotina de manutenção preventiva para reduzir a probabilidade de degradação de desempenho e tempo de inatividade.

Avaliações periódicas: O desempenho de um sistema digital radiográfico é propenso a degradação ao longo do tempo. Assim, é importante controlar o seu desempenho ao longo do tempo para garantir que ele esteja dentro de limites aceitáveis. 


\subsubsection{Calibração do DDA.}

Os sistemas radiográficos digitais são suscetíveis a apresentar imagens não uniformes devido à falta de linearidade dos sensores. Tais imagens ou "artefatos", em geral, são corrigidos por um procedimento de calibração, que é realizado de acordo com as recomendações do fabricante. Para alguns sistemas, esta calibração precisa ser executada em uma base diária antes do início da utilização, enquanto outros precisam ser feitos com freqüências menores, ou seja, em base mensal.

Dependendo da característica da peça que se deseja inspecionar, algumas vezes são necessárias calibrações específicas para o procedimento que irá ser executado.

Na Figura 3.67(a) se podem observar exemplos de artefatos que podem aparecer nas imagens geradas pelo DDA e comparar com a Figura 3.67(b) com um detector adequadamente calibrado (BAVENDIEK; 2005).

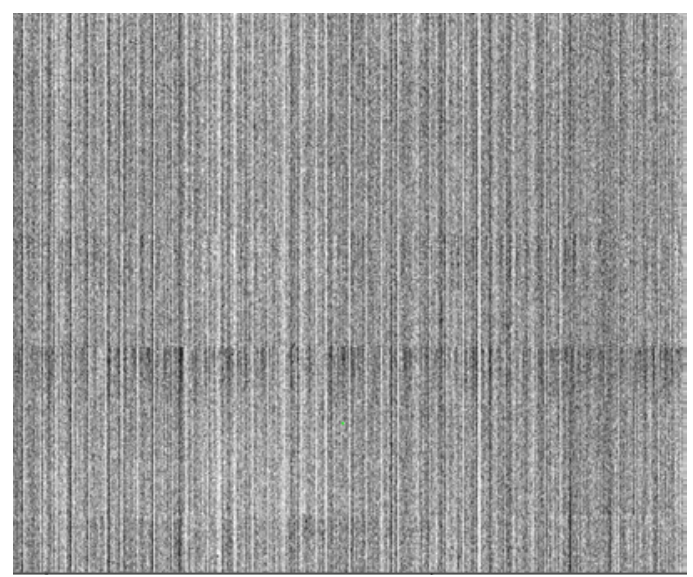

(a)

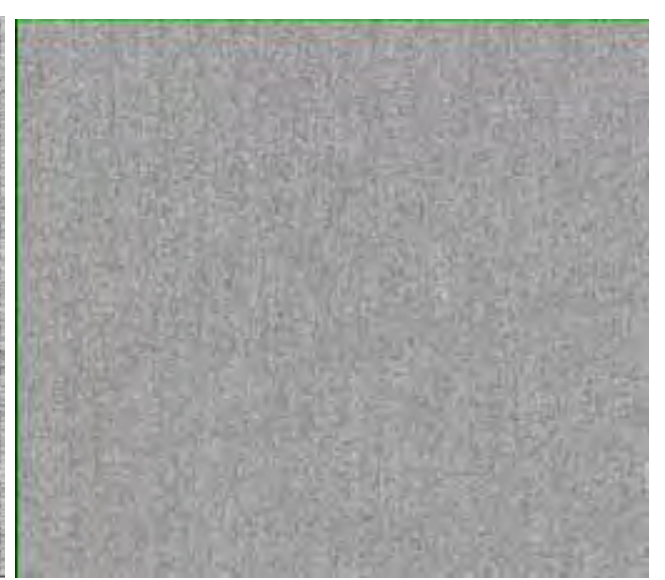

(b)

Figura 3.67 - Exemplo de calibração do DDA (a) Imagem inadequada. (b) Imagem adequada (BAVENDIEK; 2005).

Dependendo do nível de precisão e sensibilidade que se deseja obter do sistema digital e, conseqüentemente, das imagens geradas, além das intervenções corretivas e preventivas, feitas por especialistas devidamente habilitados pelo fabricante do DDA, um programa de avaliação periódica de forma rotineira deve ser executado. Devido à possível degradação ao longo do tempo do sistema digital radiográfico é importante controlar o desempenho deste para garantir a manutenção da qualidade e sensibilidade da imagem. Os testes devem, no mínimo, incluir a verificação da resolução, do ruído, artefatos, ganhos, mapa indicando o pixel com defeito, sensibilidade e outros aspectos recomendados pelo fabricante, e relacionados com o desempenho do sistema 
(RORABAUGH; 1993). Na Figura 3.68 podem-se observar alguns tipos de defeitos característicos de um DDA (BAVENDIEK; 2005).
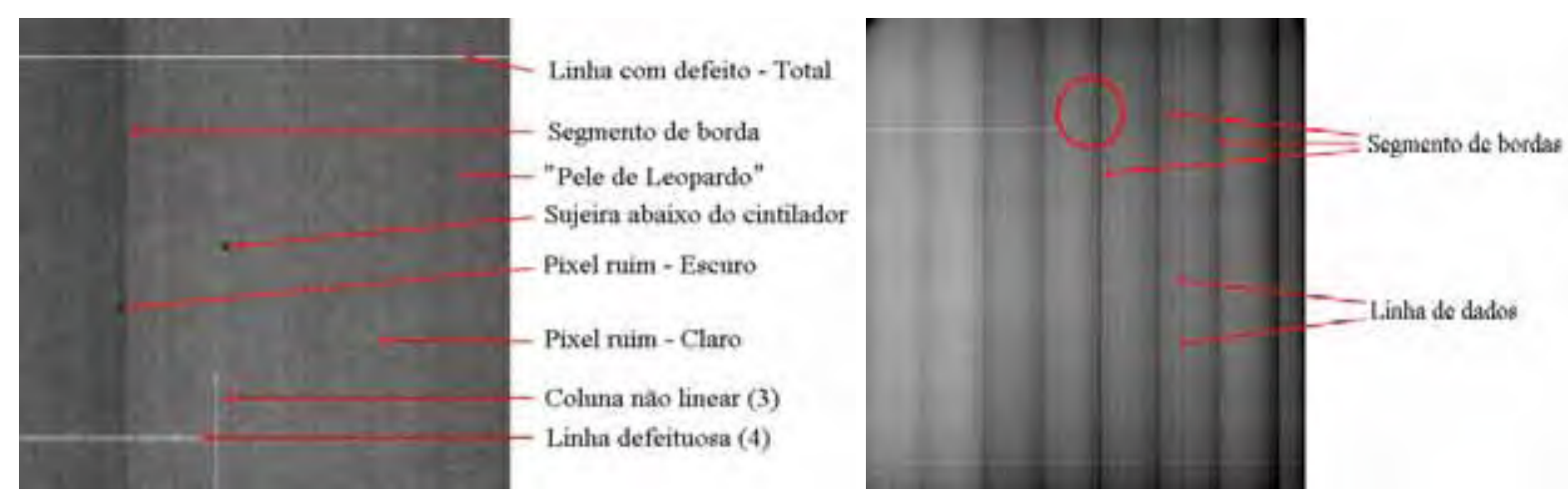

Figura 3.68 - Defeitos comuns em um DDA (BAVENDIEK; 2005).

\subsubsection{Tratamento para pixel morto.}

Um pixel morto é um pixel defeituoso que permanece apagado em uma tela de exibição, eventualmente vindo a ocorrer em telas de LCD, ou CCD, ou em um sensor CMOS de câmeras digitais. Um pixel branco permanentemente aceso é chamado de pixel quente e um de cor sólida, como o verde, o vermelho ou o azul, é chamado de pixel preso. Um pixel é uma unidade composta, geralmente, por três sub-pixels, nas cores azul, vermelho e verde. Assim, o processo se assemelha ao CRT (tubo de raios catódicos). Cada sub-pixel é independente e funciona como uma janela que abre e fecha em diferentes ângulos. Assim, se ela estiver totalmente fechada o sub-pixel estará apagado. Já se estiver totalmente aberta o sub-pixel estará com toda luminosidade (ZSCHERPEL, BAVENDIEK, 2005).

Os monitores passam por processos de teste e verificação. Os DDA's que estão 100\% livres de pixels defeituosos são usados em áreas técnicas médica, engenharia, e por isto, custam mais caros. Os DDA's com até 04 pixels, dependendo da norma usada, são comercializados normalmente, e esta irregularidade não é caracterizada como um defeito e sim como uma limitação técnica. Não há como prever, quando da fabricação, se uma tela terá 0 ou 100 pixels defeituosos. Como os pixels são independentes, um não contamina o outro e não se tem registro de pixel morto que foram surgindo com o tempo. Na Figura 3.69 é mostrado um exemplo de uma tela com um pixel morto na região central. 


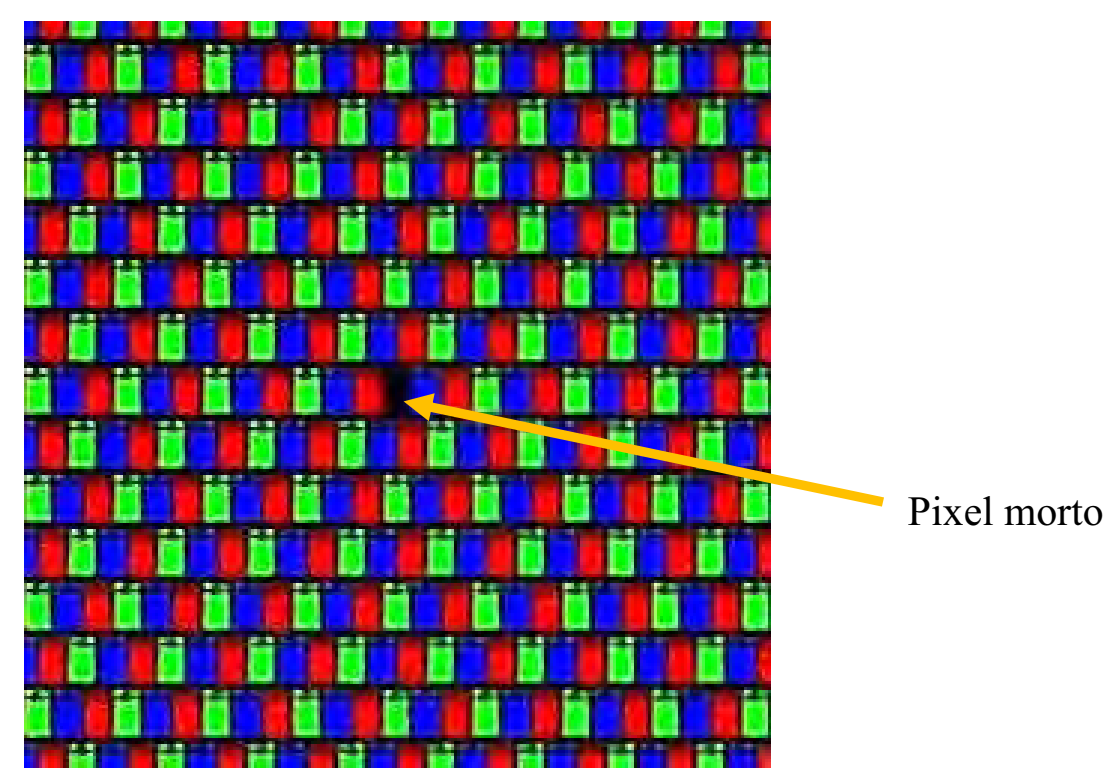

Figura 3.69 - Tela em funcionamento, um pixel morto na região central (ZSCHERPEL; BAVENDIEK, 2005).

Inúmeras estratégias utilizadas em softwares e algoritmos são desenvolvidas para que o tratamento do pixel morto possa ser compensado pelo desempenho conjunto com seus pixels vizinhos, e assim poder restabelecer o desempenho de um monitor ou mesmo uma matriz de detectores digitais, DDA. Na Figura 3.70 são mostradas algumas regras aplicáveis a recuperação de uma matriz de sensores (ZSCHERPEL; BAVENDIEK, 2005).

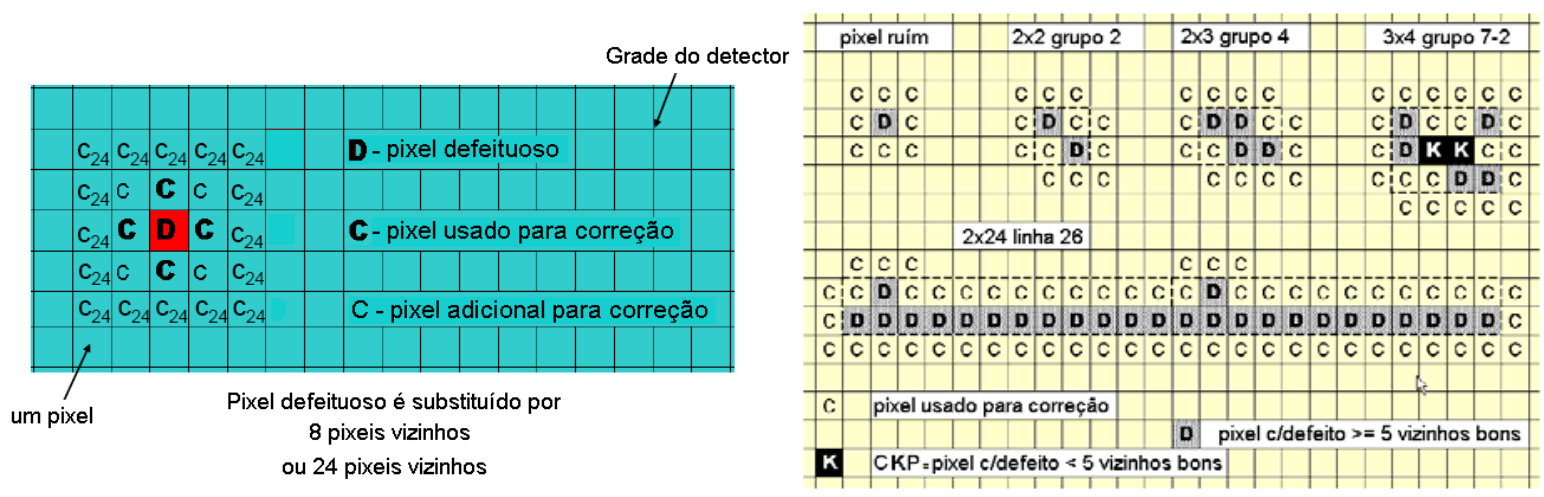

(a)

(b)

Figura 3.70 - Estratégia para correção de pixel com defeito. (a) Pixel morto. (b) Conjunto de pixels defeituosos (ZSCHERPEL; BAVENDIEK, 2005). 


\section{Capítulo 4 \\ Procedimento experimental e metodologia}

\subsection{Planejamento experimental}

Para entendimento das principais etapas envolvidas no procedimento experimental, foi elaborado um fluxograma, conforme mostrado na Figura 4.1.

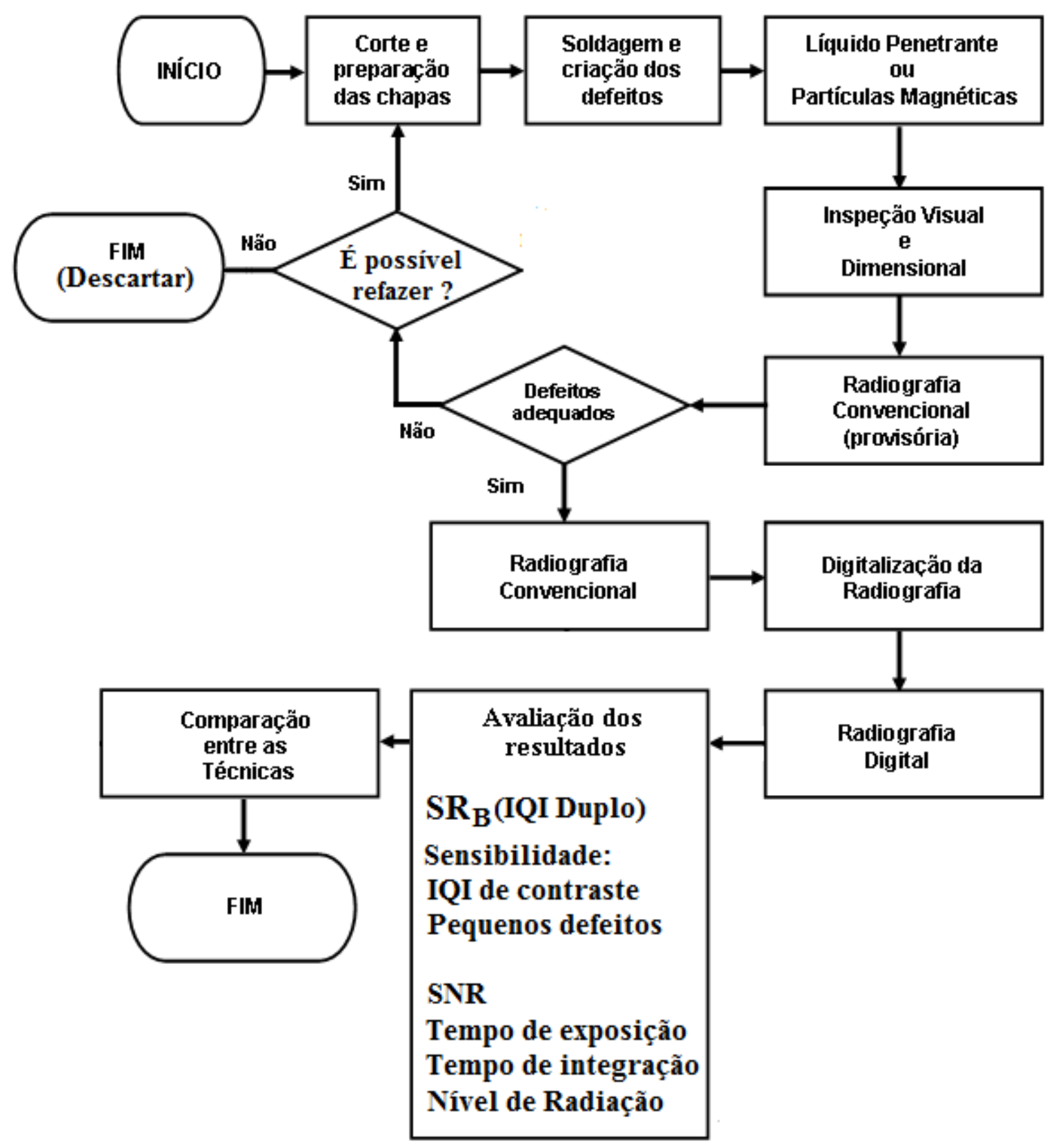

Figura 4.1 - Fluxograma das etapas do trabalho. 


\subsection{Material}

As chapas utilizadas nestes experimentos são de aço comumente chamado de ARBL (Alta Resistência e Baixa Liga), classificado como API 5L, nos graus X60 e X70 que possuem respectivamente o valor mínimo de limite de escoamento de 60.200 e 70.300 psi, conforme descrito na Tabela 4.1. A diferença no grau do material não é relevante para o ensaio radiográfico, visto que, estes materiais são classificados como categoria 1, por terem características de absorção da radiação similares (ASTM E 1025, 2005; N-1595, 2004).

Tabela 4.1 - Valores exigidos no ensaio de tração (API 5L, 2007).

\begin{tabular}{lcc}
\hline Propriedade & Grau X60 & Grau X70 \\
\hline Limite de Resistência Máximo, psi & 110.200 & 110.200 \\
Limite de Resistência Mínimo, psi & 75.400 & 82.700 \\
Limite de Escoamento Máximo (0,5\%), psi & 81.900 & 92.100 \\
Limite de Escoamento Mínimo (0,5\%), psi & 60.200 & 70.300 \\
Alongamento, \% & 24 & 22 \\
Relação LE/LR, Máximo & 0,93 & 0,93 \\
\hline
\end{tabular}

Estes tipos de aço são destinados à fabricação de tubos para uso no setor de petróleo e petroquímico em gasodutos e oleodutos, terrestres e marítimos (API 5L, 2007; COTA et. al, 2005). Foram utilizadas chapas nas espessuras de 4,9; 6,4; 9,7; 19,$2 ; 25,3$ e $32,3 \mathrm{~mm}$ sendo que estas foram cortadas em forma retangular nas dimensões de $300 \mathrm{~mm}$ de comprimento e $150 \mathrm{~mm}$ de largura. Estes ensaios foram realizadas na máquina de ensaios universais marca MFL SYSTEM, modelo UPD100, do laboratório mecânico da empresa TenarisConfab, e foram feitos de acordo com o método indicado na norma ASTM A 370 (ASTM A-370, 2009).

A composição química, exigida pela especificação API 5L para os aços grau X60 e X70, está apresentada pelas porcentagens dos elementos de liga (\% em peso), conforme descrito na Tabela 4.2.

\begin{tabular}{|c|c|c|}
\hline \multirow[t]{2}{*}{ Elemento } & \multicolumn{2}{|c|}{ \% em Peso Máximo } \\
\hline & Grau X60 & Grau X70 \\
\hline Carbono & 0,26 & 0,26 \\
\hline Manganês & 1,40 & 1,65 \\
\hline Fósforo & 0,030 & 0,030 \\
\hline Enxofre & 0,030 & 0,030 \\
\hline Niobio & $(*)$ & (*) \\
\hline Vanádio & $(*)$ & (*) \\
\hline Titânio & $(*)$ & (*) \\
\hline \multicolumn{3}{|c|}{ (*) A soma das $\%$ de $\mathrm{Nb}, \mathrm{V}$ e $\mathrm{Ti} \leq 0,15 \%$} \\
\hline
\end{tabular}


A análise da composição química destes materiais foi realizada, para fins de comparação com os valores exigidos pela especificação API 5L para os graus X60 e X70 para o nível de especificação de produto 1 (PSL1), no espectrômetro de emissão óptica a vácuo, marca Thermo Electron Corporation, modelo ARL 3460 Metals Analyzer, de 26 canais, do Laboratório Químico da empresa TenarisConfab, e foi feita de acordo com o método indicado na norma ASTM A 751 (ASTM A-751, 2008).

\subsubsection{Corpos-de-prova}

As chapas foram preparadas para soldagem e soldadas na posição plana $(1 \mathrm{G})$ e os passes de solda foram sendo depositados até o completo preenchimento da junta. Como a finalidade destes corpos-de-prova foi provocar os defeitos dos tipos: trinca (TR), falta de penetração (FP), falta de fusão (FF), porosidade (PO) e inclusão de escória (IE) na junta soldada, foi escolhido o processo de solda GMAW (Gas Metal Arc Welding), que é mais adequado para esta atividade. Foram utilizandos eletrodos ER70S-6, AWS A5.18 com diâmetro de 1,2 mm e as combinações entre espessuras e tipos de juntas em V e X, escolhido de acordo com a espessura a ser soldada (AWS A5.18, 2005).

Foram preparados 20 corpos-de-prova de juntas soldadas, distribuídos em 06 diferentes espessuras, conforme apresentado na Tabela 4.3. Cada corpo-de-prova recebeu um número seqüencial, sendo que aqueles que depois de avaliado por radiografia e os que não apresentaram defeitos adequados, foram rejeitados.

Tabela 4.3 - Relação de corpos-de-prova.

\begin{tabular}{ccc}
\hline Experimento & Espessura, $\mathrm{mm}$ & Código \\
\hline 1 & 4,9 & CP04 - CP11 - CP14 - CP22 \\
2 & 6,4 & CP06 - CP12 - CP15 \\
3 & 9,7 & CP07 - CP10 - CP16 \\
4 & 19,2 & CP01 - CP09 - CP17 \\
5 & 25,3 & CP02 - CP03 - CP13 - CP21 \\
6 & 32,3 & CP05 - CP08 - CP18 \\
\hline
\end{tabular}

Devido à necessidade de que fossem gerados os 05 tipos de defeitos para cada uma das espessuras envolvidas e no fato de que os defeitos não deveriam estar 
sobrepostos, para não ter dificuldades na interpretação das imagens radiográficas, a quantidade de corpos-de-prova ficou entre 03 e 04 por espessura. A Tabela 4.4 mostra as combinações entre espessura, tipo de chanfro e tipo de defeito criado (N-1738, 2003).

Tabela 4.4 - Junta soldada e tipos de defeitos criados.

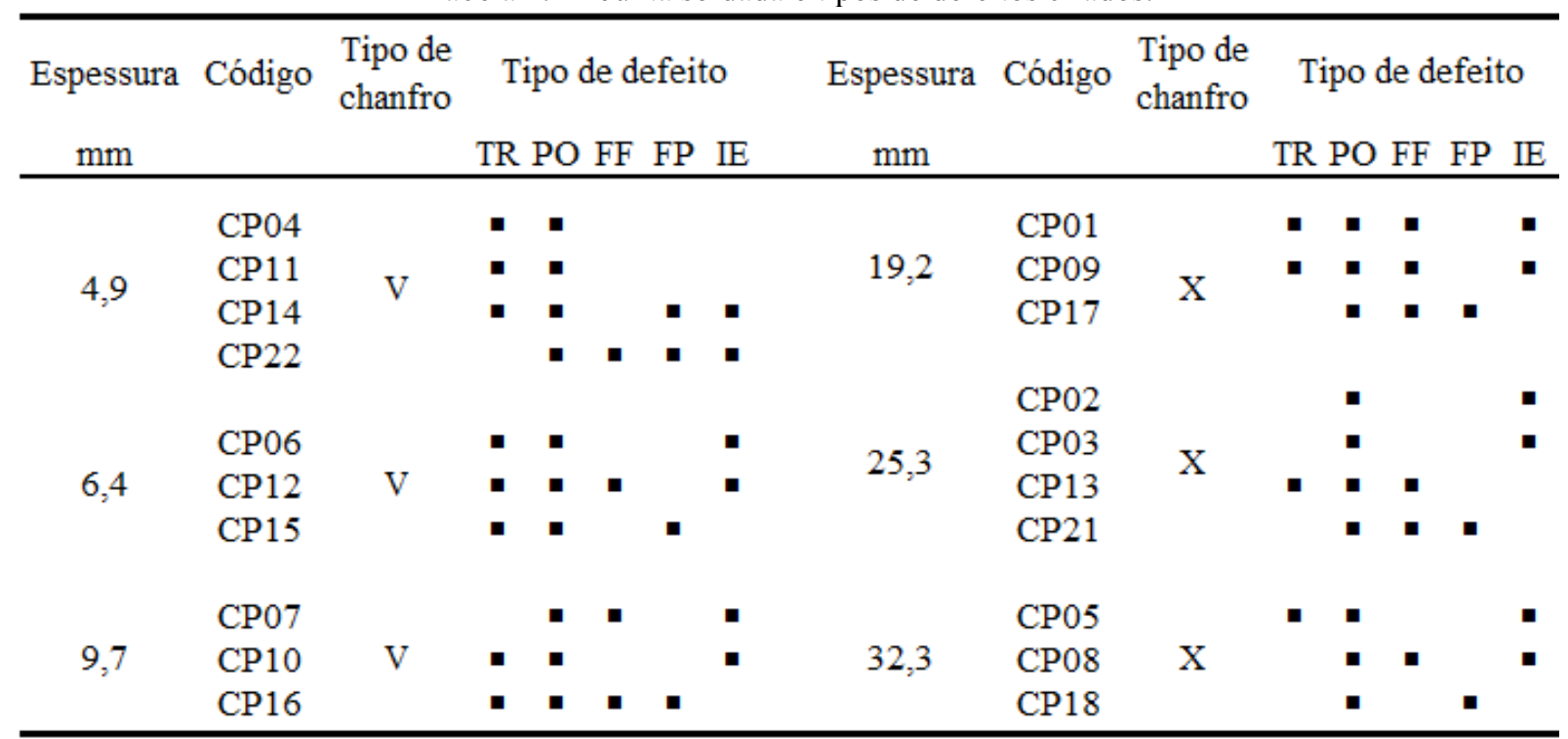

\subsection{Ensaio radiográfico dos corpos-de-prova}

Com o objetivo de comparar as imagens radiográficas obtidas dos 20 corpos-deprova preparados para abranger as 06 espessuras e com os 05 tipos de defeitos, foram executados os ensaios radiográficos na técnica convencional, que utiliza filmes radiográficos industriais, e também na técnica digital, utilizando um detector plano. $\mathrm{O}$ método de ensaio utilizado foi conforme a ISO/DIS 10893-6 e ISO 12096, obedecendo as exigências da técnica com sensibilidade melhorada, classe B. (ISO 17636, 2003; ISO 12096, 1996).

\subsubsection{Técnica convencional}

Os testes utilizando a técnica convencional foram realizados em sua totalidade nas instalações de raios $\mathrm{X}$ da empresa TenarisConfab. Todas as amostras foram radiografadas com os filmes AGFA Gevaert D4 e Kodak M100, que são os mais sensíveis atualmente utilizados na indústria. Estes filmes possuem classificação como Classe I pela norma ASTM e T1 conforme a ISO 11699-1, conforme apresentado na Tabela 4.5 (ASTM E-1815, 2008; ISO 11699-1, 2008). 
Tabela 4.5 - Características dos filmes utilizados

\begin{tabular}{cccccc}
\hline Marca & Modelo & Classe & Velocidade & Contraste & Grão \\
\hline Kodak Industrex & M100 & I & Baixa & Muito alto & Muito fino \\
AGFA & D4 & I & Baixa & Muito alto & Extra Fino \\
\hline
\end{tabular}

Os filmes foram expostos e revelados de acordo com as instruções dos fabricantes para obter o menor tempo de exposição possível, observando que as densidades radiográficas finais nas regiões com reforço e nas áreas esmerilhadas estivessem entre 1,8 a 3,5. Os parâmetros utilizados estão listados na Tabela 4.6. As dimensões dos filmes foram de $431 \mathrm{~mm}$ x $89 \mathrm{~mm}$.

Tabela 4.6 - Parâmetros utilizados para ensaio com filmes.

\begin{tabular}{|c|c|c|c|c|c|c|c|}
\hline \multirow{2}{*}{$\begin{array}{l}\text { Espessura } \\
\text { (mm) }\end{array}$} & \multirow{2}{*}{$\begin{array}{c}\text { Distância Foco-Filme } \\
\text { (mm) }\end{array}$} & \multicolumn{3}{|c|}{ Kodak M100 } & \multicolumn{3}{|c|}{ AGFA D4 } \\
\hline & & $\begin{array}{c}\text { Voltagem } \\
(\mathrm{kV})\end{array}$ & $\begin{array}{c}\text { Corrente } \\
(\mathrm{mA})\end{array}$ & $\begin{array}{c}\text { Tempo } \\
\text { (s) }\end{array}$ & $\begin{array}{c}\text { Voltagem } \\
(\mathrm{kV})\end{array}$ & $\begin{array}{c}\text { Corrente } \\
(\mathrm{mA})\end{array}$ & $\begin{array}{c}\text { Tempo } \\
\text { (s) }\end{array}$ \\
\hline 4,9 & 700 & 135 & 13 & 40 & 135 & 13 & 26 \\
\hline 6,4 & 700 & 135 & 13 & 70 & 135 & 13 & 55 \\
\hline 9,7 & 700 & 170 & 13 & 50 & 170 & 13 & 36 \\
\hline 19,2 & 700 & 200 & 13 & 90 & 200 & 13 & 70 \\
\hline 25,3 & 700 & 216 & 13 & 140 & 216 & 13 & 110 \\
\hline 32,3 & 800 & 217 & 13 & 370 & 217 & 13 & 240 \\
\hline
\end{tabular}

Para a execução das radiografias foi utilizado um aparelho de raios X e acessórios da empresa TenarisConfab, descritos a seguir:
Marca:
YXLON International X Ray GMBH.
Modelo:
MG 320 - Potencial Constante.
Ampola:
Y.TU 320-D03.
Foco:
4x4 mm, conforme EN 12543-1. (EN 12543-1;1999).
Ecran:
De chumbo espessura de $0.027 \mathrm{~mm}$.
IQI de contraste:
De fio conforme ISO 19232-1.
IQI resolução espacial: $\quad$ De fio duplo ISO 19232-5.
Processadora:
Kodak B2000.
Densitômetro:
AGFA D102.
Negatoscópio:
BRASREMKO AT II.
Filme:
Classe I - Kodak M100 e AGFA D4.

Após a execução das radiografias elas foram digitalizadas, obedecendo às normas ISO 14096-1 e 14096-2, em um digitalizar de filmes à laser no laboratório do "Federal Institute for Materials and Testing, Laboratory VIII 3.1 Radiation Techniques" (BAM) 
em Berlin, na Alemanha, com equipamento marca Array Corporation, modelo Array 2905 HD, que possui alta precisão ótica com um feixe de laser Helio-Neon, tamanho de pixel de $50 \mu \mathrm{m}$ e uma resolução digital 12 bit (BECKMANN et al., 2008; ISO 14096-1, ISO 14096-2; 2005).

\subsubsection{Técnica Digital}

A técnica da radiografia digital está baseada na utilização de um detector plano para receber a imagem radiográfica, conhecido como radiografia direta ou também como DDA (Direct Digital Array). Para os experimentos, devido às suas dimensões e características, foi selecionado um detector plano fabricado pela Varian modelo PaxScan 2520V, conforme mostrado na Figura 4.2.

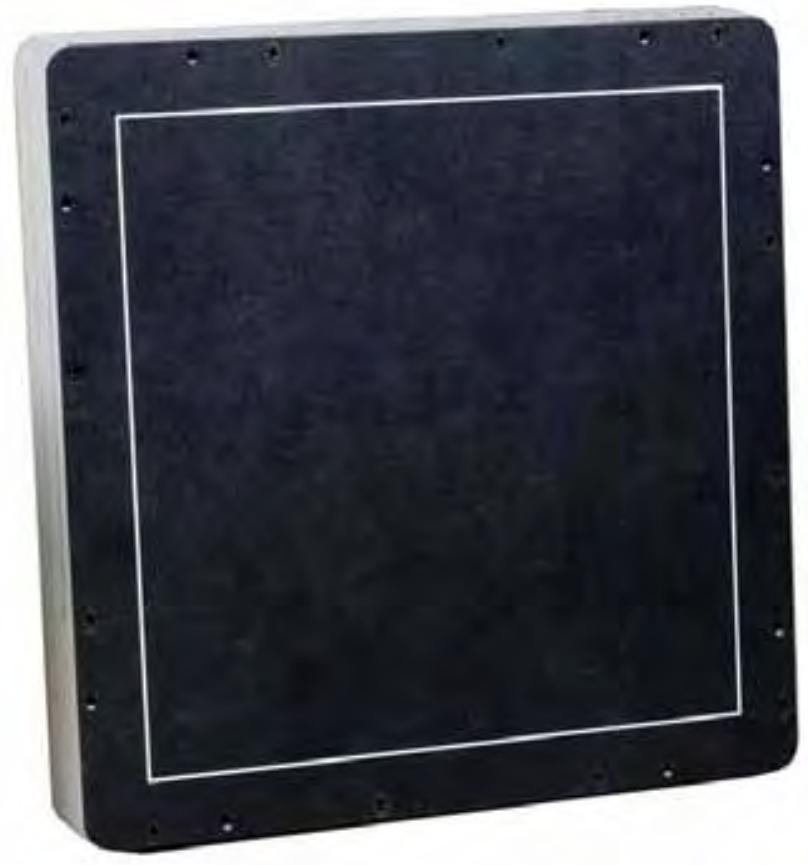

Figura 4.2 - Detector plano Varian PaxScan 2520V.

O detector PaxScan $2520 \mathrm{~V}$ possui sensores do tipo silício amorfo e tela do cintilador de oxisulfito de gadolínio $\left(\mathrm{Gd}_{2} \mathrm{O}_{2} \mathrm{~S}\right)$, com mais de 2,9 milhão de pixels (1920 x 1536), de alta resolução com tamanho do pixel de $127 \mu \mathrm{m}, 1,97 \mathrm{pl} / \mathrm{mm}$ e de 12 bits. Tem dimensões ativas de 250 x $200 \mathrm{~mm}$, trabalha em uma faixa de energia de 40 a 225 kV (ASTM E 2597, 2007). As características técnicas deste detector estão descritas na Tabela 4.7. 
Tabela 4.7 - Especificação do Detector plano PaxScan 2520V.

\begin{tabular}{ll}
\hline Parâmetro & \multicolumn{1}{c}{ Característica } \\
\hline Fabricante: & Varian Medical Systems \\
Modelo: & PaxScan 2520V \\
Tipo de receptor: & Silício Amorfo \\
Tela de conversão: & Oxisulfito de gadolínio \\
Área de pixel total: & $250 \times 200 \mathrm{~mm}$ \\
Área de pixel ativos: & $240 \times 179 \mathrm{~mm}$ \\
Matrix de pixel total: & $1920 \times 1536(3,9 \mathrm{Mp})$ \\
Fator de enchimento: & $57 \%$ \\
Tamanho do pixel: & $127 \mu \mathrm{m}$ \\
Energia de radiação: & $40-225 \mathrm{kV}$ \\
Faixa dinâmica: & $\geq 2000: 1$ \\
Método de varredura: & Progressivo, Unidirecional \\
Conversor A/D: & $12 \mathrm{bits}$ \\
Resolução: & $3,9 \mathrm{pl} / \mathrm{mm}$ (1a 10 telas $/ \mathrm{s})$ e $1,97 \mathrm{pl} / \mathrm{mm}(15$ a 30 telas $/ \mathrm{s})$ \\
\hline
\end{tabular}

\subsubsection{Cálculos para determinação das distâncias.}

Antes da execução dos testes foram calculadas as distâncias mínimas e máximas entre o detector e a superfície do tubo, pois o detector plano é instalado internamente utilizando uma lança, para que este se posicione automaticamente nos extremos e em posições intermediárias ao longo do comprimento dos tubos, cujas dimensões são: diâmetros de 406,4 mm (16 pol.) a 1.219,2 mm (48 pol.) nas espessuras entre 4,9 a 32,3 mm. É definido pelas especificações API 5L e ISO 3183 que o comprimento mínimo a ser radiografado em cada uma das extremidades do tubo é de 203,2 mm (a). Como o detector tem um comprimento ativo de $240 \mathrm{~mm}$ (b), a máxima ampliação possível é de 1,18, conforme mostrado na Figura 4.3.

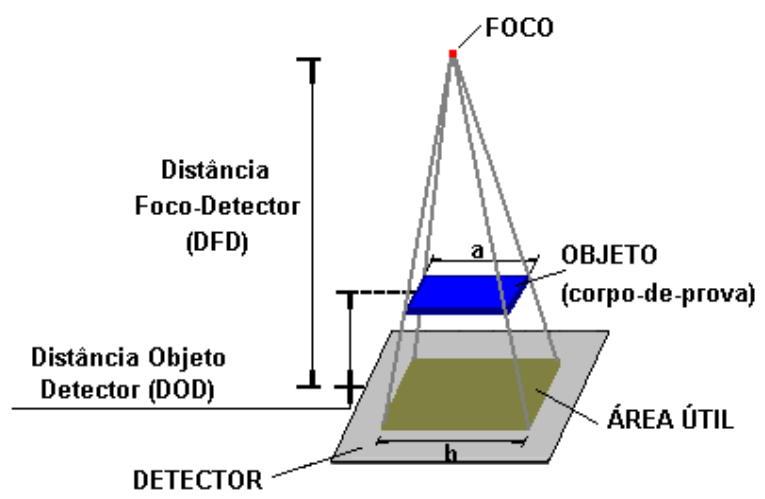

Figura 4.3 - Ampliação da imagem radiográfica

Nos fornecimentos de tubos onde as exigências de inspeção devam atender a norma DNV OS-F-101, o comprimento mínimo a ser inspecionado é de $300 \mathrm{~mm}$, e, portanto, duas exposições serão necessárias. Neste caso, pode-se, por exemplo, utilizar 
ampliação de até 1,4 para uma inspeção individual de $170 \mathrm{~mm}$, com uma sobreposição de $20 \mathrm{~mm}(13 \%)$.

Com o valor da ampliação da imagem radiográfica necessária e utilizando a equação (4.1), mostrada abaixo, que utiliza o comprimento da área útil do detector (b), o comprimento a ser inspecionado (a) obtém-se a relação entre as distâncias focodetector (DFD) e objeto-detector (DOD), que estão representadas na Figura 4.3.

Fator de ampliação; $\quad \frac{\mathbf{b}}{\mathbf{a}}=\frac{\text { DFD }}{(\text { DFD }- \text { DOD })}$

Para estabelecimento das distâncias do objeto ao detector (DOD) mínima e máxima, utilizando um fator de ampliação da imagem radiográfica de até 1,18 , outros fatores devem ser considerados tais como: largura e altura do detector, diâmetro e espessura do tubo, altura do reforço externo de solda, dimensões da lança e do mecanismo de movimentação do detector e a distância do foco ao detector (DFD).

Na Figura 4.4 é representado um esquema da montagem do detector na lança e o respectivo posicionamento dentro do tubo. É importante notar que as linhas cor de rosa indicam um fator de segurança para esta montagem, que também é mostrado pelo círculo. Este fator garante um valor mínimo de $28 \mathrm{~mm}$ de afastamento da parede interna do tubo.

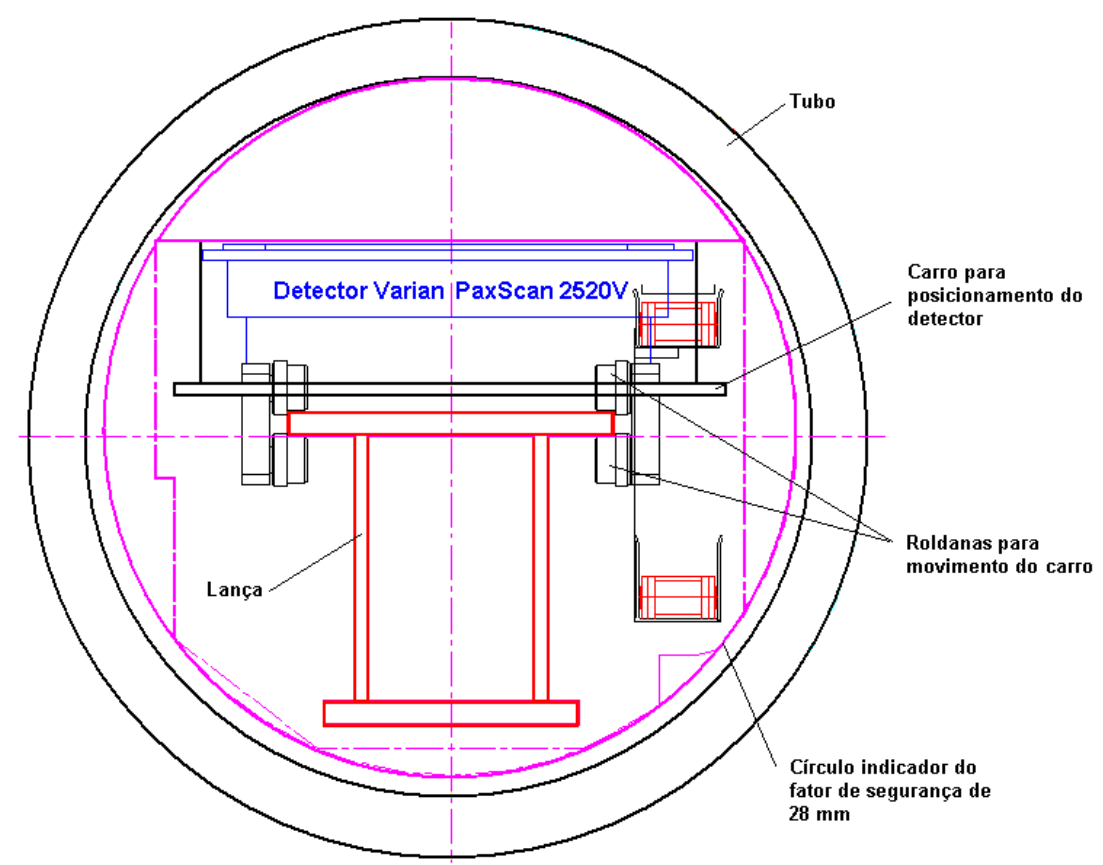

Figura 4.4 - Esquema da colocação do detector dentro do tubo. 
Para determinação das distâncias mínimas possíveis, para colocação do detector dentro do tubo a uma distância segura de $28 \mathrm{~mm}$ da parede interna do tubo, foram utilizadas as relações encontradas na Figura 4.5.

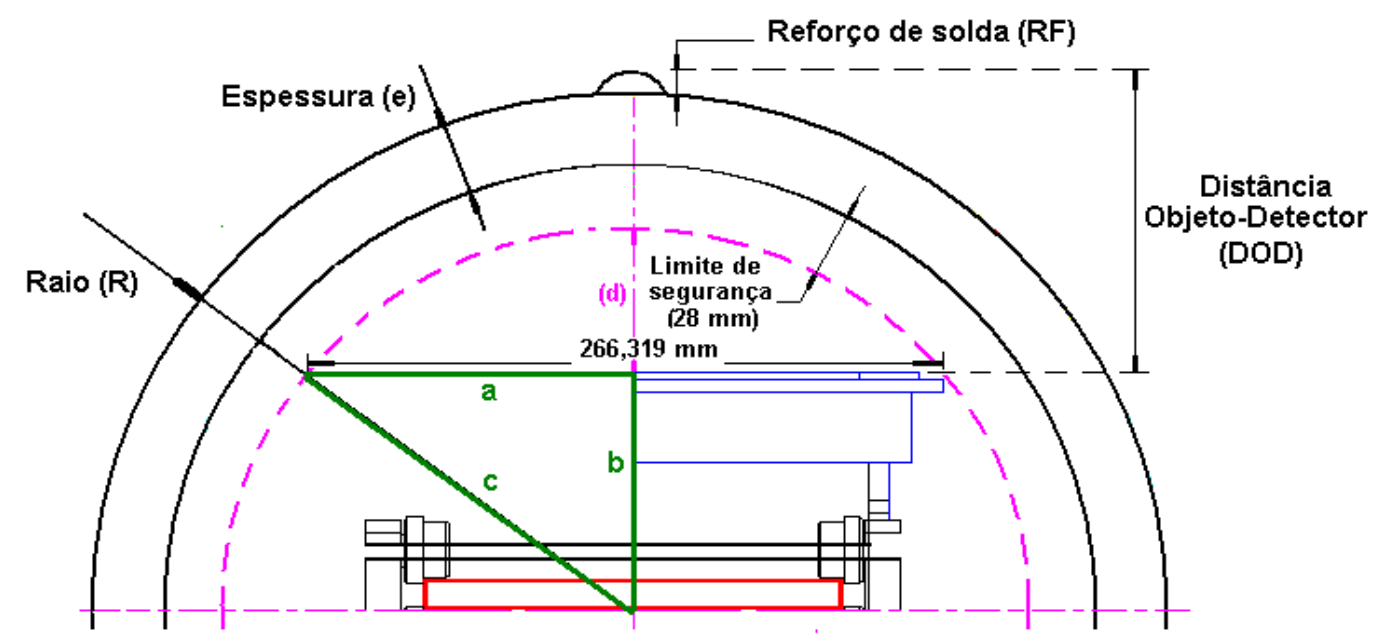

Figura 4.5 - Determinação da Distância Mínima Objeto-Detector.

Utilizando a Figura 4.5 se obtém as seguintes equações:

$$
\begin{aligned}
& \text { DOD }=R F+e+28+d \\
& d=R-e-28-b \\
& b=\left(c^{2}-a^{2}\right)^{1 / 2} \\
& c=R-e-28
\end{aligned}
$$

Sendo o valor (a) a metade da largura do detector PaxScan $2520 \mathrm{~V}$ que é igual a $266,32 / 2$ = 133,16 mm, substituindo o valor (d) na equação 4.2 pela equação 4.3 temse que:

$$
\mathrm{DOD}=\mathrm{RF}+\mathrm{e}+28+\mathrm{R}-\mathrm{e}-28-\mathrm{b}
$$

Substituindo o valor (b) na equação 4.6 pela equação 4.4 e o valor de (c) dado na equação 4.5, tem-se que:

$$
\mathrm{DOD}=\mathrm{RF}+\mathrm{e}+28+\mathrm{R}-\mathrm{e}-28-\left[(\mathrm{R}-\mathrm{e}-28)^{2}-(133,16)^{2}\right]^{1 / 2}
$$

Resolvendo, tem-se: $\quad \mathrm{DOD}=\mathrm{RF}+\mathrm{R}-\left[(\mathrm{R}-\mathrm{e}-28)^{2}-(133,16)^{2}\right]^{1 / 2}$

Baseado nos valores da altura do reforço de solda $(R F)$, raio do tubo $(R)$ e a espessura da parede do tubo (e) utilizando a equação 4.7, na Tabela 4.8 estão descritos 
os valores das mínimas distâncias Objeto-Detector (DOD) para as espessuras dos corpos-de-prova utilizados neste experimento e os diâmetros típicos fabricados.

\begin{tabular}{|c|c|c|c|c|c|c|c|c|c|c|c|c|c|c|c|c|c|c|}
\hline \multirow[b]{2}{*}{$\begin{array}{l}\text { Espessura } \\
(\mathrm{mm})\end{array}$} & \multirow{2}{*}{$\begin{array}{c}\text { Reforço } \\
\text { de Solda } \\
(\mathrm{mm})\end{array}$} & \multicolumn{17}{|c|}{ Diâmetro (mm) } \\
\hline & & 406 & 457 & 508 & 559 & $\begin{array}{r}610 \\
\mathbf{M} \\
\end{array}$ & 660 & & 762 & 813 & 864 & 914 & 965 & 1016 & 1067 & 1118 & 1168 & 1219 \\
\hline 4,9 & 3 & 38 & 37 & 37 & 37 & 37 & 37 & 37 & 37 & 37 & 37 & 37 & 37 & 37 & 37 & 37 & 36 & 36 \\
\hline 6,4 & 3 & 39 & 39 & 39 & 39 & 39 & 39 & 38 & 38 & 38 & 38 & 38 & 38 & 38 & 38 & 38 & 38 & 38 \\
\hline 9,7 & 3 & 43 & 42 & 42 & 42 & 42 & 42 & 42 & 42 & 42 & 42 & 42 & 42 & 41 & 41 & 41 & 41 & 41 \\
\hline 19,2 & 3 & 52 & 52 & 52 & 51 & 51 & 51 & 51 & 51 & 51 & 51 & 51 & 51 & 51 & 51 & 51 & 51 & 51 \\
\hline 25,3 & 3 & 58 & 58 & 58 & 58 & 58 & 57 & 57 & 57 & 57 & 57 & 57 & 57 & 57 & 57 & 57 & 57 & 57 \\
\hline 32,3 & 3 & 65 & 65 & 65 & 65 & 65 & 65 & 64 & 64 & 64 & 64 & 64 & 64 & 64 & 64 & 64 & 64 & 64 \\
\hline
\end{tabular}

Utilizando os valores mínimos das distâncias do Objeto ao Detector obtidos na Tabela 4.8, pode-se calcular o fator de ampliação para cada uma das relações diâmetro e espessura. Na Tabela 4.9 estão descritos os valores dos fatores de ampliação para uma distância do foco ao detector (DFD) de $700 \mathrm{~mm}$.

Tabela 4.9 - Fator de ampliação para DOD mínimo e DFD de 700 mm.

\begin{tabular}{|c|c|c|c|c|c|c|c|c|c|c|c|c|c|c|c|c|c|c|}
\hline \multirow[b]{2}{*}{$\begin{array}{l}\text { Espessura } \\
(\mathrm{mm})\end{array}$} & \multirow{2}{*}{$\begin{array}{c}\text { Reforço } \\
\text { de } \\
\text { Solda } \\
(\mathrm{mm})\end{array}$} & \multicolumn{17}{|c|}{ Diâmetro (mm) } \\
\hline & & 406 & 457 & 508 & 559 & 610 & 660 & 711 & $\begin{array}{r}762 \\
\text { Gator } \\
\end{array}$ & de am & 864 & 914 & 965 & 1016 & 1067 & 1118 & 1168 & 1219 \\
\hline 4,9 & 3 & 1,17 & 1,14 & 1,13 & 1,12 & 1,11 & 1,11 & 1,10 & 1,10 & 1,09 & 1,09 & 1,09 & 1,09 & 1,09 & 1,08 & 1,08 & 1,08 & 1,08 \\
\hline 6,4 & 3 & 1,17 & 1,15 & 1,13 & 1,12 & 1,12 & 1,11 & 1,10 & 1,10 & 1,10 & 1,09 & 1,09 & 1,09 & 1,09 & 1,09 & 1,08 & 1,08 & 1,08 \\
\hline 9,7 & 3 & 1,18 & 1,16 & 1,14 & 1,13 & 1,12 & 1,12 & 1,11 & 1,11 & 1,10 & 1,10 & 1,10 & 1,10 & 1,09 & 1,09 & 1,09 & 1,09 & 1,09 \\
\hline 19,2 & 3 & 22 & 1,18 & 1,16 & 1,15 & 1,14 & 1,14 & 1,13 & 1,13 & 1,12 & 1,12 & 1,12 & 1,11 & 1,11 & 1,11 & 1,11 & 1,11 & 1,10 \\
\hline 25,3 & 3 & 1,24 & 1,20 & 1,18 & 1,17 & 1,16 & 1,15 & 1,14 & 1,14 & 1,13 & 1,13 & 1,13 & 1,12 & 1,12 & 1,12 & 1,12 & 1,12 & 1,12 \\
\hline 32,3 & 3 & 1,28 & 1,23 & 1,20 & 1,18 & 1,17 & 1,16 & 1,16 & 1,15 & 1,15 & 1,14 & 1,14 & 1,14 & 1,14 & 1,13 & 1,13 & 1,13 & 1,13 \\
\hline
\end{tabular}

Na Tabela 4.9 é indicado, em vermelho, que para os menores diâmetros combinados com as maiores espessuras $(19,2 ; 25,3$ e $32,3 \mathrm{~mm})$ os valores do fator de ampliação são maiores que 1,18, para a distância do foco ao detector (DFD) de 700 $\mathrm{mm}$. Para que estes fatores sejam menores, as DFD devem ser aumentadas nos experimentos, veja item 4.3.2.1.

Recalculando a distância do foco ao detector, para os 06 valores em destaque (vermelho), pode-se observar na Tabela 4.10 os novos valores mínimos de DFD para garantir a ampliação de 1,18. 
Tabela 4.10 - Distância mínima do foco ao detector, para fator de ampliação de 1,18.

\begin{tabular}{ccccc}
\hline $\begin{array}{c}\text { Espessura } \\
(\mathrm{mm})\end{array}$ & $\begin{array}{c}\text { Reforço de } \\
\text { Solda (mm) }\end{array}$ & 406 & $\begin{array}{c}\text { Diâmetro (mm) } \\
457\end{array}$ & 508 \\
& \multicolumn{5}{c}{ Distância do Foco ao Detector (mm) } \\
\hline 19,2 & 3 & 819 & & \\
25,3 & 3 & 900 & 770 & \\
32,3 & 3 & 1012 & 844 & 763 \\
\hline
\end{tabular}

Os corpos-de-prova foram enviados ao Laboratório de Aplicações da empresa Yxlon International em Hamburg, na Alemanha, e utilizando o detector plano PaxScan $2520 \mathrm{~V}$ e os valores de mínimos e máximos de DFD e DOD, calculados anteriormente para cada uma das 06 espessuras envolvidas no experimento, foram feitas as exposições para a obtenção das imagens digitais do cordão de solda dos corpos-deprova. O arranjo utilizado está mostrado na Figura 4.6.

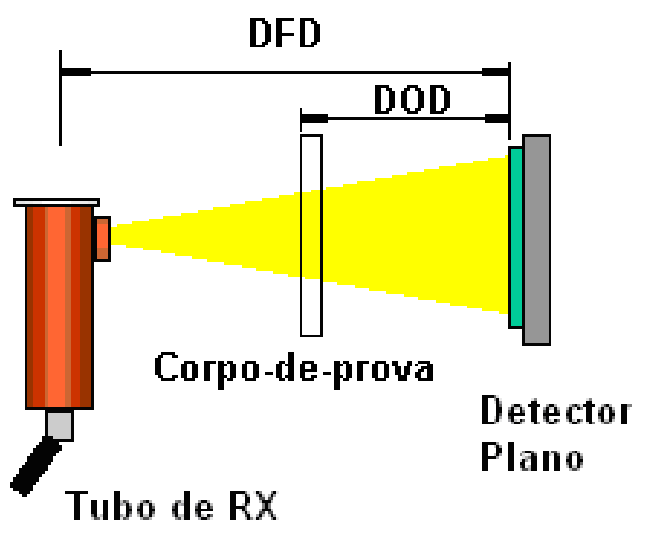

(a)

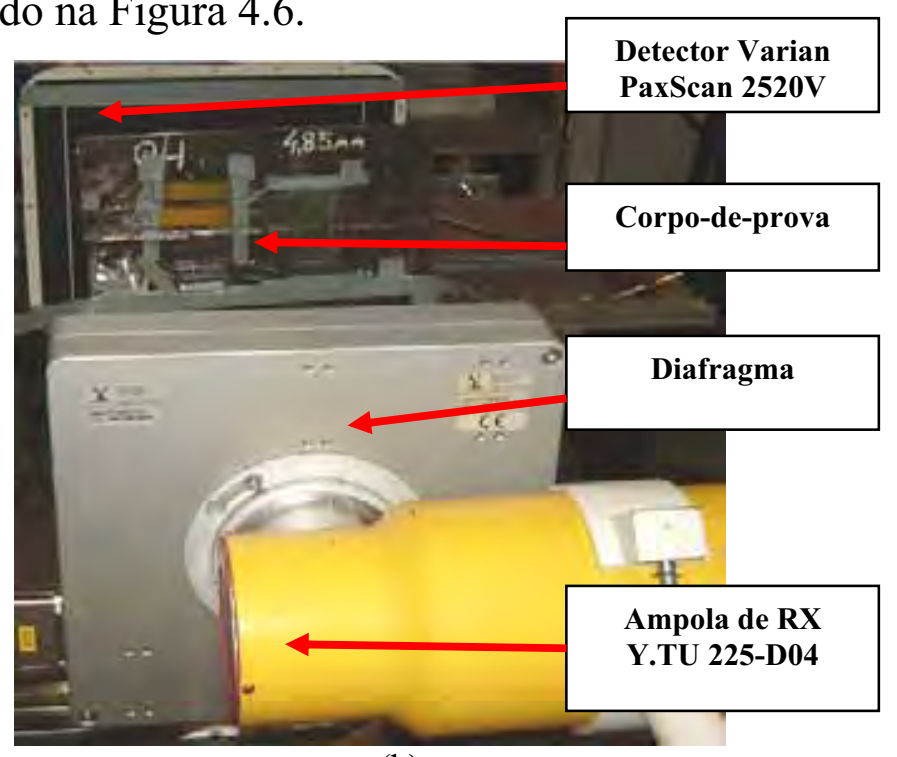

(b)

Figura 4.6 - Arranjo para a radiografia digital. (a) Esquema (PURSCHKE, 2004) e (b) Detalhamento.

Para execução da radiografia digital foram utilizados os aparelhos e acessórios:

Marca:

Modelo:

Ampola:

Foco:

Detector Plano:

Sistema de Imagem:

IQI de contraste: IQI Resolução Espacial: Imagens:
YXLON International X Ray GmbH.

MG 225.

Y.TU 225 D04

0,4 e 1,0 mm conforme EN 12543-1.

Marca Varian, modelo PaxScan 2520V.

3500FR - YXLON.

De arame conforme ISO 19232-1.

Arame Duplo conforme ISO 19232-5.

16 bits. 
Devido à máxima voltagem da ampola e da energia da radiação permissível para o detector plano disponível, os testes são limitados ao valor de $225 \mathrm{kV}$ para ampola que tinha um tamanho focal de 1,0 mm. A ampola utilizada modelo Y.TU 225 D04 possui potência máxima de acordo com a dimensão do tamanho focal, sendo que a máxima amperagem foi de $3,6 \mathrm{~mA}$ e $0,8 \mathrm{~kW}$ de potência permissível para o tamanho focal de $0,4 \mathrm{~mm}$.

Quando ajustada para o tamanho focal de 1,0 mm, a máxima amperagem foi de $8,0 \mathrm{~mA}$ e a potência máxima permissível foi de $1,8 \mathrm{~kW}$. O tamanho focal menor foi escolhido para as menores espessuras visando ganhar sensibilidade, e para as maiores espessuras o tamanho focal de 1,0 mm foi escolhido, pois possibilita condições de trabalho com maior energia, reduzindo os tempos de integração e números de telas por segundo sem perda significativa de sensibilidade. Os parâmetros finais utilizados para a execução do ensaio radiográfico digital encontram-se listados na Tabela 4.11.

Tabela 4.11 - Parâmetros utilizados para radiografia digital.

\begin{tabular}{lcccccc}
\hline Espessura, mm & 4,9 & 6,4 & 9,7 & 19,2 & 25,3 & 32,3 \\
\hline Distância Foco Detector (DFD), mm & 700 & 700 & 700 & 700 e 820 & 700 e 900 & 700 e 1013 \\
Distância Objeto Detector (DOD), mm & 100 & 103 & 57 e 108 & 66 e 125 & 73 e 137 & 80 e 155 \\
Tamanho focal, mm & 0,4 & 0,4 & 0,4 & 1,0 & 1,0 & 1,0 \\
Voltagem, kV & 180 & 200 & 225 & 225 & 225 & 225 \\
Amperagem, mA & 4 & 4 & 3,55 & 8 & 8 & 8 \\
Fator de ampliação & 1,17 & 1,17 & 1,09 e 1,18 & 1,04 e 1,18 & 1,12 e 1,18 & 1,13 e 1,18 \\
Telas por segundo. & 10 & 10 & 10 & 1 & 1 & 1 \\
Tempo de integração, s & $1 ; 2 ; 4 ; 8 ; 1 ; 2 ; 4 ; 8 ;$ & $1 ; 2 ; 4 ; 8 ;$ & $1 ; 2 ; 4 ; 8 ;$ & $1 ; 2 ; 4 ; 8 ;$ & $1 ; 2 ; 4 ; 8 ; 16 ; 32 ; 64 ;$ \\
& $16 ; 32$ & $16 ; 32$ & $16 ; 32$ & $16 ; 32$ & $16 ; 32$ & $128 ; 256 ; 512$ \\
\hline
\end{tabular}

\subsubsection{Determinação da Resolução Espacial Básica.}

Para avaliação da resolução espacial básica foram utilizados 02 métodos indicados pela norma EN 14784-1, o método direto utilizando o IQI de arame duplo e o método da Função de transferência de Modulação (MTF). O IQI de arame duplo, que é fabricado de acordo com ISO 19323-5 foi colocado na região do metal base com um ângulo aproximadamente de $5^{\circ}$ da direção do alinhamento dos pixels do detector. 
Para comparação dos resultados, este IQI de arame duplo foi colocado do lado da fonte, diretamente no metal de base e outro com calço metálico, para compensar as alturas dos reforços de soldas existentes nos corpos-de-prova (ISO 19232-5, 2005). O material destes calços foi selecionado de forma a ter características de absorção da radiação similares aos das soldas empregadas para que apresentassem imagens radiográficas com densidades similares (ASTM E 1025, 2005; N-1595, 2004). A Tabela 4.12 mostra os valores de espessura dos calços que foram utilizados para cada corpo-de-prova.

Tabela 4.12 - Espessura dos calços utilizados.

\begin{tabular}{cccccc}
\hline $\begin{array}{c}\text { Código do } \\
\text { corpo-de-prova }\end{array}$ & $\begin{array}{c}\text { Altura do reforço } \\
\text { total, mm }\end{array}$ & $\begin{array}{c}\text { Espessura do } \\
\text { calço, mm }\end{array}$ & $\begin{array}{c}\text { Código do } \\
\text { corpo-de-prova }\end{array}$ & $\begin{array}{c}\text { Altura do reforço } \\
\text { total, mm }\end{array}$ & $\begin{array}{c}\text { Espessura do } \\
\text { calço, mm }\end{array}$ \\
\hline CP01 & 4,0 & 4,0 & CP11 & 2,9 & 4,0 \\
CP02 & 4,6 & 4,5 & CP12 & 3,2 & 3,0 \\
CP03 & 5,5 & 5,5 & CP13 & 0,0 & 0,0 \\
CP04 & 4,2 & 4,0 & CP14 & 1,0 & 1,0 \\
CP05 & 4,0 & 4,0 & CP15 & 1,7 & 1,5 \\
CP06 & 3,5 & 3,5 & CP16 & 1,1 & 1,0 \\
CP07 & 5,5 & 5,5 & CP17 & 3,7 & 3,5 \\
CP08 & 4,3 & 4,5 & CP18 & 4,3 & 4,5 \\
CP09 & 4,2 & 4,0 & CP21 & 6,1 & 6,0 \\
CP10 & 3,6 & 3,5 & CP22 & 2,9 & 3,0 \\
\hline
\end{tabular}

O esquema de colocação dos IQI's citados, para a execução das imagens digitais, encontra-se indicado na Figura 4.7.

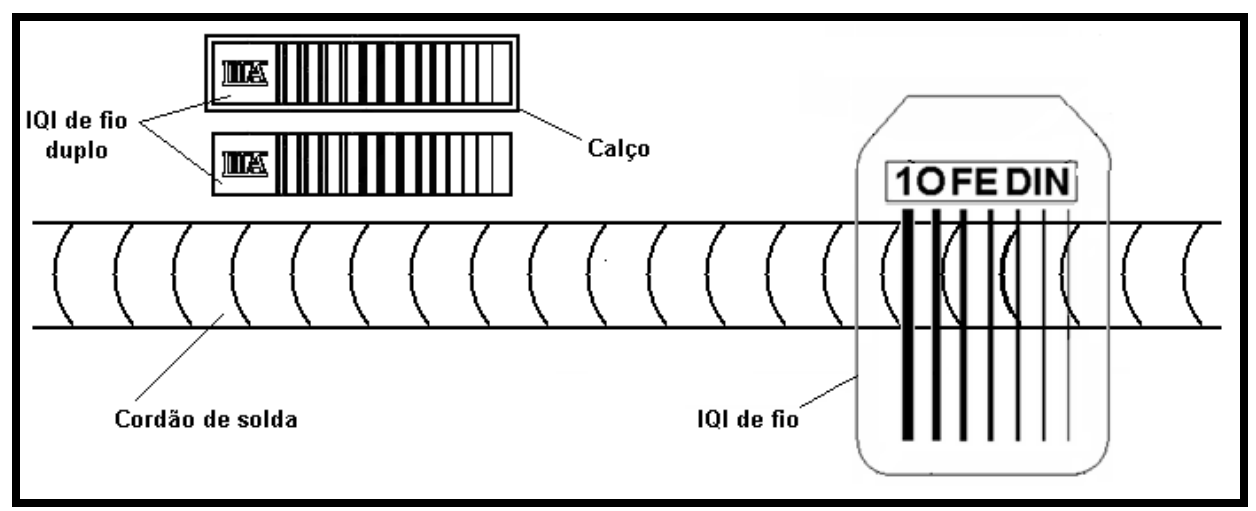

Figura 4.7 - Colocação dos Indicadores de Qualidade de Imagem.

A imagem da penumbra $\left(\mathrm{U}_{\mathrm{g}}\right)$ deve ser medida e o valor da resolução espacial básica $\left(\mathrm{SR}_{\mathbf{B}}\right)$ do detector é determinada com a equação 4.8 .

$$
S R_{B}=1 / 2 \cdot U_{g}
$$


O valor da penumbra $\left(\mathrm{U}_{\mathbf{g}}\right)$ é obtido experimentalmente, utilizando o IQI de arame duplo, colocado do lado da fonte, e é determinado com o auxílio de uma linha de perfil de medição do nível de cinza que é passada pelos arames do IQI de arame duplo. O valor de penumbra obtida é aquele par de arames mais fino que possua uma separação entre fios com valores menores que $20 \%$.

Uma das ferramentas para a medição da resolução espacial básica $\left(\mathrm{SR}_{\mathrm{B}}\right)$ que mede o espaçamento entre os arames, está exemplificada na Figura 4.8. Neste exemplo o ajuste feito obteve o par de arames D9, cujo diâmetro é de $0,130 \mathrm{~mm}$, pois como pode ser observado na Figura 4.8, os espaçamentos dos arames duplos mais grossos incluindo o D8 ( com valor de 22,1\%) mostraram valores maiores que $20 \%$.

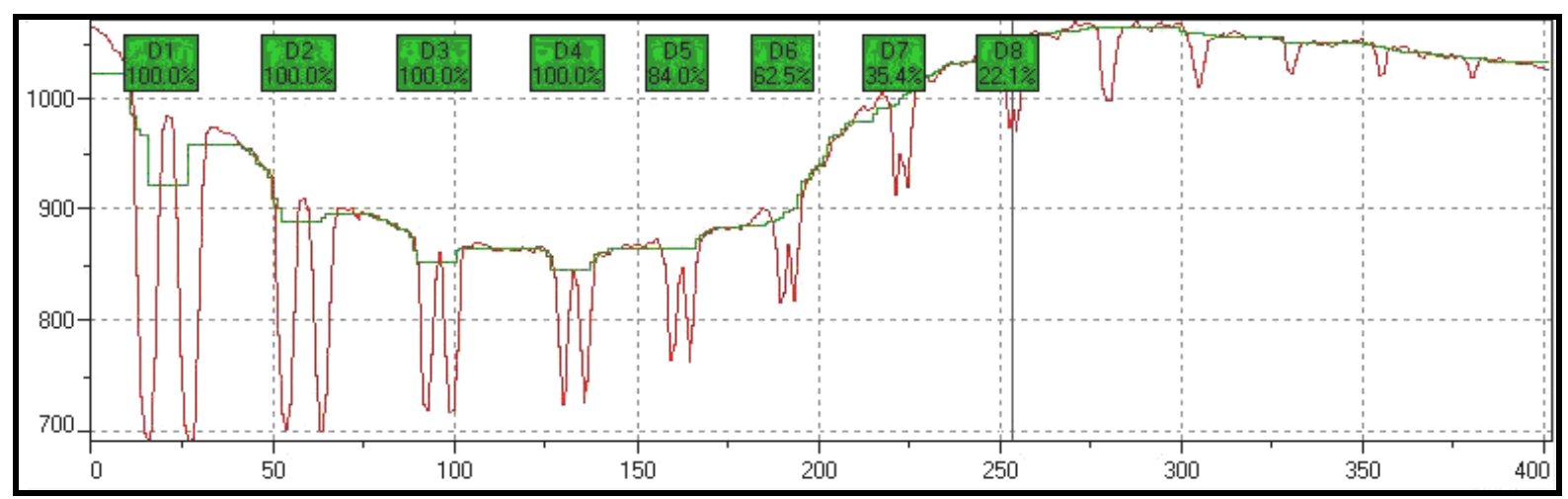

Figura 4.8 - Medição da Resolução espacial básica.

Outra forma de realizar a medição da resolução espacial básica $\left(\mathrm{SR}_{\mathrm{B}}\right)$ é utilizar o software ISee!, desenvolvido pelo Laboratório Federal de Materiais (BAM), situado na cidade de Berlin na Alemanha (ISee!, 2007). Utilizando a opção "Perfil", colocou-se a ferramenta de medição de perfil sobre a imagem dos arames duplos, identificando aquele par onde seja possível visualizar um espaçamento entre eles, no caso a seguir é o par 9D. Colocando o cursor verde na região da base dos valores de cinza (11785), mostrado na Figura 4.9(a), e o cursor azul na região entre os arames (10930), se obtém o valor da diferença em vermelho de 855,5. 


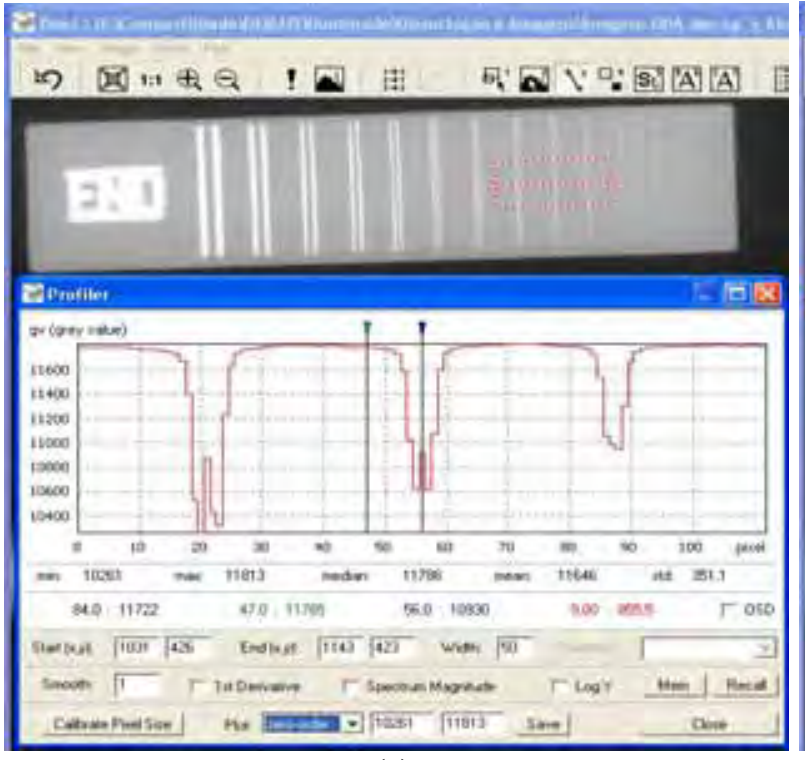

(a)

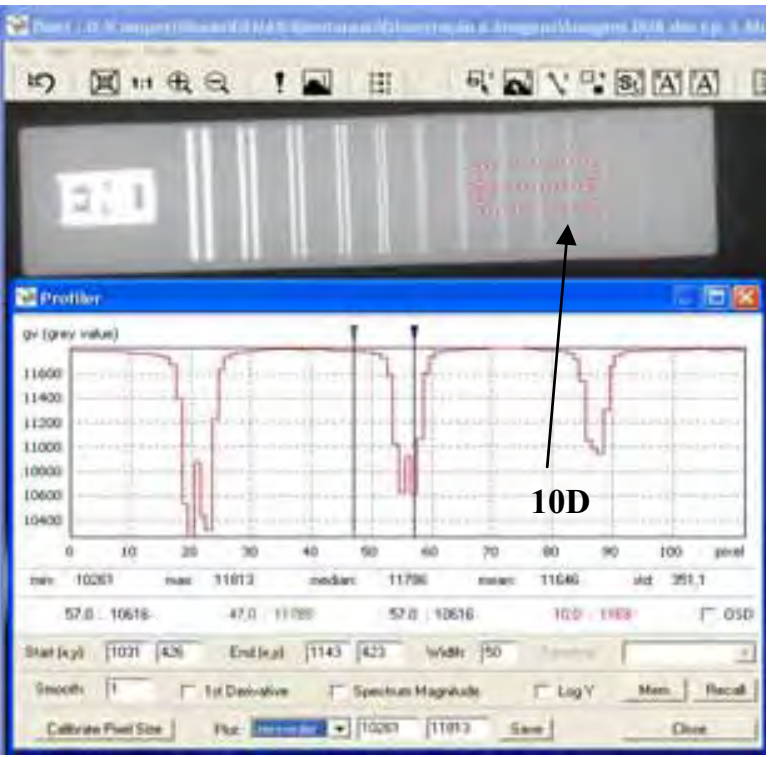

(b)

Figura 4.9 - Método alternativo para medição dos valores de $\mathrm{SR}_{\mathrm{B}}$.

Na Figura 4.9(b) pode-se observar a outra medição do pico correspondente ao arame (valor de cinza 10616) e em relação à base (valor de cinza 11785) e se obtém o valor da diferença de 1169. Assim para se determinar o valor da resolução espacial básica $\left(\mathrm{SR}_{\mathbf{B}}\right)$, deve-se obter o valor da diferença entre 1169 e 855,5 $(313,5)$ e divide-se por 1169 , obtendo-se o valor de 0,268 que corresponde a 26,8\%. Pela norma a resolução espacial básica obtida é o 10D.

De acordo com a EN 14784-1, a resolução espacial básica $\left(\mathrm{SR}_{\mathrm{B}}\right)$ do sistema pode ser determinada também pelo método da Função de Transferência de Modulação (MTF). Para cada uma das espessuras envolvidas nos experimentos, foram utilizados dois IQI's de arame duplo, ambos colocados no metal base, sendo que um foi utilizado sem calço metálico e o outro com calço metálico, com a espessura correspondente ao reforço de solda existente no corpo-de-prova. Com estes IQI's determinou-se a curva MTF para cada situação. A MTF é calculada a partir da primeira derivada do perfil através do cálculo da amplitude máxima do espectro de Fourier e, normalizando a 1, na freqüência zero. Além disto, a resolução espacial básica, $\mathrm{SR}_{\mathrm{B}}$, do sistema é determinada a partir do valor da MTF em 20\%. O valor da resolução espacial corresponde, SR, é calculado pela equação (4.9).

$$
S R=\frac{1}{\left(2 \times M T F_{20}\right)}
$$


Notar que, se existirem diferenças entre o valor lido pelo método MTF e o método do arame duplo, o método do arame duplo deverá ser utilizado para a verificação do procedimento (EN 14784-1, 2005).

A seguir, é descrito como construir a curva Função Transferência de Modulação, MTF. Utilizando o programa ISee! do BAM, foi traçado o perfil de todos os pares de arames do IQI duplo Figura 4.10(a). Os valores dos níveis de cinza foram obtidos posicionando os cursores sobre os pontos mínimos do primeiro par de arames e posteriormente no valor máximo entre os arames. Os valores obtidos estão indicados na parte inferior, conforme está apresentado na Figura 4.10(b) e (c). Neste exemplo os valores são 3150,3174 e 3837.
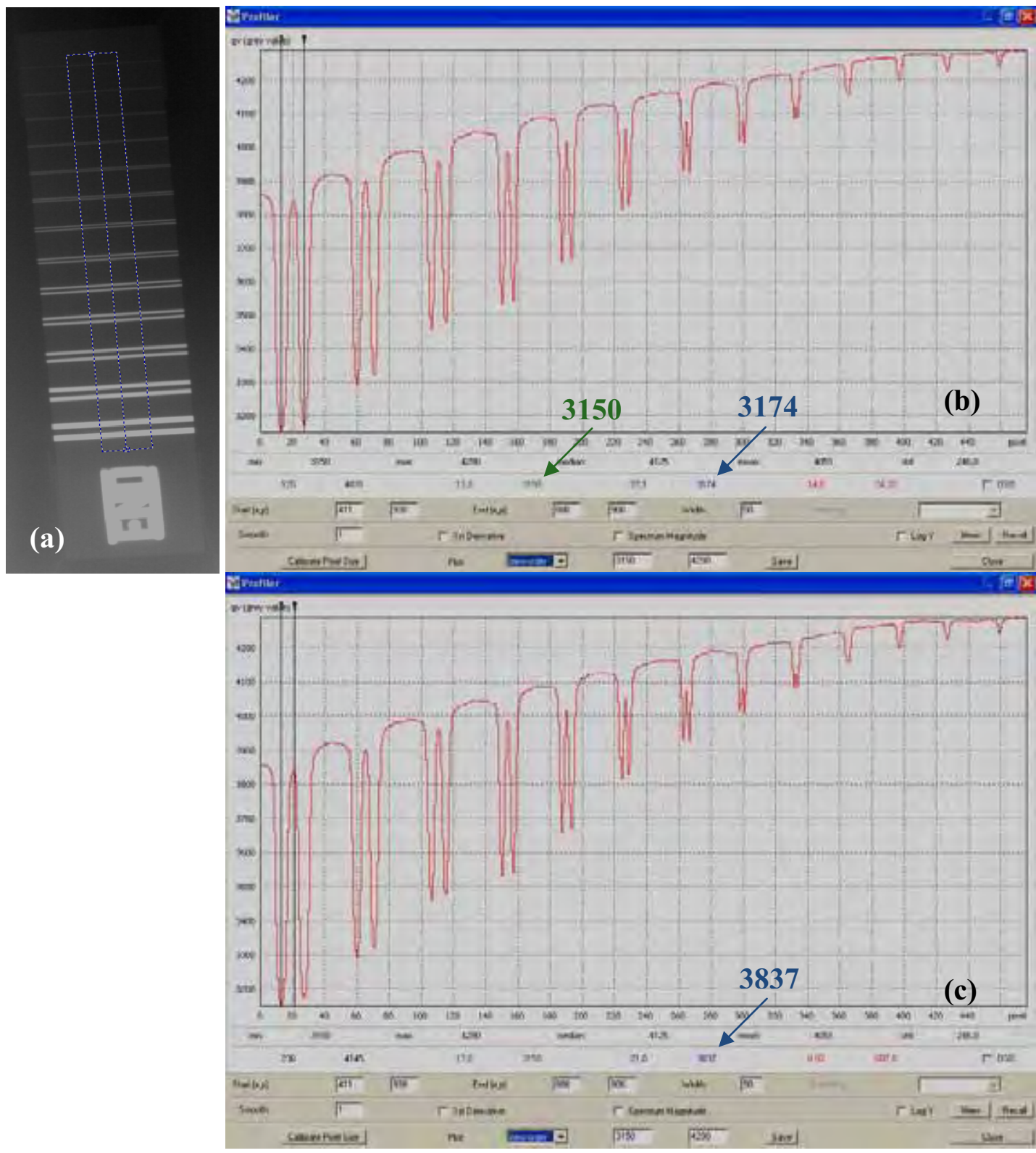

Figura 4.10 - Perfil do IQI de Arame duplo para curva MTF. 
O valor da amplitude será igual à média dos valores obtidos na Figura 4.10(b) menos o valor obtido na Figura 4.10(c).

$$
\text { Amplitude }=\frac{(3150+3174)}{2}-3837=675
$$

Esta operação deve ser repetida para cada um dos pares até que não haja separação entre os arames. A amplitude de 675 do primeiro par (Arame 1D) deve ser igualada a 100\% (MTF 100\%), o primeiro par de fios não discernível deve ter o seu valor igualado a MTF 0\%. Para os demais os valores das amplitudes da MTF em \% são obtidos através da equação abaixo (4.10).

$$
\text { MTF\% }=\frac{\text { Amplitude } \cdot \text { do } \cdot \text { par } \cdot \text { nD }}{\text { Amplitude } \cdot \text { do } \cdot \text { par } \cdot 1 \mathrm{D}} \times 100 \%
$$

De posse das percentagens de MTF, para cada par do IQI de arame duplo, deve ser elaborada uma tabela em função dos valores de pares de linhas $/ \mathrm{mm}(\mathrm{pl} / \mathrm{mm})$. Os valores de pl/mm de cada par de arame estão mostrados na Tabela 4.13.

\begin{tabular}{ccccc}
\multicolumn{2}{c}{ Tabela 4.13 - Valores dimensionais do IQI de Arame Duplo (ISO 19232-5). } \\
\hline Elemento & $\begin{array}{c}\text { Penumbra } \\
\text { (mm) }\end{array}$ & $\begin{array}{c}\text { Diâmetro do } \\
\text { Arame (mm) }\end{array}$ & $\begin{array}{c}\text { Tolerância } \\
\text { (mm) }\end{array}$ & pl/mm \\
\hline 13D & 0,10 & 0,050 & & 10,000 \\
12D & 0,13 & 0,063 & $+/-0,006$ & 7,936 \\
11D & 0,16 & 0,080 & 5,250 \\
1OD & 0,20 & 0,100 & & 3,846 \\
9D & 0,26 & 0,130 & & 3,125 \\
8D & 0,32 & 0,160 & & 2,500 \\
7D & 0,40 & 0,200 & $+/-0,010$ & 2,000 \\
6D & 0,50 & 0,250 & 1,563 \\
5D & 0,64 & 0,320 & & 1,250 \\
4D & 0,80 & 0,400 & & 1,000 \\
3D & 1,00 & 0,500 & & 0,794 \\
2D & 1,26 & 0,630 & $+/-0,020$ & 0,625 \\
1D & 1,60 & 0,800 & & \\
\hline
\end{tabular}

Continuando a construção da curva, conforme o exemplo que está sendo mostrado, na Tabela 4.14 pode-se observar os valores de X (pl/mm) e Y (MTF\%).

Tabela 4.14 - Dados para construção da curva MTF.

\begin{tabular}{cccc}
\hline Elemento & Intensidade & $\mathrm{X}(\mathrm{pl} / \mathrm{mm})$ & $\mathrm{Y}(\%)$ \\
\hline 1D & 675 & 0,625 & 100 \\
2D & 586 & 0,794 & 86,83 \\
3D & 499 & 1 & 73,88 \\
4D & 447 & 1,25 & 66,19 \\
5D & 352 & 1,563 & 52,14 \\
6D & 219 & 2 & 32,39 \\
7D & 150 & 2,5 & 22,25 \\
8D & 67 & 3,125 & 9,87 \\
9D & 38 & 3,846 & 5,64 \\
10D & & 5 & 0 \\
11D & & 6,25 & 0 \\
12D & & 7,936 & 0 \\
13D & & 10 & 0 \\
\hline
\end{tabular}


Utilizando o programa Origin 8.1 e aplicando os conceitos informados previamente, para cada espessura e na condição do IQI de arame duplo, com e sem calço metálico, pode-se construir a curva na seguinte seqüência:

Os novos valores dos dados de ajuste da curva serão mostrados, e devem ser usados na equação obtida para determinar a MTF $20 \%$.

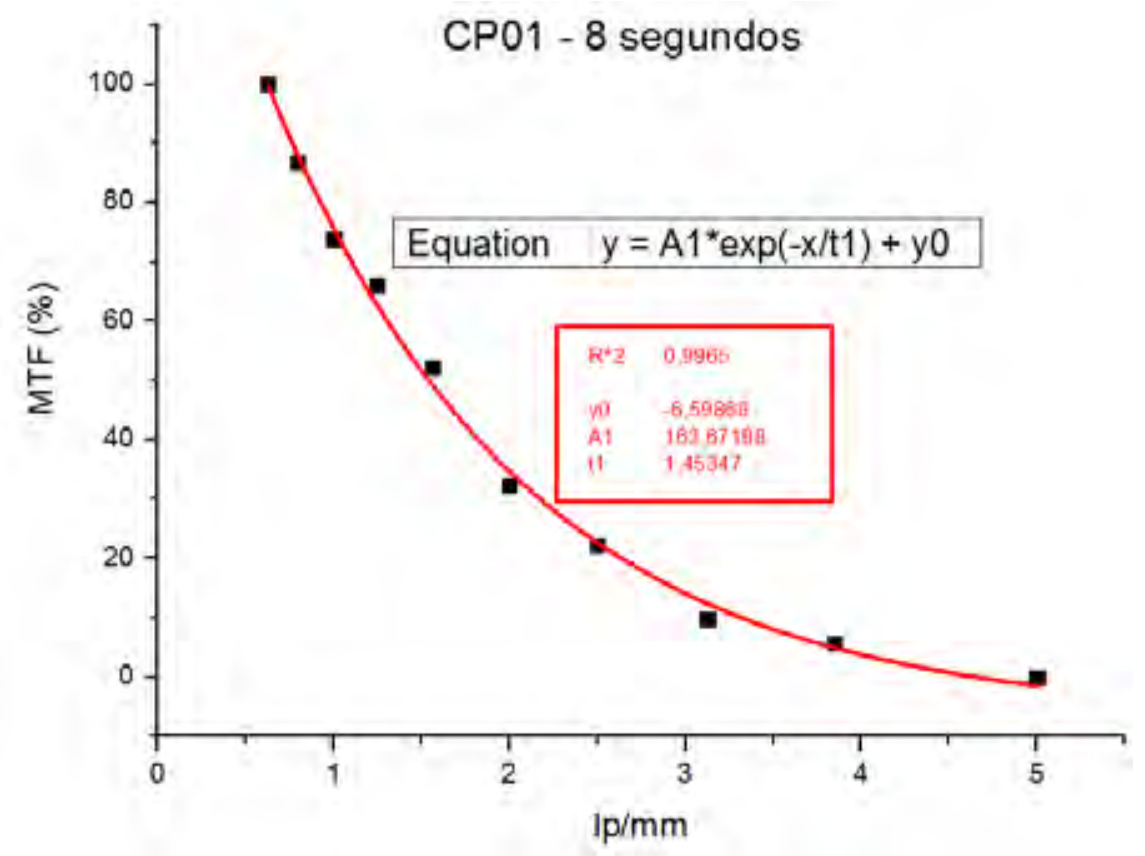

Figura 4.11 - Curva de MTF para o CP 01 com tempo de integração de 8 segundos

Como se pode observar na Figura 4.11 a partir dos dados das Tabelas 4.13 e 4.14 foi ajustada a equação 4.11 .

$$
y=A 1 \cdot e^{-x / t 1}+y 0
$$

Onde:

y = MTF, Função de Transferência de Modulação, $\mathrm{x}=$ Valor correspondente em pares de linha/mm $(\mathrm{pl} / \mathrm{mm})$.

Os valores de y0, A1 e t1, são mostrados na Figura 4.11, utilizando o calço metálico e sem sua utilização, nas 06 espessuras envolvidas e com as imagens digitais correspondentes aos tempos de integração de $1 \mathrm{~s}, 2 \mathrm{~s}, 4 \mathrm{~s}, 8 \mathrm{~s}, 16 \mathrm{~s}$ e $32 \mathrm{~s}$ para as respectivas espessuras de 4,9 mm, 6,4 mm, 9,7 mm, 19,2 mm, 25,3 mm e 32,3 mm. Estes tempos foram utilizados, pois suas imagens atenderam todas as exigências da norma ISO/DIS 10893-7. Para se obter os valores de x, correspondente a quantidade de pares de linhas/mm, a equação 4.11 foi invertida e é mostrada como a equação 4.12 . 


$$
x=-\ln \left[\frac{y-y 0}{A 1}\right] \cdot t 1
$$

Utilizando a equação (4.12) para o valor de 0,2 $\left(\mathrm{MTF}_{20 \%}\right)$ se obtém o valor correspondente de $\mathrm{x}$, em pares de linhas/mm. Para determinar o valor da resolução espacial neste ponto $\left(\mathrm{RS}_{20 \%}\right)$ utiliza-se a equação (4.10). Os valores calculados da resolução espacial estão mostrados na Tabela 4.15 .

\begin{tabular}{|c|c|c|}
\hline MTF & \multicolumn{2}{|c|}{ Resolução Espacial ( $\mu \mathrm{m})$} \\
\hline$(\%)$ & Sem calço & Com calço \\
\hline 20 & 189 & 196 \\
\hline 80 & 540 & 540 \\
\hline $\mathrm{SRB}$ & 100 & 100 \\
\hline
\end{tabular}

\subsubsection{Determinação da Sensibilidade ao Contraste, IQI do tipo Arame.}

O IQI de fio de contraste foi colocado com seus fios transversais ao eixo do cordão de solda e deslocado de forma que fosse possível avaliar seu aparecimento dos fios tanto na região da solda como no metal base, pois as normas DNV-OS-F101, API 5L e ISO 3183 exigem que a avaliação dos arames sejam feitas no cordão de solda e a ISO/DIS 10893-7 no metal base. O esquema de posicionamento do IQI de contraste do tipo arame está indicado na Figura 4.7.

\section{API 5L e ISO 3183, 2007.}

De acordo com o ANEXO E, item E4 da especificação API 5L e ISO 3183, 44 ${ }^{\underline{a}}$ Edição de 01 de Outubro de 2007, é exigido que a homogeneidade do cordão de solda deve ser examinada por meio do método radiológico usando uma fonte de raios $\mathrm{X}$, que seja capaz de criar uma imagem aceitável em um filme radiográfico ou outro meio de imagem, desde que a sensibilidade exigida pela ISO 12096 para a classe de imagem R1 seja demonstrada (ISO 12096, 1996). Quando o IQI de contraste do tipo arame de acordo com a ISO 19232-1 é utilizado, o arame essencial a ser visualizado é escolhido 
de acordo com a espessura do cordão de solda, que é a soma da espessura da parede do tubo e a altura do reforço de solda aplicável (ISO 19232-1, 2004).

Para IQI de contraste do tipo arame, a sensibilidade é obtida quando o arame essencial é claramente visível para o operador na área da solda. O número e diâmetro do arame essencial exigidos estão indicados na Tabela 4.16.

\begin{tabular}{cccc}
\multicolumn{3}{c}{ Tabela 4.16-Arame essencial para IQI de contraste de arame (API 5L, 2007) } \\
\hline Espessura (mm) & $\begin{array}{c}\text { Diâmetro do arame } \\
\text { essencial (mm) }\end{array}$ & $\begin{array}{c}\text { Número do } \\
\text { arame } \\
\text { essencial }\end{array}$ \\
\hline-- & 8 & 0,16 & 14 \\
8 & 11 & 0,20 & 13 \\
11 & 14 & 0,25 & 12 \\
14 & 18 & 0,32 & 11 \\
18 & 25 & 0,40 & 10 \\
25 & 32 & 0,50 & 9 \\
32 & 41 & 0,63 & 8 \\
\hline
\end{tabular}

DNV-OS-F101, 2007.

De acordo com a norma DNV-OS-F101, Edição de outubro de 2007, no apêndice $\mathrm{D}$, item $\mathrm{H}$ 432, as exigências para o ensaio radiográfico dos tubos fabricados são que o ensaio seja realizado de acordo com a ISO 12096, e que a classe de imagem seja R1 com IQI de fio fabricados de acordo com a ISO 19323-1. No item H 433 é aceito radioscopia, desde que o equipamento tenha demonstrado a sensibilidade e a detecção equivalente ao filme com raios X, de acordo com a ISO 12096. Na Tabela 4.17 pode-se observar o arame essencial exigido, de acordo com a espessura do cordão de solda, que é a soma da espessura da parede do tubo e a altura do reforço de solda.

\begin{tabular}{cccc}
\multicolumn{2}{c}{ Tabela 4.17 - Arame essencial exigido conforme DNV-OS-F101-2007. } \\
Ecima & Até & $\begin{array}{c}\text { Diâmetro do arame } \\
\text { essencial (mm) }\end{array}$ & $\begin{array}{c}\text { Número do } \\
\text { arame } \\
\text { essencial }\end{array}$ \\
\hline 4,5 & 10 & 0,16 & 14 \\
10 & 16 & 0,20 & 13 \\
16 & 25 & 0,25 & 12 \\
25 & 32 & 0,32 & 11 \\
32 & 40 & 0,40 & 10 \\
40 & 60 & 0,50 & 9 \\
\hline
\end{tabular}




\section{ISO/DIS 10893-7, 2009.}

Nesta proposta de norma, os seguintes parâmetros devem ser avaliados e atendidos: a sensibilidade medida com o IQI de contraste, a resolução espacial básica $\left(\mathrm{SR}_{\mathrm{B}}\right)$ e os valores mínimos da relação sinal ruído normalizado $\left(\mathrm{SNR}_{\mathrm{N}}\right)$.

Para a avaliação da sensibilidade são utilizados os IQI de contraste do tipo arame, fabricados de acordo com a ISO 19323-1 (ISO 19323-1, 2004). Deve-se observar que a seleção do IQI é feita pela espessura do metal base, ou seja, de acordo com a espessura da parede do tubo, conforme está indicado na Tabela 4.18.

Tabela 4.18 - Arame essencial proposto pela ISO/DIS 10893-7, 2009.

\begin{tabular}{|c|c|c|c|}
\hline \multicolumn{2}{|c|}{$\begin{array}{c}\text { Espessura do Metal } \\
\text { Base (mm) }\end{array}$} & \multirow{2}{*}{$\begin{array}{l}\text { Diâmetro do arame } \\
\text { essencial (mm) }\end{array}$} & \multirow{2}{*}{$\begin{array}{c}\text { Número do } \\
\text { arame } \\
\text { essencial }\end{array}$} \\
\hline Acima & Até & & \\
\hline 3,5 & 5 & 0,10 & 16 \\
\hline 5 & 7 & 0,13 & 15 \\
\hline 7 & 10 & 0,16 & 14 \\
\hline 10 & 15 & 0,20 & 13 \\
\hline 15 & 25 & 0,25 & 12 \\
\hline 25 & 32 & 0,32 & 11 \\
\hline 32 & 40 & 0,40 & 10 \\
\hline
\end{tabular}

Na Tabela 4.19 pode-se observar os valores de penumbra $\left(\mathrm{U}_{\mathbf{g}}\right)$ e a resolução espacial básica $\left(\mathrm{SR}_{\mathbf{B}}\right)$, exigidos de acordo com a espessura do metal base.

Tabela 4.19 - Arame duplo proposto pela ISO/DIS 10893-7, 2009.

\begin{tabular}{ccccc}
\hline \multicolumn{2}{c}{$\begin{array}{c}\text { Espessura do Metal } \\
\text { Base (mm) }\end{array}$} & Penumbra & $\begin{array}{c}\text { Resolução } \\
\text { Espacial } \\
\text { Básica }\end{array}$ & $\begin{array}{c}\text { Diâmetro do Arame } \\
\text { e Espaçamento } \\
\text { (mm) }\end{array}$ \\
\hline 4 & 8 & 0,13 & $12 \mathrm{D}$ & 0,063 \\
8 & 12 & 0,16 & $11 \mathrm{D}$ & 0,080 \\
12 & 40 & 0,20 & $10 \mathrm{D}$ & 0,100 \\
\hline
\end{tabular}

É importante salientar que, de acordo com a proposta da norma ISO/DIS 10893-7, é possível utilizar o "Princípio da compensação" que prevê a compensação da resolução espacial básica, medida pelo aparecimento de arame simples mais fino, ou 
seja, se os dois indicadores de qualidade de imagem, tanto o simples como o duplo não forem obtidos, um aumento da visibilidade do contraste através do arame simples, pode compensar valores experimentais mais altos de penumbra exigidos. Exemplificando, se o 12D e o arame simples 14 não são obtidos ao mesmo tempo para um ajuste específico, uma sensibilidade de detecção igual é conseguida se o arame $16 \mathrm{e}$ 10D são obtidos.

\subsubsection{Determinação da Relação Sinal Ruído Normalizado, $\mathrm{SNR}_{\mathrm{N}}$ •}

Para medição da relação sinal ruído das imagens radiográficas foi utilizado o software ISee!, do BAM, e os valores mínimos de $\mathrm{SNR}_{\mathrm{N}}$ especificados pela ISO/DIS 10893-7, medido no metal base, para as classes A e B são de 70 e 100 respectivamente. $\mathrm{O}$ valor da relação sinal ruído normalizado na região adjacente a solda da imagem é calculado pela equação 4.13. Para detalhe da medida do $\mathrm{SNR}_{\mathbf{N}}$ as normas EN 14784-1, ASTM E 2446 podem ser consultadas (EN 14784-1, 2005; ASTM E 2446, 2005).

$$
S N R_{N}=\frac{S N R \times 88,6 \times \mu m}{S R_{B}}
$$

Foram medidos 06 pontos na região do metal base próximos ao cordão de solda, sendo que a distribuição das medições em cada uma das imagens está esquematizada na Figura 4.12.

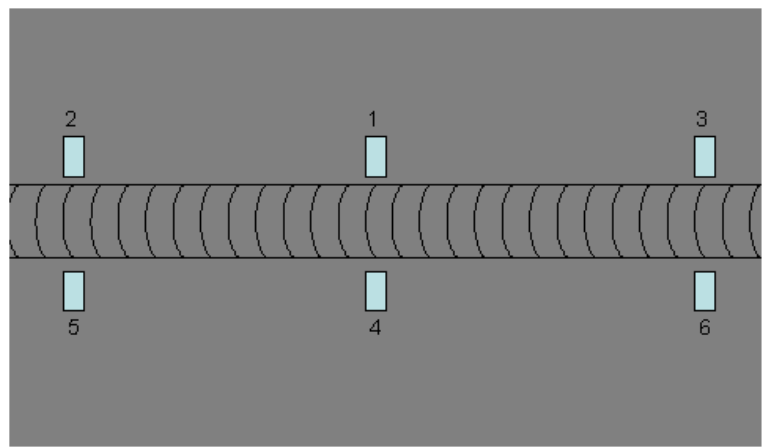

Figura 4.12 - Esquema de medição dos valores de $\mathrm{SNR}_{\mathbf{N}}$.

Para medição destes valores é recomendado que se utilize uma janela de medição de 1100 (20x55) e, para o valor da resolução espacial básica, deve-se utilizar o resultado experimental do diâmetro, conseguido do fio duplo pela técnica empregada (EN 14784-1, 2005). Na Figura 4.13 pode ser visualizado um exemplo de medição do 
valor da relação sinal ruído normalizado $\left(\mathrm{SNR}_{\mathrm{N}}\right)$ em um local próximo a região da solda, onde na parte experimental se obteve a resolução espacial básica 10D, cujo diâmetro do arame é de $0,100 \mathrm{~mm}$. O valor do $\mathrm{SNR}_{\mathrm{N}}$ obtido para o procedimento deste exemplo é de 498.

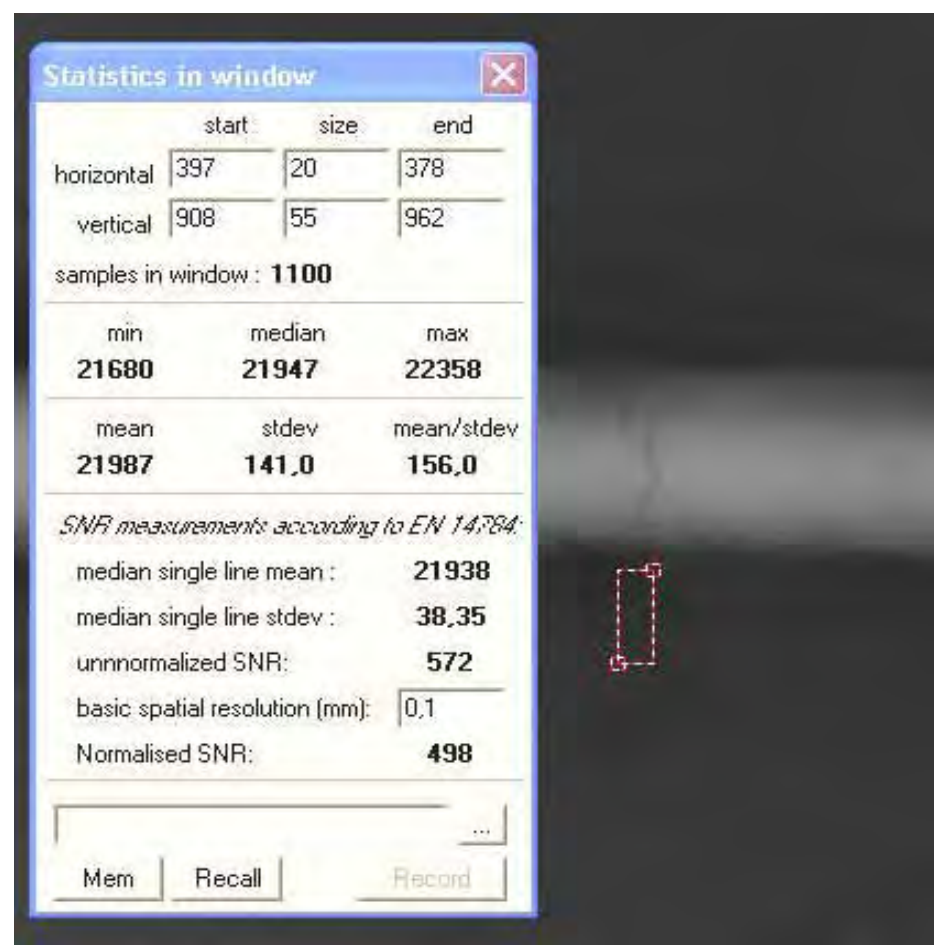

Figura 4.13 - Medição dos valores de $\mathrm{SNR}_{\mathrm{N}}$.

\subsubsection{Verificação da sensibilidade a defeitos reais.}

Outro parâmetro importante, apesar de não ser diretamente exigido pelas normas, é a comprovação de que a técnica digital tem no mínimo a mesma sensibilidade da técnica convencional a defeitos críticos reais, tais como trinca, falta de fusão, falta de penetração, porosidade e inclusão de escoria.

Para isto foram criados os 20 corpos-de-prova com estes tipos de defeitos, nas 06 espessuras envolvidas.

A metodologia empregada é de comparação entre as imagens escaneadas e as imagens geradas digitalmente "como obtidas" pelo sistema sem a aplicação de qualquer tipo de melhoria de imagem, em um monitor em uma sala com penumbra e que atendia as características mínimas exigidas pela norma ISO/DIS 10893-7, ou seja, 
mínimo brilho de $250 \mathrm{~cd} / \mathrm{m}^{2}, 256$ níveis de cinza, razão de densidade de luz de 1:250 e mínimo 1.000 x 1.000 pixels com tamanho máximo de $0,25 \mathrm{~mm}$.

Para fins de apresentação nestas imagens, foram aplicados um filtro passa alto que não requer qualquer tipo de ajuste de parâmetros, através do software ISee!, criado pelo BAM, e que possibilita a comparação das duas técnicas, nas imagens que foram anexadas aos resultados obtidos.

\subsection{Certificação do pessoal}

Visando dar uma melhor confiabilidade aos laudos apresentados, os resultados foram analisados por pessoas devidamente qualificadas e certificadas conforme NBR ISO 9712, ISO 9712, e EN 473 (NBR ISO 9712, 2004; ISO 9712, 2005; EN 473 2005). As radiografias convencionais e as imagens das radiografias digitais foram avaliadas pelo doutorando e depois confrontadas com mais dois inspetores qualificados e certificados conforme a NBR ISO 9712 pelo Sistema Nacional de Qualificação e Certificação (SNQC) de inspetores de ensaios não destrutivos por meio da Associação Brasileira de Ensaios Não Destrutivos e Inspeção - ABENDI (NBR ISO 9712, 2004). 


\section{Capítulo 5}

\section{Resultados e discussões}

Conforme descrito no Capítulo 4, várias análises foram realizadas nos 20 corposde-prova preparados para este trabalho que estão divididos nos seguintes itens: análise química e ensaio de tração das chapas utilizadas nos corpos-de-prova e ensaio radiográfico convencional e digital no cordão de solda e na região do metal base.

Tanto a técnica convencional, como a digital, foi avaliada e comparada, em termos de resolução espacial básica $\left(\mathrm{SR}_{\mathrm{B}}\right)$ utilizando o método do IQI de arame duplo, a sensibilidade do IQI de contraste do tipo arame e a sensibilidade à detecção de defeitos reais. Adicionalmente, as imagens geradas pela técnica digital foram avaliadas em termos de valores da relação sinal ruído normalizado $\left(\mathrm{SNR}_{\mathrm{N}}\right)$, da $\mathrm{SR}_{\mathrm{B}}$ pelo método da freqüência de transferência de modulação (MTF). Finalmente foram realizadas comparações entre os tempos de exposição e de integração, as exposições relativas e a comparação da redução dos níveis de radiação gerados utilizando-se cada uma das técnicas. A seguir, são apresentados os resultados e as respectivas discussões.

\subsection{Ensaio de tração do material}

Em termos de propriedades mecânicas, no ensaio de tração as chapas utilizadas apresentaram os valores indicados na Tabela 5.1.

Tabela 5.1. Valores obtidos do ensaio de tração dos corpos-de-prova.

\begin{tabular}{lcc}
\hline Propriedade & Grau X60 & Grau X70 \\
\hline Limite de Resistência, psi & 81.275 & 94.047 \\
Limite de Escoamento Máximo (0,5\%), psi & 66.156 & 74.599 \\
Alongamento, \% & 56,3 & 39,4 \\
Relação LE/LR, Máximo & 0,81 & 0,79 \\
\hline
\end{tabular}

Os valores mostrados atendem as exigências da especificação API 5L nos graus X60 e X70, conforme está indicado na Tabela 4.1. 


\subsection{Análise química do material}

Os corpos-de-prova foram preparados com chapas fabricadas de acordo com a especificação API 5L, nos graus X60 e X70. Na Tabela 5.2 podem-se observar os resultados das análises químicas realizadas.

Tabela 5.2. Análise química dos corpos-de-prova.

\begin{tabular}{lcc}
\hline \multicolumn{3}{c}{ Anásile Química dos Corpos-de-prova } \\
\hline Elemento & \% em Peso, Máximo \\
& Grau X60 & Grau X70 \\
Carbono & 0,07 & 0,15 \\
Manganês & 1,38 & 0,83 \\
Fósforo & 0,016 & 0,024 \\
Enxofre & 0,003 & 0,014 \\
Nióbio & 0,055 & 0,001 \\
Vanádio & 0,031 & 0,001 \\
Titânio & 0,016 & 0,001 \\
\hline
\end{tabular}

Os valores encontrados de carbono, manganês, fósforo, enxofre, nióbio, vanádio e titânio no material dos corpos-de-prova, atendem as exigências da especificação API 5L nos graus X60 e X70 para PSL1, conforme está indicado na Tabela 4.2. A soma dos valores do teor de nióbio, vanádio e titânio para o material grau X60, de 0,102\%, e X70, de 0,003\%, estão abaixo do valor máximo permitido de $0,15 \%$.

\subsection{Avaliação pelo ensaio radiográfico}

Em cada um dos 20 corpos-de-prova foi executado o ensaio radiográfico aplicando a técnica convencional e a técnica digital. Na técnica convencional, as radiografias foram analisadas em negatoscópio apropriado de acordo com a norma ISO/DIS 10893-6. Na técnica digital, as imagens foram arquivadas na forma "como obtida", sem a aplicação de nenhum tipo de melhoria de imagem e os resultados apresentados de sensibilidade e comparação dos defeitos foram analisados em equipamento atendendo as exigências da norma ISO/DIS 10893-7.

A seguir, serão apresentados os resultados e discussões para os 39 experimentos realizados, avaliando-se os parâmetros: resolução espacial básica $\left(\mathrm{SR}_{\mathrm{B}}\right)$, sensibilidade 
ao IQI de contraste de arame, relação sinal ruído normalizado $\left(\mathrm{SNR}_{\mathrm{N}}\right)$, a sensibilidade a defeitos reais, a comparação entre os tempos de exposição e os tempos de integração e a comparação da redução do nível de radiação para a técnica convencional e digital.

\subsubsection{Resolução espacial básica, $\mathrm{SR}_{\mathrm{B}}$}

Os valores da resolução espacial básica, $\mathrm{SR}_{\mathrm{B}}$ e da penumbra, $\mathrm{U}_{\mathrm{g}}$, foram obtidas experimentalmente através das imagens escaneadas dos filmes e as geradas no caso da radiografia digital. Utilizando o IQI de arame duplo colocado do lado da fonte e com o auxílio da linha de perfil de medição do nível de cinza se determinou o número do arame duplo obtido e assim se obteve valor de penumbra correspondente.

No caso da radiografia digital utilizou-se um IQI de arame duplo, colocado diretamente no metal base e outro, com calço metálico para compensar a altura do reforço de solda, de cada corpo-de-prova.

Além disso, determinou-se os valores da resolução espacial básica pelo método da Função de Transferência de Modulação (MTF) de acordo com a EN 14784-1, para a comparação com os valores obtidos pela leitura direta no IQI duplo (EN 14784-1, 2005).

Na técnica convencional as 40 radiografias obtidas com filmes Kodak M100 e AGFA D4 foram avaliados como imagem digital após a digitalização dos filmes.

$\mathrm{Na}$ Tabela 5.3 estão descritos os valores calculados da penumbra, máxima penumbra permitida, as resoluções espaciais básicas, $\mathbf{S R}_{\mathbf{B}}$ experimentais e os respectivos valores de penumbra, $\mathrm{U}_{\mathrm{g}}$. 
Tabela 5.3 - Resolução Espacial Básica $\left(\mathrm{SR}_{\mathrm{B}}\right)$ para a Técnica Convencional.

\begin{tabular}{|c|c|c|c|c|}
\hline \multirow{3}{*}{$\begin{array}{l}\text { Espessura } \\
\text { do CP } \\
(\mathrm{mm})\end{array}$} & \multirow{3}{*}{$\begin{array}{l}\text { Penumbra } \\
\text { Calculada } \\
\text { Ug }(\mu \mathrm{m})\end{array}$} & \multirow{3}{*}{$\begin{array}{c}\text { Máxima Penumbra } \\
\text { ISO/DIS 10893-6 Classe B } \\
\mathrm{Ug}(\mu \mathrm{m})\end{array}$} & \multicolumn{2}{|c|}{ Experimental } \\
\hline & & & SRB & Ug \\
\hline & & & $(\mu \mathrm{m})$ & $(\mu \mathrm{m})$ \\
\hline 4,9 & 50 & 120 & $12 \mathrm{D}(63)$ & 130 \\
\hline 6,4 & 50 & 130 & $12 \mathrm{D}(63)$ & 130 \\
\hline 9,7 & 80 & 150 & $12 \mathrm{D}(63)$ & 130 \\
\hline 19,2 & 150 & 190 & $11 \mathrm{D}(80)$ & 160 \\
\hline 25,3 & 200 & 200 & $10 \mathrm{D}(100)$ & 200 \\
\hline 32,3 & 220 & 220 & $10 \mathrm{D}(100)$ & 200 \\
\hline
\end{tabular}

Na Figura 5.1, estão mostrados os valores de $\mathrm{SR}_{\mathrm{B}}$, encontrados, para cada uma das 6 espessuras do experimento.

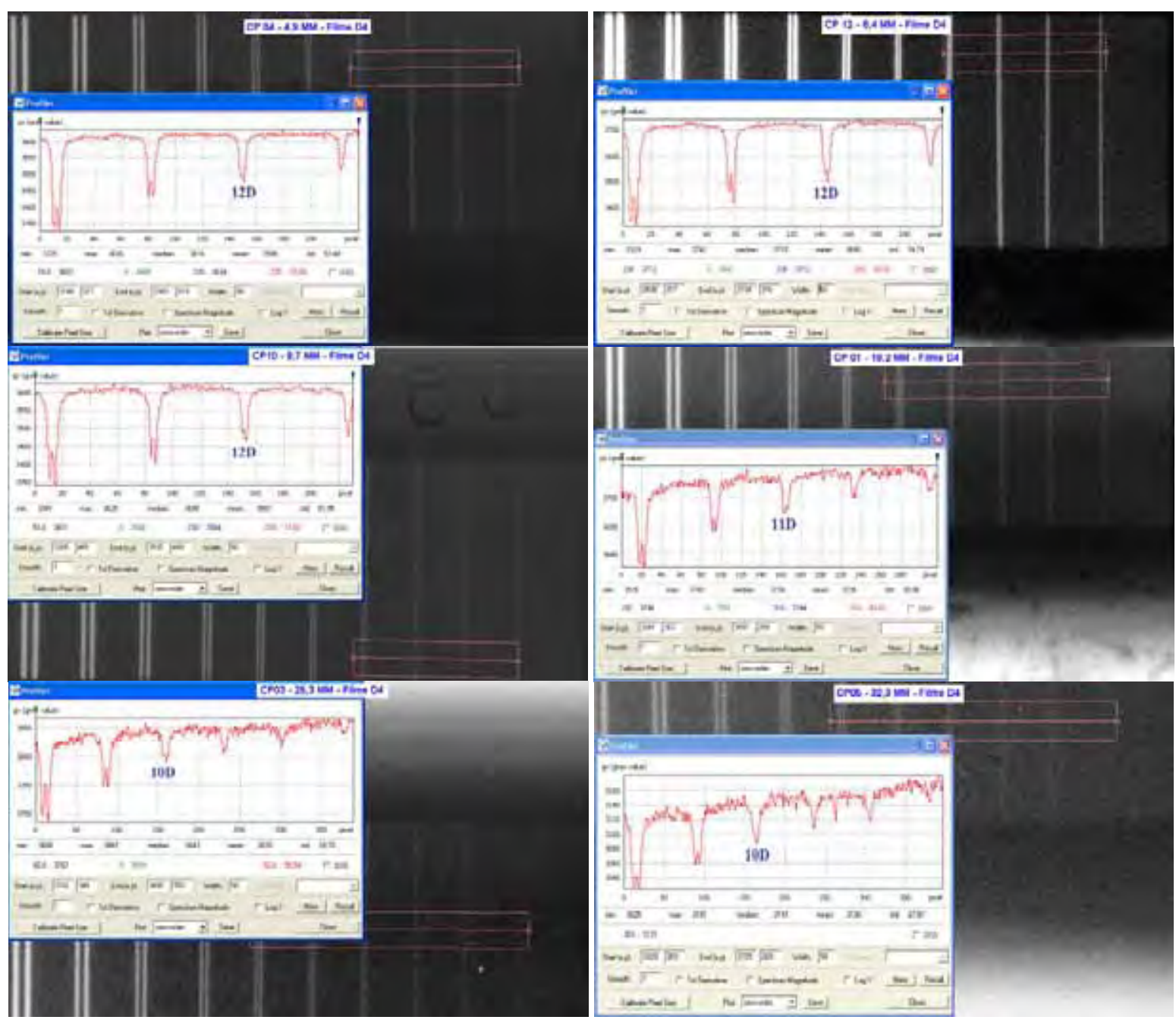

Figura 5.1 - Medições da resolução espacial básica para a técnica convencional. 
Como pode-se observar na Tabela 5.3 e na Figura 5.1, os valores obtidos de $\mathrm{SR}_{\mathrm{B}}$ são totalmente dependentes da espessura dos corpos-de-prova e que os valores calculados da resolução espacial básica estão dentro dos valores máximos propostos pela ISO/DIS 10893-6. Também se observa que experimentalmente exceto para a espessura 4,9 mm, as espessuras atendem os valores máximos propostos.

No caso da técnica digital, os valores obtidos da resolução espacial básica $\left(\mathrm{SR}_{\mathrm{B}}\right)$ propostos pela norma ISO/DIS 10893-7, os obtidas experimentalmente nas imagens geradas para cada espessura, tempo de integração, distância foco detector (DFD), distância objeto detector (DOD), além dos valores experimentais de penumbra $\left(\mathrm{U}_{\mathrm{g}}\right)$ obtidos, estão mostrados na Tabela 5.4 .

Tabela 5.4 - Resolução Espacial Básica $\left(\mathrm{SR}_{\mathrm{B}}\right)$ para a Técnica Digital - Experimental

\begin{tabular}{|c|c|c|c|c|c|}
\hline \multirow{2}{*}{$\begin{array}{c}\text { Espessura } \\
\text { (mm) }\end{array}$} & \multicolumn{2}{|c|}{ Local - Metal Base } & \multirow{2}{*}{$\begin{array}{r}\text { Exigido } \\
\text { SRB }(\mu \mathrm{m})\end{array}$} & \multicolumn{2}{|c|}{ Experimental } \\
\hline & Com calço & Sem calço & & $\mathrm{SRB}(\mu \mathrm{m})$ & $\mathrm{Ug},(\mu \mathrm{m})$ \\
\hline 4,9 & $\mathrm{x}$ & $\mathrm{x}$ & $12 \mathrm{D}(63)$ & $10 \mathrm{D}(100)$ & 200 \\
\hline 6,4 & $\mathrm{x}$ & $\mathrm{x}$ & $12 \mathrm{D}(63)$ & $10 \mathrm{D}(100)$ & 200 \\
\hline 9,7 & $\mathrm{x}$ & $\mathrm{x}$ & $11 \mathrm{D}(80)$ & $10 \mathrm{D}(100)$ & 200 \\
\hline 19,2 & $\mathrm{x}$ & $\mathrm{x}$ & $10 \mathrm{D}(100)$ & $10 \mathrm{D}(100)$ & 200 \\
\hline 25,3 & $\mathrm{x}$ & $\mathrm{x}$ & $10 \mathrm{D}(100)$ & $10 \mathrm{D}(100)$ & 200 \\
\hline 32,2 & $\mathrm{x}$ & $\mathrm{x}$ & $10 \mathrm{D}(100)$ & $10 \mathrm{D}(100)$ & 200 \\
\hline
\end{tabular}

$\mathrm{Na}$ Tabela 5.4 pode-se observar que o valor da resolução espacial básica $\left(\mathrm{SR}_{\mathrm{B}}\right)$ obtido experimentalmente para as espessuras de 4,9 mm, 6,4 $\mathrm{mm}$ e 9,7 mm não atendem as exigências. Porém, conforme prevê a norma ISO 10893-7, é possível utilizar o "Princípio da Compensação" e assim se o IQI de contraste do tipo arame tiver um aumento de visibilidade na mesma proporção dos valores mais baixos da resolução espacial básica é entendido que as exigências foram atendidas. Desta forma, os requisitos de $\mathrm{SR}_{\mathrm{B}}$ da espessura 4,9 $\mathrm{mm}$ e $6,4 \mathrm{~mm}$ são atendidos se os IQI's de contraste apresentarem, no mínimo, 02 arames mais finos e no caso da espessura 9,7 mm, no mínimo de 01 arame mais fino. Na Figuras 5.2 e 5.3 podem-se observar as medições realizadas experimentalmente e o número do arame duplo obtido do IQI que foi colocado no metal base com e sem o calço metálico. 

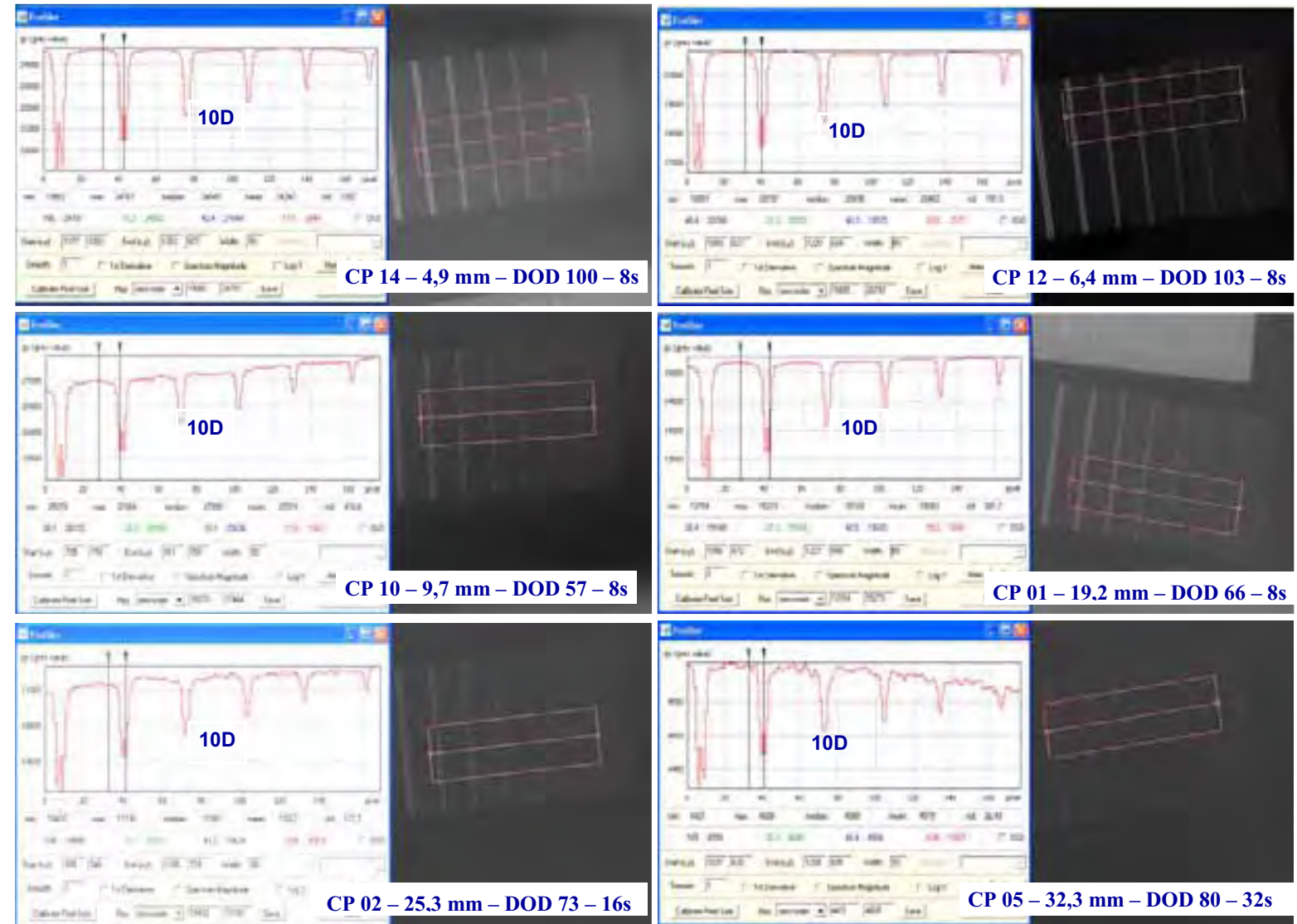

Figura 5.2 - Medições da resolução espacial básica para a técnica digital, sem calço metálico.

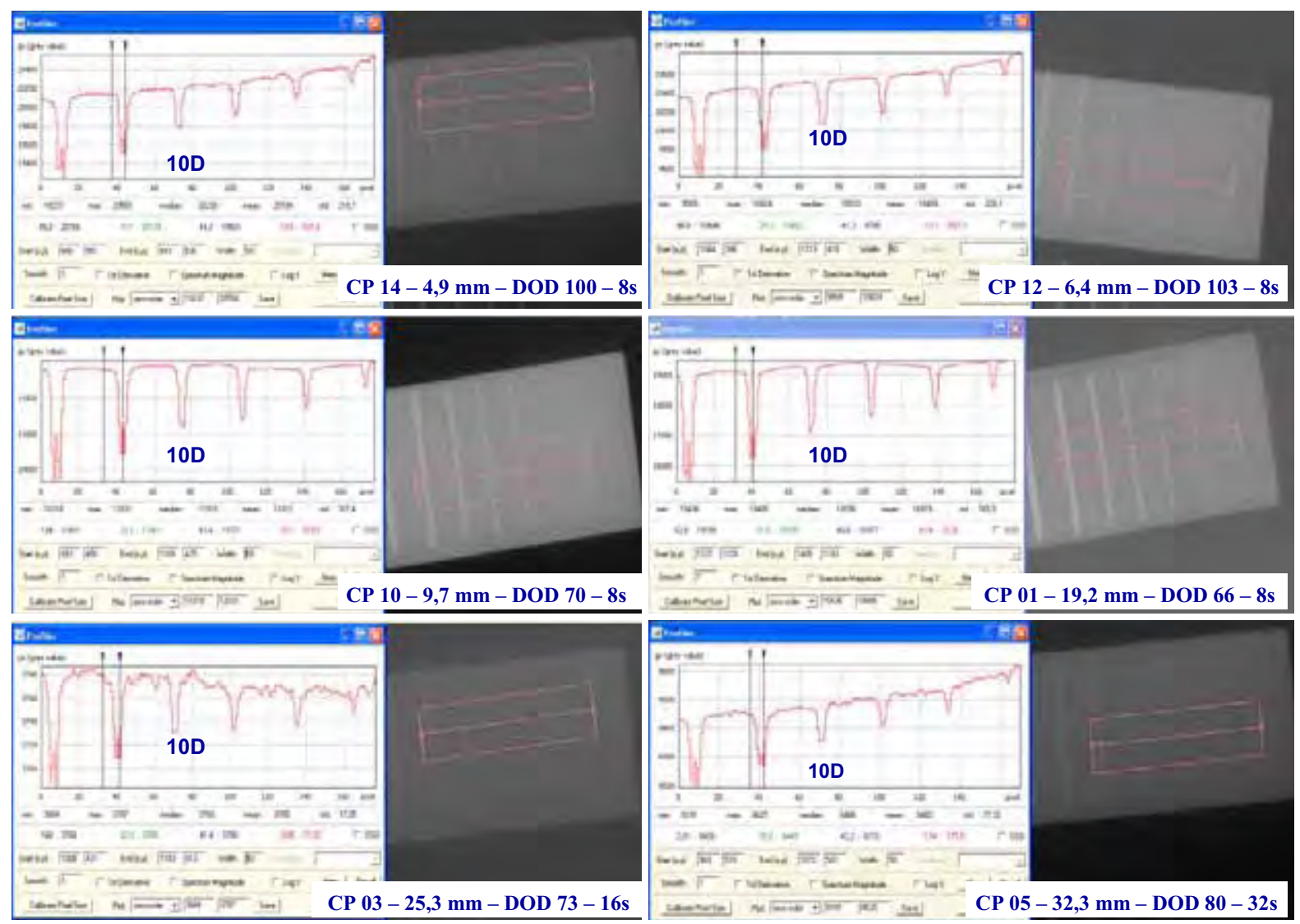

Figura 5.3 - Medições da resolução espacial básica para a técnica digital, com calço metálico. 
A fim de comparar os resultados da resolução espacial básica, $\mathrm{SR}_{\mathrm{B}}$ obtida pelo método experimental, foram determinados para as 06 espessuras, os valores pelo método da Função de Transferência de Modulação (MTF), de acordo com a EN 147841 (EN 14784-1, 2005). A Figura 5.4 mostra as figuras obtidas.

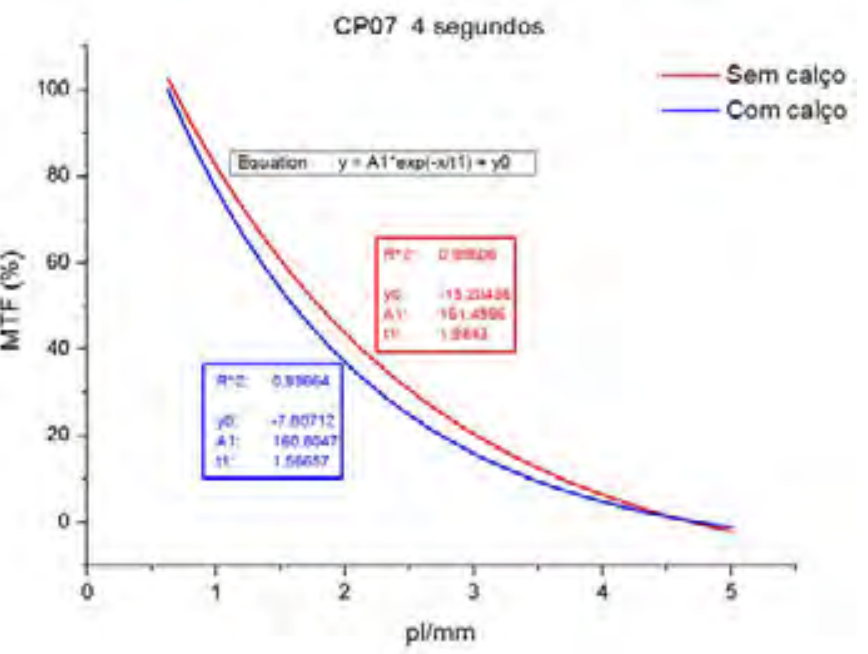

(a) Espessura 4,9 mm

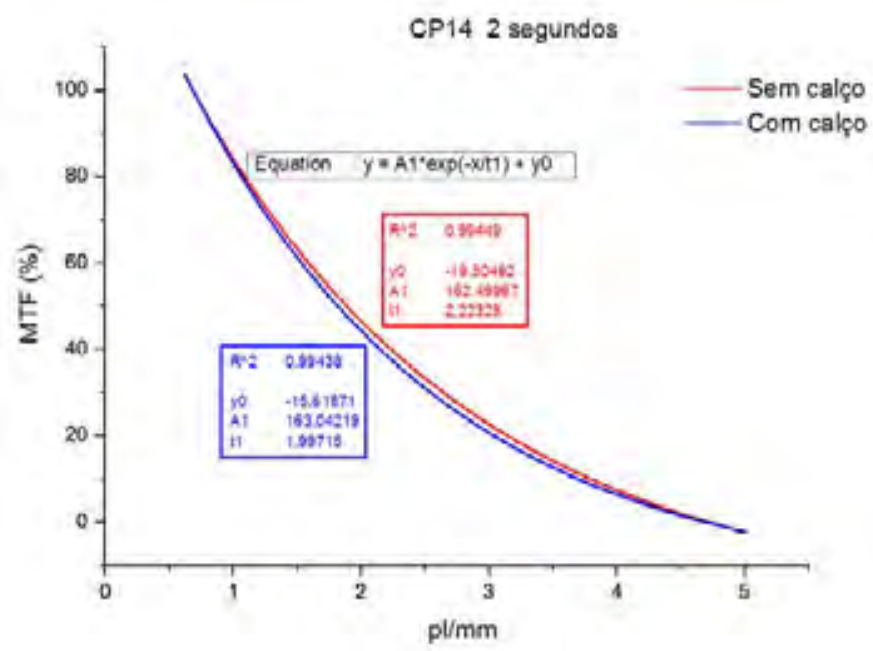

(b) Espessura 6,4 mm

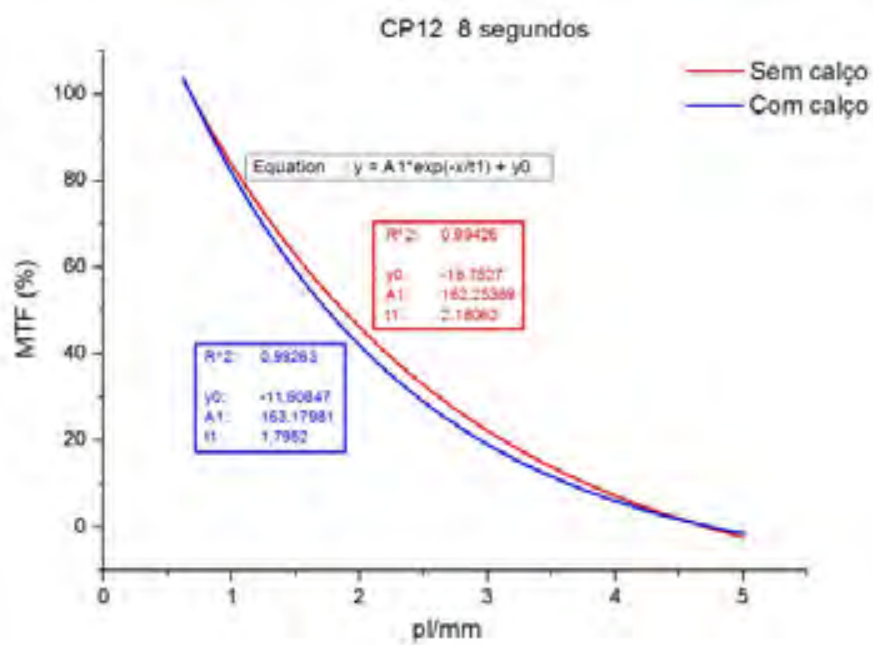

(c) Espessura 9,7 mm

Figura 5.4 - Curvas MTF - (a) CP07. (b) CP14. (c) CP12. 
(d) Espessura 19,2 $\mathrm{mm}$
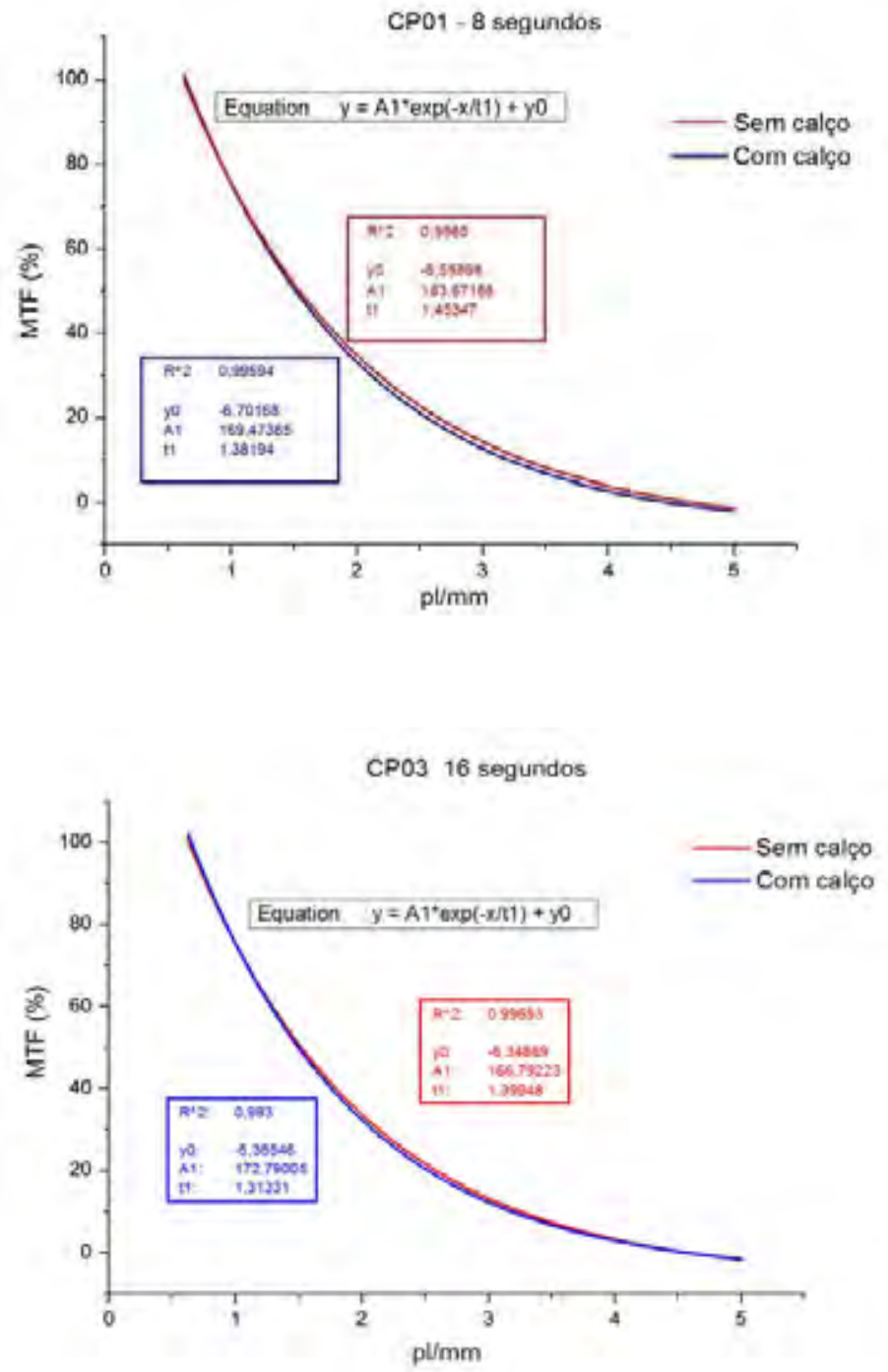

(e) Espessura 25,3 mm

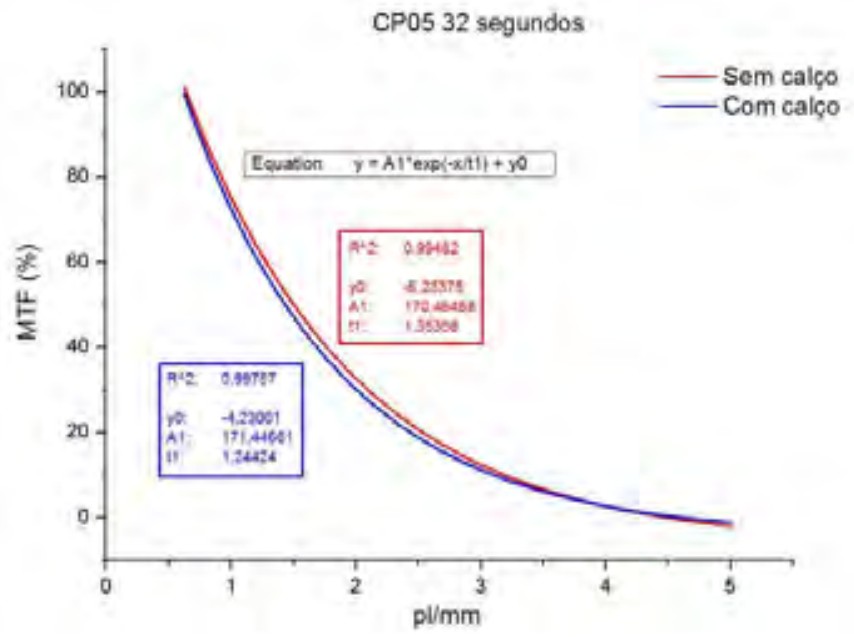

(f) Espessura 32,3 mm

Figura 5.4 (Continuação) Curvas MTF - (d) CP01. (e) CP03. (f) CP05. 
Como se pode observar na Figura 5.4(a) até (f), para todas as curvas foi gerada a mesma equação 5.1 .

$$
y=A 1 \cdot e^{-x / t 1}+y 0
$$

Onde:

y = MTF, Função de Transferência de Modulação,

$\mathrm{x}=$ Valor correspondente em pares de linhas $/ \mathrm{mm}(\mathrm{pl} / \mathrm{mm})$.

Os valores de y0, A1 e t1, são mostrados na Figura 5.4(a) até (f), utilizando o calço metálico e sem sua utilização, nas 06 espessuras envolvidas e com as imagens digitais correspondentes aos tempos de integração de $1 \mathrm{~s}, 2 \mathrm{~s}, 4 \mathrm{~s}, 8 \mathrm{~s}, 16 \mathrm{~s}$ e $32 \mathrm{~s}$ para as respectivas espessuras de 4,9 mm, 6,4 mm, 9,7 mm, 19,2 mm, 25,3 mm e 32,3 mm. Estes tempos foram utilizados, pois suas imagens atenderam todas as exigências da norma ISO/DIS 10893-7. Para se obter os valores de x, correspondente a quantidade de pares de linhas/mm, a equação (5.1) foi invertida e é mostrada como a equação 5.2.

$$
x=-\ln \left[\frac{y-y 0}{A 1}\right] \cdot t 1
$$

Utilizando a equação (5.2) para o valor de $0,2\left(\mathrm{MTF}_{20 \%}\right)$ obtém-se o valor correspondente de $\mathrm{x}$, em pares de linha/mm.

Para determinar o valor da resolução espacial neste ponto $\left(\mathrm{RS}_{20 \%}\right)$ utiliza-se a equação (4.10). Os valores calculados da resolução espacial estão mostrados na Tabela 5.5 .

Tabela 5.5 - Valores da resolução espacial do sistema - MTF 20\%.

\begin{tabular}{ccccc}
\hline $\begin{array}{c}\text { Espessura } \\
(\mathbf{m m})\end{array}$ & Corpo-de Prova & $\begin{array}{c}\text { Tempo de } \\
\text { Integração, } \mathbf{s}\end{array}$ & \multicolumn{2}{c}{ Resolução Espacial, $\boldsymbol{\mu m}$} \\
com calço & sem calço \\
\hline 4,9 & $\mathrm{CP} 14$ & 2 & 159 & 165 \\
6,4 & $\mathrm{CP} 07$ & 4 & 165 & 182 \\
9,7 & $\mathrm{CP} 12$ & 8 & 160 & 170 \\
19,2 & $\mathrm{CP} 01$ & 8 & 189 & 196 \\
25,3 & $\mathrm{CP} 03$ & 16 & 194 & 198 \\
32,3 & $\mathrm{CP} 05$ & 32 & 197 & 205 \\
\hline
\end{tabular}


Comparando os valores de resolução espacial, obtidos experimentalmente, mostrados na Tabela 5.4 e os valores calculados pelo método da Função de Transferência de Modulação (MTF), que estão mostrados na Tabela 5.5, conclui-se que os valores experimentais obtidos de $100 \mu \mathrm{m}$ (10D), são menores do que os calculados pelo método de Transferência de Modulação. Conforme prevê a norma EN 14784-1, se existirem diferenças entre o valor obtido pelo método MTF e o método experimental do arame duplo, o método do arame duplo deverá ser utilizado (EN 14784-1, 2005).

Notar que, para as situações avaliadas, a técnica convencional apresentou, experimentalmente, para as espessuras de 4,9,6,4, 9,7 e 19,2 $\mathrm{mm}$ valores menores da resolução espacial básica $\left(\mathrm{SR}_{\mathrm{B}}\right)$ de 65 e $80 \mu \mathrm{m}(12 \mathrm{D}$ e $11 \mathrm{D})$ do que os encontrados na técnica digital que foram de $100 \mu \mathrm{m}(10 \mathrm{D})$. Os valores de penumbra encontrados na técnica convencional foram de 130 e $160 \mu \mathrm{m}$ e, na técnica digital, o valor encontrado foi de $200 \mu \mathrm{m}$. Nas demais espessuras não houve diferenças da resolução espacial básica $\left(\mathrm{SR}_{\mathrm{B}}\right)$ e da penumbra comparando-se as técnicas.

No caso da técnica digital, ao contrario da técnica convencional, a penumbra das imagens geradas pelo sistema digital testado é independente da espessura do corpo-deprova avaliado e o seu valor é determinado pela resolução espacial do detector utilizado. Em todos os casos o valor de penumbra obtido foi de $200 \mu \mathrm{m}$. O detector plano PaxScan 2520V, tem o valor do tamanho do pixel de $127 \mu \mathrm{m}$, equivalente a resolução espacial básica de aproximadamente $130 \mu \mathrm{m}$ (penumbra de $260 \mu \mathrm{m}$ ), fator de ampliação geométrica de até 1,19 .

Com isto, pode-se concluir que para os experimentos realizados, em todas as espessuras envolvidas, os valores da resolução espacial finais são de $100 \mu \mathrm{m}$ (10D) e que, de acordo com o princípio da compensação, como prevê a norma ISO/DIS 108937, as exigências para a sensibilidade ao IQI de contraste de arame passam a ser consideradas conforme estão mostrados na Tabela 5.6. 
Tabela 5.6 - Exigência do IQI de contraste para IQI de arame duplo 10D - Técnica Digital.

\begin{tabular}{ccc}
\hline Espessura & $\begin{array}{c}\text { IQI de Contraste e Duplo } \\
\text { Exigidos } \\
\text { ISO/DIS 10893-7 } \\
\text { Classe B }\end{array}$ & $\begin{array}{c}\text { IQI de Contraste e Duplo } \\
\text { Exigidos ISO/DIS 10893-7 } \\
\text { Classe B }\end{array}$ \\
\hline 4,9 & $16-12 \mathrm{D}$ & $\begin{array}{c}\text { Para IQI 10D) } \\
\text { (mm }\end{array}$ \\
6,4 & $15-12 \mathrm{D}$ & $17-10 \mathrm{D}$ \\
9,7 & $14-11 \mathrm{D}$ & $15-10 \mathrm{D}$ \\
19,2 & $13-10 \mathrm{D}$ & $13-10 \mathrm{D}$ \\
25,3 & $12-10 \mathrm{D}$ & $12-10 \mathrm{D}$ \\
32,3 & $11-10 \mathrm{D}$ & $11-10 \mathrm{D}$ \\
\hline
\end{tabular}

\subsubsection{Sensibilidade ao IQI de contraste do tipo arame}

A sensibilidade radiográfica medida pelo indicador de qualidade de imagem de contraste do tipo arame foi avaliada tanto na técnica convencional como na digital baseando-se nas normas e especificações API 5L, ISO 3183 de 2007, ISO/DIS 10893-6 Classe B de 2009 e a DNV-OS-F101, edição de 2007.

É importante observar que há uma diferença básica entre as normas, pois os requisitos da norma ISO/DIS 10893-6 são para que as medições sejam feitas com os arames colocados no metal base e já as demais normas estabelecem que as avaliações sejam feitas sobre o cordão de solda, ou seja, incluem a altura do reforço de solda. Esta regra faz com que se obtenham diferentes resultados em termos de sensibilidade.

Na técnica convencional a sensibilidade do IQI de contraste de arame foi verificada, diretamente em um negatoscópio e os resultados encontrados em termos de arame visível e seus respectivos diâmetros, tanto na região do metal base como na região do cordão de solda, estão mostrados na Tabela 5.7 para os filmes Kodak M100 e AGFA D4. Nesta tabela pode-se também observar as exigências das normas envolvidas. 
Tabela 5.7 - Arame exigido e experimental - Técnica convencional, filme AGFA D4 e KODAK M100

\begin{tabular}{|c|c|c|c|c|c|c|c|c|c|}
\hline \multirow{2}{*}{$\begin{array}{l}\text { Espessura } \\
\text { Metal Base } \\
\quad(\mathrm{mm})\end{array}$} & \multirow{2}{*}{$\mathbf{C P}$} & \multirow{2}{*}{$\begin{array}{c}\text { Espessura } \\
\text { na Solda } \\
(\mathrm{mm})\end{array}$} & \multirow{2}{*}{$\begin{array}{c}\text { Exigido } \\
\text { API 5L } \\
\text { ISO 3183 } \\
\text { Solda (mm) } \\
\end{array}$} & \multirow{2}{*}{$\begin{array}{c}\text { Exigido } \\
\text { DNV 2007 } \\
\text { Solda } \\
(\mathrm{mm}) \\
\end{array}$} & \multirow{2}{*}{$\begin{array}{c}\text { Exigido } \\
\text { ISO/DIS 10893-6 } \\
\text { Classe B } \\
\text { Metal Base (mm) } \\
\end{array}$} & \multicolumn{2}{|c|}{$\begin{array}{l}\text { Experimental } \\
\text { Na Solda }(\mathrm{mm})\end{array}$} & \multicolumn{2}{|c|}{$\begin{array}{c}\text { Experimental } \\
\text { Metal Base (mm) }\end{array}$} \\
\hline & & & & & & $\begin{array}{c}\text { KODAK } \\
\text { M100 } \\
\end{array}$ & $\begin{array}{c}\text { AGFA } \\
\text { D4 }\end{array}$ & $\begin{array}{c}\text { KODAK } \\
\text { M100 } \\
\end{array}$ & $\begin{array}{c}\text { AGFA } \\
\text { D4 } \\
\end{array}$ \\
\hline \multirow{4}{*}{4,9} & CP04 & 9,1 & $13(0,20)$ & $14(0,16)$ & 16( & $15(0,13)$ & $15(0,13)$ & $14(0,16)$ & $14(0,16)$ \\
\hline & CP11 & 7,8 & 14( & $14(0,16)$ & $16(0,10)$ & $15(0,13)$ & $15(0,13)$ & $15(0,13)$ & $15(0,13)$ \\
\hline & CP14 & 5,9 & $14(0,16)$ & $14(0,16)$ & $16(0,10)$ & $15(0,13)$ & $15(0,13)$ & $15(0,13)$ & $15(0,13)$ \\
\hline & $\mathrm{CP} 22$ & 7,8 & $14(0,16)$ & $14(0,16)$ & 16( & $15(0,13)$ & $15(0,13)$ & $15(0,13)$ & $15(0,13)$ \\
\hline \multirow{3}{*}{6,4} & CP06 & 9,9 & $13(0,20)$ & $14(0,16)$ & $15(0$ & $15(0,13)$ & $14(0,16)$ & $14(0,16)$ & $14(0,16)$ \\
\hline & CP12 & & $13(0,20)$ & $14(0,16)$ & $15(0,13)$ & $14(0,16)$ & $14(0,16)$ & $15(0,13)$ & $15(0,13)$ \\
\hline & CP15 & & $13(0,20)$ & $14(0,16)$ & $15(0,13)$ & $15(0,13)$ & $15(0,1$ & $15(0,13)$ & $14(0,16)$ \\
\hline \multirow{3}{*}{9,7} & $\mathrm{CP} 07$ & & $11(0,32)$ & $13(0,20)$ & 14 & $13(0,20)$ & $13(0,20)$ & $14(0,16)$ & $14(0,16)$ \\
\hline & CP10 & 13,3 & $12(0,25)$ & $13(0,20)$ & $14(0,16)$ & $14(0,16)$ & $14(0,16)$ & $14(0,16)$ & $14(0,16)$ \\
\hline & CP16 & 10,8 & $13(0,20)$ & $13(0,20)$ & $14(0,16)$ & $13(0,20)$ & $13(0,20)$ & $13(0,20)$ & $13(0,20)$ \\
\hline \multirow{3}{*}{19,2} & CP01 & 2 & $10(0,40)$ & $12(0,25)$ & 13( & $13(0,20)$ & $13(0,20)$ & $13(0,20)$ & $13(0,20)$ \\
\hline & СР09 & 23,4 & $10(0,40)$ & $12(0,25)$ & $13(0,20)$ & $13(0,20)$ & $13(0,20)$ & $13(0,20)$ & $13(0,20)$ \\
\hline & CP17 & 22,9 & $10(0,40)$ & $12(0,25)$ & 13( & $12(0,25)$ & $12(0,25)$ & $13(0,20)$ & $13(0,20)$ \\
\hline \multirow{4}{*}{25,3} & $\mathrm{CP} 02$ & & $9(0,50)$ & $11(0,32)$ & 12( & $12(0,25)$ & $12(0,25)$ & $12(0,25)$ & $11(0,32)$ \\
\hline & $\mathrm{CP} 03$ & 30,8 & $9(0,50)$ & $11(0,32)$ & $12(0,25)$ & $12(0,25)$ & $12(0,25)$ & $12(0,25)$ & $12(0,25)$ \\
\hline & CP13 & 25,3 & $9(0,50)$ & $11(0,32)$ & $12(0,25)$ & $11(0,32)$ & $12(0,25)$ & $11(0,32)$ & $12(0,25)$ \\
\hline & CP21 & 31,4 & $9(0,50)$ & $11(0,32)$ & $12(0,25)$ & $12(0,25)$ & $12(0,25)$ & $12(0,25)$ & $12(0,25)$ \\
\hline \multirow{3}{*}{32,3} & $\mathrm{CP} 05$ & 36,3 & $8(0,63)$ & $10(0,40)$ & $11(0,32)$ & $12(0,25)$ & $11(0,32)$ & $12(0,25)$ & $12(0,25)$ \\
\hline & CP08 & 36,6 & $8(0,63)$ & $10(0,40)$ & $11(0,32)$ & $11(0,32)$ & $11(0,32)$ & $11(0,32)$ & $11(0,32)$ \\
\hline & CP18 & 36,1 & $8(0,63)$ & $10(0,40)$ & $11(0,32)$ & $10(0,40)$ & $11(0,32)$ & $11(0,32)$ & $11(0,32)$ \\
\hline
\end{tabular}

Analisando a Tabela 5.7, pode-se verificar que as exigências das normas em sua maioria são atendidas experimentalmente e que para os corpos-de-prova da espessura de 4,9 mm encontraram na maioria dos casos o arame 15 na região do metal base e, portanto não atendem o exigido (arame 16) de acordo com a norma ISO/DIS 10893-6. É importante lembrar que os parâmetros utilizados para execução da radiografia convencional seguiram as rotinas da linha de produção, que agregam compromissos entre o tempo de ciclo e as exigências das normas aplicáveis.

Na técnica digital as sensibilidades do IQI de contraste de arame encontrados estão mostradas nas Figuras 5.5 e 5.6 para as medições realizadas no metal base, segundo as propostas da norma ISO/DIS 10893-7 e nas Figuras 5.7 a 5.11 para as medições na região da solda, de acordo com as exigências da DNV-OS-F-101, API 5L e ISO 3183.

Os valores dos arames visíveis para esta técnica estão em função do tempo de integração e das distâncias do objeto ao detector (DOD). Para as espessuras envolvidas 
os tamanhos do foco foram de 0.4 e $1,0 \mathrm{~mm}$ e distância da fonte ao detector (DFD) de 700 a $1018 \mathrm{~mm}$. O número de telas por segundo foi de 10 para espessuras até 9,7 $\mathrm{mm}$ e 1 tela por segundo para as maiores espessuras.

Os números dos arames exigidos mostrados através das linhas azuis e vermelhas nas Figuras 5.5 a 5.11, já incluem a aplicação do "Princípio da compensação" previsto na ISO/DIS 10983-7, e indicado na Tabela 5.6.

Considerando que a aplicação do princípio da compensação é uma pratica fundamental para o uso da radiografia digital, foram aplicadas as normas DNV-OS-F101, API 5L e ISO 3183, independente destas, atualmente, não estarem exigindo o uso da verificação do IQI de arame duplo para determinação da resolução espacial.

Nas Figuras 5.5 e 5.6 é observado o desempenho da radiografia digital em termos de sensibilidade ao IQI de contraste do tipo arame, em função dos tempos de integração de 1, 2, 4, 8, 16 e 32 segundos, e em relação ao exigido pela norma ISO/DIS 10893-7.

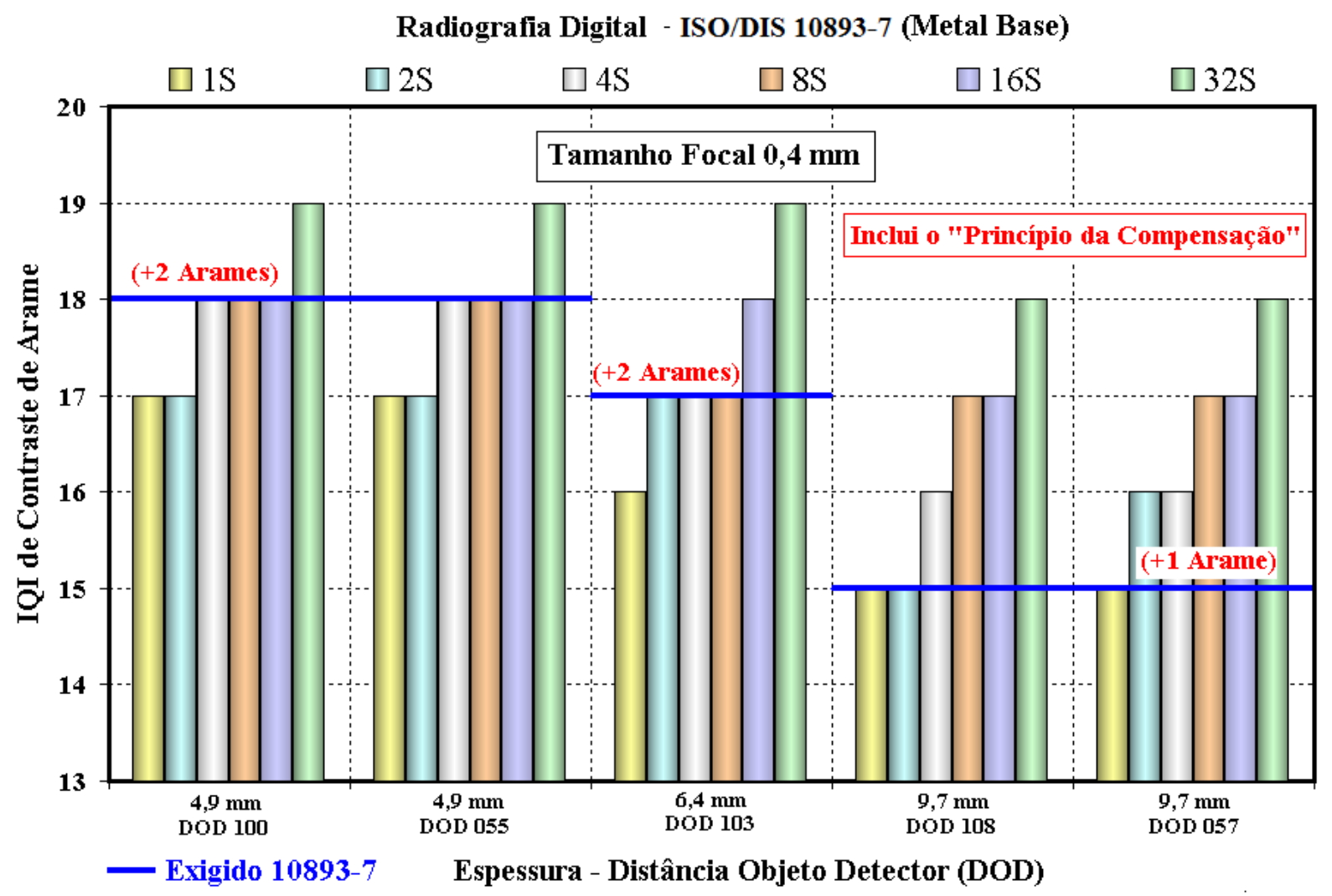

Figura 5.5 - Sensibilidade ao IQI de contraste tipo arame. Espessuras 4,9; 6,4 e 9,7 mm (ISO/DIS 10893-7). 


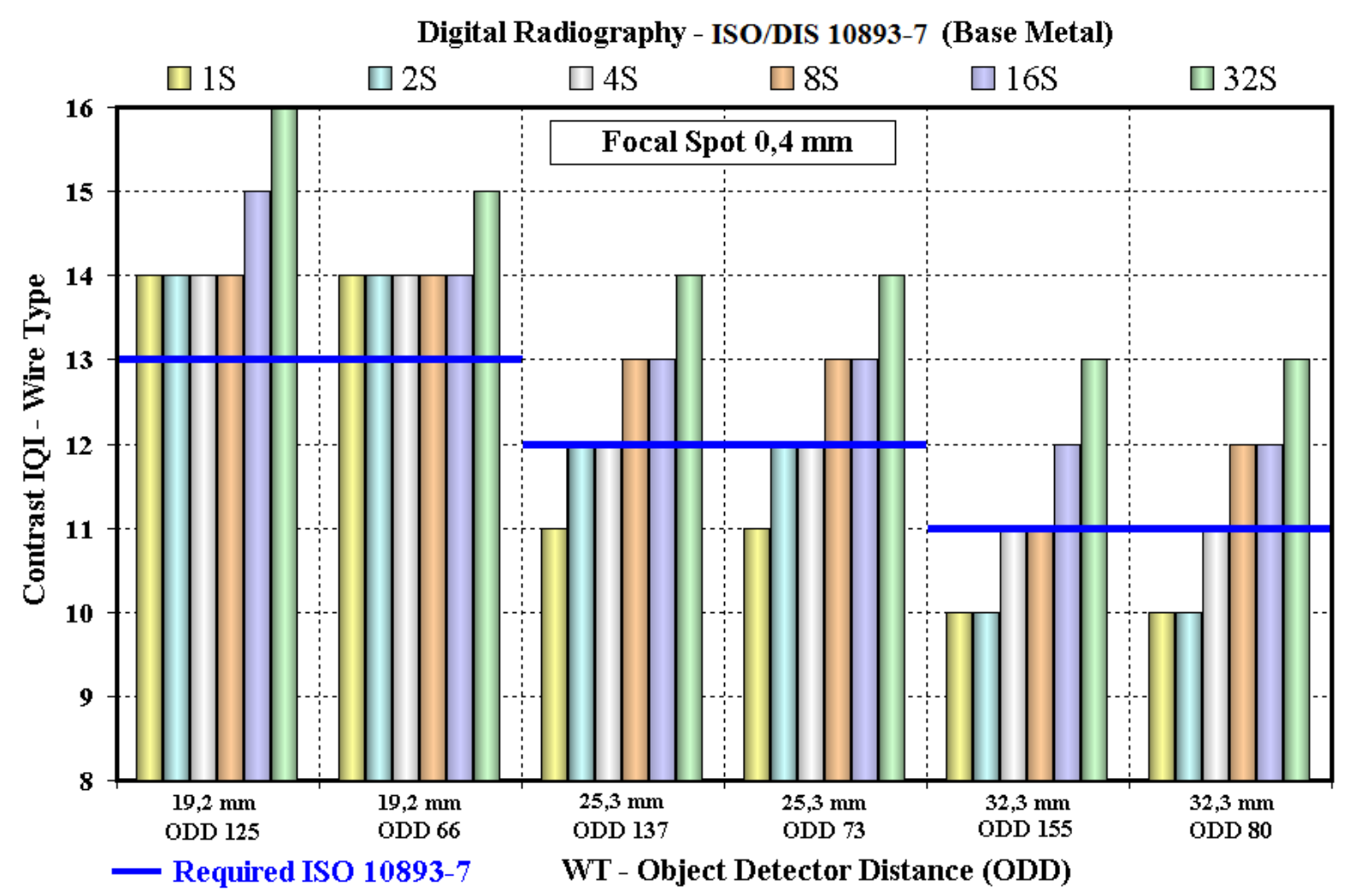

Figura 5.6 - Sensibilidade ao IQI de contraste tipo arame. Espessuras 19,2; 25,3 e 32,3 mm (ISO/DIS 10893-7).

Analisando os resultados apresentados na Figura 5.5 de acordo com as exigências da ISO/DIS 10893-7, em termos da sensibilidade do IQI de contraste medido no metal base, pode-se verificar que as sensibilidades exigidas foram conseguidas com tempos de integração de $4 \mathrm{~s}$ (arame 18, diâmetro de 0,063 mm), $2 \mathrm{~s}$ (arame 17, diâmetro de 0,080 mm) e 1s (arame 15, diâmetro de 0,13 mm) para as espessuras de 4,9 mm, 6,4 e 9,7 mm respectivamente. Na Figura 5.6 pode-se observar que as sensibilidades exigidas foram conseguidas com tempos de integração de $1 \mathrm{~s}$ (arame 14, diâmetro de 0,16 mm), 2s (arame 12, diâmetro de 0,25 mm) e 4s (arame 11, diâmetro de 0,32 mm) para as espessuras de $19,2 \mathrm{~mm}, 25,3$ e $32,3 \mathrm{~mm}$ respectivamente.

Para o tempo de integração de $32 \mathrm{~s}$ foram obtidos os arames número 19 (diâmetro de $0,050 \mathrm{~mm}$ ) para as espessuras de 4,9 e 6,4 $\mathrm{mm}$ e 18 para a espessura de 9,7 mm, 16 (diâmetro de 0,100 mm) e 15 (DOD 66mm) para a espessura de 19,2 mm, 14 para a espessura de $25,3 \mathrm{~mm}$ e 13 (diâmetro de $0,20 \mathrm{~mm}$ ) para a espessura de 32,3 $\mathrm{mm}$. 


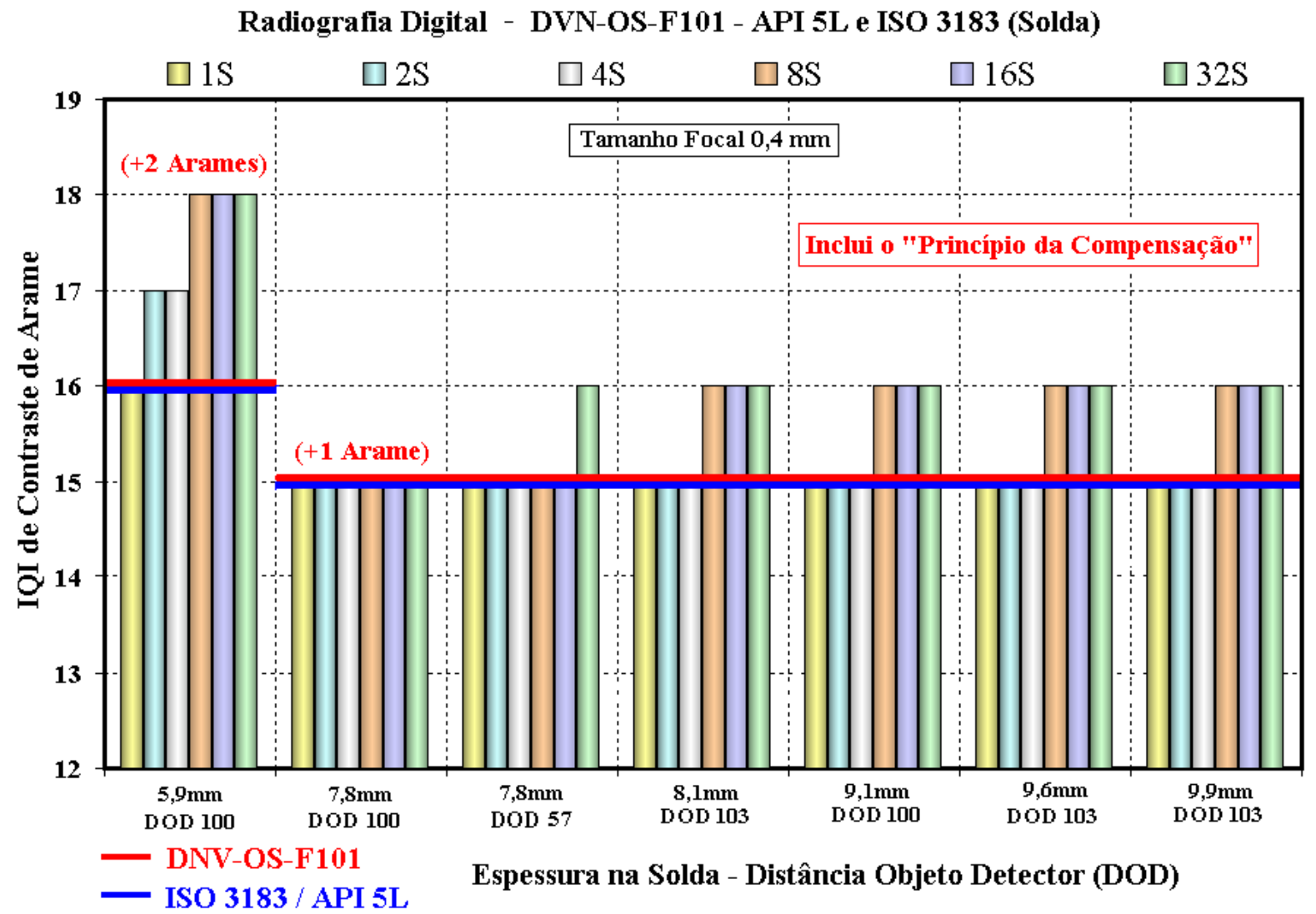

Figura 5.7 - Sensibilidade ao IQI de contraste tipo arame. Espessuras 4,9 e 6,4 mm (Solda).

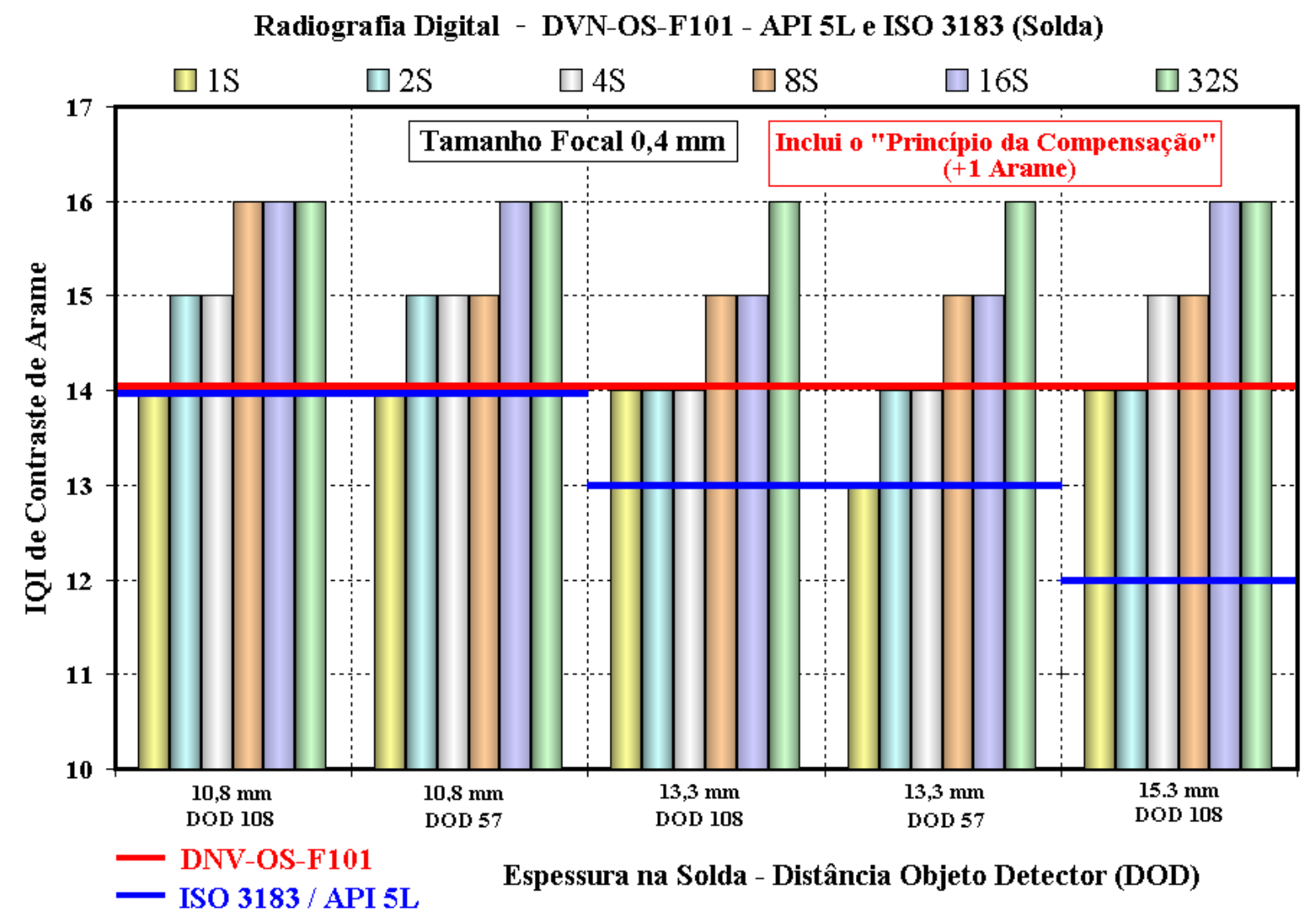

Figura 5.8 - Sensibilidade ao IQI de contraste tipo arame. Espessuras 9,7 mm (Solda). 


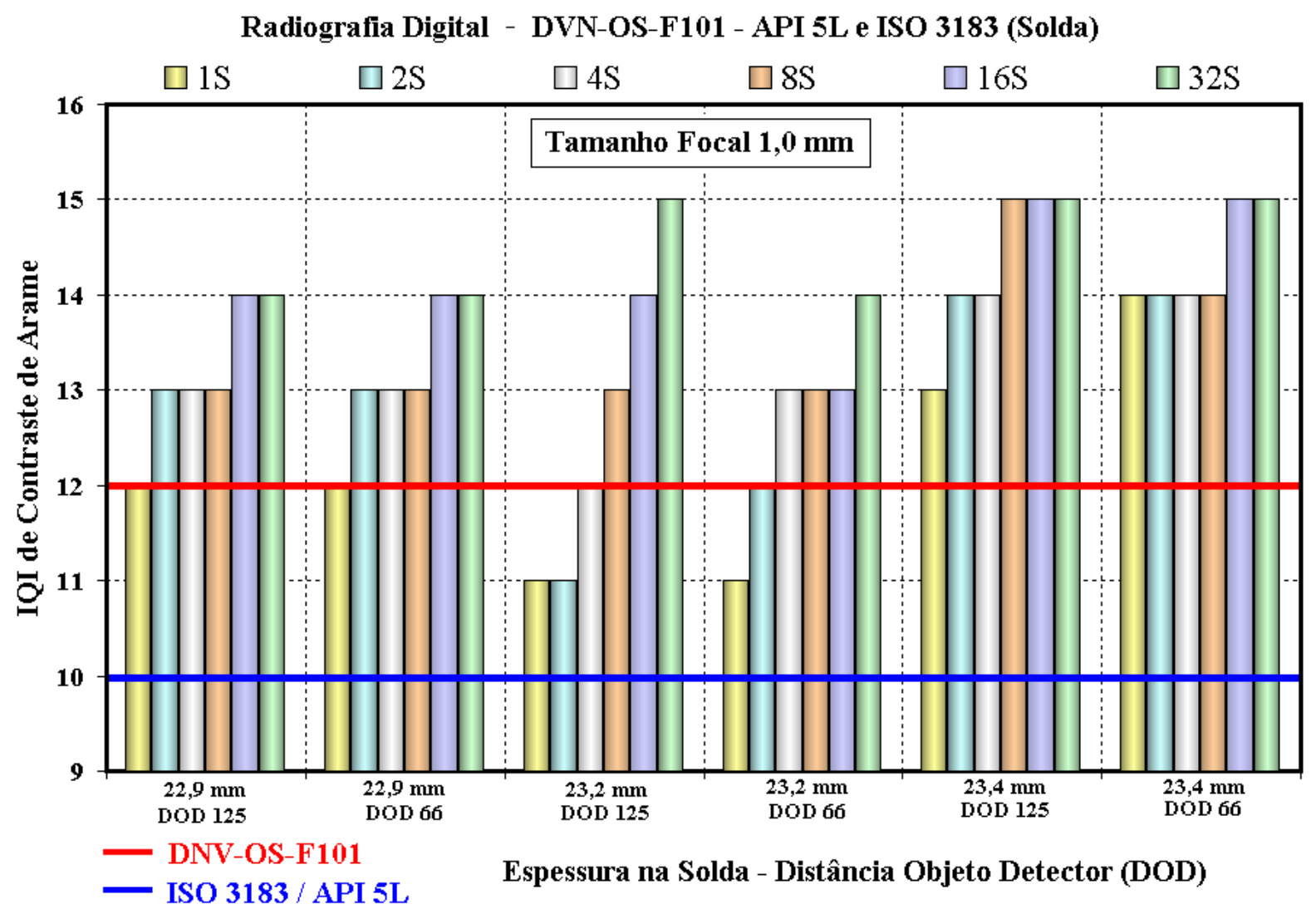

Figura 5.9 - Sensibilidade ao IQI de contraste tipo arame. Espessuras 19,2 mm (Solda).

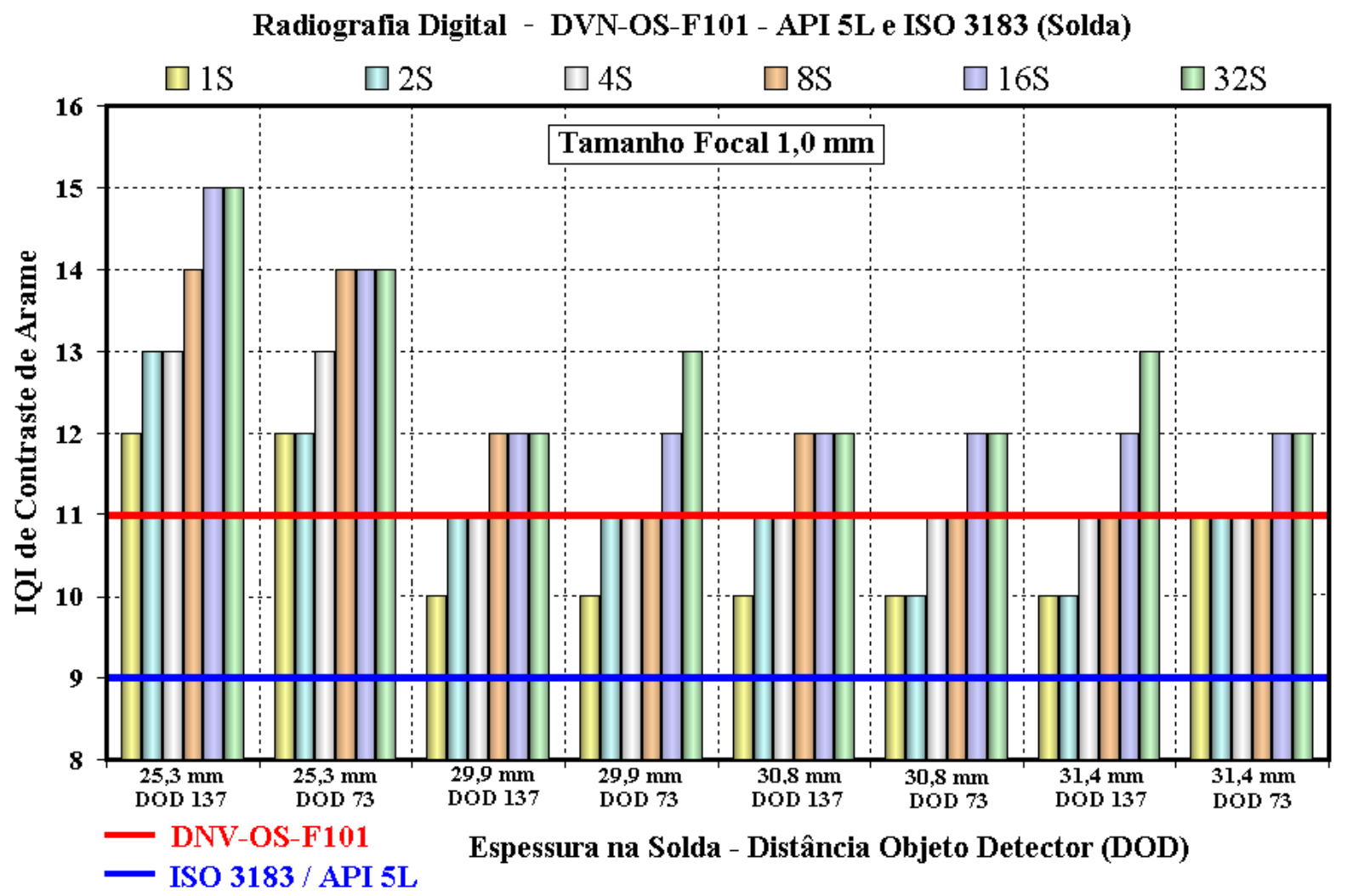

Figura 5.10 - Sensibilidade ao IQI de contraste tipo arame. Espessura 25,3 mm (solda). 


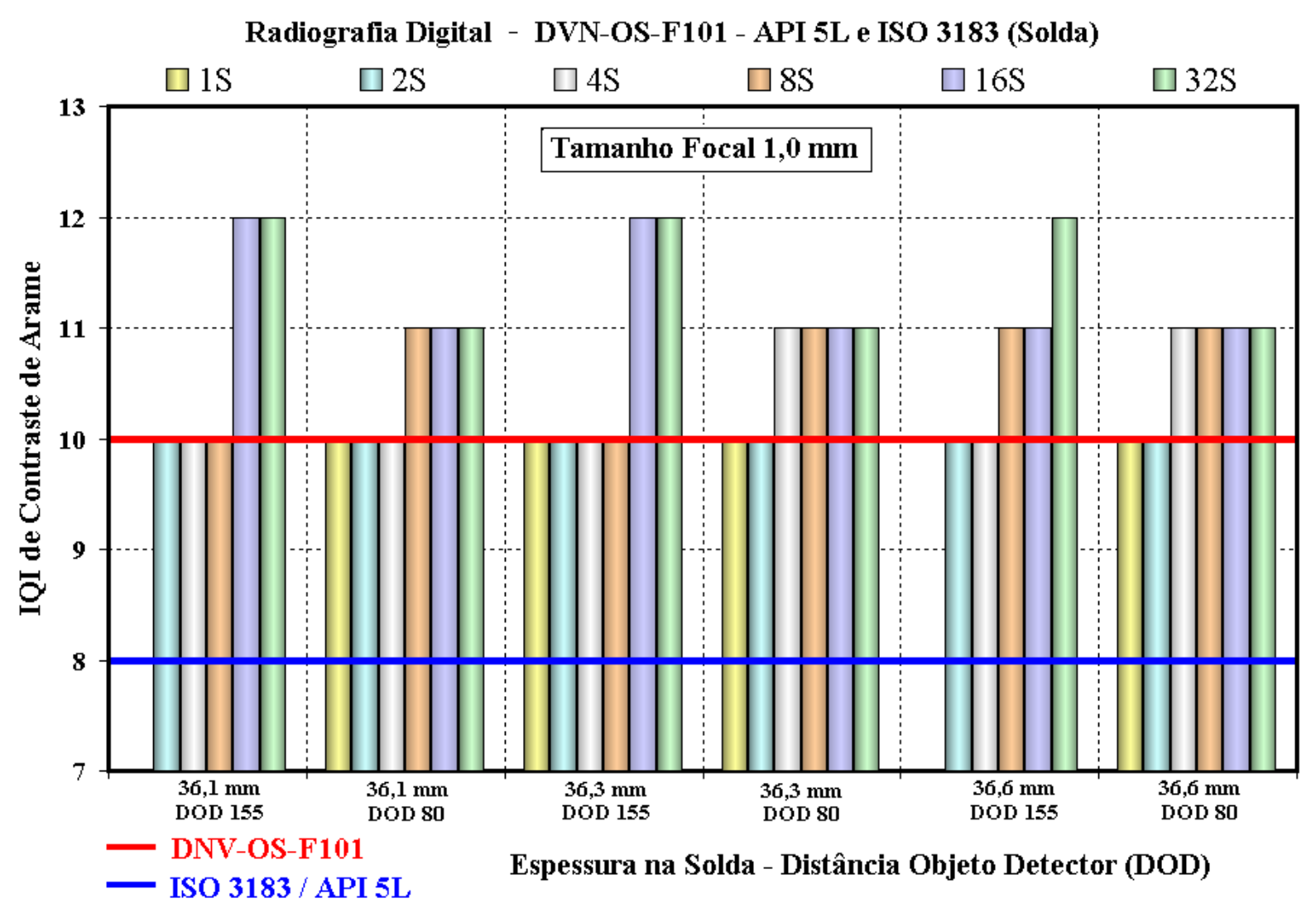

Figura 5.11 - Sensibilidade ao IQI de contraste tipo arame. Espessura de 32,3 mm (solda).

Analisando os resultados apresentados nas Figuras 5.7 a 5.11, de acordo com as exigências da API 5L e ISO 3183, em termos da sensibilidade do IQI de contraste medido no cordão de solda, pode-se observar que as sensibilidades mínimas exigidas foram conseguidas com tempos de integração de 1s para todas as espessuras utilizadas nos experimentos, sendo que de 5,9 a 36,6 $\mathrm{mm}$ (exceto DOD de $155 \mathrm{~mm}$ para as espessuras de 36,1 e $36,6 \mathrm{~mm}$, que necessitaram 2s).

Avaliando os resultados para atendimento das sensibilidades mínimas exigidas pela norma DNV-OS-F101, pode-se observar que foram necessários tempos de integração entre 1s e 4s para todos os 39 experimentos realizados. Destes experimentos, 06 situações necessitaram de tempo de integração de 2s: espessura de 13,3 mm/DOD de $57 \mathrm{~mm}, 23,2 \mathrm{~mm} /$ DOD $66 \mathrm{~mm}, 29,9 \mathrm{~mm}, 30,8 \mathrm{~mm} /$ DOD $137 \mathrm{~mm}$, 36,1 e $36,6 \mathrm{~mm} / \mathrm{DOD}$ de $155 \mathrm{~mm}$. Mais 03 situações necessitaram 4s de tempo de integração, a saber: as espessuras de 23,2mm/DOD $125 \mathrm{~mm}, 30,8 \mathrm{~mm} / \mathrm{DOD}$ de $73 \mathrm{~mm}$ e $31,4 \mathrm{~mm} / \mathrm{DOD}$ de $137 \mathrm{~mm}$. 
Ainda analisando a região do cordão da solda, conforme previsto pelas normas DNV-OS-F101, API 5L e ISO 3183, pode-se observar que com tempos de integração de $32 \mathrm{~s}$ foram obtidos os arames número 18 para as espessuras de $5,9 \mathrm{~mm}$, arame 16 para espessuras de 7,8 a 15,3 $\mathrm{mm}$ (exceto 13,3 mm/DOD $57 \mathrm{~mm}$ ), arame 15 de 23,2 a $25,3 \mathrm{~mm}$ ( exceto 23,2 mm/DOD $66 \mathrm{~mm}$ ), arame 14 para espessura de 22,9 $\mathrm{mm}$ e 23,2 $\mathrm{mm} / \mathrm{DOD}$ de $66 \mathrm{~mm}$ e espessura de 25,3 mm/DOD de $73 \mathrm{~mm}$. O arame 13 foi obtido nas espessuras 29,9 mm/DOD $73 \mathrm{~mm}$ e 31,4 mm/DOD $137 \mathrm{~mm}$. O arame 12 foi obtido nas espessuras de 29,9 mm/DOD $137 \mathrm{~mm}, 30,8 \mathrm{~mm}, 31,4 \mathrm{~mm} / \mathrm{DOD}$ de $73 \mathrm{~mm}$, DOD de $155 \mathrm{~mm}$ para as espessuras de $36,1 \mathrm{~mm}, 36,3 \mathrm{~mm}$ e $36,6 \mathrm{~mm}$ e finalmente arame 11 para DOD de $80 \mathrm{~mm}$ para as espessuras de $36,1 \mathrm{~mm}, 36,3 \mathrm{~mm}$ e $36,6 \mathrm{~mm}$. 


\subsubsection{Relação sinal ruído normalizado, $\mathrm{SNR}_{\mathrm{N}}$}

Em cada um dos corpos-de-prova foram medidos 06 pontos na região do metal base próximos ao cordão de solda e os valores encontrados encontram-se apresentadas na Tabela 5.8 e estão divididos de acordo com a espessura no metal base dos corposde-prova, pelas distâncias da fonte ao detector (DFD), distâncias do objeto ao detector (DOD), pelos tempos de integração em segundos. Os valores mostrados correspondem às médias das medidas encontradas, dos corpos-de-prova de mesma espessura.

Tabela 5.8 Valores da $\mathrm{SNR}_{\mathrm{N}}$ por espessura.

\begin{tabular}{|c|c|c|c|c|c|c|}
\hline \multicolumn{7}{|c|}{ MÉdLA DOS C } \\
\hline \multicolumn{7}{|c|}{$\begin{array}{c}\text { Espessura 4,9 mm } \\
\text { DFD } 700 \mathrm{~mm}-\text { DOD } 100 \mathrm{~mm}-\text { Foco } 0,4 \mathrm{~mm}\end{array}$} \\
\hline & $\mathbf{1}$ & 2 & 3 & 4 & 5 & 6 \\
\hline $1 \mathrm{~s}$ & 280 & 255 & 248 & 258 & 247 & 243 \\
\hline $2 \mathrm{~s}$ & 368 & 341 & 348 & 353 & 336 & 339 \\
\hline $4 \mathrm{~s}$ & 477 & 442 & 425 & 420 & 410 & 400 \\
\hline $8 \mathrm{~s}$ & 623 & 565 & 581 & 521 & 539 & 511 \\
\hline $16 \mathrm{~s}$ & 754 & 658 & 699 & 655 & 736 & 663 \\
\hline $32 \mathrm{~s}$ & 860 & 772 & 815 & 736 & 859 & 717 \\
\hline
\end{tabular}

$\begin{array}{ccccccc} & 1 & 2 & 3 & 4 & 5 & 6 \\ \text { 1 s } & 199 & 180 & 175 & 200 & 173 & 173 \\ \text { 2 s } & 269 & 223 & 246 & 258 & 218 & 230 \\ 4 \text { s } & \mathbf{3 8 3} & \mathbf{3 4 0} & \mathbf{3 2 5} & \mathbf{3 7 7} & \mathbf{3 3 3} & \mathbf{3 3 9} \\ \text { 8 s } & 495 & 402 & \mathbf{4 1 5} & \mathbf{4 7 2} & \mathbf{4 1 4} & \mathbf{4 1 3} \\ 16 \text { s } & \mathbf{6 0 6} & \mathbf{4 8 2} & \mathbf{5 1 8} & \mathbf{5 9 2} & \mathbf{4 9 4} & \mathbf{5 1 9} \\ 32 \text { s } & 755 & \mathbf{6 0 4} & \mathbf{6 0 1} & \mathbf{7 6 1} & \mathbf{5 8 7} & \mathbf{6 0 4}\end{array}$
DFD $820 \mathrm{~mm}$ - DOD $125 \mathrm{~mm}$ - Foco $1,0 \mathrm{~mm}$

\begin{tabular}{ccccccc} 
& 1 & 2 & 3 & 4 & 5 & 6 \\
1 s & 185 & 166 & 169 & 178 & 157 & 161 \\
2 s & 224 & 206 & 204 & 218 & 197 & 203 \\
4 s & 284 & 246 & 248 & 275 & 235 & 248 \\
8 s & 352 & 305 & 308 & 335 & 296 & 306 \\
16 s & 451 & 367 & 392 & 424 & 360 & 389 \\
32 s & 551 & 441 & 451 & 524 & 436 & 464 \\
\multicolumn{7}{c}{ Espessura 25,3 mm } \\
\end{tabular}

\section{DFD $900 \mathrm{~mm}$ - DOD $137 \mathrm{~mm}$ - Foco 1,0 mm}

\begin{tabular}{ccccccc} 
& 1 & 2 & 3 & 4 & 5 & 6 \\
1 s & 100 & 91 & 97 & 101 & 87 & 92 \\
2 s & 122 & 108 & 111 & 117 & 105 & 108 \\
4 s & 157 & 138 & 149 & 155 & 131 & 140 \\
8 s & 201 & 181 & 191 & 201 & 171 & 180 \\
16 s & 253 & 229 & 244 & 252 & 223 & 232 \\
32 s & 316 & 269 & 293 & 304 & 262 & 287 \\
\multicolumn{7}{c}{ Espessura 32,3 mm }
\end{tabular}

DFD $1013 \mathrm{~mm}$ - DOD $155 \mathrm{~mm}$ - Foco 1,0 mm

\begin{tabular}{ccccccc} 
& 1 & 2 & 3 & 4 & 5 & 6 \\
1 s & 53 & 51 & 46 & 53 & 48 & 43 \\
2 s & 64 & 61 & 56 & 62 & 58 & 53 \\
4 s & 83 & 76 & 70 & 80 & 73 & 68 \\
8 s & 109 & 96 & 91 & 92 & 97 & 86 \\
16 s & 139 & 124 & 116 & 136 & 122 & 113 \\
32 s & 173 & 162 & 150 & 167 & 155 & 147 \\
\hline
\end{tabular}

Espessura 6,4 mm

DFD $700 \mathrm{~mm}$ - DOD $103 \mathrm{~mm}$ - Foco $0,4 \mathrm{~mm}$

\begin{tabular}{ccccccc} 
& 1 & 2 & 3 & 4 & 5 & 6 \\
1 s & 270 & 247 & 247 & 272 & 246 & 250 \\
2 s & 365 & 326 & 336 & 351 & 324 & 331 \\
4 s & 468 & 425 & 440 & 474 & 432 & 444 \\
8 s & 633 & 565 & 601 & 646 & 591 & 599 \\
16 s & 759 & 695 & 690 & 744 & 705 & 702 \\
32 s & 876 & 820 & 781 & 891 & 809 & 829 \\
& \multicolumn{7}{c}{ Espessura $9,7 \mathrm{~mm}$}
\end{tabular}

DFD $700 \mathrm{~mm}$ - DOD $57 \mathrm{~mm}$ - Foco 0,4 mm

$\begin{array}{ccccccc} & 1 & 2 & 3 & 4 & 5 & 6 \\ \text { 1 s } & 206 & 172 & 176 & 197 & 164 & 166 \\ \text { 2 s } & 295 & 239 & 231 & 291 & 224 & 213 \\ \text { 4 s } & 391 & 326 & 308 & 384 & 323 & 310 \\ \text { 8 s } & 483 & 366 & 364 & 479 & 371 & 366 \\ 16 \text { s } & 626 & 433 & 458 & 611 & 426 & 447 \\ 32 \text { s } & 831 & 527 & 523 & 814 & 536 & 525\end{array}$

Espessura 19,2 mm

DFD $700 \mathrm{~mm}$ - DOD $66 \mathrm{~mm}$ - Foco 1,0 mm

$\begin{array}{ccccccc} & 1 & 2 & 3 & 4 & 5 & 6 \\ 1 \text { s } & 234 & 197 & 198 & 229 & 197 & 192 \\ \text { 2 s } & 291 & 232 & 242 & 282 & 233 & 229 \\ \text { 4 s } & \mathbf{3 4 5} & 294 & 282 & \mathbf{3 3 2} & 272 & 267 \\ \text { 8 s } & 411 & \mathbf{3 2 3} & \mathbf{3 1 5} & \mathbf{4 2 5} & \mathbf{3 2 4} & \mathbf{3 0 6} \\ 16 \text { s } & \mathbf{5 2 0} & \mathbf{3 8 9} & \mathbf{4 0 7} & \mathbf{5 0 3} & \mathbf{3 9 4} & \mathbf{3 9 7} \\ 32 \text { s } & 600 & \mathbf{4 6 2} & \mathbf{4 6 7} & \mathbf{5 8 7} & 439 & 562\end{array}$

Espessura 25,3 mm

DFD $700 \mathrm{~mm}$ - DOD $73 \mathrm{~mm}$ - Foco 1,0 mm

\begin{tabular}{ccccccc} 
& 1 & 2 & 3 & 4 & 5 & 6 \\
1 s & 149 & 128 & 131 & 141 & 124 & 121 \\
2 s & 174 & 157 & 160 & 166 & 145 & 153 \\
4 s & 226 & 190 & 196 & 211 & 180 & 190 \\
8 s & 287 & 222 & 223 & 276 & 222 & 224 \\
16 s & 338 & 259 & 236 & 325 & 270 & 246 \\
32 s & 398 & 328 & 330 & 400 & 336 & 336 \\
& \multicolumn{7}{c}{ Espessura 32,3 mm } & &
\end{tabular}

DFD $700 \mathrm{~mm}$ - DOD $80 \mathrm{~mm}$ - Foco 1,0 mm

\begin{tabular}{ccccccc} 
& 1 & 2 & 3 & 4 & 5 & 6 \\
1 s & 83 & 78 & 73 & 83 & 73 & 72 \\
2 s & 114 & 98 & 93 & 109 & 93 & 88 \\
4 s & 134 & 116 & 107 & 131 & 113 & 105 \\
8 s & 167 & 144 & 134 & 164 & 138 & 130 \\
16 s & 196 & 173 & 166 & 194 & 167 & 153 \\
32 s & 223 & 187 & 179 & 209 & 181 & 176 \\
\hline
\end{tabular}


$\mathrm{Na}$ Figura 5.12, podem-se observar as curvas de tendências dos valores médios de $\mathrm{SNR}_{\mathrm{N}}$ encontrados nos corpos-de-prova, em função dos tempos de integração de 1 , 2, 4, 8, 16 e 32 segundos, por espessura de 4,9 a 25,3 $\mathrm{mm}$ e por DOD.
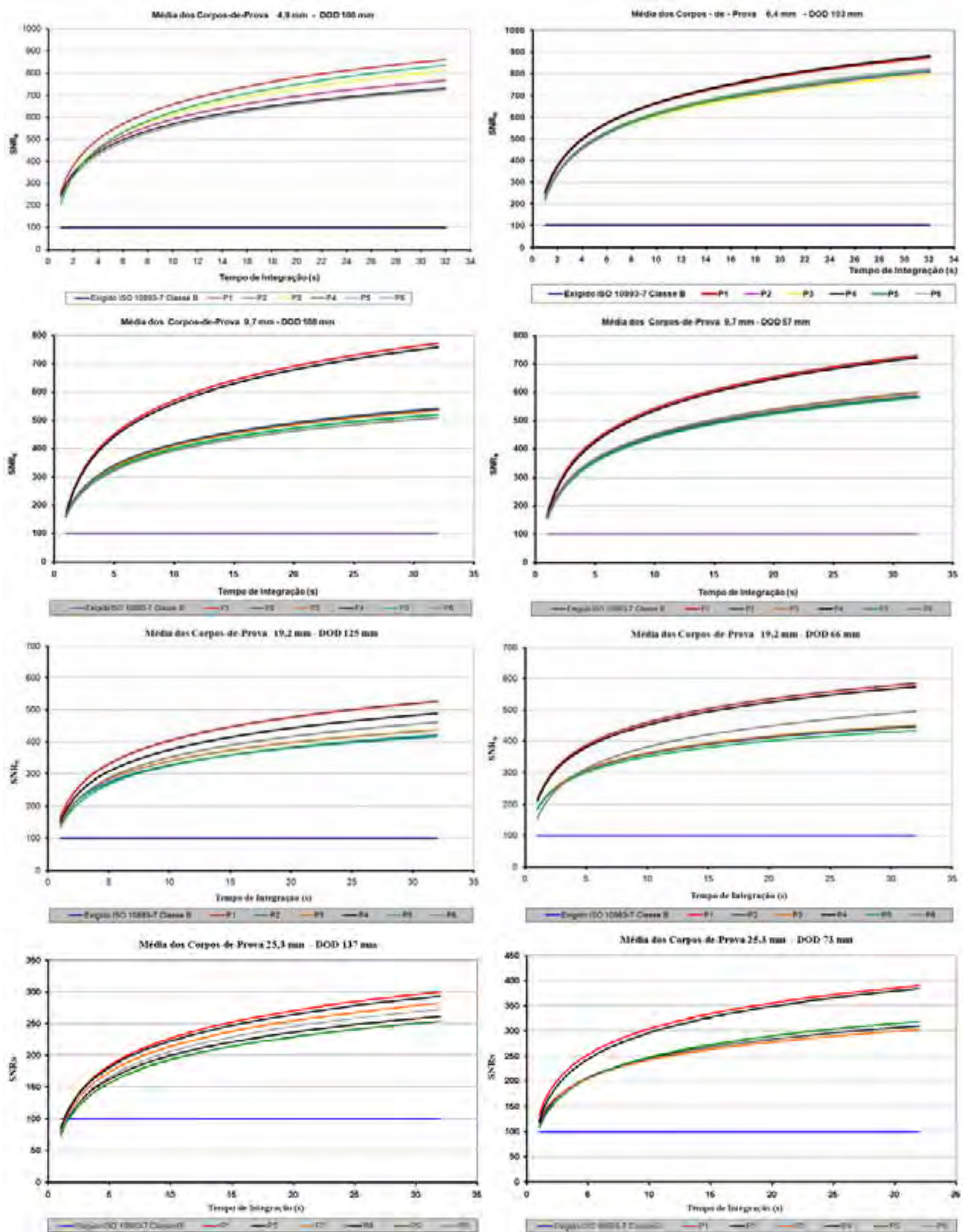

Figura 5.12 - Valores médios obtidos da $\mathrm{SNR}_{\mathrm{N}}$ para as espessuras de 4,9, 6,4, 9,7, 19,2 e 25,3 mm. 
É importante observar na Figura 5.12, que os valores encontrados estão acima do nível mínimo do $\mathrm{SNR}_{\mathrm{N}}$ proposto (100) para a classe $\mathrm{B}$, que é a mais rigorosa da ISO/DIS 10893-7, sendo que para a espessura de 25,3 mm e DOD $137 \mathrm{~mm}$ isto acontece com tempo de integração a partir de $2 \mathrm{~s}$.

$\mathrm{Na}$ Figura 5.13, pode-se observar as curvas de tendências dos valores médios de $\mathrm{SNR}_{\mathrm{N}}$ encontrados nos corpos-de-prova, em função dos tempos de integração de 1, 2, $4,8,16$ e 32 segundos para a espessura de $32,3 \mathrm{~mm}$ e para os valores de DOD de 155 e $80 \mathrm{~mm}$.
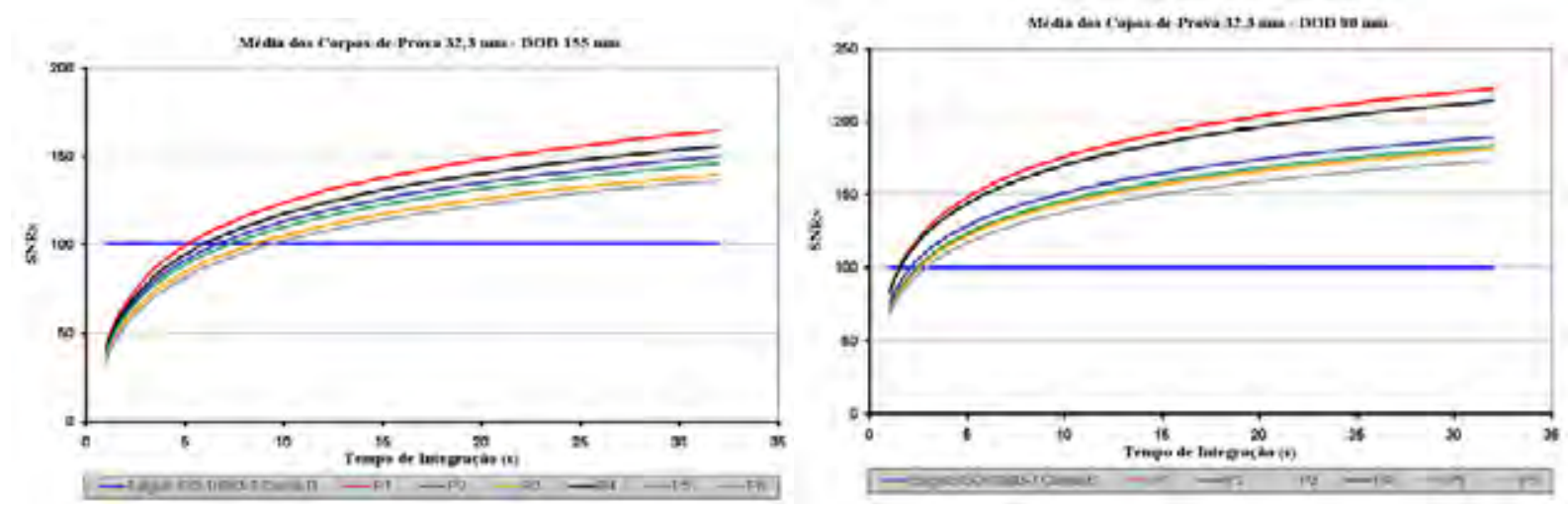

Figura 5.13 - Valores médios obtidos da $\mathrm{SNR}_{\mathrm{N}}$ para espessura de 32,3 mm - DOD 155 e $80 \mathrm{~mm}$.

Observa-se a partir da Figura 5.13 e da Tabela 5.8, que acima de 8 s para DOD $155 \mathrm{~mm}$ e acima de $4 \mathrm{~s}$ para DOD de $80 \mathrm{~mm}$, todos os valores medidos encontram-se acima do nível mínimo do $\mathrm{SNR}_{\mathrm{N}}$ proposto (100) para a classe $\mathrm{B}$, a mais rigorosa da norma ISO/DIS 10893-7.

Para o CP18, 32,2 $\mathrm{mm}$ de espessura, os valores de $\mathrm{SNR}_{\mathrm{N}}$ obtidos para os tempos de integração de 1, 2, 4, 6, 32, 64, 128, 256 e 512 s estão mostrados na Tabela 5.9.

Tabela 5.9 Valores da $\mathrm{SNR}_{\mathrm{N}}$ para CP18 com longa exposição.

\begin{tabular}{ccccccc}
\hline Tempo (s) & \multicolumn{7}{c}{ DOD 80 mm } \\
\hline & 1 & 2 & 3 & 4 & 5 & 6 \\
1 & $\mathbf{8 9}$ & $\mathbf{8 3}$ & 77 & $\mathbf{8 8}$ & 77 & 77 \\
2 & 110 & 91 & 92 & 109 & $\mathbf{8 8}$ & $\mathbf{8 5}$ \\
4 & 132 & 110 & 109 & 128 & 110 & 105 \\
8 & 161 & 139 & 133 & 163 & 137 & 126 \\
16 & 200 & 166 & 171 & 195 & 171 & 156 \\
32 & 224 & 173 & 178 & 207 & 170 & 178 \\
64 & $\mathbf{3 6 7}$ & $\mathbf{2 9 9}$ & $\mathbf{2 8 4}$ & $\mathbf{3 4 4}$ & $\mathbf{2 6 7}$ & $\mathbf{2 7 8}$ \\
128 & 421 & $\mathbf{3 1 3}$ & $\mathbf{2 9 3}$ & $\mathbf{3 9 7}$ & $\mathbf{3 3 1}$ & $\mathbf{3 2 8}$ \\
$\mathbf{2 5 6}$ & $\mathbf{4 5 5}$ & $\mathbf{3 6 1}$ & $\mathbf{3 2 2}$ & $\mathbf{4 4 5}$ & $\mathbf{3 3 5}$ & $\mathbf{3 5 9}$ \\
$\mathbf{5 1 2}$ & 502 & $\mathbf{4 2 0}$ & $\mathbf{3 2 6}$ & $\mathbf{4 8 7}$ & $\mathbf{3 6 0}$ & $\mathbf{3 9 7}$ \\
\hline
\end{tabular}


Na Figura 5.14 pode-se observar as curvas de tendências dos valores de $\mathrm{SNR}_{\mathrm{N}}$ encontrados no CP18, espessura de $32,3 \mathrm{~mm}$, em função dos tempos de integração de $1,2,4,8,16,32,64,128,256$ e 512 segundos para o valor de DOD de $80 \mathrm{~mm}$.

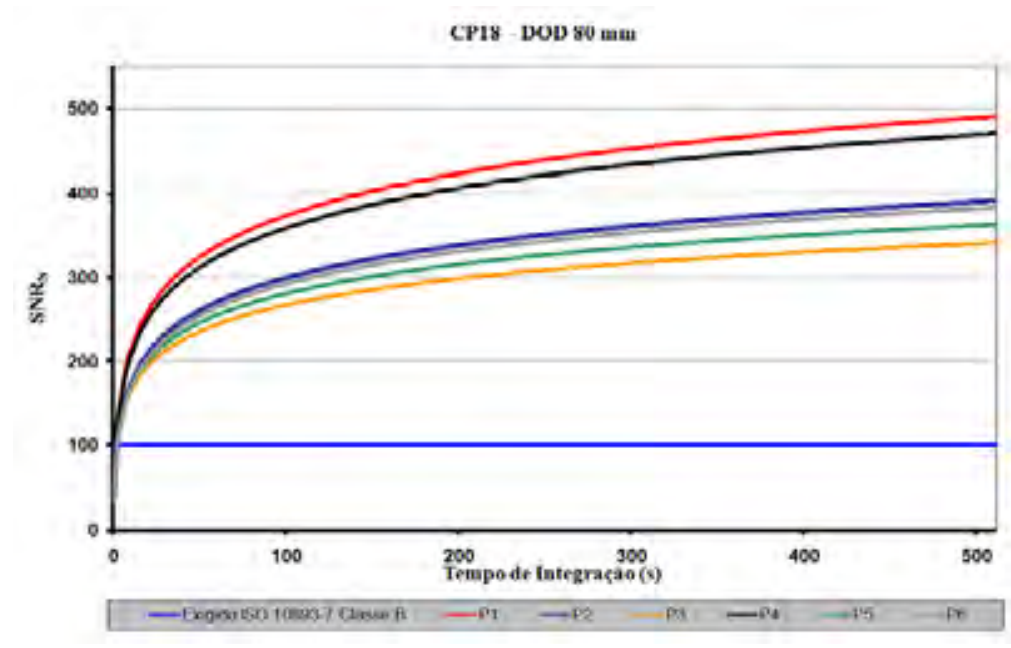

Figura 5.14 - Valores da $\mathrm{SNR}_{\mathrm{N}}$ para o CP18 - DOD $80 \mathrm{~mm}$.

Em geral todas as espessuras e distâncias do objeto ao detector (DOD) apresentaram valores acima do limite mínimo exigido pela classe mais rigorosa da ISO/DIS 10893-7 para tempos de integração muito baixos em comparação aos praticados com a técnica convencional. Com estes resultados pode-se notar que a técnica digital aplicada consegue, com baixos tempos de integração, a qualidade de imagem necessária para atendimento das exigências da norma citada e que pode-se obter imagens radiográficas digitais ricas em detalhes e sensibilidade, devido à garantia de altos valores conseguidos de $\mathrm{SNR}_{\mathrm{N}}$.

Na Figura 5.15 encontra-se apresentada a sensibilidade medida por meio do indicador de qualidade de contraste (IQI) de arame em função dos valores da relação sinal ruido normalizado $\left(\mathrm{SNR}_{\mathrm{N}}\right)$ e do tempo de integração para o corpo-de-prova, CP18, com espessura de $32,3 \mathrm{~mm}$, com integração de 1 tela por segundo. Para este estudo, os parâmetros utilizados foram $225 \mathrm{kV}$ e $8 \mathrm{~mA}$, para uma distância da fonte ao detector (DFD) de $700 \mathrm{~mm}$ e distância objeto detector (DOD) de $80 \mathrm{~mm}$. Os tempos de integração foram variados de 1 a $512 \mathrm{~s}$ e foram medidos próximo ao cordão de solda, na região onde o IQI de contraste de arame foi colocado. 


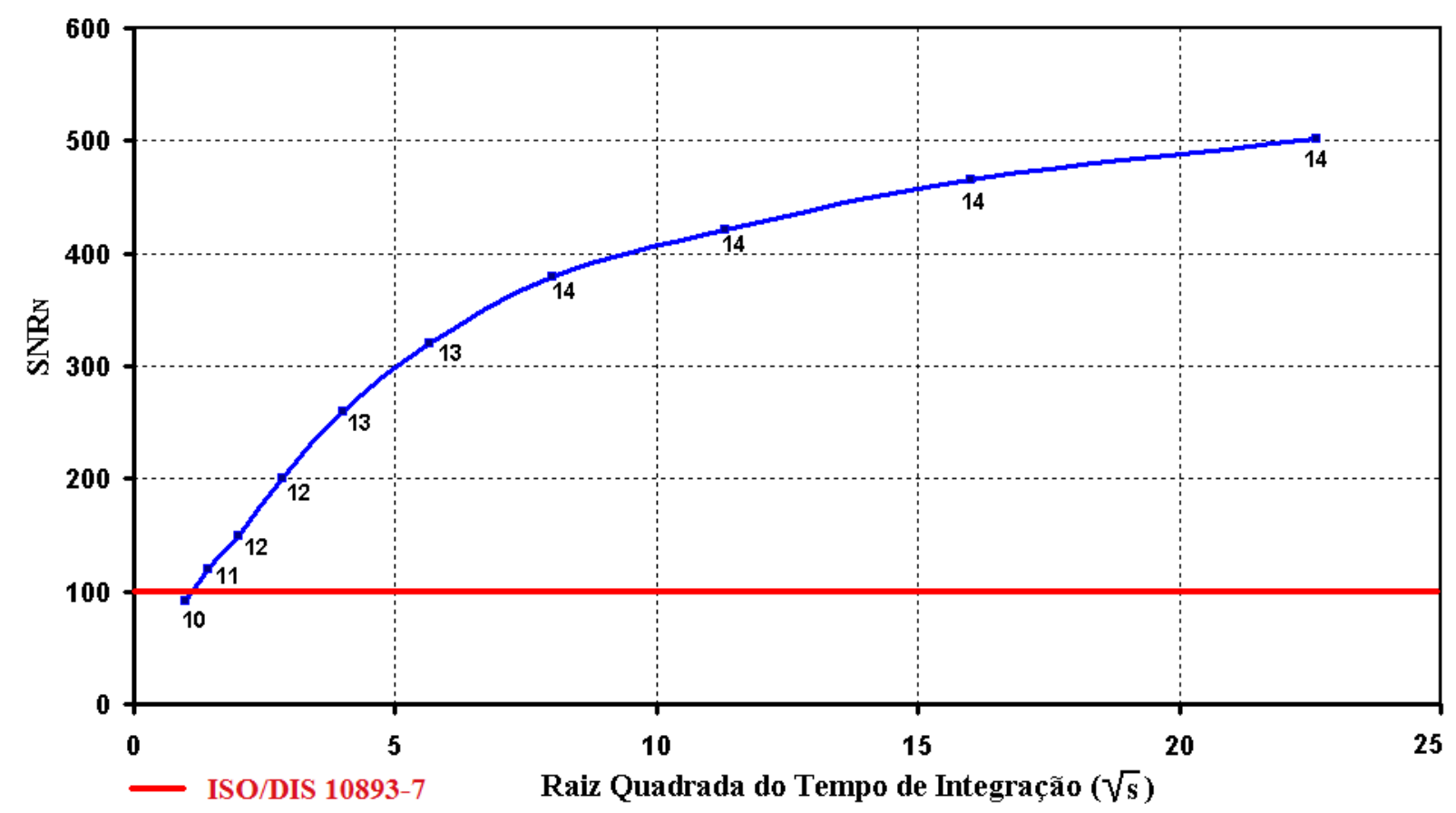

Figura 5.15 - Sensibilidade ao contraste (IQI de arame) em função da $\mathrm{SNR}_{N}$ e do Tempo de Integração - CP18.

Na Figura 5.15 pode-se notar que para a espessura de 32,3 $\mathrm{mm}$ (CP18), o arame exigido número 11 foi obtido para valores de $\mathrm{SNR}_{\mathbf{N}}$, acima de 100 conforme é proposto para a classe B da norma ISO/DIS 10893-7.

É interessante verificar que com o acréscimo do tempo de integração de $62 \mathrm{~s}$ (de 2 para 64s), pode-se melhorar facilmente a sensibilidade ao contraste da técnica digital. Neste caso aumentou, em termos do número do arame visível, de 11 para 14, o que significa uma melhoria de sensibilidade ao contraste do arame com diâmetro de 320 $\mu \mathrm{m}$ para $160 \mu \mathrm{m}$.

Comparando estes resultados com os obtidos com filmes, conforme apresentado na Tabela 5.7 para a espessura de $32,3 \mathrm{~mm}$ observa-se que na técnica convencional obteve-se, no melhor caso, o arame $12(250 \mu \mathrm{m})$.

Por outro lado, também observa-se certa "estabilidade", após o tempo de integração de 64 segundos, raiz quadrada 8, onde não há melhoria na sensibilidade mesmo com o aumento do tempo de integração de até 512 s, ou seja 8 minutos e 32 segundos. 


\subsubsection{Sensibilidade a defeitos reais.}

Por meio das imagens apresentadas a seguir foram feitas as comparações das imagens radiográficas obtidas dos filmes digitalizados e as imagens da radiografia digital. As imagens mostradas contêm os defeitos críticos gerados artificialmente para este fim. As imagens nas Figuras 5.16 a 5.22, foram geradas no programa "ISee!" e foram resultado da aplicação de filtro passa alto. Este filtro não requer qualquer tipo de ajuste de parâmetros e foi utilizado para efeito de comparação das duas técnicas, a fim de melhorar a apresentação das imagens das soldas.

São mostradas, para cada espessura, exemplos dos corpos-de-prova com regiões contendo os defeitos e com diferentes tempos de integração. Nas Figuras 5.16 a 5.22, podem-se observar as comparações entre as imagens obtidas com filme AGFA D4 e pela radiografia digital com variados tempos de integração.

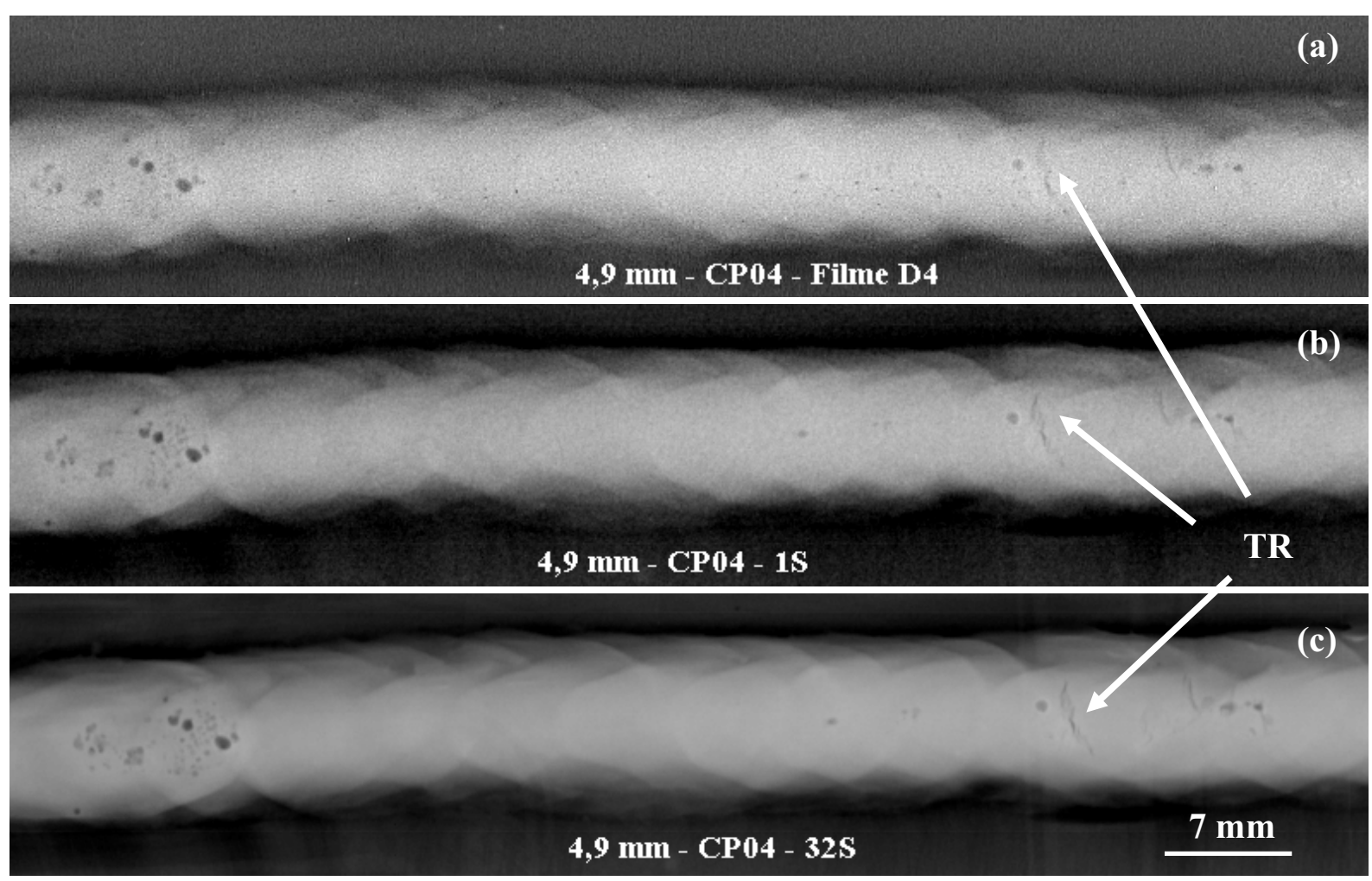

Figura 5.16 - Espessura de 4,9 mm - (a) Filme D4. (b) 1s. (c) $32 \mathrm{~s}$. 


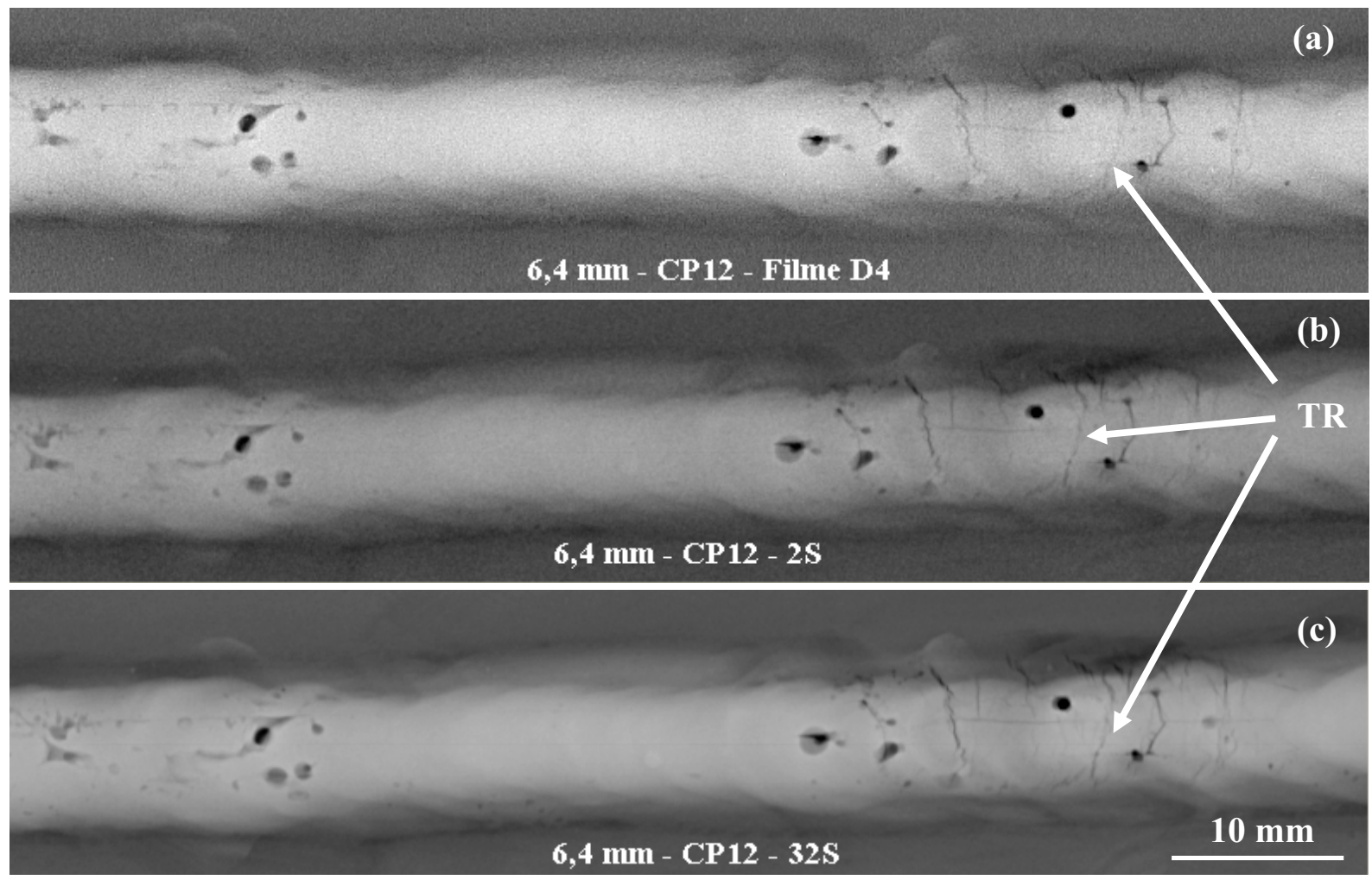

Figura 5.17 - Espessura de 6,4 mm - (a) Filme D4. (b) 2s. (c) $32 \mathrm{~s}$.

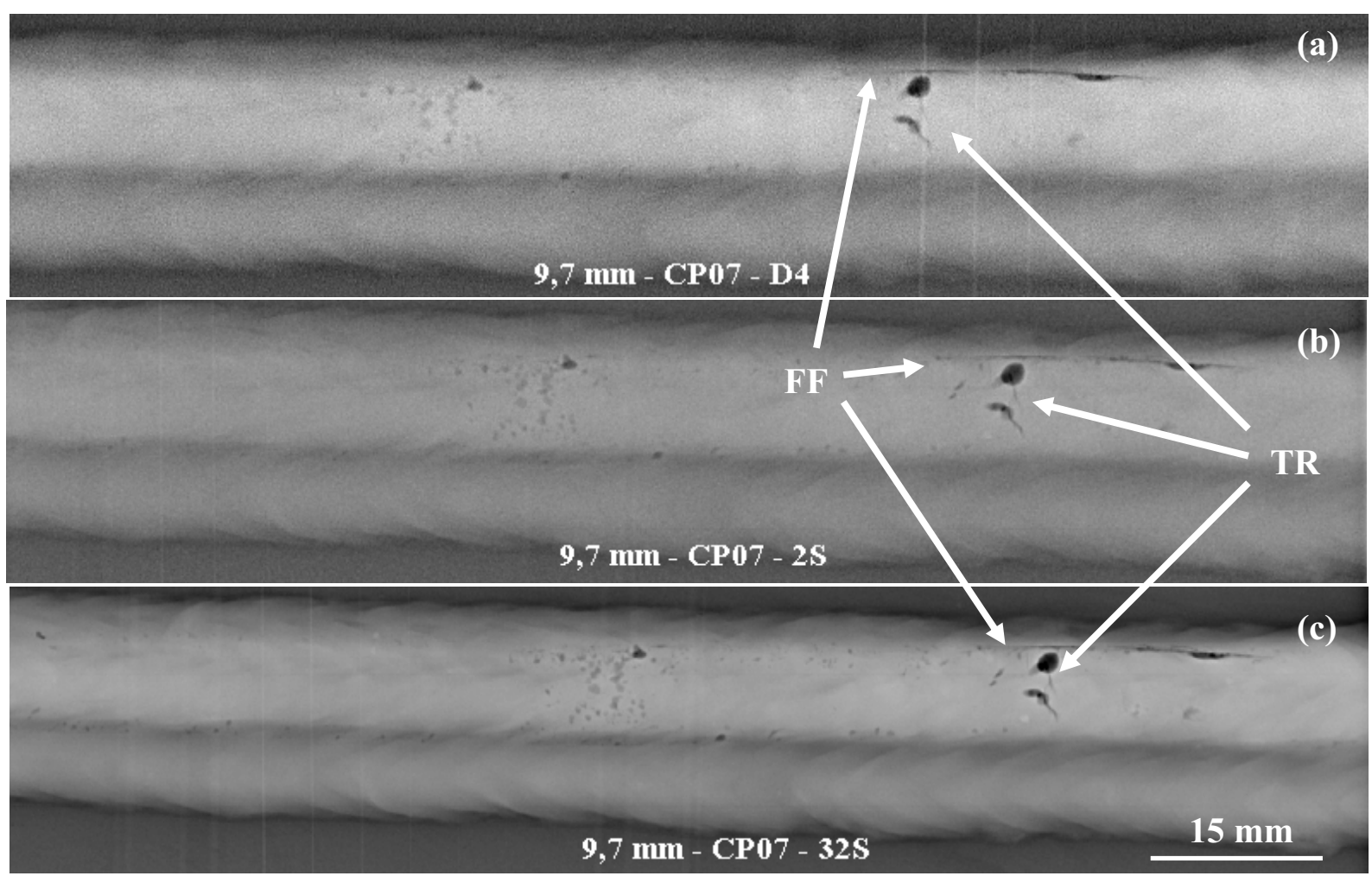

Figura 5.18 - Espessura de 9,7 mm - (a) Filme D4. (b) 2s. (c) 32s. 


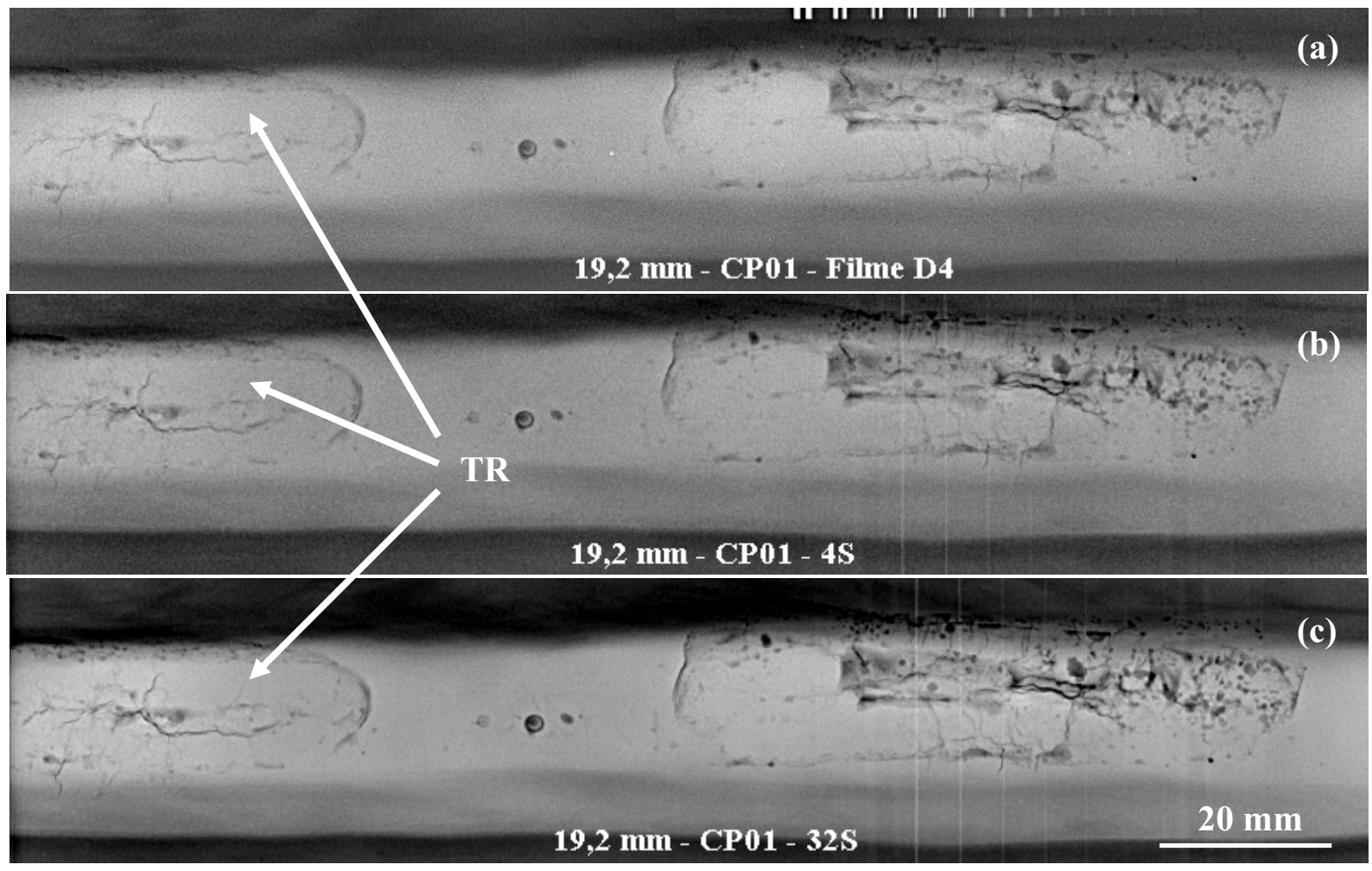

Figura 5.19 - Espessura de 19,2 mm - (a) Filme D4. (b) 4s. (c) 32s.

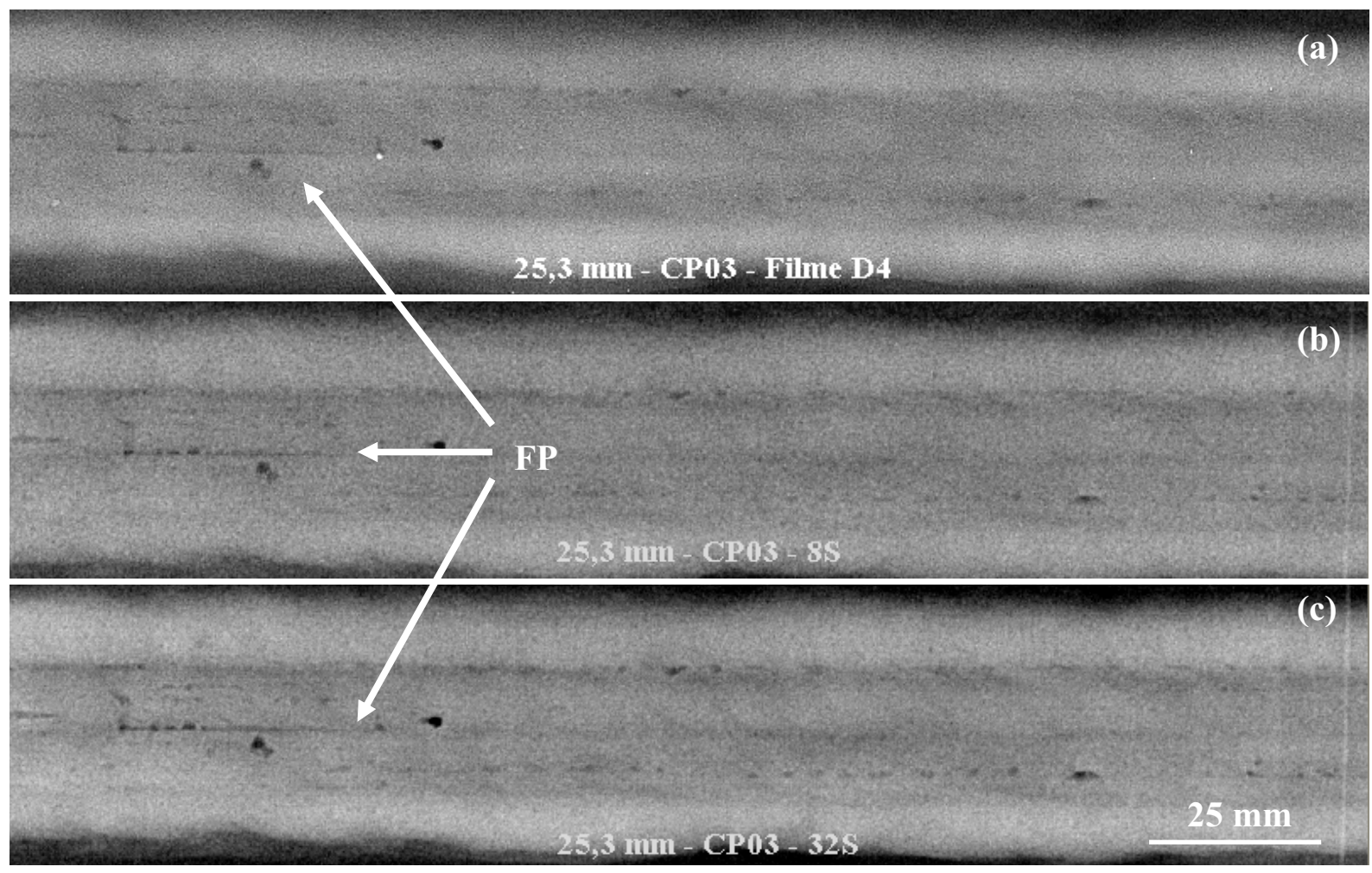

Figura 5.20 - Espessura de 25,3 mm - (a) Filme D4. (b) 8s. (c) 32s. 


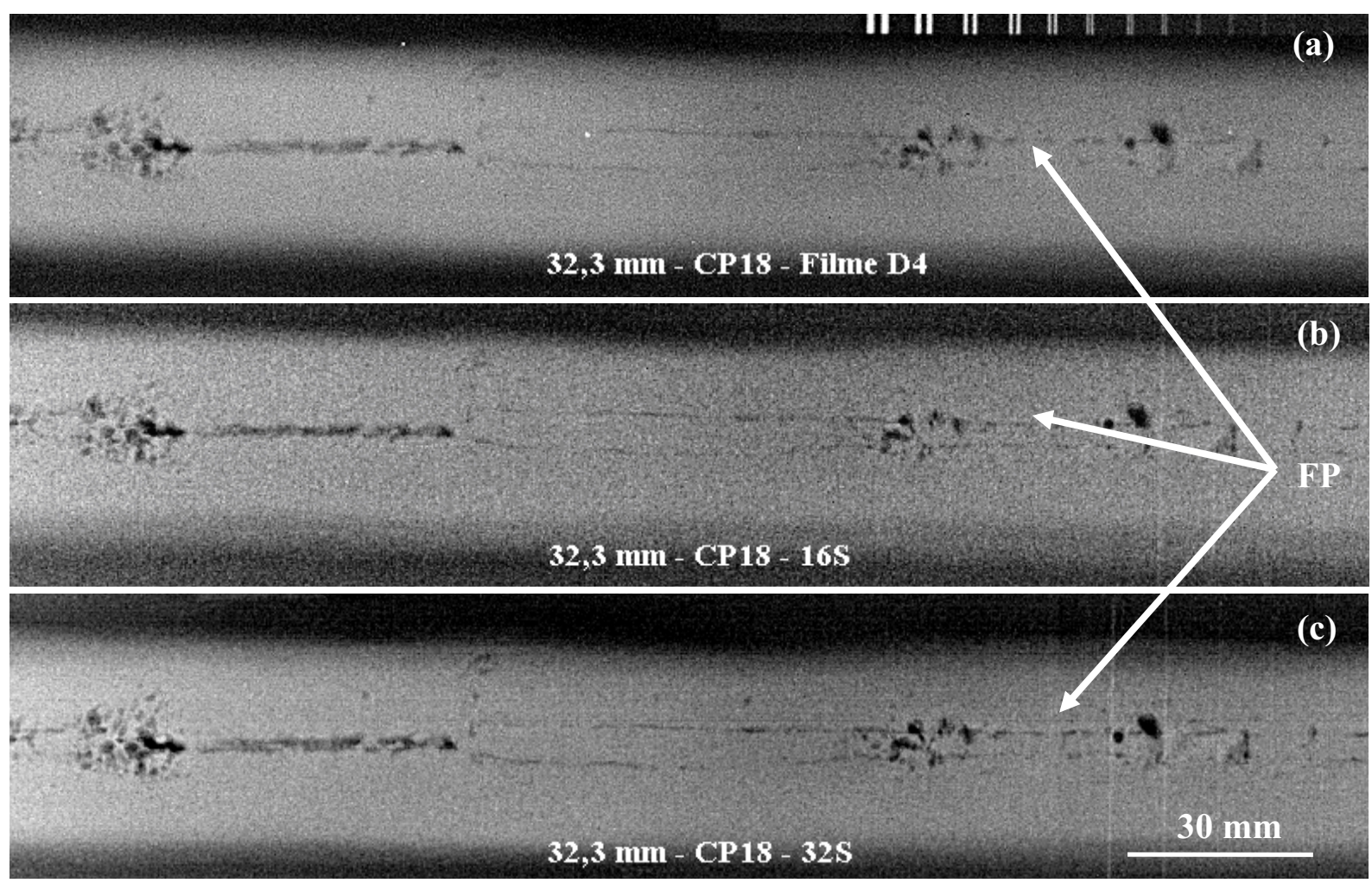

Figura 5.21 - Espessura de 32,3 mm - (a) Filme D4 (b) 16s. (c) 32s.

Nas Figuras 5.16 a 5.21, se observa descontinuidades do tipo porosidade, falta de fusão, falta de penetração, inclusão de escória e trincas longitudinais e transversais finas, que são mais facilmente vistas nas imagens da técnica digital, com tempos de integração reduzidos.

Para a definição dos tempos de integração necessários para se obter imagens iguais ou superiores as conseguidas com os filmes, foram analisadas todas as imagens e para cada espessura foram indicadas e apresentadas nas Figuras 5.16 a 5.21.

Nas Figuras 5.16 a 5.21 estão indicados pelas setas brancas alguns defeitos para que seja possível comparar os níveis de ruído destas imagens obtidas pela técnica digital e as encontradas nos filmes. Observa-se neste estudo que a percepção dos detalhes das descontinuidades são melhores na técnica digital. 


\subsubsection{Galeria de imagens de defeitos e comparação entre as técnicas.}

Nas Figuras 5.22 e 5.23, podem se observar as comparações entre as imagens obtidas na técnica convencional e a digital. As imagens foram ampliadas para que fosse possível realizar as comparações mantendo-se os mesmos critérios para as duas técnicas. Os pequenos detalhes dos defeitos indicados pelas setas na imagem digital mostrados na segunda linha de cada grupo de 04 defeitos, devem ser comparados com a imagem do mesmo defeito obtido com filme D4 mostrado na primeira linha.
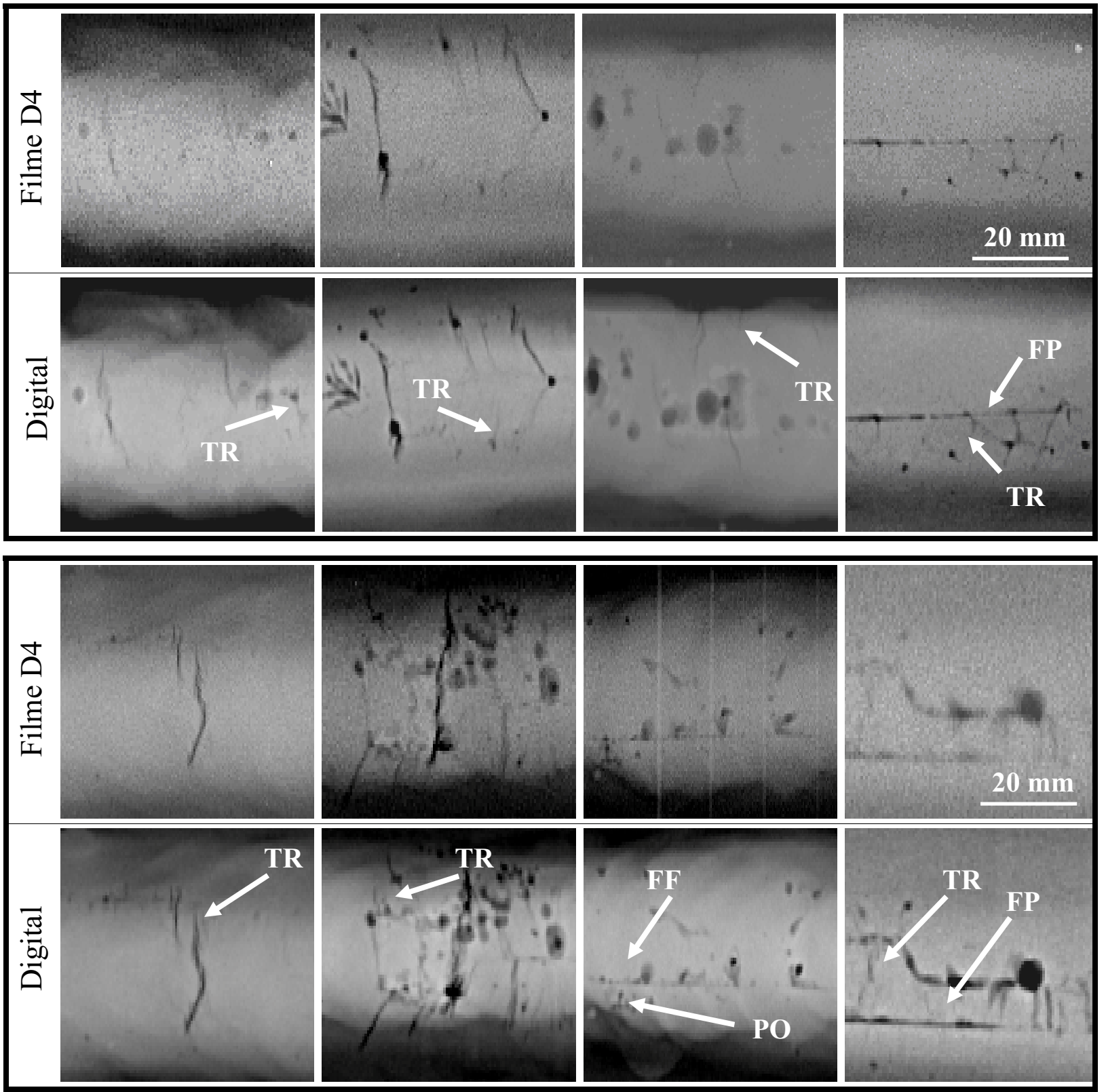

Figura 5.22 - Defeitos críticos - Comparação entre as técnicas. 

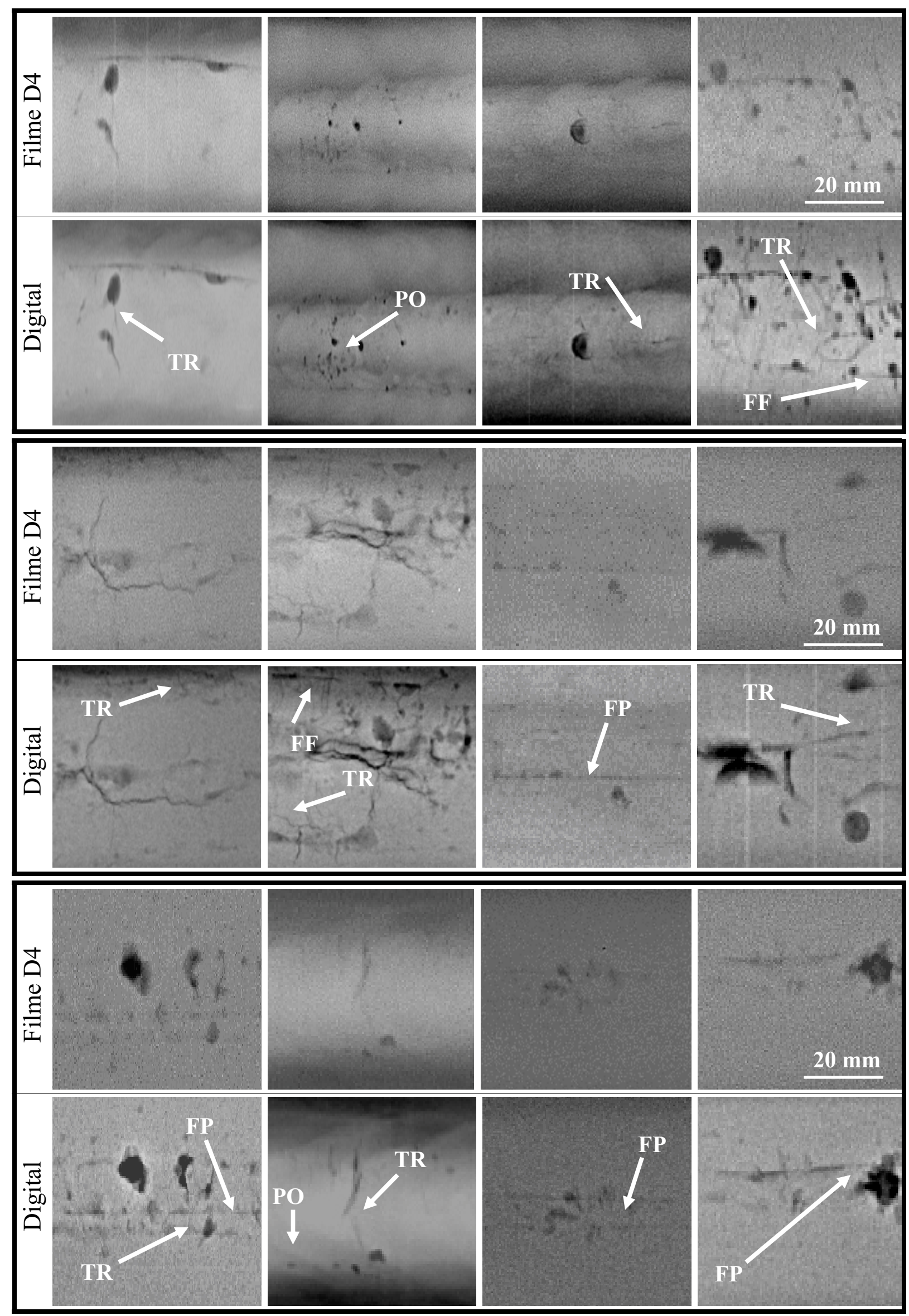

Figura 5.23 - Defeitos críticos complementares - Comparação entre as técnicas. 


\subsection{Tempo de integração mínimo.}

Observando os resultados apresentados nos itens anteriores, se fez necessário avaliar as mínimas situações aceitáveis para cada um dos experimentos realizados, considerando uma avaliação conjunta dos resultados, tendo como referência as normas envolvidas. Nos itens anteriores foram apresentados, separadamente, as exigências individuais em termos de indicador de qualidade de imagem (IQI), sendo que este já inclui as exigências da resolução espacial básica $\left(\mathrm{SR}_{\mathbf{B}}\right)$, através do "Princípio da Compensação", proposto na norma ISO/DIS 10893-7. Adicionalmente foram analisados os valores obtidos da relação sinal ruído normalisado $\left(\mathrm{SNR}_{\mathbf{N}}\right)$ e, finalmente, a avaliação utilizando os defeitos críticos feitos para verificar a sensibilidade entre as técnicas. A metodologia aplicada foi identificar, entre os resultados, a condição mais crítica para cada experimento e assim estes foram utilizados para definir o tempo de integração mínimo (final), visando garantir a obtenção da melhor sensibilidade.

Na Tabela 5.10 pode-se observar os mínimos tempos de integração, necessários para atendentimento dos parâmetros citados nos itens 5.3.1, 5.3.2, 5.3.3 e 5.3.4, no que se refere as propostas da norma ISO/DIS 10893-7 e a sensibilidade a defeitos reais.

Tabela 5.10 - Tempos de Integração Mínimos conforme ISO/DIS 10893-7.

\begin{tabular}{|c|c|c|c|c|c|c|}
\hline $\begin{array}{c}\text { Espessura } \\
\text { do } \mathbf{C P} \\
(\mathrm{mm}) \\
\end{array}$ & $\begin{array}{r}\text { SF } \\
\text { de } C \\
\text { Ite }\end{array}$ & $\begin{array}{l}\text { B e IQI } \\
\text { ontraste } \\
\text { m } 5.3 .2 \\
\text { (s) }\end{array}$ & & $\begin{array}{c}\mathbf{S N R}_{\mathbf{N}} \\
\text { Item } 5.3 .3 \\
(\mathrm{~s}) \\
\end{array}$ & $\begin{array}{c}\text { Sensibilidade a } \\
\text { defeitos reais } \\
\text { Item } 5.3 .4 \\
(\mathrm{~s}) \\
\end{array}$ & $\begin{array}{c}\text { Tempo de } \\
\text { Integração } \\
\text { Mínimo, Final } \\
\text { (s) }\end{array}$ \\
\hline 4,9 & 4 & (Fig. 5.5) & 1 & (Fig. 5.12 e Tab. 5.8) & 1 (Fig. 5.16 b) & 4 \\
\hline 6,4 & 2 & (Fig. 5.5) & 1 & (Fig. 5.12 e Tab. 5.8) & 2 (Fig. 5.17 b) & 2 \\
\hline 9,7 & 1 & (Fig. 5.5) & 1 & (Fig. 5.12 e Tab. 5.8) & 2 (Fig. $5.18 \mathrm{~b}$ ) & 2 \\
\hline 19,2 & 1 & (Fig. 5.6) & 1 & (Fig. 5.12 e Tab. 5.8) & 4 (Fig. 5.19 b) & 4 \\
\hline 25,3 & 2 & (Fig. 5.6) & 2 & (Fig. 5.12 e Tab. 5.8) & 8 (Fig. 5.20 b) & 8 \\
\hline 32,3 & 4 & (Fig. 5.6) & 16 & (Fig. 5.13 e Tab. 5.9) & 16 (Fig. $5.21 \mathrm{~b}$ ) & 16 \\
\hline
\end{tabular}

Observando os dados apresentados na Tabela 5.10, onde as avaliações do IQI de contraste do tipo arame são feitos no metal base, devido a proposta da norma ISO/DIS 
10893-7, pode-se observar que para espessuras de 4,9 a 19,2 $\mathrm{mm}$ os tempos de integração mínimos para atender todas as exigências estão entre 2 e $4 \mathrm{~s}$ e para as espessuras de 25,3 e 32,3 mm são de 8 e 16 s respectivamente. Em uma avaliação mais detalhada é verificado, por meio da Figura 5.13, que para a espessura de $32,3 \mathrm{~mm}$, e uma DOD de $80 \mathrm{~mm}$, com o tempo de integração de aproximadamente $10 \mathrm{~s}$ pode-se obter valores superiores de $\mathrm{SNR}_{\mathbf{N}}$ de 100.

Analisando os resultados, no que se refere as exigências da DNV-OS-F101, API 5L e ISO 3183, e também utilizando as exigencias de $\mathrm{SNR}_{\mathrm{N}}$ e $\mathrm{SR}_{\mathrm{B}}$, propostos pela ISO/DIS 10893-7, pode-se observar na Tabela 5.11, os tempos mínimos de integração necessários para atendentimento dos parametros citados nos itens 5.3.2 (incluí item 5.3.1), 5.3.3 e 5.3.4

Tabela 5.11 - Tempos de Integração Mínimos para DNV-OS-F101, API 5L e ISO 3183.

\begin{tabular}{|c|c|c|c|c|c|c|c|c|c|}
\hline \multirow{3}{*}{$\begin{array}{c}\begin{array}{c}\text { Espessura } \\
\text { da Solda } \\
(\mathbf{m m})\end{array} \\
5,9 \text { e } 10,8\end{array}$} & \multicolumn{3}{|c|}{$\begin{array}{c}\mathrm{SR}_{\mathrm{B}} \text { e IQI de Contraste } \\
\text { Item 5.3.2 } \\
\text { (s) }\end{array}$} & \multirow{2}{*}{\multicolumn{2}{|c|}{$\begin{array}{c}\text { SNRN } \\
\text { item 5.3.3 } \\
(\mathrm{s}) \\
\text { ISO/DIS 10893-7 }\end{array}$}} & \multirow{2}{*}{\multicolumn{2}{|c|}{$\begin{array}{c}\text { Sensibilidade a } \\
\text { defeitos reais } \\
\text { Item 5.3.4 (s) }\end{array}$}} & \multicolumn{2}{|c|}{$\begin{array}{c}\text { Tempo de } \\
\text { Integração } \\
\text { Final (s) }\end{array}$} \\
\hline & \multirow{2}{*}{$\frac{\text { DNV }}{1}$} & \multicolumn{2}{|c|}{ API5L e ISO3183 } & & & & & DNV & $\begin{array}{c}\text { API5L } \\
\text { ISO3183 }\end{array}$ \\
\hline & & 1 & (Fig. 5.7 e 5.8 ) & 1 & (Fig. 5.12 e Tab. 5.8) & 1 & (Fig. 5.16 b) & 1 & 1 \\
\hline 13,3 & 2 & 1 & (Fig. 5.8) & 1 & (Fig. 5.12 e Tab. 5.8) & 2 & (Fig. 5.17 b) & 2 & 2 \\
\hline 15,3 & 1 & 1 & (Fig. 5.8) & 1 & (Fig. 5.12 e Tab. 5.8) & 2 & (Fig. 5.18 b) & 2 & 2 \\
\hline 22,9 & 1 & 1 & (Fig. 5.9) & 1 & (Fig. 5.12 e Tab. 5.8) & 4 & (Fig. 5.19 b) & 4 & 4 \\
\hline 23,2 & 4 & 1 & (Fig. 5.9) & 1 & (Fig. 5.12 e Tab. 5.8) & 4 & (Fig. 5.19 b) & 4 & 4 \\
\hline 23,4 e 25,3 & 1 & 1 & (Fig. 5.9 e 5.10 ) & 2 & (Fig. 5.12 e Tab. 5.8) & 8 & (Fig. $5.20 \mathrm{~b}$ ) & 8 & 8 \\
\hline 29,9 & 2 & 1 & (Fig. 5.10) & 2 & (Fig. 5.12 e Tab. 5.8) & 8 & (Fig. 5.20 b) & 8 & 8 \\
\hline 30,8 e 31,4 & 4 & 1 & (Fig. 5.10) & 2 & (Fig. 5.12 e Tab. 5.8) & 8 & (Fig. $5.20 \mathrm{~b}$ ) & 8 & 8 \\
\hline 36,1 & 2 & 1 & (Fig. 5.11) & 16 & (Fig. 5.13 e Tab. 5.9) & 16 & (Fig. $5.21 \mathrm{~b}$ ) & 16 & 16 \\
\hline 36,3 e 36,6 & 2 & 2 & (Fig. 5.11) & 16 & (Fig. 5.13 e Tab. 5.9) & 16 & (Fig. 5.21 b) & 16 & 16 \\
\hline
\end{tabular}

Na Tabela 5.11, onde as avaliações do IQI de contraste do tipo arame são feitos na região do cordão de solda, pode-se observar que para espessuras de 5,9 a $23.2 \mathrm{~mm}$ os tempos de integração mínimos para atender adicionalmente todas as exigências da ISO/DIS 10893-7 estão entre 2 e 4 s. Para espessuras maiores ou iguais a 23,4 mm, os tempos foram de 8 a $16 \mathrm{~s}$. 
É importante notar que, tanto para a aplicação da norma ISO/DIS 10893-7 como das normas DNV-OS-F101, API 5L e ISO 3183, os tempos de integração de 2s, $4 \mathrm{~s}$ e 8 s, identificados com a cor amarela na Tabela 5.10 e Tabela 5.11, indicam que o uso do critério da sensibilidade a defeitos reais devem ser considerados para o estabelecimento dos tempos de integração mínimos.

Na Figura 5.24 pode-se observar a comparação dos tempos de exposição utilizados na técnica convencional com os 02 tipos de filmes e os tempos de integração utilizados na técnica digital e mostrados nas Tabelas 5.10 e 5.11

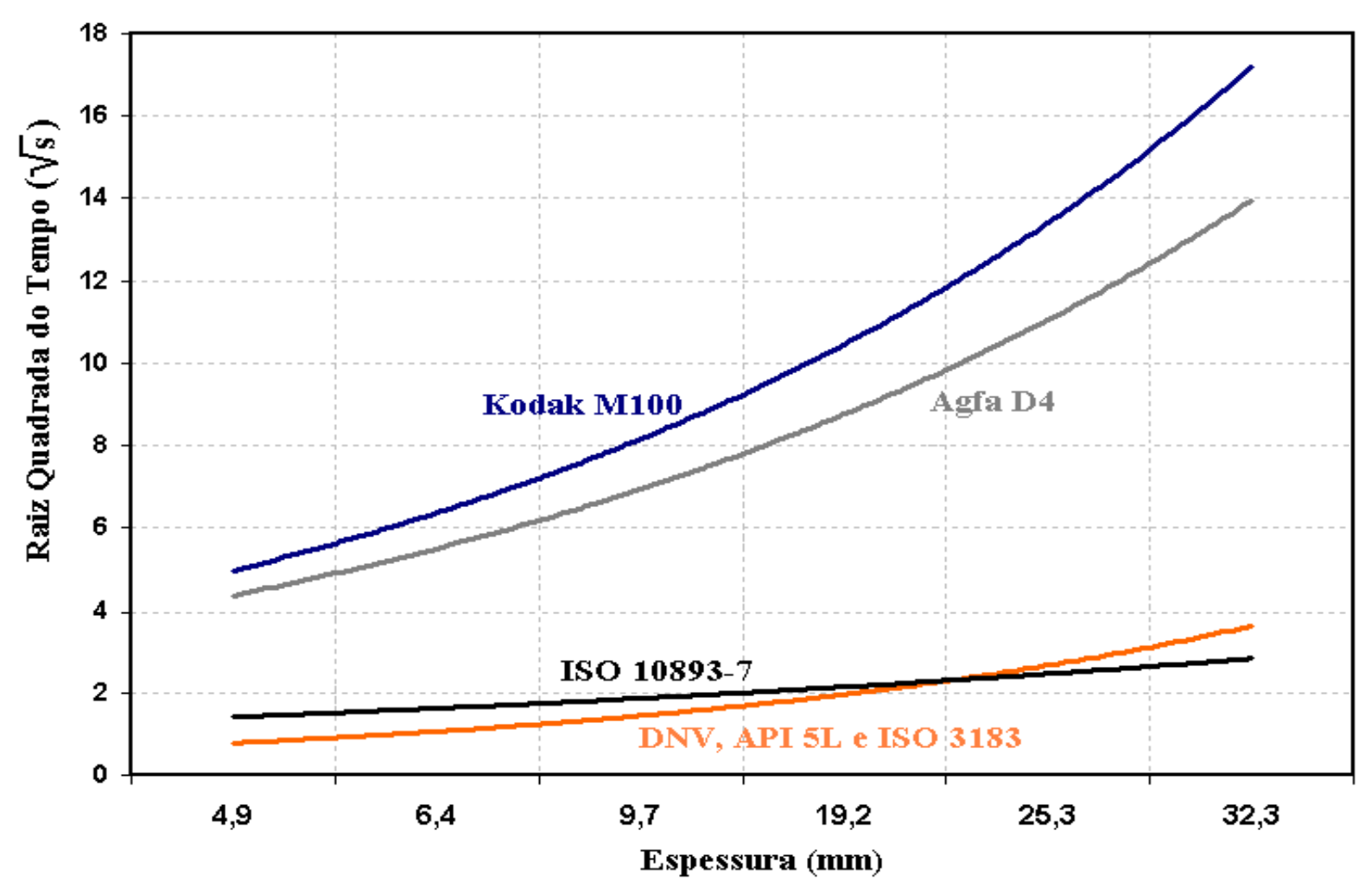

Figura 5.24 - Comparação dos Tempos de Exposição e Integração.

Baseado nas curvas mostradas na Figura 5.24, pode-se verificar que os tempos de integração utilizados na técnica digital são muito pequenos, independente da norma utilizada, em comparação aos tempos de exposição praticados quando se utilizam os tradicionais filmes industriais.

Com o filme Kodak M100, Classe 1, para a espessura de 4,9 mm esta variação é de 7 e para as demais espessuras, variam entre 22 a 40 vezes. Para o filme AGFA D4, Classe 1, para a espessura de $4,9 \mathrm{~mm}$ a variação é de 5 vezes e para as demais espessuras de 15 a 28 vezes. 


\subsection{Comparação das exposições relativas entre as técnicas.}

Baseado na comparação dos tempos empregados em cada uma das técnicas, na Figura 5.25, pode se observar as exposições relativas estimadas, que são apresentadas como a raiz quadrada do produto da amperagem (mA), tempo de exposição, em minutos (min) e o número de exposições (Exp), para um período de um ano, realizando aproximadamente 400.000 radiografias. Este número de radiografia foi baseado em 1.500 filmes/dia, 264 dias trabalhados por ano.

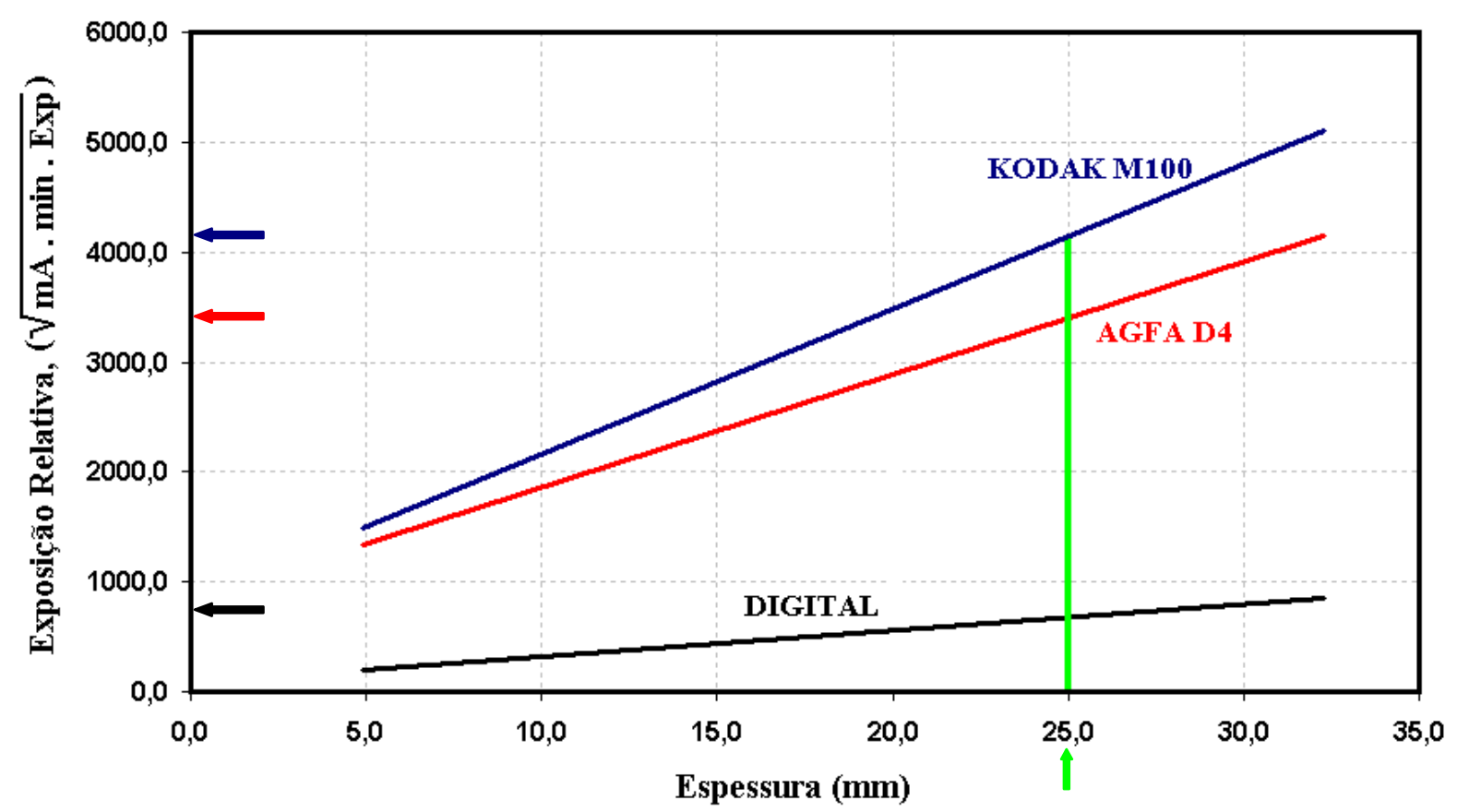

Figura 5.25 - Comparação das Exposições Relativas entre a Técnica Digital e Convencional.

Como pode-se observar na Figura 5.25, a utilização da radiografia digital contribui de forma significativa para os projetos de Meio Ambiente e da Saúde do trabalhador, pois o ambiente fica sujeito as exposições relativas menores, do que as praticadas quando se trabalha com a técnica convencional.

Analisando a utilização da técnica digital para a espessura de 25,0 mm pode-se estimar uma redução das exposições relativas à técnica convencional que varia de 22 a 32 vezes, comparando com os filmes AGFA D4 e KODAK M100. 


\section{Capítulo 6}

\section{Conclusões e sugestões para trabalhos futuros}

\subsection{Conclusões}

Baseado nos resultados apresentados e discutidos no Capitulo 5, pode-se listar as seguintes conclusões:

\section{Resolução Espacial Básica, $\mathbf{S R}_{\mathrm{B}}$.}

Os valores propostos para a resolução espacial básica, $\boldsymbol{S R}_{\boldsymbol{B}}$, na norma ISO/DIS 10893-7 classe B, não foram atendidos nas espessuras de 4,9, 6,4 e 9,7 mm, porém, como os resultados experimentais da sensibilidade ao contraste apresentaram valores melhores que os propostos, em até 3 de arames mais finos, com a combinação destes resultados (resolução espacial básica versus a sensibilidade ao contraste) foi possível aplicar o "princípio da compensação", previsto na referida norma e assim atender as exigencias. Nas espessuras de 19,2, 25,3 e 32,3 $\mathrm{mm}$ os valores propostos foram atendidos totalmente, sem o uso deste princípio.

Os resultados experimentias mostraram, para as espessuras de 4,9 até 19,2 mm, indicam que a técnica convencional obteve menores (melhores) valores de $\mathbf{S R}_{\mathbf{B}}$, de 63 e $80 \mu \mathrm{m}$ (IQI de arame duplo 12D e 11D), do que os obtidos na técnica digital, que para todas as espessuras testadas foi de $100 \mu \mathrm{m}$, (IQI de arame duplo 10D). Os valores experimentais encontrados na técnica digital, comprovaram, para todas as espessuras testadas, a dependência dos resultados da $\mathbf{S R}_{\mathbf{B}}$ com o tamanho pixel do detector PaxScan 2520V, que é de $127 \mu \mathrm{m}$.

Os valores experimentais da $\mathbf{S R}_{\mathbf{B}}$, pelo método da Função de Transferência da Modulação, MTF, apresentaram valores maiores (159 a $205 \mu \mathrm{m}$ ) do que os obtidos pelo método direto $(100 \mu \mathrm{m})$. O uso, ou não, do calço metálico não alterou os valores obtidos da $\mathbf{S R}_{\mathbf{B}}$ e da MTF. 


\section{Sensibilidade ao Contraste, CS.}

Para todas as espessuras testadas, a técnica digital, utilizando o IQI do tipo arame, obteve, na região do metal base, a sensibilidade ao contraste, visualizando até 3 arames mais finos, já incluídos os acréscimos gerados pelos altos valores da $\mathrm{SR}_{\mathrm{B}}$, do que os valores propostos, pela classe mais rigorosa, da norma ISO/DIS 10893-7. Em relação as avaliações realizadas na região do cordão de solda, os experimentos apresentaram sensibilidades de até 4 arames mais finos do que as exigências da norma DNV-OSF101, e de até 6, para as normas API 5L e ISO 3183. Adicionalmente aos valores previstos nestas normas, foram incluidos os acréscimos devido aos valores da $\mathrm{SR}_{\mathrm{B}}$.

Os valores obtidos de sensibilidade ao contraste, $\mathbf{C S}$, na técnica digital, tanto na região do metal base como na do cordão de solda, apresentaram melhores resultados que as obtidas pela técnica convencional, com filmes AGFA D4 e KODAK M100. A melhor sensibilidade obtida pela técnica digital foi de $50 \mu \mathrm{m}$, enquanto na técnica convencional foi de $130 \mu \mathrm{m}$.

Pelos parâmetros utilizados nestes experimentos, pode-se concluir que as variações realizadas nas distâncias do objeto ao detector, DOD, não causaram diferenças significativas, nos resultados da sensibilidade ao contraste, CS.

\section{Relação Sinal Ruído Normalizado, $\mathrm{SNR}_{\mathrm{N}}$.}

Baseado nos resultados apresentados, para todas as espessuras avaliadas, os valores da relação sinal ruído normalizado, $\mathbf{S N R}_{\mathbf{N}}$, atenderam o mínimo valor previsto na mais rigorosa classe proposta na norma ISO/DIS 10893-7, que é de 100.

Para as espessuras até 19,2 mm, com os aparelhos testados, os valores de $\mathbf{S N R}_{\mathbf{N}}$ foram superiores a 150, independente da distância do objeto ao detector, DOD e do tempo de integração utilizado. Para as espessuras de 25,3 e 32,3 mm o tempo de integração utilizado possou a ser significativo, sendo que com aproximadamente $10 \mathrm{~s}$ estes os valores permanecem acima de 100, independente da DOD.

Para a espessura de $32,3 \mathrm{~mm}$, utilizando tempo de integração de até $512 \mathrm{~s}$, se observou a contribuição do aumento dos valores de $\mathbf{S N R}_{\mathbf{N}}$ para o melhoria da sensibilidade ao contraste, CS. Se conclui também que, esta melhoria passa a não ser 
significativa após o tempo de integração acima de $64 \mathrm{~s}$, considerados impraticáveis, por fatores de produtividade.

\section{Sensibilidade na detecção de defeitos críticos.}

Avaliando os resultados obtidos, a inspeção com o sistema digital utilizado apresentou uma melhor sensibilidade na detecção de defeitos críticos, quando comparamos com os obtidos na técnica convencional.

O procedimento proposto, nesta tese, em termos de avaliar a detecção de defeitos críticos se conclui ser uma prática adequada para a avaliação do desempenho da radiografia digital e do estabelecimento do tempo de integração mínimo, independentemente de não estar prevista nas normas usuais.

\section{Comparação do tempo de exposição e de integração.}

Em termos de comparação dos tempos de integração utilizados na técnica digital e os tempos de exposição praticados pela técnica convencional, conclui-se para estes experimentos, que a utilização da radiografia digital traz uma redução, principalmente nas maiores espessuras, em até 40 vezes.

\section{Comparação das exposições relativas.}

Com base nos resultados apresentados, em relação aos valores de exposição relativa, se conclui que, a radiografia digital traz melhorias de até 40 vezes quando comparado com a técnica convencional, além disto utiliza energia, $\mathrm{kV}$, com menores intensidades.

\section{Considerações finais.}

Baseado nos resultados obtidos, pode-se concluir que a radiografia digital utilizando o DDA, atende adequadamente as exigências das normas DNV-OS-F101, API 5L e ISO 3183 e as propostas da classe B da norma ISO/DIS 10893-7 em elaboração e assim pode ser utilizado para a inspeção de tubos para gasodutos e oleodutos, terrestres e marítimos.

O uso do DDA, para este segmento de produto, traz benefícios de sensibilidade, redução dos tempos de ciclo de inspeção e das doses recebidas. Melhora as condições 
das atividades do pessoal envolvido nesta atividade. Traz melhorias, em termos de meio ambiente, radioproteção e aspectos da saúde e segurança.

Finalmente, baseado nas afirmações previamente emitidas, pode-se concluir que este trabalho contribui significativamente para o estabelecimento dos critérios e para a sua viabilização técnica e economica para a aplicação da radiografia digital neste segmento de produto.

\subsection{Sugestões para trabalhos futuros}

Como sugestão para desenvolvimentos futuros pode-se listar:

Para espessuras a partir de $25,3 \mathrm{~mm}$, utilizar a ampola e o detector que possam trabalhar com voltagem maior de $225 \mathrm{kV}$, mantendo-se o máximo tamanho de pixel de $127 \mu \mathrm{m}$ do detector e o tamanho do ponto focal de $1,0 \mathrm{~mm}$ que resulte em uma potencia maior de $1800 \mathrm{~kW}$.

Utilizar um detector com o conversor A/D maior de 12 bits, aumentando a quantidade dos níveis de cinza e que poderão resultar em uma melhoria da qualidade da imagem. 


\section{REFERENCIAS BIBLIOGRÁFICAS}

ALLEN M., DRAKE S., Performance evaluation of a computed radiography system. Digital Imaging VIII, ISBN 1-57117-135-5, Mashantucket, USA, 2005.

AMERICAN PETROLEUM INSTITUTE, API 5L. Specification for Line Pipe. Washington, 2007.

AMERICAN SOCIETY FOR TESTING AND MATERIALS, ASTM A-370, Standard Test Methods and Definitions for Mechanical Testing of Steel Products, West Conshohocken, PA, 2009.

AMERICAN SOCIETY FOR TESTING AND MATERIALS, ASTM A-751, Standard test methods, practices, and terminology for chemical analysis of steel products. West Conshohocken, PA, 2008.

AMERICAN SOCIETY FOR TESTING AND MATERIALS, ASTM E-1000, Standard Guide for Radioscopy. West Conshohocken, PA, 2009.

AMERICAN SOCIETY FOR TESTING AND MATERIALS, ASTM E-1025, Standard practice for design, manufacture, and material group classification of Holetype image quality indicators (IQI) used for radiology. West Conshohocken, PA, 2005.

AMERICAN SOCIETY FOR TESTING AND MATERIALS, ASTM E 1815, Standard test method for classification of film systems for industrial Radiography. West Conshohocken, PA, 2008.

AMERICAN SOCIETY FOR TESTING AND MATERIALS, ASTM E 2339, Standard Practice for Digital Imaging and Communication in Nondestructive Evaluation "DICONDE", West Conshohocken, PA, 2006.

AMERICAN SOCIETY FOR TESTING AND MATERIALS, ASTM E 2445, Standard Practice for Qualification and Long-Term Stability of Computed Radiology Systems, West Conshohocken, PA, 2005.

AMERICAN SOCIETY FOR TESTING AND MATERIALS, ASTM E 2446, Standard Practice for Classification of Computed Radiology Systems, West Conshohocken, PA, 2005.

AMERICAN SOCIETY FOR TESTING AND MATERIALS, ASTM E 2597, Standard practice for manufacturing characterization of digital detector arrays, West Conshohocken, PA, 2007.

AMERICAN WELDING SOCIETY, AWS A 5.18, Specification for carbon steel electrodes and fluxes for submerged arc welding, Miami, 2005. 
AMIN E. S., Application of artificial neural networks to evaluate weld defects of nuclear components, Journal of Nuclear and Radiation Physics, Volume 3, No. 2, pp. 83-92, 2008.

ASM METALS HANDBOOK, Volume 17 - Nondestructive evaluation and quality control, 9th Edition, Publisher: ASM International, 1608p, 1997.

ASSOCIAÇÃO BRASILEIRA DE ENSAIOS NÃO DESTRUTIVOS E INSPEÇÃO. Curso de inspetor de fabricação - Modulo de Ensaios Não Destrutivos, São Paulo, 2005.

ASSOCIAÇÃO BRASILEIRA DE NORMAS TÉCNICAS. ABNT NBR ISO 9712, Ensaios não-destrutivos - Qualificação e certificação de pessoal, São Paulo, 2007.

BAVENDIEK K., Flat Panel Detector Calibration for a high SNR, http://www.ndt.net. The NDT Database \& Journal, ISSN: 1435-4934, European Conference of NDT, Berlin, Germany, 2005.

BAVENDIEK, K.; EWERT U.; ZSCHERPEL U.; Digital Detector Array - DDA, International Workshop on Imaging NDE, Kalpakkam, India, 2007

BAVENDIEK K.; HEROLD F.; GRIGAT R., A New Analysis and Classification Method for Automatic Defect Recognition in X-Ray Images of Castings, 8th European Conference of NDT, Barcelona, 2002.

BAVENDIEK K.; HEIKE U.; MEADE W. D.; ZSCHERPEL U.; EWERT U., New Digital Radiography Procedure Exceeds Film Sensitivity Considerably in Aerospace Applications, European Conference of NDT, Berlin, Germany, 2006.

BECKMANN J.; RACHNY S.; ZSCHERPEL U.; EWERT U., Improved Procedure for Computed Radiography - A Comparative Study on Welded Tube Sections by Film Radiography and Computed Radiography - 17th World Conference on Nondestructive Testing, Shanghai, China, 2008.

BETTUZZI M.; CORNACCHIA S.; ROSSI M.; PALTRINIERI E.; MORIGI M. P.; BRANCACCIO R.; ROMANI D.; CASALI F., A new linear array detector for high resolution and low dose digital radiography, Nuclear Instruments and Methods in Physics Research, Section B: Beam Interactions with Materials and Atoms, Volume 213 pp. 227-230, Elsevier, 2004.

BLAKELEY B., SPARTIOTIS K. S.; Digital Radiography for the Inspection of Small Defects, European Conference of NDT, Berlin, Germany, 2006

BOIY L., Successful conversion to digital X-Ray detectors, http://www.ndt.net. The NDT Database \& Journal, ISSN: 1435-4934, European Conference of NDT, Berlin, 2006. 
BOSSI, R. H.; IDDINGS F. A.; WHEELER G. C.; MOORE P. O., Radiographic Testing Handbook, Publisher: American Society for Nondestructive Testing, New York, USA, 2002.

COMISSÃO NACIONAL DE ENERGIA NUCLEAR, CNEN-NN-3.01, Diretrizes básicas de proteção radiológica, Rio de Janeiro, 2005.

COTA A. B.; RODRIGUES P. C. M.; BARBOSA R. A. N. M.; SANTOS D. B., Influência da deformação na região de não recristalização da austenita sobre a transformação em resfriamento continuo em um aço bainítico de baixo carbono, Revista Escola de Minas, Volume 58, nº 2, Ouro Preto, 2005.

CZICHOS H.; SAITO T.; SMITH L.; Springer Handbook of Materials Measurement Methods, Publisher: Springer Science, New York, USA, 2006.

DET NORSEK VERITAS, DNV-OS-F101, Submarine pipeline systems, Hovik, 2007.

EUROPEAN STANDARD, EN 14784-1, Non-destructive testing. Industrial computed radiography with storage phosphor imaging plates - Part 1: Classification of systems, Bruxelas, 2005.

EUROPEAN STANDARD, EN 14784-2, Non-destructive testing. Industrial computed radiography with storage phosphor imaging plates - Part 2: General principles for testing of metallic materials using X-rays and gamma rays, Bruxelas, 2005.

EUROPEAN STANDARD, EN 12543-1, Nondestructive testing - Characteristics of focal spots in industrial X-ray systems for use in nondestructive testing - Part 1 Scanning method, Bruxelas, 1999.

EUROPEAN STANDARD, EN 473, Qualification and certification of NDT personnel- General principles, Bruxelas, 2005.

EWERT U.; ZSCHERPEL U.; BELLON C.; JAENISH G.R.; BECKMANN J.; JECHOW M., Flaw Size Dependent Contrast Reduction and Additional Unsharpness by Scattered Radiation in Radiography - Film and Digital Detectors in Comparison, 17th World Conference on Nondestructive Testing, Shanghai, China, 2008 .

FARMAN A. G.; LEVATO C. M.; GANE D.; SCARFE W. C.; In practice: How going digital will affect the dental office, 2008, The Journal of the Dental Association, Disponível em: http://.www.jada.ada.org, Acesso em: 08 out. 2009.

FERREIRA, C. A. M. Radiografia Computadorizada Aplicada na Inspeção de Soldas de Tubulações nos Limites da Técnica de Parede Dupla Vista Dupla (PDVD). 105 f. Dissertação (Mestrado em Engenharia Metalúrgica e de Materiais) COPPE - Universidade Federal do Rio de Janeiro, Rio de Janeiro, 2009. 
GEIT, Radiographer's weld interpretation reference, General Electric Company, 2004.

GONZALEZ R.; WOODS R., Digital Image Processing, Second Edition, Prentice Hall, New Jersey, USA, 2002.

HEROLD F., GRIGAT R., BAVENDIEK K., A Third generation automatic defect recognition system. 16th World Conference on NDT, Montreal, Canada, 2004. Disponível em: www.ndt.net/article/wcndt2004/pdf/automotive/192_herold.pdf. Acesso em Agosto 2009.

INTERNATIONAL ATOMIC ENERGY AGENCY, IAEA, TECDOC-1445 Development of protocols for corrosion and deposits evaluation in pipes by radiography, Industrial Applications and Chemistry Section International Atomic Energy Agency, Vienna, Austria, 2005.

INTERNATIONAL ORGANIZATION FOR STANDARDIZATION, ISO 3183, Petroleum and natural gas industries - Steel pipes for pipeline transportation systems, Genebra, 2007.

INTERNATIONAL ORGANIZATION FOR STANDARDIZATION, ISO 9712, Nondestructive testing - Qualification and certification of personnel, Genebra, 2005.

INTERNATIONAL ORGANIZATION FOR STANDARDIZATION, ISO/DIS 10893-6, Non-destructive testing of steel tubes - Part 6: Radiographic testing of the weld seam of welded steel tubes for the detection of imperfections, Genebra, 2009.

INTERNATIONAL ORGANIZATION FOR STANDARDIZATION, ISO/DIS 10893-7, Non-destructive testing of steel tubes - Part 7: Digital radiographic testing of the weld seam of welded steel tubes for the detection of imperfections, Genebra, 2009

INTERNATIONAL ORGANIZATION FOR STANDARDIZATION, ISO 11484, Steel products - Employer's qualification system for non-destructive testing (NDT) personnel, Genebra, 2008.

INTERNATIONAL ORGANIZATION FOR STANDARDIZATION, ISO 11699-1, Non-destructive testing - Industrial radiographic film - Part 1: Classification of film systems for industrial radiography, Genebra, 2008.

INTERNATIONAL ORGANIZATION FOR STANDARDIZATION, ISO 12096, Submerged arc-welded steel tubes for pressure purposes - Radiographic testing of the weld seam for the detection of imperfections, Genebra, 1996

INTERNATIONAL ORGANIZATION FOR STANDARDIZATION, ISO 14096-1, Non-destructive testing - Qualification of radiographic film digitization systems - Part 1: Definitions, quantitative measurements of image quality parameters, standard reference film and qualitative control, Genebra, 2005. 
INTERNATIONAL ORGANIZATION FOR STANDARDIZATION, ISO 14096-2, Non-destructive testing - Qualification of radiographic film digitization systems - Part 2: Minimum requirements, Genebra, 2005.

INTERNATIONAL ORGANIZATION FOR STANDARDIZATION, ISO 17363, Non-destructive testing of welds - Radiographic testing of fusion-welded joints, Genebra, 2003.

INTERNATIONAL ORGANIZATION FOR STANDARDIZATION, ISO 19232-1, Non-Destructive Testing - Image quality of radiographs - Part 1: Image quality indicators (wire type) - Determination of image quality value, Genebra, 2004.

INTERNATIONAL ORGANIZATION FO R STANDARDIZATION, ISO 19232-5, Non-Destructive Testing - Image quality of radiographs - Part 5: Image quality indicators (duplex wire type) - Determination of image quality value. Genebra, 2004.

ISee!, User manual for the measuring program ISee!, Version 1.7; http://www.kb.bam.de/ alex/ic.html, BAM VIII.3; Berlin, 2007.,

JEWELL M., Automatic Image Presentation and Interpretation, Digital Imaging VIII, ISBN 1-57117-135-5, Mashantucket, USA, 2005.

KIRSCH R., Primeira imagem digital, National Institute of Standards and Technology em 1957, Disponível em: http://pt.wikipedia.org/wiki/Russell_Kirsch, Acesso em Maio 2009.

KODAK, Radiography in Modern industry, Forth Edition, Eastman Kodak Company, New York, 1980.

MANGO S.A., Transitioning to digital radiography - HOW NDE Organization are making sense of new technology. Aerial \& Industrial Materials, Eastman Kodak Company, Rochester, USA, 2004.

MOHR G. A.; WILLEMS P., Factors affecting Probability of Detection with Computed Radiography, 17th World Conference on Nondestructive Testing, Shanghai, China, 2008.

MOREIRA E.; FRITZ M. C.; SIMOES H. R.; RABELLO J. M. B.; CAMARGO J. R., Flat-panel detectors are accepted for digital radiography in place of conventional radiography in pipeline weld inspection, IV Conferencia Panamericana de END, Buenos Aires, Argentina, 2007.

MOREIRA E.; Aplicação da radiografia digital utilizando detectores planos para a inspeção de soldas de gasodutos e oleodutos; 2007. 114 f. Dissertação (Mestrado em Engenharia Mecânica) - UNITAÚ - Universidade de Taubaté, Taubaté, Brasil, 2007. 
MOREIRA E.; LOPES R.; PEREIRA M.; RABELLO J. M. B.; ZSCHERPEL U., OLIVEIRA D., Estágio atual da aplicação da Radiografia Digital em soldas de tubos de gasodutos e oleodutos, 10a Coteq, Conferência de Tecnologia, Salvador, Brasil, 2009.

OLIVEIRA, D. F., Análise da Radiografia Computadorizada em Condições de Águas Profundas. 2007. 123 f. Dissertação (Mestrado em Engenharia Nuclear) COPPE - Universidade Federal do Rio de Janeiro, Rio de Janeiro, 2007.

PETROBRAS, N-1595, Ensaio não destrutivo - Radiografia, Rio de Janeiro, 2004.

PETROBRAS, N-1738, Descontinuidades em juntas soldadas, fundidos. Forjados e laminados, Rio de Janeiro, 2003.

PETROBRAS, N-2821, Ensaio não destrutivo - Radiografia computadorizada em juntas soldadas, Rio de Janeiro, 2007.

PETROBRAS, PRE-SAL, Projeto de dutos do pré-sal, Agencia Petrobras de Notícias, Disponível em: http://www.agenciapetrobrasdenoticias.com.br/. Acesso em 20 Novembro 2009.

PINCU R., The advantages of amorphous silicon digital radiography flat panel technology over traditional film in NDT applications, Digital Imaging VIII, ISBN 1-57117-135-5, Mashantucket, USA, 2005.

PINCU R.; KLEINBERGER O., Portable X Ray in the service of art, 9th International Conference on NDT of Art, Jerusalem Israel, 25-30 May 2008.

PRATT W. K.; Digital Image Processing, Third Edition, Publication; John Wiley \& Sons, Inc., New York, USA, 2001.

PURSCHKE M., The X-Ray inspection (RT/RS), Castell publication Inc., Wuppertal, 2004.

RABELLO J.M.B.; CAMPINHO H.S.; IGUCHI E.T.; MOREIRA E.V.; CAMARGO J.R.; Utilização da técnica de radiografia computadorizada na inspeção de soldas circunferenciais na técnica de parede dupla - vista simples, IV Conferencia Panamericana de END, Buenos Aires, Argentina, 2007.

RANGER N. T.; SAMEI E.; DOBBIS J. T.; RAVIN C. E., Assessment of Detective Quantum Efficiency: Intercomparison of a Recently Introduced International Standard with Prior Methods, Radiology - Publisher: Radiological Society of North America National Institutes of Health, Volume 243, pp. 785-795, November 2007. 
RORABAUGH C. B., Digital Filter Designer's Handbook : Featuring C Routines, Publisher: McGraw-Hill Education - Europe, 1993.

SAMEI E.; RAVIN C. E., Assuring image quality for classification of digital chest radiographs, National Institute for Occupational Safety and Health Scientific Workshop, Washington DC, USA, 2008.

SILVA, A. S. S. Estudo da otimização da qualidade da imagem digital através da razão sinal ruído diferencial (SdNR). 101 f. Dissertação (Mestrado em Engenharia Nuclear) - COPPE - Universidade Federal do Rio de Janeiro, Rio de Janeiro, 2009.

SIMÕES H.R., OLIVEIRA D.F., SILVA A.S.S., MOREIRA E.V., CAMARGO J.R., LOPES R.T., Vantagens da radiografia computadorizada para peças fundidas, Metais \& Fundição Brasil, Edição 29, Outubro, 2008.

TAUHATA L.; SALATI I. P. A.; PRINZIO R.; PRINZIO A. R., Radioproteção e dosimetria: Fundamentos, 5 $5^{\mathrm{a}}$ Revisão, Instituto de Radioproteção e Dosimetria, Comissão Nacional de Energia Nuclear, Rio de Janeiro, 2003.

TERRA, Maior imagem digital do mundo tem 143 GB, Maio de 2007, Terra tecnologia, Disponível em: http://tecnologia.terra.com.br/interna/0,,OI1596311EI4797,00.html, acesso em 06 Setembro 2009.

TSM, IBM Tivoli Storage Management Concepts, Fifth Edition, Version 5.3.3, IBM Corp., 2006.

VAN DER STELT P. F., Better imaging: The advantages of digital radiography, 2008, The Journal of the American Dental Association; Volume 139; pp. 7S-13S, Disponível em: http://.www.jada.ada.org, Acesso em: 06 Set. 2009.

VAN DER STELT P. F., Filmless imaging: The uses of digital radiography in dental practice, 2005, The Journal of the American Dental Association; Volume 136; pp. 1379-1387, Disponível em: http://.www.jada.ada.org, Acesso em: 06 Set. 2009.

VARIAN MEDICAL SYSTEM, Varian - A 60 Year History, DGfZP, Deutsche Gesellschaft für Zerstörungsfreie Prüfung Conference, June 3, 2008.

VARIAN MEDICAL SYSTEM, DDA Digital Imaging, Disponível no site da Varian: http://www.varian.com/us/xray/products/digital_radiography/paxscan_products.html, Acesso em: 10 Jul. 2009.

VENKATACHALAM R., MANOHARAN V., RAGHU C., VEDULA V., MISTRA D., PERFORMANCE CHARACTERIZATION OF AMORPHOUS SILICON DIGITAL DETECTOR ARRAYS FOR GAMMA RADIOGRAPHY, 12th AsiaPacific Conference on NDT, Auckland, New Zealand, 2006. 
VIEIRA M. A. C.; OLIVEIRA P.D.; ESCARPINATI M.C.; SCHIABEL H., Determinação da função de transferência de equipamentos mamográficos em qualquer posição do campo utilizando sensor CCD odontológico. $21^{\circ}$ Congresso Brasileiro de Engenharia Biomédica, Salvador, 2008.

ZSCHERPEL U., BAVENDIEK K., High quality radiography with digital detector arrays, ASNT, Digital Imaging VIII Conference, Foxwoods, CT, 2005. 